\title{
PHYSICAL CHARACTERISTICS OF SAND-SOIL MIXTURES UNDER REPEATED DYNAMIC LOADS
}

APRIL 1962

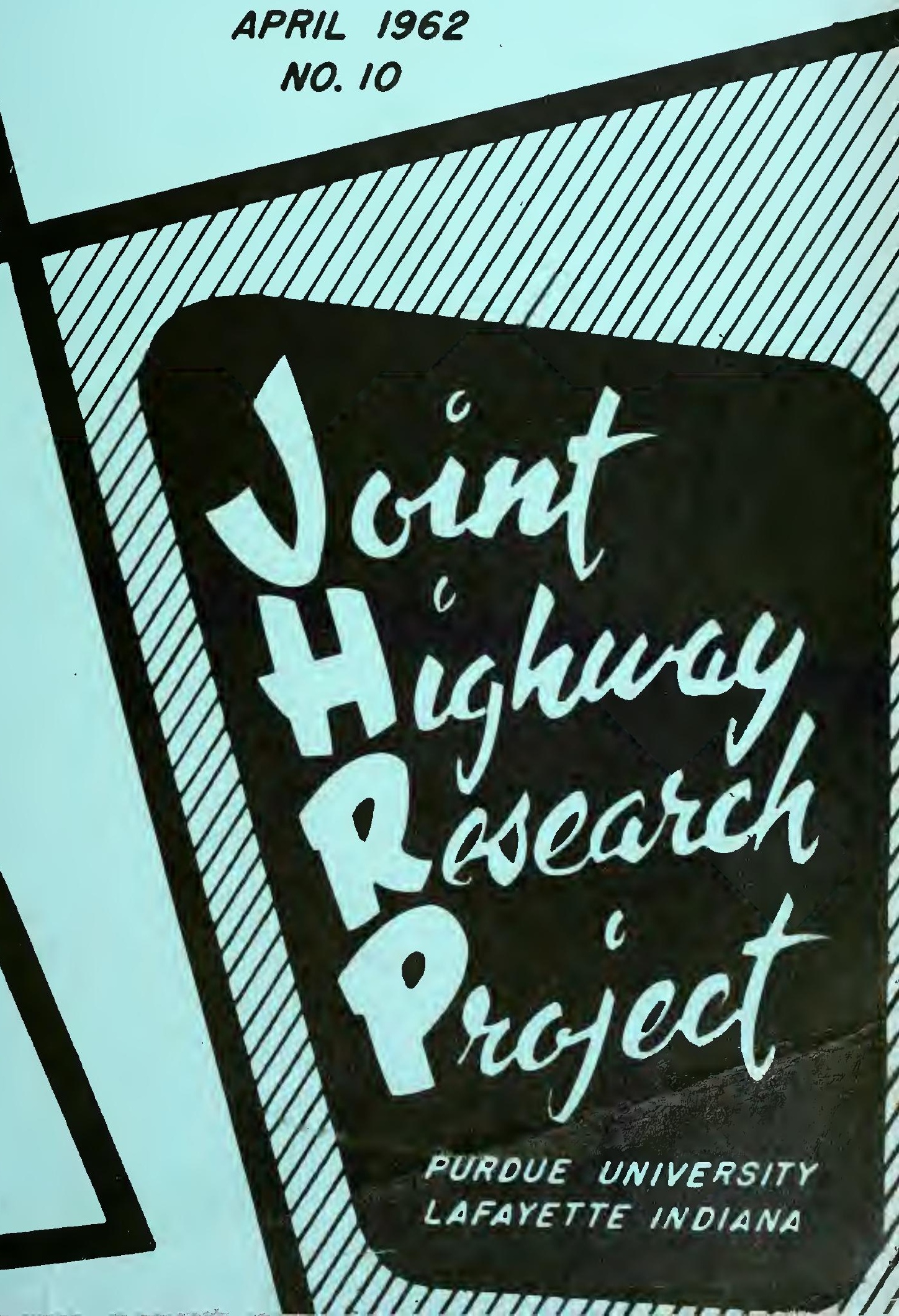





\section{PHYSICAI CHARACTERTSTICS DF SADDOSOIJ MTXIURES UNDER RHPEATED DINUIC IONDS}

ID:

K. B. Woods, Mirector

Joint Hifhway Research Project

ITROX:
H. I. Hichrel, Associste Dirsotor Joint Highray Research Project
Apri1 11, 2962

Pila: 6m 1807

Eroject: $\mathrm{C}=36.45 \mathrm{G}$

The final reporc transmitted by tians letter has been authored by M. Rodney Wo Johnson. The jesecrcis zesuiting iil the report and the preparation of the report were conducted under the superviston of Professpr $E_{0}$ J. Yoder. The repori, titled "Waysical Charasteristics of Sandosoil Mixtuxes Under Repeaced Dynemic Iosis", is subatted "o the Bonre for the record.

The research reported ws a siudy of the efiect of binder content of soll-sand mixtures on pore pressure behavior and strensth properties oi the reterials under conditions wepeatec loadings. Several resulis of the research conducted vers obialned and are detaljed in the report.

Respectiully subonitted,

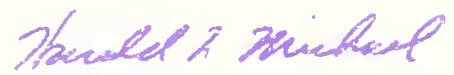

Harold I. lifchsel.s Secretary

BIN: lme

\section{Coples}

F. I. Aslibaucher

J. R. Gooper .

W. I. Dolich

V. H. Goet,

E. F。 Havey

F.S. H131

G. A. Leoneras
J. F. MeIqughtirs

R. D. HIes

R. M. M1125

M. B. Scot'

J. V. Sinythe

J. I. Waising

E. J. Yoder 
Digitized by the Internet Archive in 2011 with funding from

LYRASIS members and Sloan Foundation; Indiana Department of Transportation 
Final Report

PHISICAI CHARACIERTSIICS OF SAIVDSODJ MIXIURES

UHOER RETEEAITED DZWARTC IOADS

by

Rodney Ho Johasm

Reserrch Assistain

Joint Highray Resesach Froject

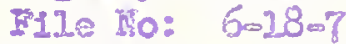

Project Iro: Ge $36.45 \mathrm{G}$

Purdue Vriversity

Lafayecte, Incians

Agxis 11, 1962 


\section{A CKNOWLEDOMENTS}

It has been sald that the value of a benefaction depends not so much on the magnitude as the time when it is given. ${ }^{l}$ So it is in the case of the assistance rendered by a muber of persons during the author's work at Purdue. Their timely advice and encouragement contributed materially to the success of the project. Grateful appreciation is expressed to the following individuals in particular.

The Joint Highway Research Project of Purdue University, Professor K. B. Woods, Director, proflded financial support for the accomplishnent of the research program.

Professor E. J. Yoder, the author's major professor gave much valuable time, guidance and encouragement during the research as well as in reviow of the thesis drafts.

Professor C. W. Lovell, Jr. generously gave tive to discussion of specific problems of testing and instrumentation.

Professor G. A. Leonards was uniquely responsible for providing technical advice in several areas of difflculty in the testing program.

Lastly, the writer wishes to express his gratitude to his wifo for her encouragement and confldence as well as typlng of the entire mamuscript.

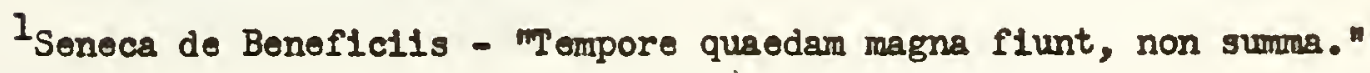


TABLE OF CONTENTS

Page

LIST OF TABLES

LIST OF IILOSTRATIONS

$\nabla 1$

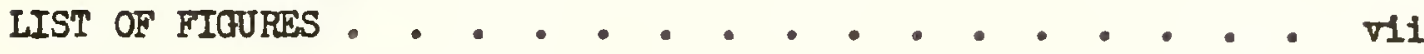

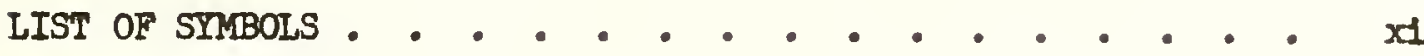

ABSTRACT • . . . . . . . . . . . . . . . . . x111

INTRODUCTION . . . - . . . . . . . . . . . . . 1

LITERATURE REVIEW - . . . . . . . . . . . . . . 3

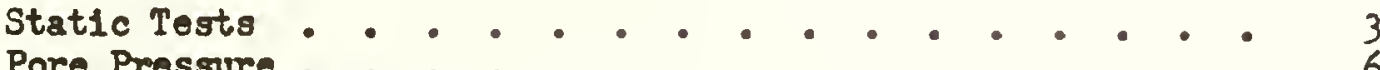

Pore Pressure . . . . . . . . . . . . . . . 6

Repeated Load Tests . . . . . . . . . . . . . 10

Volume Change . . . . . . . . . . . . . . . . 16

Mix Design . . . . . . . . . . . . . . . 17

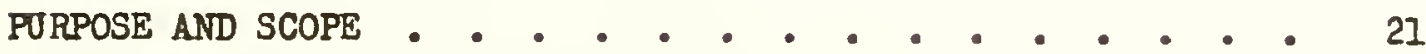

TEST EQUIPMENT • . . . . . . . . . . . . . . 24

Dynamic Triadial Loading Equipment . . . . . . . 25

Controlled Temperature Room . . . . . . . . . . . 31

Electronto Recording Equipment . . . . . . . . . 32

Sensing Elements and Calibration . . . . . . . 38

Volume Change . . . . . . . . . . . . . . 40

Test Conditions . . . . . . . . . . . . 44

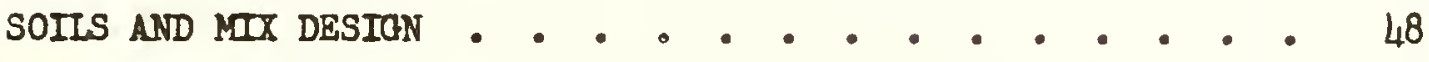

TEST PROCEDURE - • • . . . . . . . . . . . . 54

Sample Preparation . . . . . . . . . . . . 54

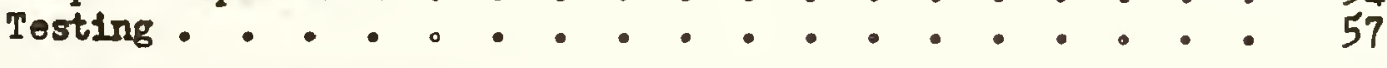

RESULTS AHD COMPUTATIONS - . . . . . . . . . . . 66

Observed Test Data . . . . . . . . . . . 66

Deformation Characterlstios - . . . . . . . . . 71

Elast1c Characterlstics . . . . . . . . . . 84

Strength Characterlotics . . . . . . . . . . 94 
Pore Pressure Behavior . . . . . . . . . . . . 98

Initial Pore Pressure Change . . . . . . . . . 100

Change in Pore Pressure Per Cycle . . . . . . . . 108

Maximum Change in Pore Pressure . . . . . . . . 115

Volume Change. . . . . . . . . . . . . . . . 122

DISCUSSION OF RESULTS • • • • • • • • • • • • • • 129

Volume Change . . . . . . . . . . . . . . 129

Deformation . . . . . . . . . . . . . . 141

Elast1c Characteristics . . . . . . . . . 142

Strength Characteristics . . . . . . . . . . 142

Pore Pressure Behavior . . . . . . . . . . . . . 143

Initial Pore Pressure . . . . . . . . . . . 145

Change in Pore Pressure Per Cycle . . . . . . . 146

Change in Maximum Pore Pressure . . . . . . . . 147

Suggested Failure Mechanism - • • • • • • • • . 149

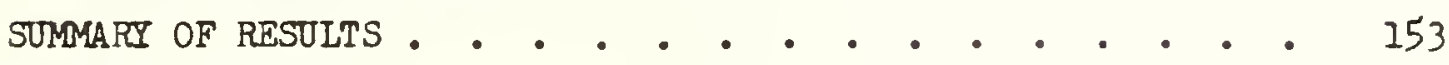

CONCLUSIONS • • • • • • • • • • • • • • • • • 157

SUGGESTIONS FOR FURTHER RESEARCH . . . . . . . . . . 160

LIST OF REFERENCES • • • • • • • • • • • • • • • 162

APPENDIX A Procedure for Putting Electronic Equipment
Into Operation - • • • • • • • 166

APPENDIX B Triaxial Q Test . . . . . . . . . . 173

APPENDIX C Volume Change Resulting From Loading Ram . . 180

APPENDIX D Dymamic Modulus of Deformation . . . . 182

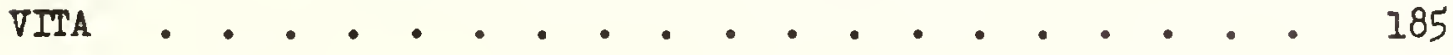




\section{LIST OF TABLES}

Table

Page

1. Sumary of Mixture Gradation Data . . . . . . 50

2. Tabulation of Data . . . . . . . . . 67

3. Tabulation of Volume Change Resulting From Application of Confining Pressure . . . . . 136 


\section{LIST OF ILUUSTRATIONS}

Plate

Page

1. Triaxial Repeated Load Apparatus . . . . . . 28

2. Electronic Equipment in Controlled

Temperature Chamber . . . . . . . . . 29

3. Trlaxial Cell With Specimen . . . . . . . 30

4. Split Saturation Mold \& Saturation Cell . . . . 56

5. Pore Pressure Sensing System Showing Calibration Tank . . . . . . . 60

6. Types of Pore Pressure Probe . . . . . . . 64

7. Typical Failed Specimens After Test, From Left, A, A, B mix . . . . . . . . . . . 99 


\section{LIST OF FIGURES}

EYgure

1. Repetitive Loading Apparatus . . . . . . . . 26

2. Schematic Dlagram of Air and Electrical

Distribution System . . . . . . . . . . 27

3. Detail of Loading Frame Anchor . . . . . . . . 33

4. Block Diagram of Electronic Sensing and Recording

Equipment . . . . . . . . . . • . 34

5. Strain Gage Bridge Unit . . . . . . . . . . 35

6. Triaxial Cell Showing Electronic Pickup Devices . . . 36

7. Apparatus for Measuring Volume Change Under Pressure. - 42

8. Typical Oscillogram Showlng Recorded Test Results . . 68

9. Deformation Characteristics; $19 \%$ Binder \& 30 psi Lateral Pressure . . . . . . . . . 72

10. Deformation Characteristics; $19 \%$ Binder \& 35 psi Lateral Pressure . . . . . . . . . 73

11. Deformation Characteristics; $19 \%$ Binder \& 40 psi Lateral Pressure . . . . . . . . . 74

12. Deformation Characteristics; $29 \%$ Binder \& 30 psi Lateral Pressure . . . . . . . . . 75

13. Deformation Characteristics; $29 \%$ Binder \& 40 psi Lateral Pressure . . . . . . . . . 76

14. Deformation Characteristics $14 \%$ Binder \& 50\% Deviator Stress . . . . . . . . . . . 77

15. Deformation Characteristics, Arlthmetic Plot, $19 \%$ Binder . . . . . . . . . . . . 78

16. Deformation Characteristics, Arithmetic Plot, 29\% Binder 
Figure

17. Deformation Characteristics, Arithmetic Plot,

$14 \%$ Binder

18. Rebound Characterlstics; $19 \%$ Binder \& 30 psi Lateral Pressure

19. Rebound Characteristics; $19 \%$ Binder \& 35 psi Lateral Pressure

20. Rebound Characterlstics; $19 \%$ Binder \& 40 psi Lateral Pressure

21. Rebound Characterlstics; $29 \%$ Binder \& 30 psi Lateral Pressure . . . . . . . . .

22. Rebound Characteristics; $29 \%$ Binder \& 40 psi Lateral Pressure

23. Rebound Characterist1cs; IL落 Binder \& $50 \%$ Devlator Stress . . . . .

24. Change in Pore Pressure Vs. Stress Difference Cycles 1 \& 2 19\% Binder, 30 psi C.P. . . . . . . 101

25. Change in Pore Pressure V. Stress Difference Gycles 1 \& 2, $19 \%$ Binder, 35 psi C.P. . . . . . . 102

26. Change in Pore Pressure $\nabla$. Stress Difference Cycles 1 \& 2, 19\% Binder, 30 psi C.P. . . . . . 103

27. Change in Pore Pressure Vs. Stress Difference Cycles 1 \& 2, 29\% Blnder, 30 psi C.P. . . . . . 104

28. Change in Pore Pressure Vs. Stress Difference Cycles 1 \& 2, $29 \%$ Binder, 40 ps1 C.P. . . . . . 105

29. Change in Pore Pressure Vs. Stress Difference Cycles 1 \& 2, $14 \%$ Binder, 50\% Dev. Str. . . . . . 106

30. Change in Pore Pressure Per Cycle, 19\% Binder 30 psi C.P.

31. Change in Pore Pressure Per Cycle, 19\% Binder, 35 ps1 C.P. . . . . . . . . . .

32. Change in Pore Pressure Per Cycle, $19 \%$ Binder, 40 psi C.P. 
Figure

33. Change in Pore Pressure Per Cycle, 29\% Binder, 30 psi C.P. . • . . . . . . • • • . 112

34. Change in Pore Pressure Per Cycle, $29 \%$ Binder, 40 psi C.P. . . . . . . . . . . . 113

35. Change in Pore Pressure Per Cycle, 14\% Binder, $50 \%$ Der. Str. . . . . . . . . . . 114

36. Maximum Change in Pore Pressure, 19\% Binder, 30 psi C.P.

37. Maximum Change in Pore Pressure, 19\% Binder, 35 psi C.P.

38. Maximum Change in Pore Pressure, 19\% Binder, 40 psi C.P.

39. Maximum Change in Pore Pressure, $29 \%$ Binder, 30 psi C.P.

40. Maximum Change in Pore Pressure, 29\% Binder,

40 psi C.P. . . . . . . . . . . 120

41. Maximum Change in Pore Pressure, $14 \%$ Binder, $50 \%$ Dev. Str.

42. Varlation of Volume Change with Load Repetition, 19\% Binder, 40 psi C.P. . . . . . . . . . 123

43. Variation of Volume Change with Load Repetition, $19 \%$ \& $29 \%$ Binder, 30 psi C.P. . . . . . . . 124

44. Variation of Volume Change with Load Repetition, $29 \%$ Binder, 40 psi C.P.

45. Variation of Volume Change with Load Repetition, $14 \%$ Binder, $50 \%$ Dev. Str.

46. Pore Pressure - Volume Change Relationship, 30 psi Confining Pressure . . . . . . . .

47. Pore Pressure-Volume Change Relationship, 19\% Binder

48. Pore Pressure-Volume Change Relationship, $29 \%$ Binder 
49. Pore Pressure-Volume Change Relationship,

$14 \%$ Binder

50. Consolidated - Undralned Tests on Design Mix, 30 psi Lateral Pressure . . . . . . . .

51. Long Duration Consolidated - Undrained Tests, 30 ps1 Lateral Pressure . . . . . . . . . 140

52. Amplifier Controls \& Connections Identification Diagram . . . . . . . . . . . . . . 172

53. Stress-Strain Curves, $19 \%$ Binder . . . . . . . 174

54. Stress-Strain Curves, 29\% Binder . . . . . . . 175

55. Stress-Strain Curves, $14 \%$ Binder . . . . . . . 176

56. Mohr Envelope in Terms of Total Stress, 19\% Blnder . . 177

57. Mohr Envelope in Terms of Total Stress, 29\% Binder - . 178

58. Mohr Envelope in Terms of Total Stress, 14\% Binder • . 179

59. Calibration Curve for Volume Change Device and Triaxlal Cell . . . . . . . . . . . 181

60. Stress and Strain 78. Time, Cycle 52,330, Sample No. $40 \mathrm{~A} 30$. . . . . . . . . . . 183

61. Modulus of Deformation, Cycle 52,330, Sample No. $4 \mathrm{OA} 30$. . . . . . . . . 184 


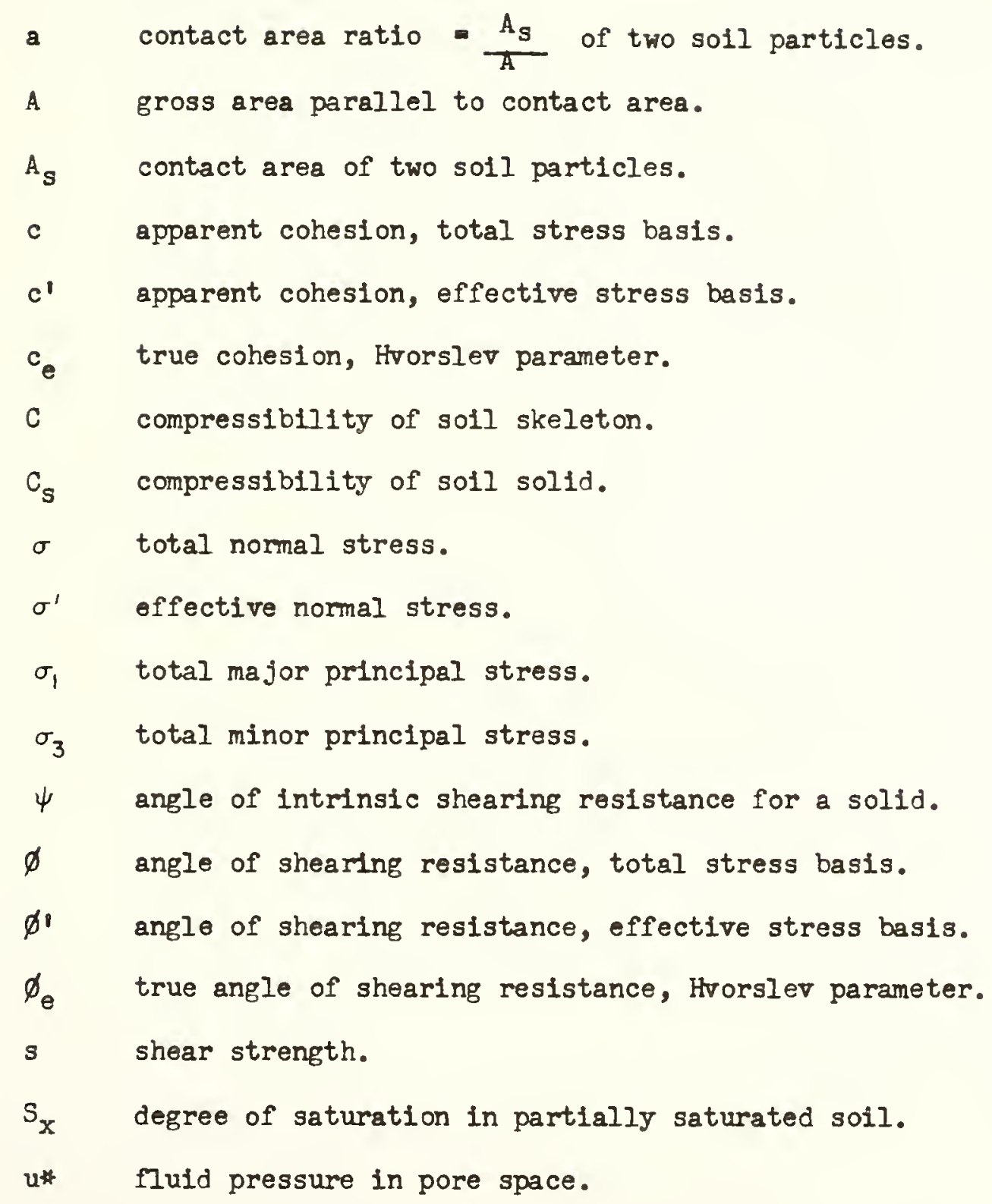


$u_{a} \quad$ alr and vapour pressure in pore space.

$u_{w} \quad$ water pressure in pore space.

$x$

dimensionless parameter related to degree of saturation, relative volume, etc. 
ABSTRACT

Johnson, Rodney Wendell. Ph.D., Purdue University, January 1962. Physical Characteristics of Sand-Soll Mixtures Under Repeated Dynamic Loads. Major Professor: Eldon J. Yoder.

A laboratory study was performed upon a series of soilsand mixtures designed on the aggregate-binder principle for which the aggregate gradation was held constant and the binder content varied. The study was initiated to establish the effect of binder content on pore pressure behavior and strength properties of the test materials under conditions of repeated loading.

Triaxial test equipment was designed and fabricated which permitted the deviator stress to be applied in a repetitive manner under varylng intervals and duration of load as desired. Electronic pore pressure sensing and recording equipment was fabricated which permitted rapid and accurate measurement of pore fluid pressure in the fallure zone of the sample. Volume change measuring equipment was also developed, based on change in volume of the cell fluid during the test.

Graded sand samples contalning binder contents (passing a No. 200 sieve) of 14 percent, 19 percent, and 29 percent were tested at varying confining pressures ( 30,35 and 40 psi) and deviator stress to determine pore pressure, deformation, volume change, and elastic properties of the soil. 
The results showed that the total deformation and rebound experienced by the samples was related to the magnitude of deviator stress and binder content. Swell prior to test with attendant change in density acted to increase the total deformation whereas pre-test compression acted to decrease the total deformation.

It was shown that a decrease in volume took place in the soil during repeated load testing. This decrease in volume with attendant change in soil structure acted to increase the strength of the soll above that for a soil with no repeated load application history. Increasing the number of laad repetitions resulted in an increase in strength gain. The concept of a critical deviator stress level was substantiated, indicating the existance of a critical deviator stress in the repeated load test.

The pore pressure behavior in partially saturated soils was explored in considerable detail. It was verified that pore pressure gradients existed in the soil prior to test, and that under the test conditions an equilibrium condition was reached after 1000 cycles at wht ch time the pore pressures were redistributed. Pore pressures measured in the fallure zone at equilibrium were average values for the entire sample.

The rosults of this research program indicate that volume change can bake place in soils compacted to high densities which in turn could cause rather high permanent deformations and eventual failure of the parement. A definition of the strength of these soils and the mechanism of failure was postulated in terms of volume change and pore pressure. 


\section{INTRODUCTION}

Highway pavement design is recognized as a complex problem for which no exact theoretical solution is possible. Many factors are involved in the present approach to pavement design, the principal ones being the magnitude and frequency of load application, the interrelationship of the ability of the pavement and base to transmit the loads to the subgrade and the ability of the subgrade to support the imposed loads. Each of these factors is affected by a number of rartables which singly may be quite simple to evaluate but which in conbination with others prove to be extremely complex. For this reason early highway design methods generally followed an empirical approach with observations of the pavement behavior with time; traffic was correlated with the design method. This was commonly based on a deflection criterion. An improvement to this approach was the attempt to control the total deformation of the pavement and at the same time prevent overstressing of the subgrade. This approach led to the development of various static tests to evaluate the strength and deformation characteristics of the base and subgrade soil, of which the California Bearing Ratio test is the best known. Such design methods are based on an index of soll strength or deformation obtained from a static test in which the load is applied slowly.

Relatively recently it has been recognized that the behavior of solls under static loading conditions is not indicative of their 
behavior under repeated loading conditions. As a result such static strength tests at times prove to be unreliable for design of highway pavements in spite of many and varied empirical correlation studies. This apparent anomaly can be attributed to the fact that a pavement subjected to repeated loads undergoes both plastic and elastic deformation and the magnitude of these deformations is a function of the number of load repetitions. Accumulated plastic deformations of the subgrade may be so excessive as to cause pavement fallure, even though excessive elastic deformation is not evident.

In order to properly assess the effect of repeated loads on solls, early investigators studied the effect of repeated loads in terms of the total deformation, which presumed fallure to be a function of both plastic and elastic deformation. Strengths of soils subjected to repeated loading were empirically correlated with strength of the same soil determined by static strength tests for which stress-strain theories exist.

Stress-strain relationships for clay soils subjected to repeated loads have been investigated on a total stress basis. Some work has been done for sands as well. These efforts represent ploneer work in the area of developing a strength theory for repeated load strength determination. In order to provide a basis for eventual development of such a theory, it is necessary that pore-pressure behavior also be investigated for repeated load conditions. This study is an attempt to extend the field of knowledge in this area by observing pore pressure, volume and stress-strain relationships in sands under repeated loads. 


\section{LITERATURE REVIEW}

\section{Static Tests}

For soils in which the roids are completely saturated Terzaghi (1) showed that the effective stress is equal to the total stress minus the pore pressure in the water:

$$
\sigma^{\prime}=\sigma-u_{w}
$$

If the shearing resistance of a clay is expressed by the Coulamb equation then:

$$
s=c+\sigma \tan \varnothing
$$

and for a dry sand

$$
s=\sigma \tan \phi \text {. }
$$

For the saturated condition the shearing resistance can be expressed on an effective stress basis by:

$$
\begin{aligned}
& s=c^{\prime}+\left(\sigma-u_{w}\right) \tan \phi^{\prime} \text { for clay } \\
& s=\left(\sigma-u_{w}\right) \tan \phi^{\prime} \text { for sand }
\end{aligned}
$$

where $c$ and $\varnothing$ are the apparent cohesion and angle of shearing resistance respectively. 
Although several different tests can be used to determine shear strength of a soll, the triaxial test has demonstrated its superiority in representing the conditions of stress of a soil in situ. The outstanding advantages of this test are control of drainage conditions and the ability to measure pore water pressure under varying magnitudes of confining pressure and axial load.

A. Casagrande is credited by Rutledge (2) with being the first to classify the three basic types of triaxial test conditions: Unconsolidated-Undrained Test (UU) - a strength test in which the soil specimen is subjected to bydrostatic confining pressure and an applied axial load is increased to failure without allowing any drainage to occur during the test.

Consolidated-Indrained Test (CU) - a strength test in which the soil specimen is first consolidated under a given hydrostatic pressure with drainage permitted and then without permitting further consolidation or drainage, an applied axial load is increased to failure.

Consolidated-Drained Test (CD) - a strength test in which the specimen is first consolidated under a given hydrostatic pressure with drainage permitted and then subjected to an applied axial load permitting full consolidation during the test until failure is reached.

In simulating conditions in which drainage cannot take place, the undrained triaxial test is used. If limited drainage is likely to occur in the prototype structure, a test under both drained and undrained conditions is made and the results are interpolated 
to arrive at the best value for the shear strength. This procedure presumes considerable knowledge of both field and test conditions in order to approach the best value. In the undrained test both the intergranular pressure and the pore pressure is unknown. If the pore pressure however, can be determined during a series of tests the effective stress can be computed and the true strength envelope determined.

Equation (4) then becomes:

$$
s=c_{e}+\left(\sigma-u_{w}\right) \text { tan } \phi_{e}
$$

Where $c_{e}$ is the true cohesion and $\phi_{e}$ is the true angle of internal friction as defined by Horslev (3).

Equations (4) and (5) mean that the same information can be obtained in the undrained test as would be secured in the drained test. While the importance of pore pressure determination in the triaxial test is recognized, its measurement is a rather difficult task and this fact has restricted its popularity to a considerable extent although the undrained test with pore pressure measurements is considered to be the most dependable and accurate method for determining the shear strength of a soil.

Another expression for the effective stress, eq. (I) was suggested by Bishop (4):

$$
\sigma^{\prime}=\sigma-u_{a}+x\left(u_{a}-u_{w}\right)
$$

for the case of partially saturated soils where $x$ is a parameter related to the degree of saturation. For a saturated soil the value of $x$ becomes unity and the equation reduces to Terzaghi's. 
Skempton (5) has expanded equation (7) above to include the angle of intrinsic friction and degree of saturation. Then the effective stress in partially saturated solls can be shown to be:

$$
\begin{aligned}
& \sigma^{\prime}=\sigma-\left(1-\frac{a \tan \psi_{1}}{\tan )^{\prime}} S_{x} \cdot u_{w}\right. \\
& \sigma^{\prime}=\sigma-\left(1-\frac{c_{s}}{c}\right)^{S_{x}} \cdot u_{w}
\end{aligned}
$$

for volume change.

For saturated soils $S_{x}$ equals unity, and under the low pressures normally encountered in solls a and $C_{S} / C$ are both very small. Under these conditions equations (8) and (9) above degenerate into Terzaghi's equation.

\section{Pore Pressure}

The work of Rendulic $(6,7)$ established the validity of Terzaghi's theory of pore pressure in soil, and demonstrated that pore pressures could be measured in laboratory tests. Taylor (8) extended the art of pore pressure measurements in saturated clay and devised several types of probe to use in the test. He found by analysis of these pore pressure data that the shear strength of a soll in the undrained test depends on the ratio of the principle stresses under which the soll is consolidated before shear occurs; therefore data on pore pressures are essential.

The Taylor method for conducting a triaxial test on a cohesive soll with measurement of pore pressure has been described by Lambe (9). Skempton (10) has shown that the change in pore pressure which 
takes place in the undrained test with a change in the principle stresses can be expressed as:

$$
\Delta \mathrm{u}=\mathrm{B}\left[\Delta \sigma_{3}-\mathrm{A}\left(\Delta \sigma_{1}-\Delta \sigma_{3}\right)\right]
$$

Where $A$ and $B$ are pore pressure coefficients. $A$ and $B$ are constants for any given test condition. The parameter $B$ is the ratio of the pore pressure recorded when the confining pressure is applied,

$$
B=\frac{\Delta u}{\Delta \sigma_{3}}
$$

and is equal to 1 for a fully saturated soil. The constant A is obtained from the pore pressure change which takes place with the application of a deviator load. Since the magnitude of A varies with stress and strain its value may be expressed for any point in the test. Skempton (10) reports values of $A$ from $-\frac{1}{2}$ to 0 for highly over consolidated clays to $\frac{1}{2}$ to 1 for normally consolidated clays. Bishop (II) has shown how these constants provide first a qualitative picture of the type of pore pressure change which can be expected in a particular soil problem and secondly, where the stress changes are known, a basis for quantitative design methods.

Nash and Dixon (12) reported on the results of pore pressures measured in sand under very rapid triaxial tests. Their measurements were made at the base of the sample but since the sand was very coarse the error was assumed to be small. They noted that failure occurred suddenly at peak strength instead of progressively and suggest that a pore pressure gradient occurs monentarily at that time in the sample which, when relieved, reduces the peak 
strength. Interestingly, for a test run at 100 psi confining pressure the maximum change in pore pressure was found to be 90 psi which occurred at an axial deformation of about 20 percent and 150 psi deviator stress.

Lambe (13) investigated "residual" pore pressures in compacted clay. Residual pressures are defined as those pore water pressures exlsting in the compacted clay prior to the addition of more water or shear stresses. He found that the higher the molding water content the higher the residual pore pressure. For the same molding water content and the same compacted density, kneading compaction gave higher residual pore pressures than did stat1c compaction, although the amount of compaction had little effect. Furthemore he showed that temperature affected the residual pore pressures greatly. Specimens compacted cool have higher residual pore pressures than those compacted warm. Cooling both the sample and mold causes an increase in pore pressure whereas heating the sample and mold causes a decrease in pore pressure. Samples which had once been wetter than the molding water content had higher residual pore pressures than those tested without the addition of water. Whitman, Richerdson and Healy (14) conducted highly significant studies on time lags in pore pressure measurements. They state that in an ideal saturated soil the flexibility of the measuring system as well as the compressibility of the mineral skeleton were the major factors which influenced the validity of the measured pore pressure. If a stress increment $\Delta \sigma$ is applied instantaneously to a saturated clay (or sand) It should produce a pore pressure of 
equal magnitude; 1.e. $\Delta u=\Delta \sigma$. However, this is commonly not the case and the recorded pore pressure may be less than $\Delta \sigma$.

Whitman, et al (14) attribute this fact first to excessive flexdbility in the measuring system which may have two effects:

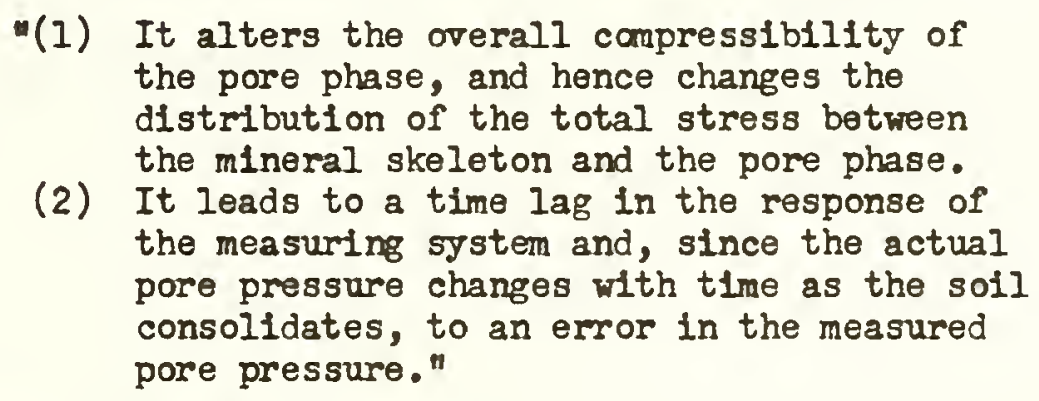

Second, the mineral skeleton may be so stiff as to approach that of water in which case the measured pore pressure would reflect this effect as well as actual pore pressure. As a result of these studies they developed a method for measuring pore pressure with an electrical pressure transducer in which the pore water pressure acted on a stiff diaphram. Rapld response times were obtained with this derice.

Healy (15) Investigated the effect of rate of strain on coarse sands in the triaxial test and found that as the sand dilates under shear, "the pare pressure decreases at an increasing rate due to the increasing stiffness of the membrane." Further, the effective stress increases thus resulting in an increase in the stiffness of the sample.

Techniques of pore fluid pressure measurement and developnent of pore fluid pressure measurement equipment have been the subject of a number of researchers. Bishop (4), Blshop and Henkel (16) 
and Bishop and Donald (17) have pioneered in the development of static triaxial testing apparatus with measurement of pore pressure. Electronic measurement of pore pressure employing strain-gage pressure transducers has reached a high degree of development under the impetus of Whitman and his associates at the Massachusetts Institute of Technology (14) (18).

\section{Repeated Load Tests}

The history of repeated load triaxial tests is one of quite recent development. The first significant work in this area must be credited to Dr. H. B. Seed of the University of California who was among the first to recognize the importance of these kind of tests in the design of parements. ${ }^{2}$ In 1955 Seed, Chan and Monismith (19) presented a paper which described the results of investigations of repeated loading on compacted clay, together with details of the apparatus employed to remove and reapply the deviator load.

The apparatus consisted of an electronically controlled hydraulic system used to ralse and lower a carriage which removed and reapplied weights on a lever-type loading frame. This system produced a square load-time oscillogram Indicating nearly instantaneous load application and removal. The interval between loads as well as duration of load was varied for the test program; a majority were run at $I$ second load time and 2 second interval. The soil, a silty clay, was compacted in the kneading compactor and then compressed

20thers, notably Kersten, Untversity of Minnesota, recognized earlier the significance of load repetition, but did not apply this principle to triaxial compression tests. 
statically until molsture was extruded resulting in 92 percent to 97 percent saturation. It was concluded from this investigation that the magnitude of the deformation of silty clay specimens subjected to repeated stress applications was greater than that experienced by identical specimens loaded statically at the same stress magnitude. Further, the deformation was dependent on the number and magnitude of stress applications and independent of the frequency of application. From this relationship, it was shorn that curves could be established for a given soil showing the number and magnitude of applied stresses required to cause the same deformation in a specimen. Significantly, the shear strength and resistance to deformation of a specimen after repeated loading was greater than that for previously unloaded specimens; in general the greater the number of load applications, the greater the increase in strength resulting from the repeated load. This increase was considered to be due partly to an increase in density as well as time effects on the soll itself.

Seed and McNelll (20) subsequently investigated two soils, a silty clay and a clayey silt with a view to shedding further light on the correlation of soil strengths and deformations in the static or nomal compression test with the sane solis in a repeated load compression test. By interpolation of the test data for the repeated load tests and the nomal compression test, they found that under sample conditions for both solls which produced similar stress strain curves in the normal compression test the total and elastic deformations were different for each of the two soils in 
the repeated load test. Moreover they found that the degree of compaction influenced both the elastic and total deformation. For the same number of stress applications (1000) a sample compacted to 95 percent modifled AASHO deformed only 3 percent whereas a sample compacted to 91 percent deformed more than three times this amount. The elastic deformation also increased inversely as the degree of compaction, but at a much smaller rate. Thus the density of a specimen has a very large effect on the total deformation, but only a small effect on the elastic deformation. This difference in deformation characteristics of the two soils exists independent of the axial strain. They postulated that resillent or elastic deformation of subgrade solls may cause flexure and fatigue crackIng of a flexible parement without plastic deformation taking place. The elastic properties of a subgrade could not necessarily be determined from normal compression tests or even related to them. Th1s Indicated that a new type test was required to evaluate elastic deformation; the repeated load test provides a rellable means of measuring this type of movement.

In a later paper Seed and Chan (21) reported on the results of a more comprehensive study of the increase in strength resulting from the action of repeated loads on a silty clay. Two specimens compacted under the same conditions were each subjected to 100 repetitions of a $5.6 \mathrm{psi}$ deviator stress (deformation equal to I percent). When one specimen was later subjected to 10,000 repetitions of the $5.6 \mathrm{psi}$ deviator stress and then increased to 7.I pal deviator stress, it deformed less than the one in which 
the deviator stress remained constant at 5.6 psi. This stiffening effect occurred in the range of 10,000 to 100,000 repatitions. Further, this stiffening was reduced with an increase in magnitude of deviator stress. It was considered that stiffening resulted from a structural change in the soil particles whereby the repeated stress may cause adsorbed water to be extruded from between the clay particles, bringing the particles closer together and increasing the strength. This concept was supported by the fact that repeated load tests on fine sand caused no increase in strength.

In this series of tests Seed and Chan (2I) found that for clays of 1 ow saturation (63 percent) the frequency of application had no effect on strength. For clays of high saturation ( 95 percent) the deformation increased markedly with an increase in frequency of repetition. This apparent contradiction with previous work (19) indicating that the increase in strength of a soll subjected to repeated loads is independent of frequency of load application was explained by the fact that all the tests on which this conclusion was based were performed on specimens having low degree of saturation and little thixotropic strength gain. This conclusion cannot be applied to specimens of the sam soil having high degrees of saturation or any soil with appreciabl thixotropic characteristics. The effect of previous stress history of a soil subjected to repeated loading was investigated by Seed, MeNeill and deGuenin (22) as a further extension of the work on compacted clay. They noted that the increase in strength on stiffness of the specimen which was observed in both the normal compression test and the repeated load 
test following repeated application of a light devlator load depended on the initial saturation of the soil. Specimens with low intial saturation experlenced strength gains of a greater magnitude than similarly prepared specimens with higher initial saturation. Repeated losding resulted in increased stiffness or resistance to deformation in both cases however, although this effect was apparently lost at strains greater than 4 percent.

In order to assess the influence of densification on the resistance to deformation, tests were conducted by Seed, et al (22) in which the relationship between density and water content and between resistance to deformation and water content for the soil at each of four different compactive efforts was established. From these data it was found by interpolation "that specimens subjected to repeated loading have greater stiffness and higher strengths than could possibly occur in specimens having the same density and water content but not previously subjected to repeated loading." Thus the increase in strength is not alone attributable to an increase In density. Subsequently Seed and Chan (23) reported on results of investigation in which thixotropic effects upon soils subjected to repeated lasds were studied. It was concluded that the strength increase resulting from repeated load tests was due, in addition to increased density, to thixotropic effects as well as changes in structural arrangement of the soil particles.

In the most recent paper by Seed and Chan (24) the effect of duration of stress application on defomation of silty sand and silty clay soll specimens subjected to repeated laading was assessed. Under 
the test conditions of varying interval between load application and varying duration of load application, they found that for the silty sand an increase in duration resulted in greater deformation and that the effect of varying duration time is greatest for the short intervals, decreasing significantly with longer intervals. These effects were postulated as being due to adsorbed water layers on the sand particles which, under the action of rapid load applications, failed to return to their unstressed position on the mineral grain resulting in high interparticle fiction. Previous stress history may also have had some effect.

For the silty clay specimens Seed and Chan (24) found that for stress applications of short duration, an increase in interval time caused a reduction in defomation; for stress applications of long duration, an increased interval time resulted in an increase in deformation.

This effect produced in the silty clay was postulated by Seed and Chan (24) to be due to thixotropic effects, structural changes or to creep. In addition, the clay particles may have separated slightly from each other during the unladed periods.

Larew (25) investigated the effects of repeated loading on a silt and a sand-clay soil with a view to development of a strengthfailure criterion. He hypothesized, that for the solls studied, essentially homogeneous and fine-grained, a critical level of deviator stress exists at which the slope of the deformation versus number of repetitions curve is a constant after a few load repetitions. Although the data do not indicate that this effect 
can be obtained by present test methods, such a relationship does appear to exist. In addition, the effect of repeated loading on elastic rebound was investigated and for the solls studied, the elastic rebound reached an equilibrium value after approximately 1000 load repetitions. Signtficantly the magnitude of the elastic rebound increased with increasing dry density at a given water content, indicating that an increase in canpactive effort results in a marked increase in the equilibrium elastic rebound. A similar effect was found by Haynes (26) in a study of repeated load tests on gravel and crushed stone base mixtures used in the AASHO road test.

\section{Volume Change}

Casagrande (27) recognized as early as 1936 the mechanism of volume change in granular materials. He attributed the volume Increase in these solls which takes place durlng load application to the necessity for individual interlocked particles to slide up and over each other to permit deformation to occur.

The type of volume change which occurs is a function of the initial density or vold ratio of the specimen. If the specimen is compacted to an initial density at which no change in volume occurs wth load application, the corresponding vold ratio is called the critical vold ratio. If the vold ratio is above the critical value, the sample will decrease in volume, while dense specinens below the critical void ratio will increase in volume during shear.

Newland and Allely (28) performed a series of triaxial tests on lead shot in an investigation of volume change in drained triaxial 
tests. They reported that after the initial contraction, the volume increased more or less linearly over most of the range and not at a decreasing rate as one might expect. Significantly the expansion begins before the peak stress is reached. In a subsequent series of tests Newland and Allely (29) conducted tests on saturated lead shot in order to study the effect on strength parameters which occurred when the soil skeleton did not remain constant. They showed that the volume expansion which the sample undergoes decreases with increasing cell pressure, allowance being mate for membrane penetration. They concluded further that in an ideal undrained test on a saturated dilatent material where no skeleton volume change occurs, the value of the apparent cohesion corresponding to the $\phi_{u}=0$ condition is determined solely by the initial porosity of the sample. In addition, for tests in which the effective minor principle stress was held constant, the rate of volume expansion increased with a decrease in the effective minor principle stress.

\section{Mix Design}

The problem of base design for highways and airfields is a complex one. Ideally a mix design should provide the optimum characteristics of high shear strength and low compressibility. A large number of investigators have considered this problem from the static load test approach and achieved diverse results. Yoder and Woods (30) pioneered in this area with a study of compaction and strength characteristics of soil-aggregate mixtures using the California Bearing Ratio test as a measure of the compacted strength. Their studies showed that the soil content required to produce 
maximum strength was slightly less than that necessary to produce maxdmum density, as could be expected. A decade later, Miller and Sowers (31) performed a significant study on the strength characteristics of soll-aggregate mixtures in which the binderaggregate percentages were varied, each $m i x$ compacted to maximum density (ASTM D698-42T) and then tested in the triaxial compression test. For the soils used in their study, Miller and Sowers (3I) found that the relationship between maximum density and proportions of aggregate and binder indicated that maximum density was produced by 26 percent binder and 74 percent aggregate by weight. Based on absolute volumes with the roids just fllled, the theoretical proportions would be 22 percent binder and 78 percent aggregate. Evidently the aggregate-binder concept is not absolutely valid. Several additional facts were revealed by this study as followe i 3 The curves of cohesion and internal friction shed further light on the binder-aggregate behavior. The aggregate alone has a high angle of internal frlction but no cohesion. The addition of a small amount of binder produces a sharp drop in the angle of friction and a rapid increase in cohesion. This indicates that sane of the binder is trapped between same of the aggregate particles, preventing aggregate to aggregate contact. As the amount of binder Increases fran 10 percent to 26 percent the cohesion increased but at a decreasing rate. This reflects increasing binder compaction and a greater degree of roid filling by the binder. The changes in curvature

Miller and Sowers, loc. c1t., pg. 20 
occur at about the same point as the changes in the percent binder compaction curre, as would be expected. The internal friction in the range from 10 to 26 percent binder decreases slightly with Increasing binder, showing that there is little additional soll trapped between the aggregate particles.

Both the cohesion and the internal friction change rapidly in going fram 26 percent to 33 percent binder. The internal friction drops to that of the binder alone, while the cohesion increases to nearly $3 / 4$ of that of the binder alone. The change begins at the same point the binder compaction curve reaches 97 percent compaction and breaks sharply. At this polnt the aggregate particles begin to be surrounded by compacted binder; beyond 33 percent binder the aggregate particles float in the compacted binder. There is no change in the internal friction beyond this point. The cohesion increases gradually, with lncreasing binder, since the total cohesive force across any plane of shear 1ncreases when the volume of aggregate decreases."

Holtz and Gibbs (32) conducted tests on free-draining gravelly sand mixtures in an attempt to relate the shear strength with the soll parameters of density, gravel content, gradation, maximum particle size and particle shape. Gradation was essentially accordIng to Fuller's curve and compaction was based on relative density. The rate of load application was varled and produced no effect on shear strength or volume change. The Investigators found that the shear envelope was slightly higher for higher densities and increase In particle size. The friction value $(\tan \phi)$ increased as the 
gravel content was increased up to 50-60 percent. Above 60 percent gravel there was no increase in shear strength. Large increases in shear strength were observed for angular material over sub-rounded to sub-angular aggregate.

In concluding this section it is noted that the division of cohesion and friction based upon ordinary test envelopes and the interpretation of the Mohr envelope in the triaxial compression test as used by Miller and Sowers (31) is not in agreement with current knowledge. The restricted terminology is noted where the cohesion is considered to be the slope intercept and the friction portion to comprise the slope of the shear envelope.

Further, the reader will encounter the use of the terms "cohesive" and "non-cohesive" applied to solls or soll behavior throughout the text. It should be noted that these are general terms as applied through common usage to definitions of high clay-content solls in the case of cohesive and to relatively clean sands and gravels in the case of non-cohesive soils. 
PURPOSE AND SCOPE

The research program described in this study was conducted with several definite objectives in mind which can be categorized as follows:

1. To design and develop a repeated deviator load triaxlal test device together with related equipment for measuring and recording changes in pore pressure and volume during the test period. Accuracy and reliability of the equipment operation would be of major importance.

2. To develop test methods and procedures which would assure the desired accuracy and reliability of the experimental portion of the program as well as to develop methods and techniques for preparing, handling and placing soil specimens in the test apparatus.

3. To establish and conduct an experimental research program on the physical characteristics of sandsoil mixtures in the repeated load test. Specific objectives of the experimental phase included:

a. Observe pore pressure behavior during the test and relate these data to existing hypotheses. 
b. Develop strength and fallure criteria for the specific soil mixture under the extablished test conditions.

c. Determine the effect of volume change on strength, pore pressure and deformation characteristics of the test specimens.

In establishing the scope of the experimental phase of the program it was detemined that three variables would be incorporated in the study. These variables were the deviator stress applied to the soll specimen, the lateral or confining pressure in the triaxial cell and the amount of binder in the aggregate-binder mixture.

In the case of the variable deviator stress, it was determined that its magnitude would vary as a percent of the peak compressive strength of the specimen as determined fram the results of a static undrained (UU) triaxial test. The percentages were fixed at 30 , 40 and 50 percent of the peak compressive strength at each confining pressure.

Since part of the experimental work was concerned with the strength of the test specimens, it appeared desireable to establish a basis for relating the strength of the specimen in the repeated load test with that detemined in the static load test. This indicated varying the confining pressure in the triaxial cell; the pressures selected were 30,35 and 40 psi.

The last variable to be considered was that related to the soll 1tself. Of the many properties and soil Indicies which could be varied, it was considered that the binder content would be a 
valuable Index to the mechanistic behavior of the soil durlng the test. For this reason, the binder content was fixed at an optimum content of 19 percent by weight, 29 percent by weight and 14 percent by we1ght.

In addition to the foregoing, it was also determined that the aggregate gradation should remain fixed and the degree of saturation should be held constant at 100 percent.

From the foregoing, an experimental program was established consisting of three serles of tests. Each serles comprised a given binder content for which the confining pressure and devlator stress was varled. Thus a total of 9 specimens was involved in each series, or a total of 27 in the entire program. This was later modified during the test perlod to delete three of the redundant specimens and incorporate additional corroboratory tests. 


\section{TEST EQU IPMENT}

Prior to initiation of any work on the equipment design, considerable thought was given to the specific objectives of the research program. While it was recognized which general areas of research would be investigated, it was also recognized that limitations in scope would have to be observed.

With the purpose and scope defined, the research program difided more or less naturally into three distinct phases as follows:

$$
\begin{aligned}
& \text { a. Equipnent design and construction } \\
& \text { b. Development of testing techniques and procedures } \\
& \text { c. Testing program and data analysis. }
\end{aligned}
$$

Equipnent design and construction was probably the most difficult phase of the program since it was desired to construct repetitive losding equipment which afforded maximum llexibility of operation and which would be adaptable to future research. It was determined that in general a dynamic triaxial testing apparatus permitting measurement of pore pressures in the sample was necessary. It was further determined that this apparatus must be designed and constructed locally after inquiry revealed that it was not commercially arailable. The test equipment thus comprised two elements s the repetitive or dymamic triaxial loading apparatus and the pore pressure sensing and recording apparatus together with related appurtenances. The equipment was designed by the author and 
fabricated in the Civil Engineering machine shop.

\section{Dynamic Triaxial Loading Equipment}

The dynamic loading equipment used for the triaxtal tests is shown schematically in Flgures $I$ and 2. This equipnent is based generally on a quite successful earlier design and used by Havers (33) in his study of subgrade pumping. The loading energy is provlded by compressed air actuating a piston type air cylinder. The magnitude of the laad carried to the soll sample by the piston can be controlled by regulating the air line pressure. Compressed air is supplied by a 3 H.P. air compressor operating at 120-150 psi outlet pressure. From the air compressor the air passes into an accumulator tank of 0.9 cu. ft. capacity and through a cambination 40 micron fliter, pressure regulator and oiler. As indicated in Flgure 2 the main supply Iine branches to the dual loading units which can be operated either singly or in unison. The system is designed for maximum flexibiltty of loading and calibrating operatIons in that the piston can be made to operate either single or double acting under dynamic loading, or maintain continuous variable static loads. The desired dynanic or static loading condition is controlled by the mamually operated air line valves together with the four-way pllot-operated solenold valves. (Flgure 2).

To energize the oystem the line switch is closed maintainting current through the normaliy closed contacts of the switch in the counter to the normally closed contacts in timer. This impulse energizes the solenold valve causing the port which is normally closed to open for the down or pressure stroke of the piston. After the 


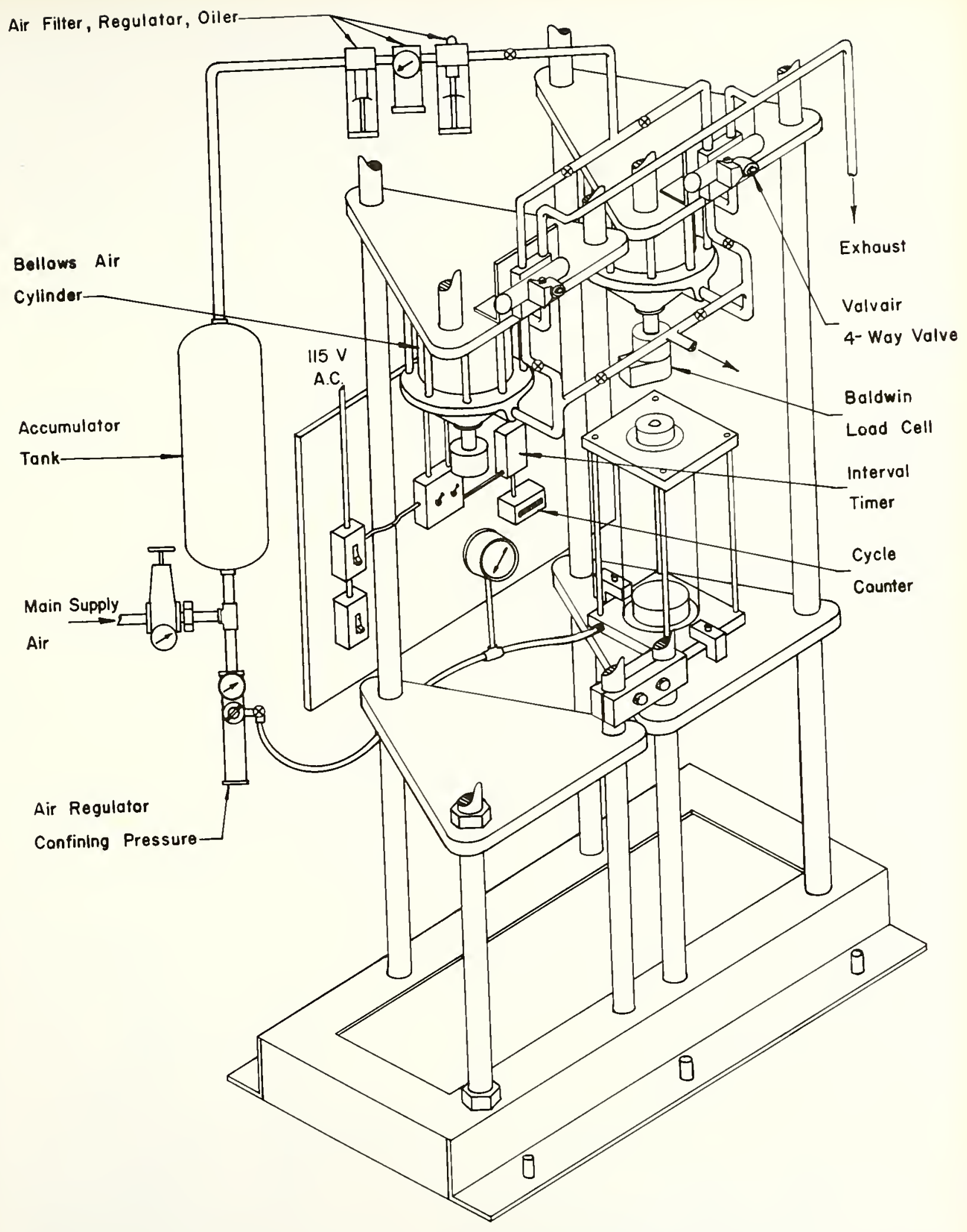

FIGURE I.

REPETITIVE

LOADING

APPARATUS 


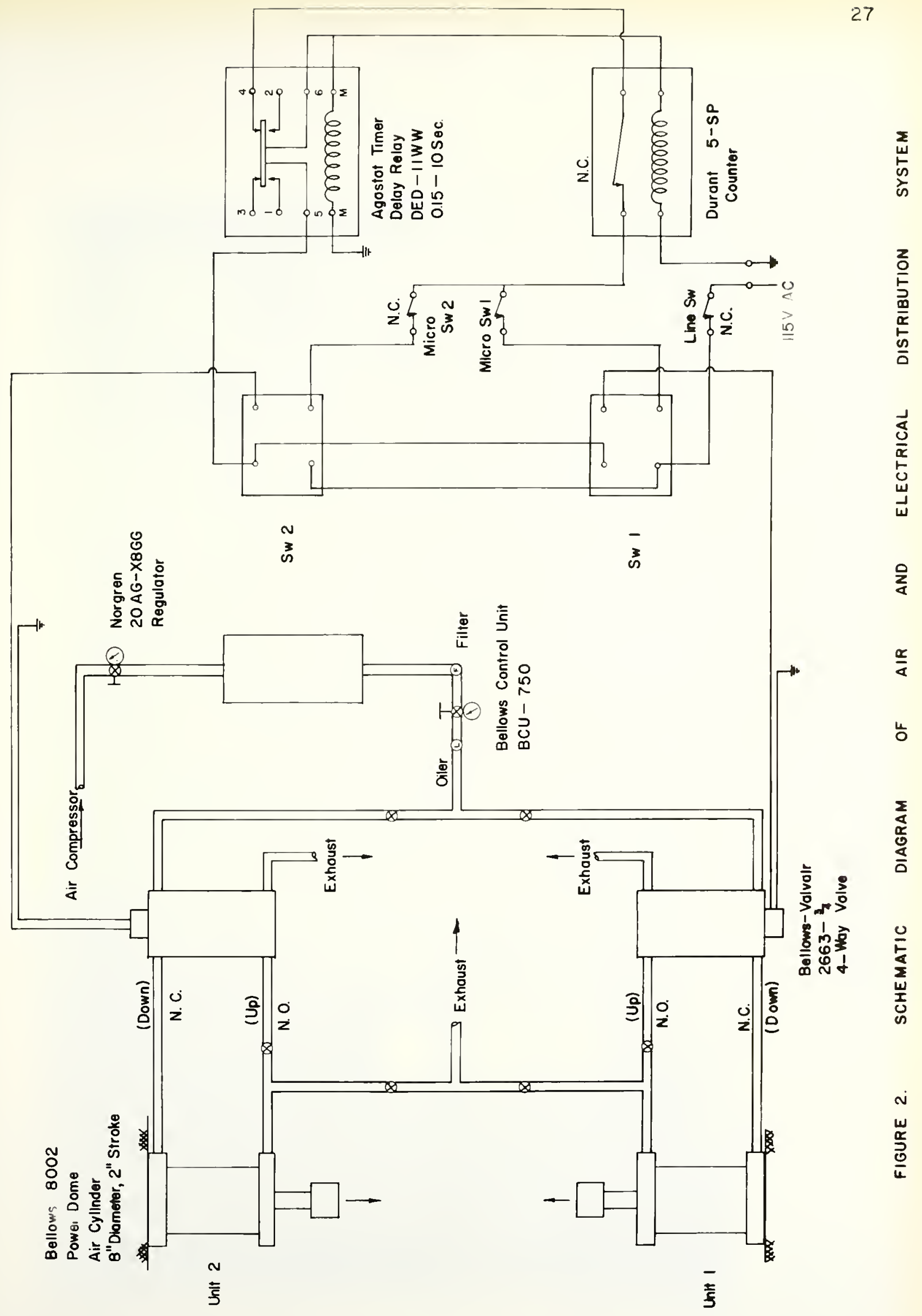




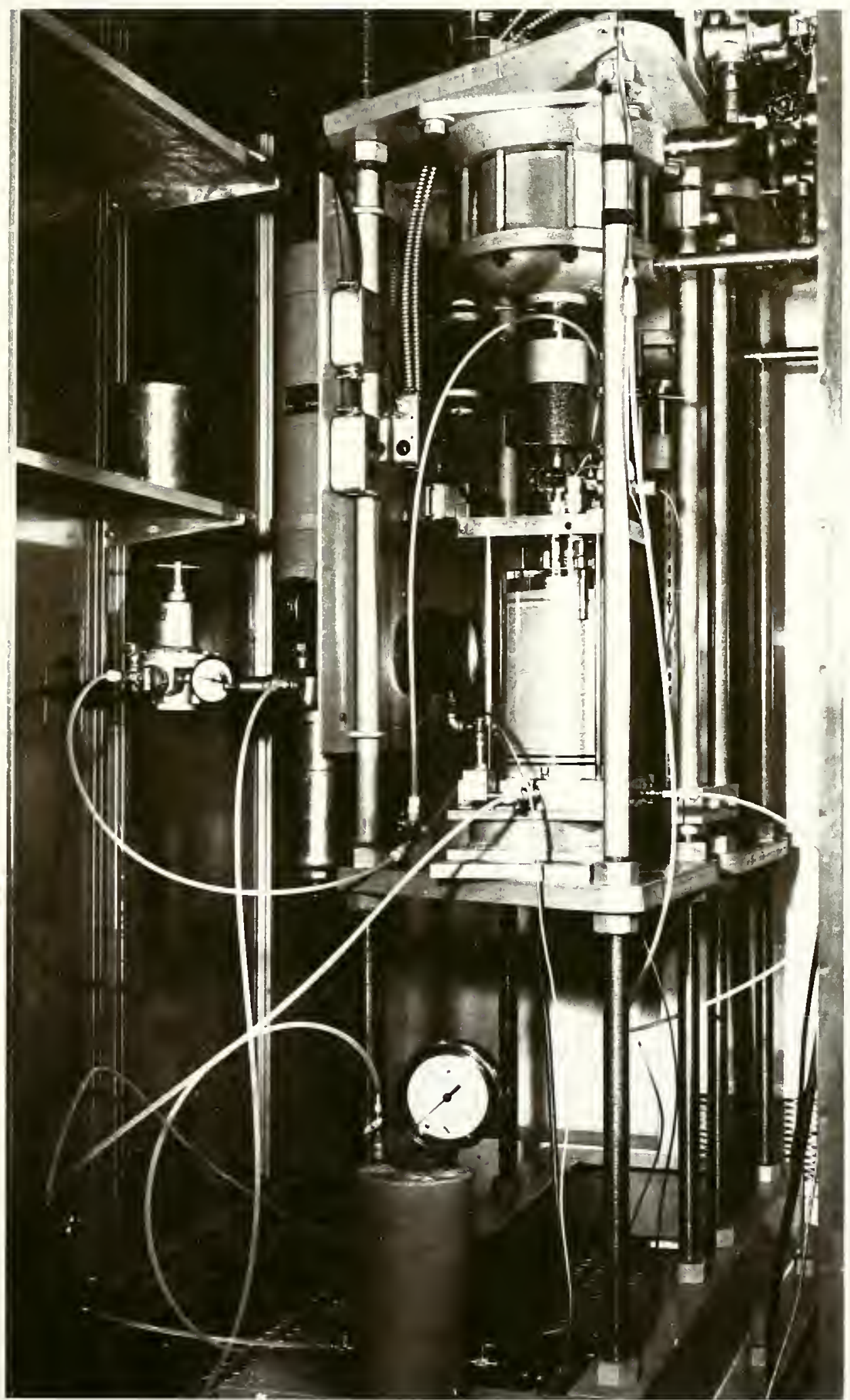




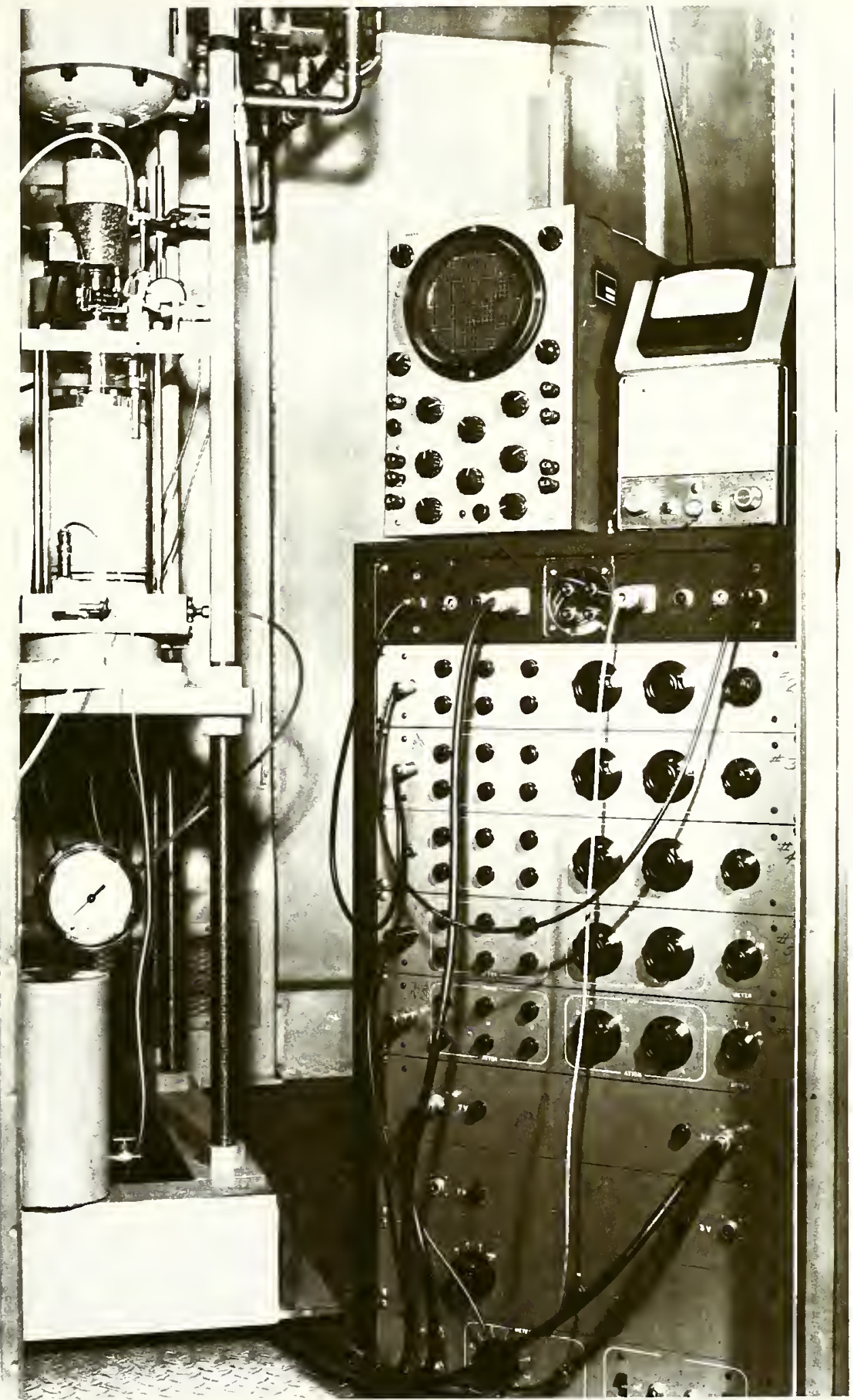

PLATE 2. ELECTRONIC EQUIPMENT IN CONTROLLED TEMPERATURE CHAMBER , 


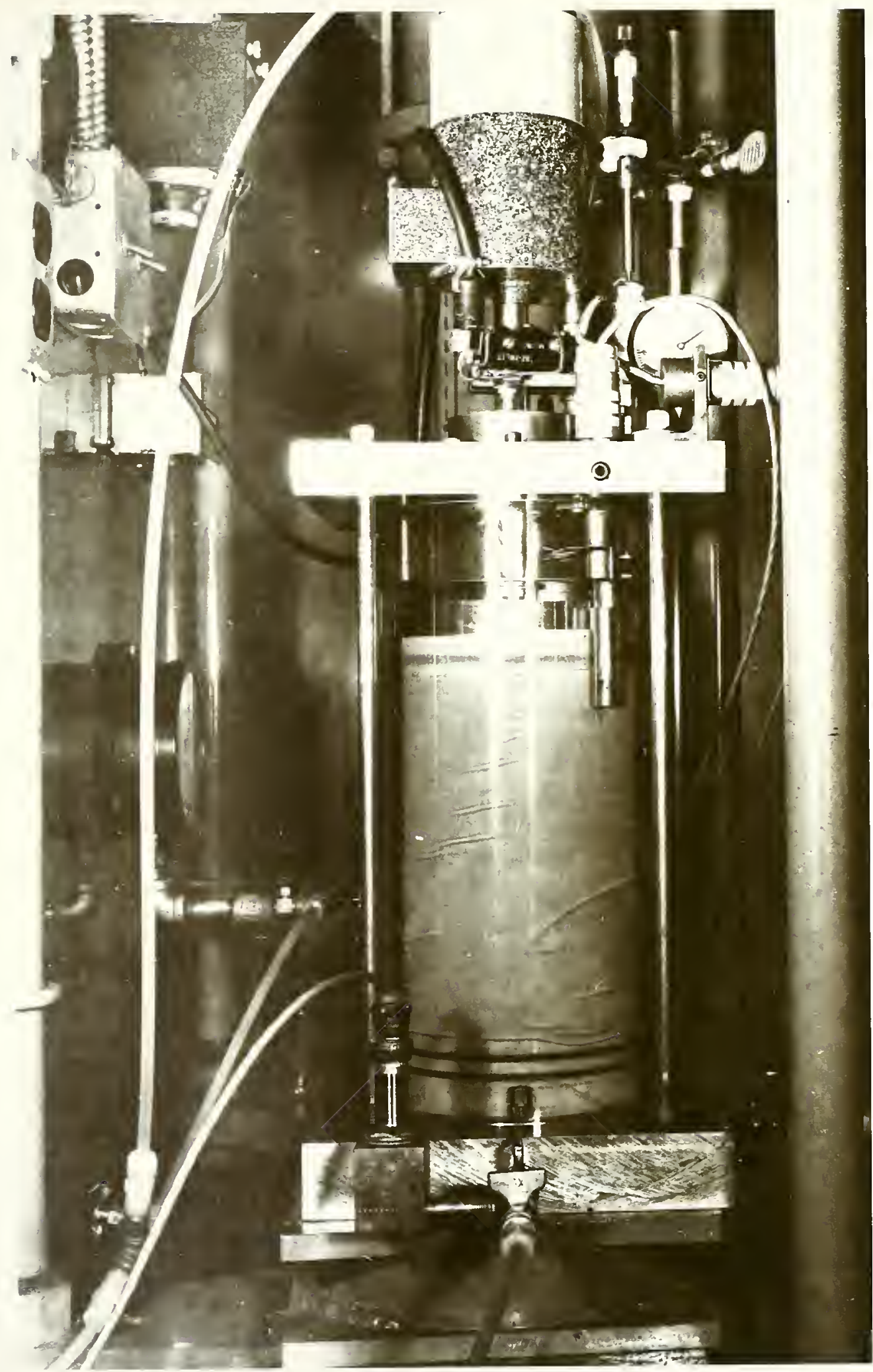

PLATE 3. TRIAXIAL CELL WITH SPECIMEN. note failure plane deVEloped in test. 
controlled delay in the timer has elapsed, the contacts in the counter open causing one count to be recorded and de-energizing the timer which de-energizes the pressure stroke of the piston. The timer controls both the duration of load as well as the interval between load applications for any desired number of repetitions as set on the counter. An adjustable microswitch set on the loading piston of the tri-axial cell w1ll shut off the entire apparatus after the sample fails or the deformation reaches a pre-determined magnitude. The foregoing sequence is that which takes place for a single-acting movenent in which it is desired that the loading piston remain in continous and complete contact with the soll sample. For operation as a double-acting system, the manual atr control valves are opened or closed as necessary to obtain the desired action; no change in the timing sequence is required.

\section{Controlled Temperature Room}

Accurate determination of pore pressures and volume changes which are temperature dependent, requires that the testing be performed in a temperature controlled enviroment. This was achieved by use of a controlled temperature chamber in which the loading apparatus and electronic gear was installed. In addition to the obvious advantage obtained by use of the chamber for fluid measurements, a secondary, though important benefit was that of a stabilized temperature for all electronic sensing and recording elements thus improving their performance and reliability.

The chamber is 6 feet wide, 8 feet long and 7 feet high. Control of temperature is obtained through heating coils and a 
refrigeration unit coupled to a thermostatic control unit. The temperature of the unit can be adjusted to operate fram $0^{\circ} \mathrm{C}$ to $40^{\circ} \mathrm{C}$ at a temperature differential of $\pm \frac{10}{2} \mathrm{C}$. Current characteristics are $230 \mathrm{VAC}$ and 4800 watts. An important feature of the chamber is the diffusion of the conditioned air by mechanical convection which assures uniform temperature and humidity at all locations in the roan. The movement of atr in the chamber tends to cause some discomfort to personnel during prolonged periods of testing and in addition the recirculated air tends to become musty. Corrosion of metal is also somewhat accelerated in such an environment.

It was important to provlde a firm anchored support for the loading apparatus entirely froe of contact with the chamber. This was achleved by carrying the welght of the apparatus through the floor of the chamber on $s 1 x$ anchor rods. These anchors are not in contact with the chamber at any point and thus extraneous disturbances by personnel in the roon are also avolded. (Flgure 3)。

\section{Electronic Recording Equipment}

The electronic recording equipment used in this study consiated for the most part of modifled components designed and used on an earlier Investigation of subgrade support characteristics (34). A block diagram of the components is shown in Flgure 4 and the bridge and calibration unit in Flgure 5. The sensing elements in Figure 4 are numerically keyed to the specinen, Flgure 6.

The system is composed of a power supply unit, a seven channel amplifying and control unit, a six channel recording galvanameter 
$x$
0
$x$
0
2
4

$\frac{w}{4}$

0
2
0
4
0
1

능

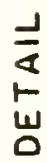
$=\infty$

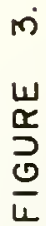




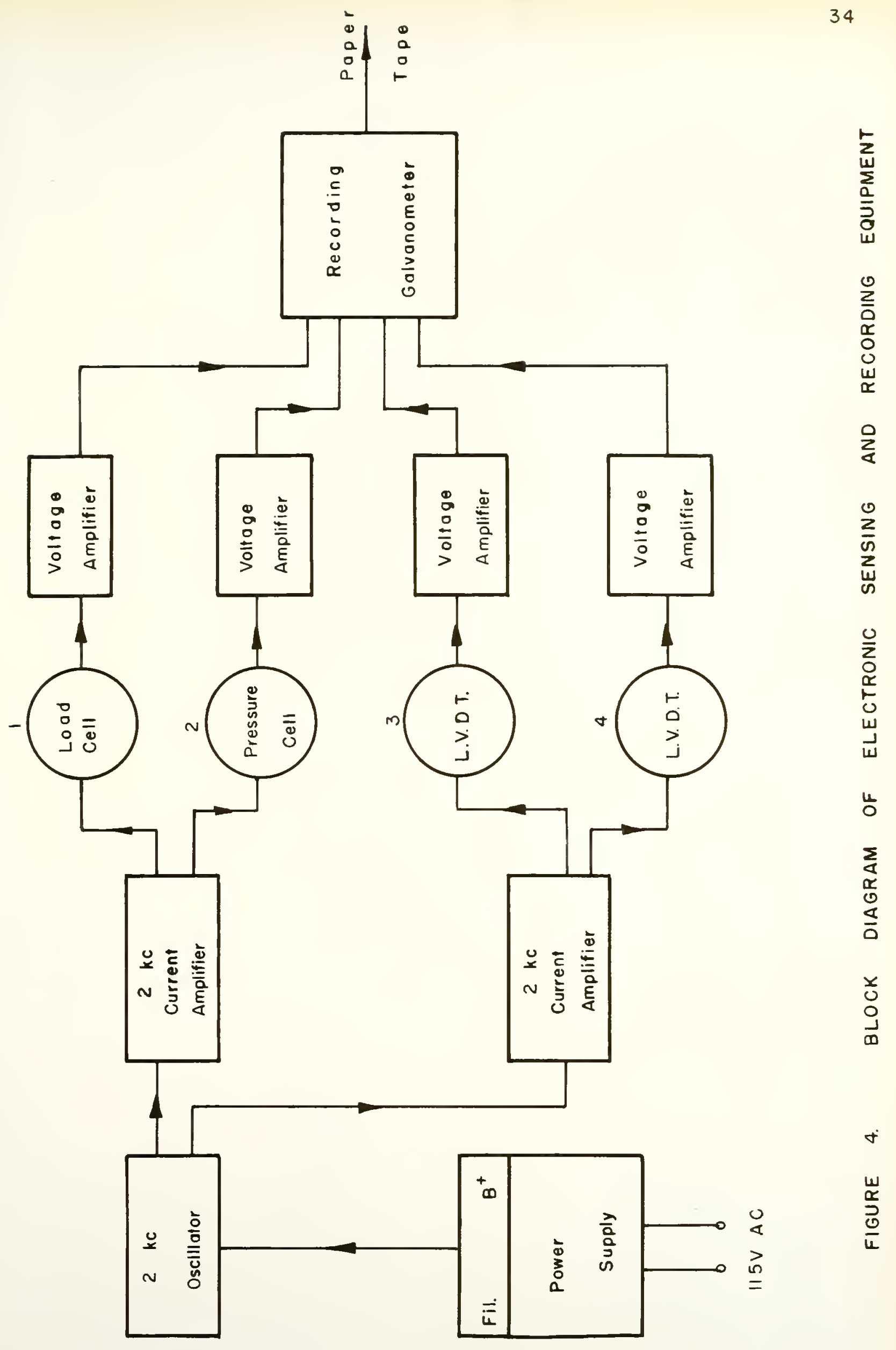




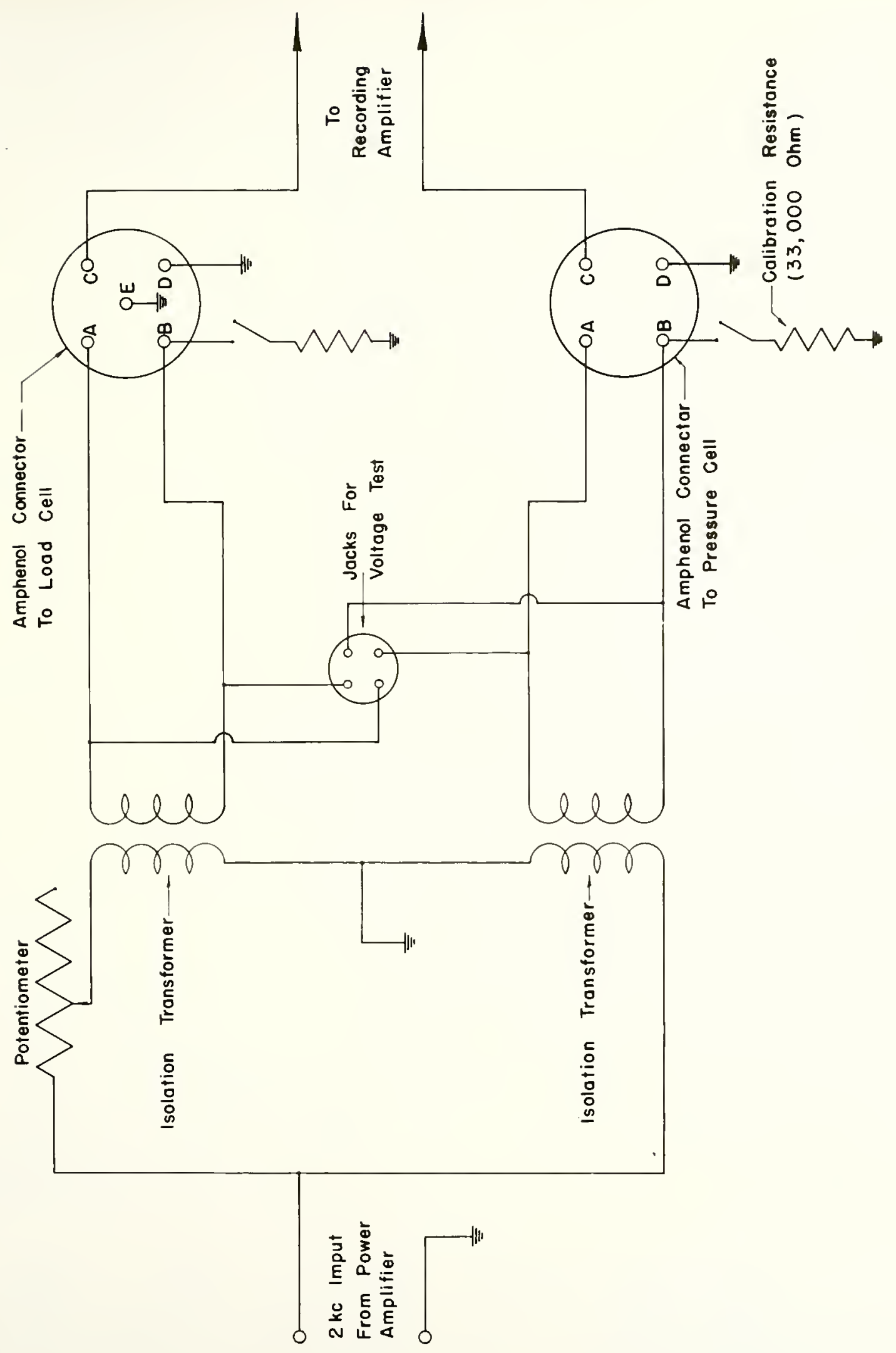

$\stackrel{5}{z}$

岕

岁

$\underset{\frac{z}{\alpha}}{\frac{z}{6}}$

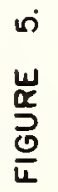




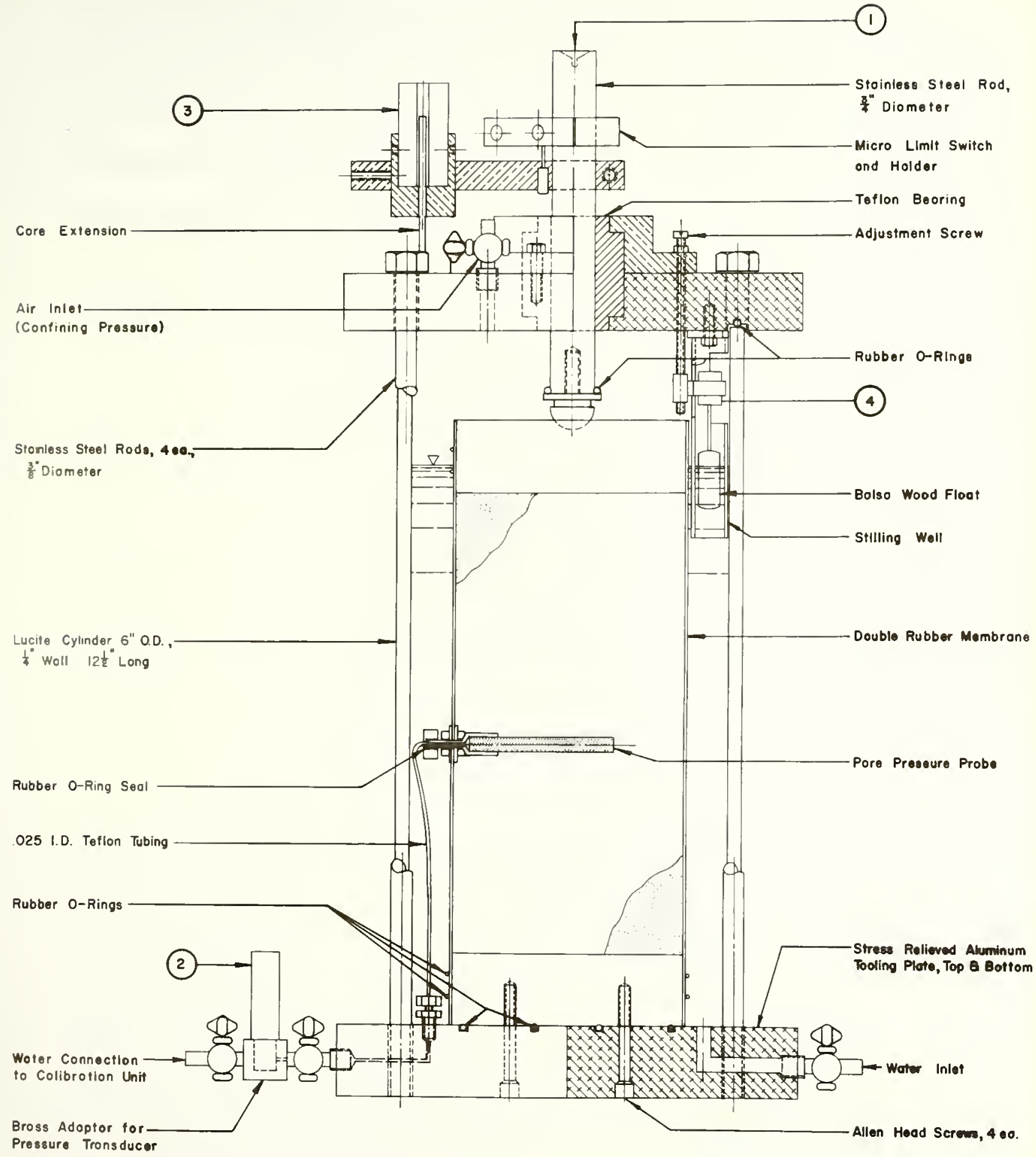

FIGURE 6. TRIAXIAL CELL SHOWING ELECTRONIC PICKUP DEVICES 
unit and the various electronic pick up derices. The amplifying and control unit contains seven amplifiers, seven frequency modulating units, seven power amplifiers for driving galvananeters, oscillators generating roltages at $30,000 \mathrm{cps}$ and $2,000 \mathrm{cps}$ and two power amplifiers. The amplifylng unit was modifled by removing one amplifier and Inserting another power amplifier to provide additional energy for the sensing elements. In addition a bridge and calibration unit (Flgure 5) was designed and constructed to permit use of strain gages with this unit since its original design was specifically for use with Schaevitz OLOL linear varlable transformers. The bridge unit was inserted in the position formerly occupied by the topmost amplifier. The rectified $30 \mathrm{ke}$ roltage is filtered and used as a blas for the power amplifier; the $2 \mathrm{kc}$ voltage is amplified by the two power amplifiers which serve as the energy source for the transducers. The power for the transducers either goes directly to the transducer as in the case of LVDT's or It is isolated from ground when used with wheatstone bridge strain gage untts.

The galvanometer unit consists of six BL-902 pen motors (input impedance $1450 \mathrm{ohms}$ ) and one event marker. All channels may be used with elther ink writing or electric writing pens on sensitized paper. In this study the electric stylus was used.

For further detalled information on the principle of operation see reference (34) and Appendix A. 


\section{Sensing Elements And Calibration}

Referring to Flgure 6, the relationship of the sensing elements to the test specimen is shown.

A $0-5000$ pound load cell (1) was used to measure the magnitude of the applied load including its own weight and that of the moving piston. The load cell utilizes four SR-4 strain gages wired in a Wheatstone Bridge circuit and has a precision of $\pm \frac{1}{4}$ percent full scale calibration accuracy. Calibration of the load cell was accompllshed by loading the cell in the environmental chamber against an accurate proving ring. Galvanometer and proving ring deflections were recorded for varying magnitudes of applied load. The amplifier gain was brought into proper adjustment and the galvanameter pen zeroed. Simultaneously the power amplifier output voltage was adjusted to operating voltage as noted on a voltage meter. Recordings were taken for several cycles of load and unload and the mean of the ralues taken as the most probable value. With the cell completely unloaded,1.e. dead load of the piston removed, the calibration resistance was switched on and the galvanameter pen deflection was noted and recorded.

For measurement of the pore pressure a PT-25, 0-100 psia pressure transducer was employed as shown in Figure 6. The cell employs a miniature strain gauge in the configuration of a fouractive-arm Wheatstone Bridge. Performance characteristics include a maximum nonlinearity of 0.5 percent full scale and repeatability maximum of 0.1 percent full scale.

Calibration of the pressure cell was accomplished in much the 
same manner as the load cell. A closed pressure chamber was constructed of about one liter capacity. The transducer adapter was threaded into the base and the chamber filled one half with de-aired water. The pressure cell was then screwed into the adapter, its base being in and below water such that no air bubbles were present in the system. Air was admitted to the top of the chamber and its pressure recorded on an accurate laboratory pressure gauge. As the pressure was varied galvanometer deflections were recorded for each increment of pressure change over a series of several cycles of loading and unloading. The mean of these values was taken as the most probable value. Power amplifier output voltage and calibration resistence deflection were also noted and recorded. A high degree of linearity was obtained for both of these devices, particularly at the middle and upper ranges of the calibration curre.

Deformation was measured by a linear varlable transformer. This was mounted in an adjustable holder which in turn was mounted in a bracket attached to the loading ram of the trlaxial cell. The transformer core with a brass extension was permitted to react against the top of the cell. Thus, even though the cell deformed very slightly under load, the IVIT measured only the true deformation of the ram and hence of the soll sample. Calibration of the LVDT is described in Appendix A. The caltbration procedure was simplified by using a micrometer attachment fitted wh an adaptor on the shaft which screwed into the transformer core. Thus, once the null position was found, the range could be set on the galvanometer by 
ralsing the core an exact amount (.1250 inch) with the micrometer. After calibration, the adaptor was screwed out of the core, the micrometer removed and the transformer was ready for use.

\section{Volume Change}

Although the importance of the relationship between pore pressure and volume change was recognized in this research program, the technique of measuring volume change was the last to be successfully accomplished. This delay was caused primarily by attempting during the early development period to measure volume changes rapidly with respect to time instead of the rolume change taking place during the conduct of the entire test. Accordingly the first volume change device, shown in Figure 6, was based on a float principle which recorded the change in cell fluld level as the test progressed. By relating the incremental increase in fluid level with the deformation, and knowing the area of the specimen cap the volume increase or decrease could be camputed. This device was eventually perfected and used for one test. It was successful in principle but unsuccessful fran the test standpoint because its range was not large enough. This in turn was directly the result of being obliged to use a small OLO LVDI due to space requirements which did not have the necessary range of movement.

The fallure of the float device required that other techniques be Investigated. An earlier research project by Schaub (35) on volume changes in bituminous mixes during the trlaxial test made use of the technique used at Imperial College of Science, University of London and descrlbed by Bishop and Henkel (17). This device was 
adapted to this research and is shown schematically in Figure 7. In partly saturated solls a volume change occurs due to densification of the soil and compressibility of the air in the pore space. This change is determined by measuring the volume of water (or other cell fluid) entering or leaving the cell as the test is conducted. The measurement is made by observing the displacement of a free surface between the water supply to the cell and some other liquid such as mercury. Any change in volume of the soil causes a change in rolume of the liquid in the cell which in turn is reflected by a change in the level of the mercury in the measuring tube. A differential head of mercury between the mercury reservoir and the measuring tube is avoided by suspending the reservoir on a callbrated spring which changes length directly as the mercury level in the measuring tube fluctuates.

Referring to Figure 7 the mechanism of the device is shown in detail. With application of pressure to the cell, a decrease in volume of the sample takes place which causes the volume of the cell liquid to increase and the level of mercury in the measuring tube to rise. For the soils studied in this research program a decrease in volume of the soll took place rapidly at the beginning of the test. This caused the mercury level to rise further until the volume change stabilized or reached an equilibrium value. In those tests where fallure did not occur and the sample was tested statically to failure, the mercury level was lowered in the measuring tube as volume expansion took place. By reading the metric scale adjacent to the measuring tube the changes in level 


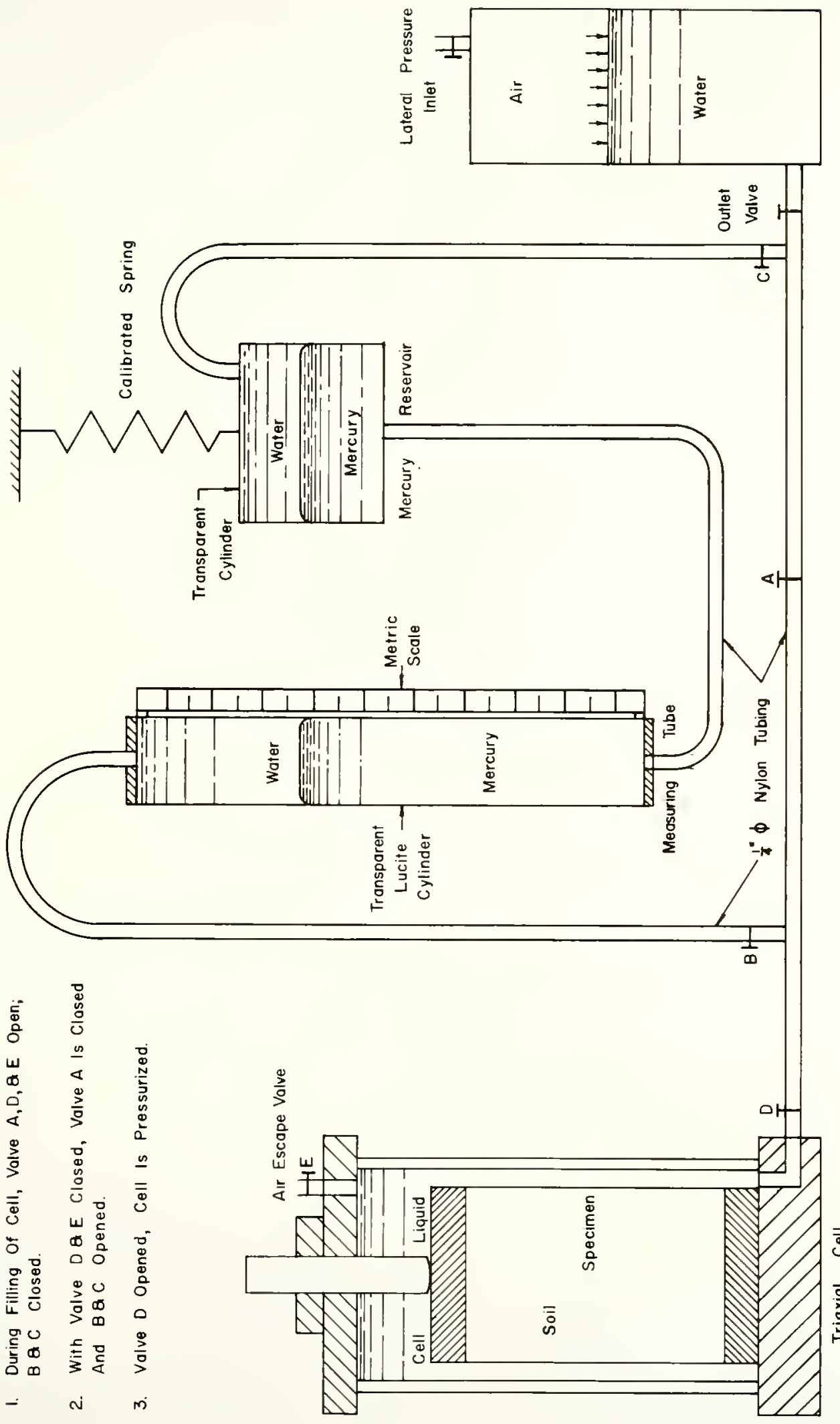

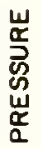

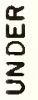

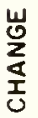

$\stackrel{\frac{u}{2}}{3}$

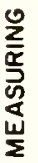

옹

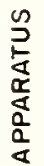

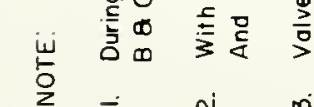


of the mercury were read to the nearest millimeter. For this device, a change in level of one millimeter corresponded to a volume change of .030321 cu. in.

The observed displacements in mercury level must be corrected for temperature differentials, expansion of the lucite cylinder under confining pressure and for volume changes reflected by movement of the loading ram. In the case of temperature changes, the use of a controlled temperature chamber prevented any significant volume changes arising from this source. During an increase in cell pressure the cell itself expands causing a volume change which must be deducted from the observed displacement of water. This change was established by conducting calibration tests at various confining pressures. An exact dummy was machined to dimensions of 4.000 in. diameter and 8.000 inches in height. This was placed in the cell and the confining pressure applied. It was noted that the change recorded for the varlous confining pressures occurred almost instantly and did not increase appreciably with time after the first 10 minutes. Accordingly the confining pressure was applied for the period of at least ten minutes before each test so that this correction did not need to be calculated out. During loading of the sample, water is displaced by the penetration of the loading ram into the cell causing a volume change which must be added to the observed decrease in volume. This change can be calculated based on the area and penetration of the ram. Data on calibration of the cell for various confining pressures as well as tabulations of volume changes resulting from penetration of the ram are presented 
In Appendix C.

There are several sources of error to be aroided in using a device of this type to measure rolume change. One of these is the possibility of entrapment of air in the top of the triaxial cell. This air wll be compressed at high confining pressures and eventually enter into solution causing erroneous volume changes. Another source of error is that arising from liquid leakage in the cell and volume change apparatus. Thus all joints must be tight and leakproof. In early tests using this apparatus some errors resulted In the measured rolune changes due to both sources (tests 30B30, $30 B 50,30 A 30)$. In addition, for tests of long duration errors may arise fran creep in the Luclte cylinder and leakage through the rubber membrane.

\section{Test Conditions}

Prior to commencing design, or purchase of any equipment considerable thought and planning was given to the conditions of test since these would control the size and type of equipment which was necessary.

The first consideration was given to sample size. A granular materlal was to be used although of small diameter. In addition the sample would be compacted after laboratory mixing in such a manner as to permit the specimen to be handled. For such samples, the $4^{\prime \prime}$ diameter sample is custamary, since the sane compaction equipment can be used as is used for the standard compaction test. Furthermore, the measurement of pore pressure utilizing a probe Indicated a sample as large as practicable. Normally an $1 / d$ ratio 
of 2.0 to 2.5 is used, thus the sample should be at least $8 \mathrm{~m}$ high.

As was mentioned earlier, the accurate messurement of pore pressure can only be accomplished under conditions where the ambient temperaturo differential is zero or close to zero, so that no pore pressure changes can be suspected as being derived from changes in temperature. Thus the equipment was placed in a controlled temperature envlronment where a constant temperature fram 00 to $40^{\circ} \mathrm{C}$ could be maintained. The decision as to what temperature to use in tegting was mainly one of canfort for the personel and economy of operation. The value of $68^{\circ} \mathrm{F}\left(20^{\circ} \mathrm{C}\right)$ was thus selected as meeting the abore conditions in addition to being a standard reference temperature for many materlals.

The matter of rate of load application was quite difficult to reconcile. Factors to consider were equipment capability, pore pressure build-up and dissipation, relation to fleld conditions and continuity with previous work. The limitation on equipment was Imposed chiefly by the port size of the reducing valve on the main air line and the volume of air necessary to bulld up the load to its maximum value. From prevlous experience (36) it was known that some time delay could be expected. In order to keep this to a minimum the alr cylinder and valves should be as close to each other as possible and the cylinder as small as possible consistent with the expected loads. Timers were not a problem. The possible range for equipnent design purposes was .I to .10 seconds interval between load applications and .5 to 10 seconds load duration.

Fran the standpolnt of pore pressures, the rate had to be slow 
enough so that the pore pressure build-up during load would have time to dissipate prior to the next load application, and fast enough to prevent redistribution of the pore pressures in the sample with load application. If performed too fast on the other hand, the response of the equipment might not indicate the true magnitude of the pore pressure change.

Seed, Chan and Monismith (19) found that for compacted clays the frequency of load application was not related to total deformation. Haynes (26) in his study of the AASHO Test Road base course materials used a frequency of 40 repetitions per minute; Larew (25) used 20 cycles per minute. Although some of the early pilot tests were run at 30 cycles per minute, it was found that the equipment performed very well at 38 to 40 cycles per minute with 1 second load duration and $\frac{1}{2}$ second interval between load applications. This rate was used for all tests except where indicated otherwise.

No program of research on soils should attempt to fix limits on or assign values to all the variables under consideration. On the other hand some intultive reasoning must be used to set some of the boundary conditions. This was particularily true of the deviator stress used for the specimens. If the stress selected is too high the specimen will fail under few load applications, and conversely if too low will result in low strains and pore pressure values. Accordingly the decision was made to $\mathrm{flx}$ the deviator stress at same percentage of the poak compressive strength of the soll sample as determined from a static undrained (UV) triaxial test. All other test conditions were to remain the same. This was done and the deviator stress 
fixed at 30, 40 and 50 percent of the peak compressive strength at each confining pressure.

Lastly the confining pressures were selected. These had to be high enough so that the pore pressure would be above the vapor pressure of water to prevent cavitation during the test 4 yet not be dangerous to the personnel. Although some pilot tests were run as high as 50 psi lateral pressure, this was changed during the test programming to 30,35 and 40 psi.

4Bishop and HenkeI, 1957, pg. 107 
SOILS AND MIX DESION

The soils used in the study were selected on the basis of research continuity. A number of research projects at Purdue, both past and present, have used local solls of essentially the same properties. Indeed, the source is usually in the same general area. The desire to expand this research in the area of dynamic testing of solls, led to the early decision to work with these solls. For correlation purposes and because of its known properties, Ottawa sand was selected for the aggregate. Ottawa sand has both a high degree of spherlcity and smoothness in sizes above the No. 100 sieve. Since little amount of the fractions below this size exist in situ, the smaller fractions are produced by crushing. These small sizes are canposed of grains having a high degree of angularity and low degree of smoothness. The maximum vibrated dry density of the test sand was found to be 108 pcf. with a corresponding porosity of 0.35 . The binder, considered for this study to be the minus No. 200 sieve fraction was chosen on the basis outlined above and is known locally as the "Crosby-B" soll.

The Crosby, B horizon is a soil very common in Indians derived fram glacial drift and can be described as a silt loam. Total clay content averages 35 percent of which the majority of the clay mineral 
is 111 te and chlorite. 5 Less than 10 percent is coarser than silt size $(.05 \mathrm{~mm})$ and 100 percent passes the No. 10 sieve. Tests show the liquid IImit to average about 34 percent and the plastic IImit 20 percent.

of the very large number of variables to consider in such a test program, it was recognized that the binder content was one of the most important. Accordingly the sand gradation was held constant based on a design gradation computed from Talbot and Richarts' expression $p=100\left(\frac{d}{D}\right)^{n}$ where $n=0.5$ as shown by Fuller for maximum density. The computations, using $D$ equal to the No. 10 sieve size resulted in a binder content which was varied as follows:

$$
\begin{aligned}
& \text { a. Maximum binder required for maximum density, } \\
& \text { b. Excess binder, } \\
& \text { c. Minimum binder. }
\end{aligned}
$$

Referring to Table 1 the percent by weight passing each sieve size can be noted $(n=0.5)$.

Thus the percent binder, or the minus No. 200 sieve fraction is seen to be 19 percent. This value of 19 percent established the binder content for the A series for which maximum density was the criterion.

5 Hampton, D., "Statistical Analysis of Soil Variability", Unpublished Ph.D. Thesis, Purdue University, June, 1961, pp. 67-69. From discussion with Dr. Hampton and inspection of the $x$-ray diffraction recordings. 
TABLE 1

Summary of Mixture Gradation Data

$\begin{array}{lccccc}\begin{array}{l}\text { Sieve } \\ \text { Numbert }\end{array} & \begin{array}{l}\text { Opening } \\ \text { Inches }\end{array} & \begin{array}{l}\text { Percent } \\ \text { Passing } \\ \text { A Mix }\end{array} & \begin{array}{l}\text { Percent } \\ \text { Passing } \\ \text { B Mix }\end{array} & \begin{array}{c}\text { Percent } \\ \text { Passing } \\ \text { C Mix }\end{array} \\ 10 & 0.0787 & 100 & 100 & 100 \\ 16 & 0.0469 & 77.2 & 80.0 & 75.8 \\ 20 & 0.0331 & 65.0 & 69.3 & 62.8 \\ 30 & 0.0232 & 54.4 & 60.0 & 51.5 \\ 40 & 0.0165 & 45.8 & 52.4 & 42.3 \\ 50 & 0.0117 & 38.6 & 46.1 & 34.6 \\ 70 & 0.0083 & 32.6 & 40.8 & 28.2 \\ 100 & 0.0059 & 27.4 & 36.2 & 22.7 \\ 200 & 0.0029 & 19.0 & 29.0 & 14.0\end{array}$

*0.S. Bureau of Standards 
Fram the work of Miller and Sowers (31) the amount of binder required for nearly cohesive behavlor was flxed at 10 percent more than for maximum density or 29 percent. In the tests conducted during the aforementioned research, Mller and Sowers found that if the volume of volds in the compacted aggregate is assumed to be just filled with compacted binder, the resulting amount was 22 percent. Similarly they found that the mix exhibited pure cohesive behavior at binder contents above 33 percent. Applying this relationship to this research led to the decision to use 10 percent more binder or a total of 29 percent in an attempt to obtain data for the boundary condition of almost pure cohesive beharior.

Similarly the lower range of 14 percent binder was arbitrarlly fixed as a reasonable lower value for which more nearly cohesionless beharior would be obtained and which at the same time would be high enough to permit relatively uniform saturation of the specimen and handling stability.

Once the elements of the test specinen had been established, the matter of compaction was considered. This was a problem of more than ordinary interest since several factors had to be considered when pore pressures were to be measured which were not applicable to ordinary compaction procedures.

One of these factors was that of placement of a probe in a sample containing aggregate compacted to a high density. Obviously this could not be accomplished after compaction was completed. Thus it must be accomplished at the time the specimon was compacted, yet the specimen must adnit of high or desired density, and 100 percent (essentially) saturation in order to obtain valld test data. 
Chamberlin (36) found that vibration of the mold for 60 to 90 seconds on the upper tray of a Gilson mechanical sieving apparatus produced maximum density for open graded base course materials. For open graded mixes this method is not only satisfactory but is nearly mandatory if degradation is to be avoided. When binder is added in any proportion such that the $m i x$ is no longer open graded two possibilities exist. Either the mold and soll can be vibrated together or dynamic loads can be applied to the soll alone to achleve compaction. The first procedure cannot be effectively utilized for dense graded mixes, hence the latter must be used. The greatest difficulty in applying vibration to the soll lies in evaluating the compactive effort or energy imparted to the soil sample.

Kneading compaction was given some consideration, primarily from the standpoint of the clay mineral structure formed in a kneading compactor as well as the similitude with field compaction methods. The clay structure is more oriented in kneading compaction than that produced by impact compaction tests. Again in the latter, the clay particles are more orlented than those in a static test. Since the binder soll averaged about 35 percent clay, a total of approximately 6.7 percent (A Series) of the sample by weight was composed of particles in which the surface forces predominated and the remainder composed of particles in which the gravity forces predominated. Evidently clay structure contributed relatively little to the strength properties of the sample.

A considerable body of respected opinion holds that impact compaction techniques no longer serve for laboratory tests. This 
fact and the foregoing discussion notwithstanding, it was determined In a comprehensive series of tests that the impact compaction method conducted in accordance with ASTM Specification D698-42T produced resulting densities highly consistent in molding water content as well as dry density; this method of compaction was used throughout.

Furthermore in vlew of the intent to measure pore pressures It was felt that a less oriented clay stmeture would Improve the degree of saturation obtained as well as reduce the tendency of the sample to swell, particularly during the period when the sample was being readied for testing and the lateral pressure was not yet applied.

The modified AASHO densities and optimum moisture contents are reported below:

\begin{tabular}{lcccc} 
Mix & $\begin{array}{l}\text { Maximum } \\
\text { Density pef }\end{array}$ & $\begin{array}{l}\text { Optimum } \\
\text { m.c. percent }\end{array}$ & & $\begin{array}{l}\text { Binder } \\
\text { Content, percent }\end{array}$ \\
\cline { 3 - 4 } & 136.5 & 6.35 & & 19.0 \\
B & 140.5 & 6.45 & 29.0 \\
C & 135.5 & 6.25 & 14.0
\end{tabular}

Hydroscopic moisture in the binder was determined and the added water then computed. Densities were computed fram oven dry weight of the sample after test; specific gravity of the soll grains averaged 2.67 and for the Ottawa sand 2.65 . It w1ll be noted that the compacted moisture contents tended to average about one-half percent below optimum. 
TEST PROCEDURE

This section of the report details the procedures followed in preparing a sample for testing, testing the sample in the repeated load apparatus and data recording procedure. Specific problems of probe design are described.

\section{Sample Preparation}

The proportion of each fraction making up the design mix being used was welghed out carefully and thoroughly mixed in the dry state. The anount of water (less hygroscoplc molsture in the binder) necessary for compaction was bolled, cooled to room temperature and mixed into the dry soll.

After mixing was campleted the soll was compacted in the 4 inch diameter by 8 inch high split mold. In each case it was desired that the sample be compacted to maximum density at optimum moisture for the design $\mathrm{mix}$ in question. During compaction a brass dummy of the same dimensions as the probe was placed in the soil at mid-depth. The dummy had a threaded screw hole in the base to facilitate removal when compaction was completed. After carefully leveling the top surface and fllling voids from loosened sand grains the specimen was removed and welghed. As quickly as possible the dummy was removed and the probe which had been de-aired by bolling for 15 minutes was inserted. The top of the probe minus 
the cap was covered with a one centineter square plece of filter paper to restrain sand grains from entering the small orifice and screw holes. Insertion of the probe was easily accomplished since the dlameter of the dumuy was made 0.005 inch greater than the diameter of the probe. In addition the round and semi-round grain shape of the Ottawa sand permited a relatively smooth surface of sliding. The use of a dumy during compaction and removal afterwards was considered to be reasonable on the basis of a remolded soll sample. Subsequent saturation in the saturation cell permitted the probe and soll to reach complete contact throughout.

When the probe had been inserted, the sample was transferred from the base of the split canpaction mold to the base of a split aluminum saturation mold (Plate 4 ). This mold was designed and fabricated for use during a previous research project by Haynes (26). It is camposed of a split thin wall aluminum tube to which a recessed aluminum top and bottom plate has been fltted and fastened by three $3 / 8$ inch diameter brass rods. Holes $1 / 8$ inch in diameter were drilled at regularly spaced intervals over the periphery of the tubing to permit flow of water into the sample. The interior dimensions of the mold are exactly 4 inches in diameter and 8 inches high when assembled.

Previously prepared damp filter paper was wrapped around the sample, smoothed and the mold clamped tightly around 1t. The saturation mold containing the sample was then lowered into the saturation tank and covered with de-aired water. The cover of the tank was positioned, the gasket wetted and the nuts turned tight. 

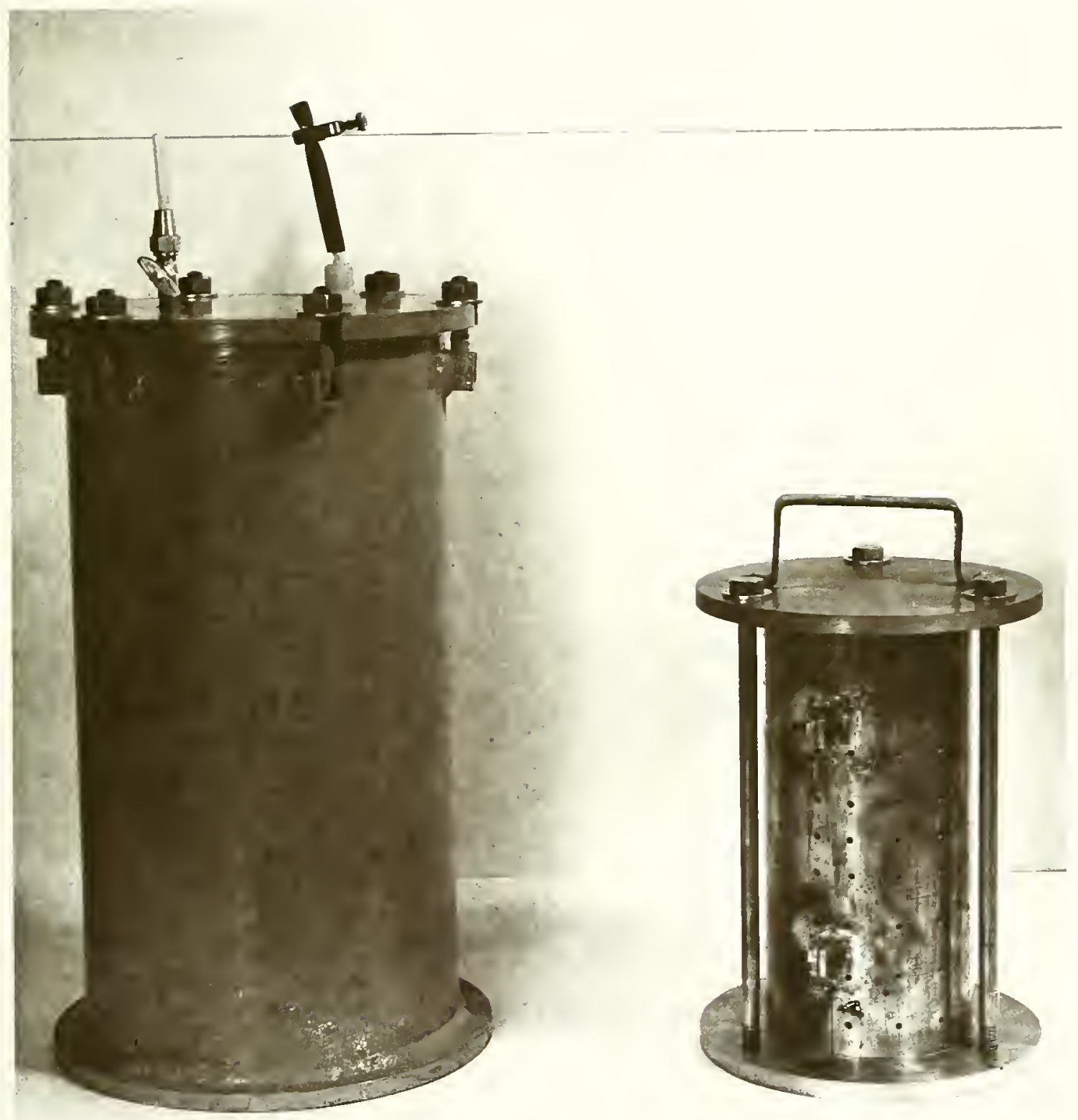

PLATE 4 SPLit SATURATION MOLD \& SATURATION CELL 
A vacuun was then applied for 15 minutes after which the hoses were clamped securely closed and the tank replaced in the controlled temperature room for 24 to 48 hours.

\section{Testing}

After considerable trial and error, modiflcations to equipment as well as experimentation, a testing technique evolved which was followed durling the majority of the tests conducted in the research program. These procedures are in general unique to these test conditions doubtless they could be improved upon in several ways.

Every plece of equipment, apparatus or appurtenance used in conducting a test was kept in the controlled temperature roan at all times. When space requirements demanded these were removed only for as long a period of time as necessary to preclude the effect of temperature differentials and thus introduce a source of error in the results.

Certain other routine procedures were consistently followed such as:

a. The base of the triaxial cell was kept in the controlled temperature chamber. Prlor to use It was submerged in de-aired water and freed of air bubbles in the system by passing deaired water through the lines repeatedly unt1l no air bubbles remained. All jolnts were made up under water. 
b. De-aired water was prepared in advance and stored under vacuum in a 20 liter far in the controlled temperature roam.

c. A beaker of water containing the two submerged membranes for the next test was kept in the chamber. 6

d. Chamber temperatures were ohecked dally by a laboratory thermometer.

e. The Norton Stone used for the probe was kept in $a$ beaker of water at all times except when in use. Prior to use it was bolled for 15 minutes to remove any trapped air. Cooling under vacuum in a desiccator jar was attempted and rejected since air was present in the sample.

f. De-aired water was used as the cell fluld in the tests, except where volume change measurements were made.

g. High vacuum grease was used as a lubricant on the triaxial cell piston. All mechanical joints were sealed with sultable compound.

Prior to placing the trlaxial cell in the loading apparatus, adjustment of the equipment for the requirements of the test being run was made. The deviator stress or magnitude of applied vertical

6 It has been shom that water will penetrate rubber membranes at a rate decreasing with time of submergence (16). 
load was first adjusted by placing an accurate load ring under the load cell and adjusting the dial indicator of the load ring to correspond to the dead load of the plston, ram and load cell. This total weight anounted to 53.48 Ibs. and contributed 4.256 Ibs. to the total stress difference. By adjustment of the main air line regulator valve, the load was increased or decreased to correspond to the calculated load ring dial indicator reading with the apparatus cycling at test condition. Fine adjustments to the cycling and timing controls were made at this time by observing the load cell oscillogram. With time, (1.e. after several days of testing), minor reajustments to the timer were sonetimes necessary. When the devlator stress adjustment was completed, the power switch was turned to the off position and the override plunger on the 4-way valve was pushed in and locked. This removed the air fram the top of the piston and perritted later lifting of the piston and load cell during placement of the triaxial cell. Finally the counter was set to zero, and the confining pressure for the test in question adjusted using the pressure tank calibrator, Plate 5 and laboratory air gauge.

The base of the triaxlal cell was next removed from the enviromental chamber and the pore liquid tubing filled with dealred water as described previously and welghed.

Remorling the saturation cell from the chamber, the vacuun was released and the test specimen removed. The screws of the saturation mold were removed and the mold withdram. The filter paper was also peeled off. As rapidly as possible, the sample was transferred 


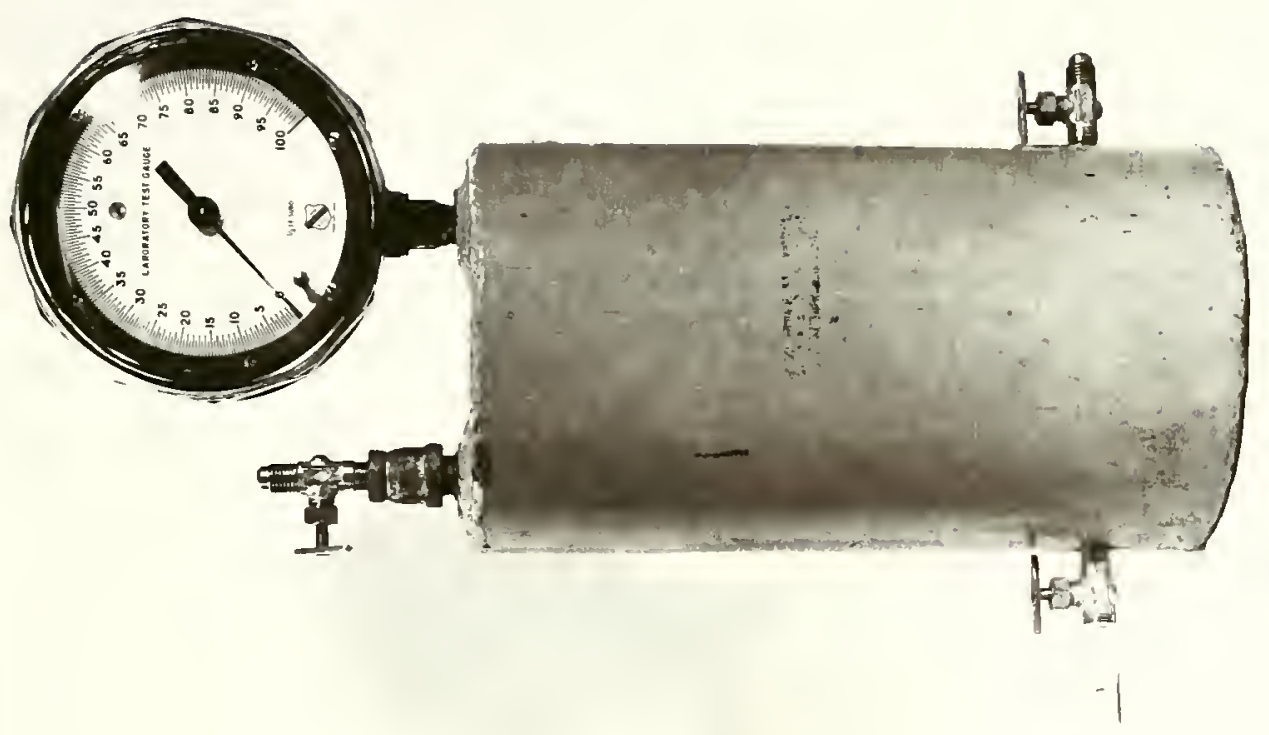

$\frac{x}{2}$

2
0
$\frac{1}{5}$
$\frac{1}{\alpha}$
$\frac{m}{1}$
$\frac{1}{4}$
0

$\frac{0}{3}$

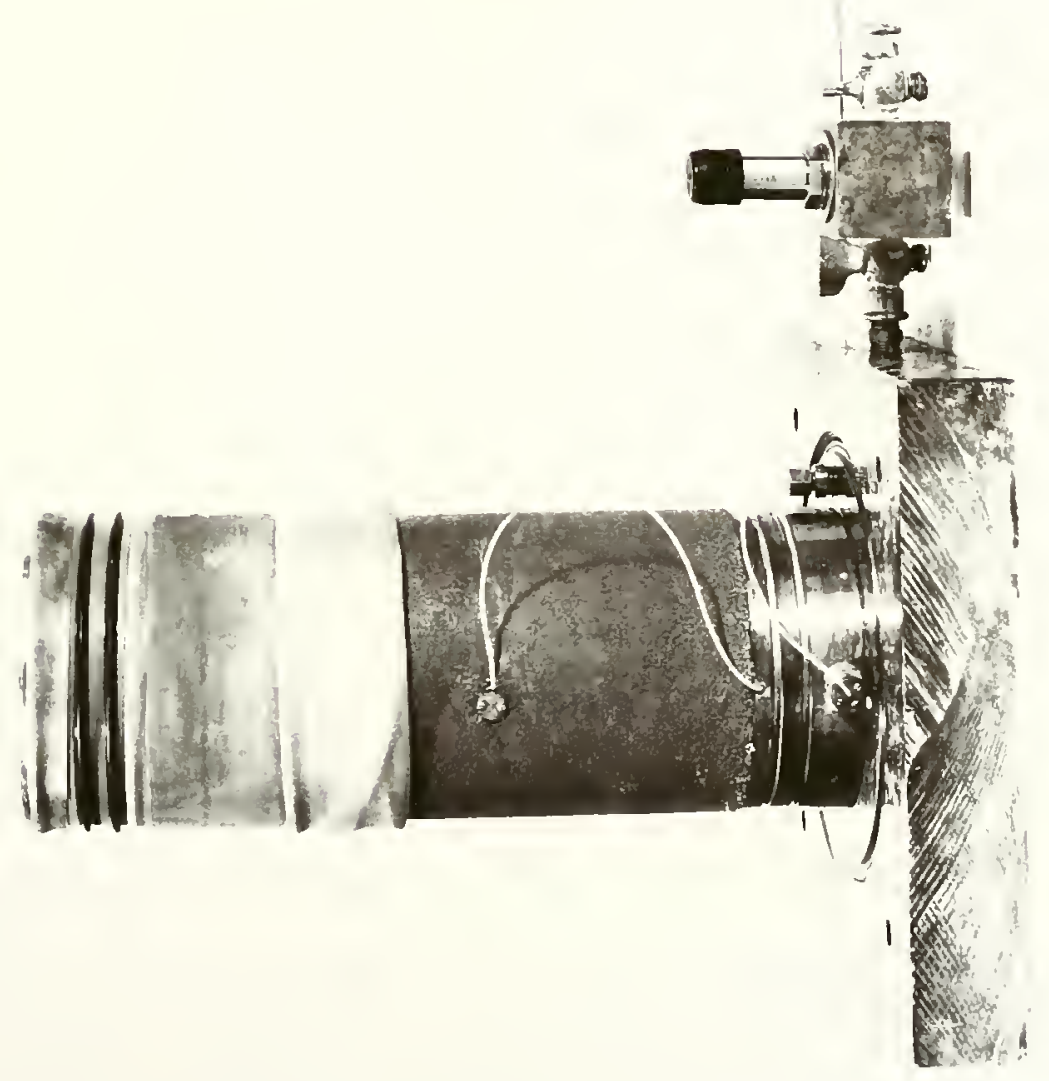

$\frac{\sum}{\omega}$

$\frac{n}{\infty}$

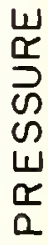

$u$
$\alpha$
0
$a$

5

$\stackrel{4}{\frac{1}{a}}$ 
to the base of trlaxial cell and welghed. The pore water IIne was pushed Into the close fltting probe hole and the cap screwed on making a tight mechanical jolnt which did not leak. It must be emphaslzed that extreme care must be taken to assure that no alr bubbles are trapped in the probe when this connection is made, or the pore pressure measurements will be either much in error or non-existant. During this process some grains of sand were removed In order to get the probe cap fitted and secured. This left a vold in the mixture around the probe which would permit air to enter the sample. To arold this possibility plaster of paris slurry was spread over the probe end. This slurry hardened around the probe and in the small voids adjacent to it, eliminating the voids when the membrane was placed. In some latter tests a soil slurry was used with equally good results.

Using a vacuum pump and a brass membrane stretcher the two wet membranes were placed over the sample and secured top and bottam with two 0-rings. If the test was to be of short duration, 1.e. less than eight hours, the membranes were not separated by silicone grease. If the test was to be longer than eight hours, grease was used, although little benefit was noted.

Next the inside of the Lucite cylinder and the inner side of the top plate of the triaxial cell were smeared with a wetting agent. This was done to prevent air bubbles fram forming as the cell was filled and was a great ald in ensuring conplete removal of air from the cell. Using the four stainless steel bolts, the cell was assembled. The IVDT calibration micrometer was attached 
beneath two of the bolts during assembly (Plate 3 ).

The cell was now taken into the chamber and set carefully beneath the loading ram. Connections to the volume measuring derlce, Figure 7 and to the pressure transducer, Figure 6 were made up. The cell was now filled with liquid using extreme care to assure that no air was trapped under the top plate of the cell. Extra tapped holes were located around the top to ald in removing all air. Note that confining pressure was not applled yet, unless a consolidation period was desired. In early tests (see results for $35 \mathrm{~A} 30,35 \mathrm{~A} 40$ $35 \mathrm{~A} 50$ ) this was the usual case unt1l the effect of volume change became known.

The LVDT for deformation recording was calibrated next according to the procedure given in Appendix A. Similarly the pressure transducer was calibrated as described under Sensing Elements and Calibration using the loading cell method shown in Plate L. At this time the rolume change device was read prior to pressurizing the cell and the cell pressurized. A reading was agaln taken on the measuring tube scale. The zero reading on the dial indicator for vertical deformation was also read and recorded. Chart feed for the galvanameter recorder was set at $10 \mathrm{~mm} / \mathrm{sec}$. and the over-ride plunger on the four-way valve pulled out simultaneously turning the timer switch to "on" position. The test was then in operation and readings were taken as quickly as possible for all measurlng devices. After 30 cycles or so, readings were taken at every 10 cycles up to 100 cycles and thereafter at every 100 cycles to 1000 cycles. As the test progressed, readings were taken at intervals increasing up 
to 4 to 6 hours towards the end of the test.

The procedure described above, although rather straightforward appearing was not developed at once, but represents rather the evolution of procedure as the tests were run and refinements to both equipment and technique incorporated.

In this regard it is considered pertinent to describe the evolution of the pore fluid sensing element; the probe. Referring to Plate 6 a series of four probes are seen. The early tests, 1.e. those on $A-m i x e s$ (except $40 \mathrm{~A} 30$ and $40 \mathrm{ALO}$ ), used probes Type $B$ and C. Type B, the very first one used and that shown in Figure 6 was not very successful due to difficulty in preventing leakage around the membrane. Further, since the stem protruded out nearly one-half inch fram the socket, the probe could not be placed In the semple and saturated with the sample. This meant that complete contact of the probe with the soil grains was not assured even with care in remoring the dumuy. Too, the membranes could not be re-used after each test and lastly much time was lost in placing and connecting the probe. As a result it was decided to place the probe and pore water tube completely under the membranes. Plate 5 shows how this was accomplished. At the same time a new probe was used employing a mechanlcal joint at the socket. A No. 56 hole was drilled in the center of the socket along the longitudinal axis. Another No. 56 hole was then located at the exact joint between the cap and socket and $90^{\circ}$ to the first hole. The tube was then inserted and secured with two 0-80 N.F. screws. This entailed some rather refined machine work but produced a leak- 

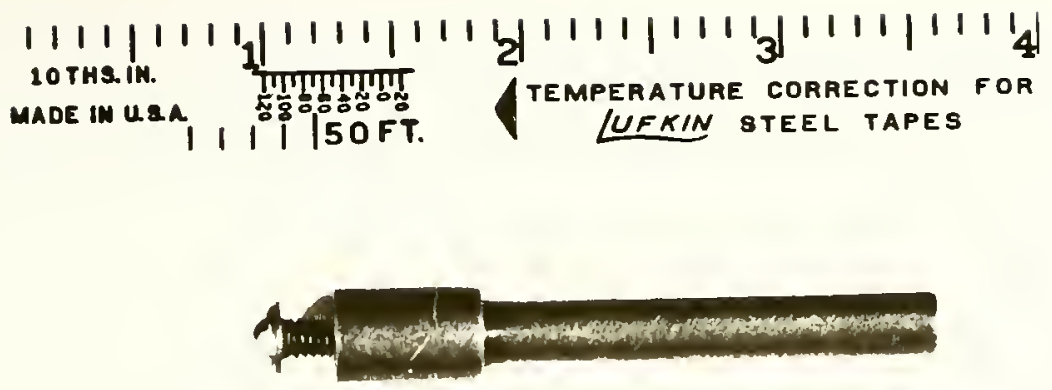

A. DUMMY PROBE

B. PROBE THROUGH MEMBRANE

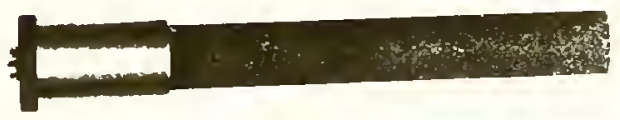
C. FROBE UNDER MEMBRANE USED WITH DUMMY

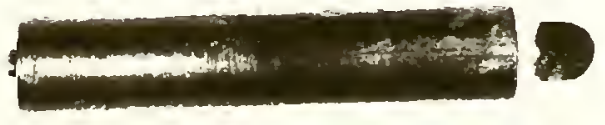
D. PROBE UNDER MEMBRANE COMPACTED IN SPECIMEN


proof joint. Now the dumny could be withdrawn after compaction and the probe inserted during the saturation perfod. This technique did not produce a single failure in making pore pressure measurements.

In running the tests on the B-mixes, it became apparent rather early that considerable swell was taking place prlor to application of the cell confining pressure. Therefore probe Type $D$ was developed which permitted only the pore fluld pressure in the exact center of volume of the sample to be measured. At the same time due to the short ceramic portion on the probe, it could and was campacted into the sample. It worked very well for the B mixes (29 percent) binder but not as well as the Type $C$ did for the $A$ and $C$ mixes. Varlous grits were tried but due to the partial saturation problem caused by swell, the 180 grit probe gave the best results. Future tests are contemplated using a very fine "India" stone produced by Nort on Abrasives which is harder and more durable and shows great promise as a probe ceramic. 


\section{RESULTS AND COMPUTATIONS}

In this section are summarized the test data, results of tests and computational analyses. Topical headings denote the major areas investigated.

\section{Observed Test Data}

Table 2 summarizes the data reflecting sample preparation as well as that obtained during test observation. Preparation and compaction of the test specimen was based on standard laboratory test procedures. Compaction dry density, saturation molsture content and vold ratio were computed fran the best specific gravity values; volume determinations were based on weights which were determined to the nearest one-half gram. Volume change and deformation readings were taken, from which axial strain was computed. Time was not a major test varlables however, where time data were required they were obtained from the known galvanometer chart speeds. Load repetitions were obtained directly from the electro-mechanical counter and verified where necessary by the oscillogram data. Pore pressure, axial load and deformation data were obtained fram the oscillograph tapes. A portion of a typical oscillogram is shown in Flgure 8.

The sample 1dentification number indicated for each test is a coded number indicating the general test conditions. The first part of the number indicates the confining pressure; the letter 


\begin{tabular}{|c|c|c|c|c|c|c|c|c|c|c|c|c|c|c|c|c|c|c|c|c|c|c|c|c|c|c|c|}
\hline 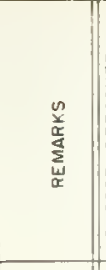 & 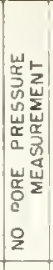 & & & 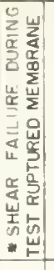 & & & 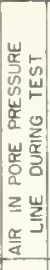 & & & & 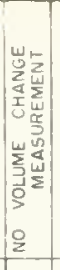 & & & $\mid \begin{array}{c}5 \\
3 \\
5 \\
1 \\
0\end{array}$ & $\mid \begin{array}{l}5 \\
5 \\
\breve{w} \\
5 \\
0\end{array}$ & & 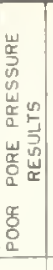 & & & & & 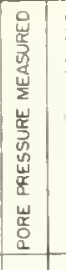 & 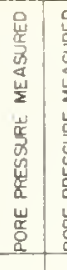 & 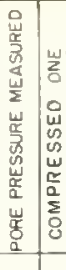 & 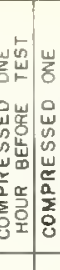 & & 要 \\
\hline 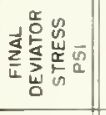 & $\begin{array}{l}\infty \\
0 \\
\sigma \\
\sigma \\
\sigma\end{array}$ & $\begin{array}{l}n \\
\sigma \\
\square \\
0\end{array}$ & $\frac{\tilde{\sigma}}{\infty}$ & $\begin{array}{l}\vec{\infty} \\
\dot{n}\end{array}$ & $\begin{array}{l}0 \\
8 \\
0 \\
2\end{array}$ & $\begin{array}{l}3 \\
5 \\
5\end{array}$ & $\begin{array}{l}0 \\
\tilde{N} \\
- \\
\end{array}$ & $\mid \begin{array}{l}0 \\
0 \\
0 \\
\infty\end{array}$ & $\begin{array}{l}0 \\
0 \\
0 \\
0 \\
0\end{array}$ & 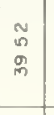 & 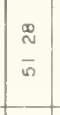 & $\mid \begin{array}{l}0 \\
g \\
0 \\
0\end{array}$ & 1 & ? & 1 & $\begin{array}{l}\sigma \\
\sigma \\
\sigma \\
\sigma \\
\sigma\end{array}$ & $\begin{array}{l}0 \\
0 \\
0 \\
0 \\
0\end{array}$ & \begin{tabular}{l|l}
0 & \\
0 \\
0
\end{tabular} & $\begin{array}{l}2 \\
2 \\
0 \\
1\end{array}$ & 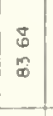 & 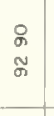 & $\mid \begin{array}{l}w \\
w \\
\sigma \\
\sigma\end{array}$ & 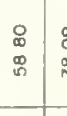 & \begin{tabular}{l|l}
0 & \multicolumn{1}{c}{} \\
0 & 0 \\
$\infty$ & 0 \\
0 & 0 \\
0
\end{tabular} & 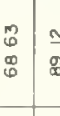 & & $\begin{array}{l}\tilde{N} \\
\tilde{f} \\
\tilde{n}\end{array}$ \\
\hline 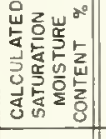 & 总 & פ & $\begin{array}{l}8 \\
8 \\
0\end{array}$ & $\begin{array}{l}8 \\
6\end{array}$ & $\stackrel{N}{\sim}$ & i & 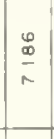 & $\begin{array}{l}8 \\
6\end{array}$ & ָָ & $\stackrel{D}{D}$ & \begin{tabular}{|l|l|l} 
\\
0 \\
0
\end{tabular} & $\mid \begin{array}{l}0 \\
\vdots \\
2\end{array}$ & $\begin{array}{l}0 \\
\dot{y} \\
r\end{array}$ & 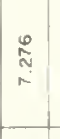 & $\mid \begin{array}{l}0 \\
0 \\
⿱ ⺊ 口 \\
\sigma \\
\sigma\end{array}$ & 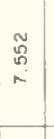 & $\frac{0}{a}$ & $\begin{array}{l}\sigma \\
\overline{0} \\
-1\end{array}$ & $\begin{array}{l}\frac{n}{N} \\
\sigma\end{array}$ & $\mid \begin{array}{l}0 \\
0 \\
0 \\
\sigma \\
\sigma\end{array}$ & 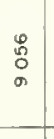 & 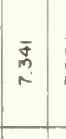 & $\stackrel{\substack{d \\
N}}{N}$ & 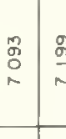 & 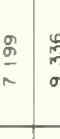 & & 总 \\
\hline 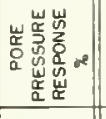 & | & in & $\stackrel{\circ}{0}$ & 5 & $\begin{array}{l}0 \\
0 \\
0\end{array}$ & $\bar{r}$ & $\overrightarrow{0}$ & 1 & 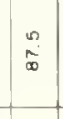 & 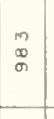 & $\begin{array}{l}\infty \\
\infty \\
\infty\end{array}$ & $\mid \begin{array}{l}m \\
0 \\
\infty\end{array}$ & $:$ & $\mid \begin{array}{l}\infty \\
\infty \\
0\end{array}$ & $\stackrel{\circ}{\circ}$ & $\stackrel{\circ}{\circ}$ & 道 & 负 & $\stackrel{8}{\circ}$ & $\begin{array}{l}m \\
\vdots \\
1\end{array}$ & 足 & $\left|\begin{array}{c}\tilde{o} \\
o\end{array}\right|$ & \begin{tabular}{l|l}
0 \\
$i$ \\
$i$
\end{tabular} & \begin{tabular}{c|c}
0 & $n$ \\
0 & 0 \\
0 & $\infty$
\end{tabular} & 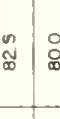 & & i \\
\hline$\frac{T}{0} \frac{1}{4}$ & \begin{tabular}{|l|} 
\\
0 \\
0 \\
0 \\
\end{tabular} & 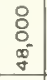 & \begin{tabular}{|l|} 
\\
0 \\
0 \\
0 \\
$m$ \\
$m$ \\
\end{tabular} & 1 & 1 & 1 & $\begin{array}{l}0 \\
0 \\
0 \\
0 \\
0 \\
\end{array}$ & 1 & 1 & 1 & 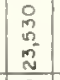 & $\mid$ & 1 & 1 & 1 & 1 & 1 & 1 & 1 & 1 & 1 & 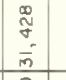 & 1 & 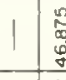 & 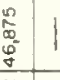 & & \\
\hline 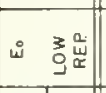 & 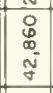 & $\begin{array}{l} \\
0 \\
0 \\
\vdots \\
0\end{array}$ & 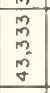 & $\mid$\begin{tabular}{|c}
0 \\
0 \\
0 \\
0 \\
0 \\
$n$ \\
\end{tabular} & \begin{tabular}{|l|}
0 \\
0 \\
0 \\
\\
\end{tabular} & \begin{tabular}{|l|} 
\\
\\
0 \\
0 \\
0 \\
0
\end{tabular} & $\mid$\begin{tabular}{|c|}
0 \\
0 \\
0 \\
-1 \\
\end{tabular} & 1 & \begin{tabular}{|l|} 
\\
0 \\
0 \\
0 \\
$n$ \\
$n$ \\
$m$
\end{tabular} & 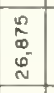 & \begin{tabular}{|l|} 
\\
\\
0 \\
8 \\
8
\end{tabular} & 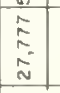 & 1 & 1 & 1 & $\begin{array}{l} \\
\vdots \\
\bar{i} \\
\end{array}$ & 1 & $\begin{array}{ll}n \\
0 \\
n \\
n \\
n \\
n\end{array}$ & 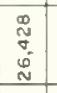 & \begin{tabular}{|l|}
0 \\
0 \\
0 \\
0 \\
\end{tabular} & \begin{tabular}{|l|} 
\\
\\
0 \\
0 \\
0
\end{tabular} & \begin{tabular}{|l|} 
\\
\\
0 \\
0 \\
$y$ \\
$y$ \\
\end{tabular} & 1 & 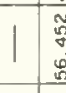 & 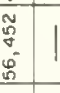 & & 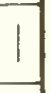 \\
\hline 8 & \begin{tabular}{|l|}
$\bar{N}$ \\
$\bar{\alpha}$ \\
\end{tabular} & \begin{tabular}{|l|} 
\\
0 \\
0 \\
0
\end{tabular} & $\begin{array}{l}0 \\
0 \\
0 \\
0 \\
\end{array}$ & 1 & \begin{tabular}{|l|}
8 \\
0 \\
0
\end{tabular} & 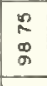 & \begin{tabular}{|l|} 
\\
$\vdots$ \\
$\vdots$ \\
5 \\
\end{tabular} & \begin{tabular}{|l|} 
\\
\\
0 \\
$\infty$ \\
$\infty$ \\
\end{tabular} & \begin{tabular}{|l|} 
\\
$N$ \\
$n$ \\
$\sigma$ \\
\end{tabular} & \begin{tabular}{|l|}
8 \\
8 \\
8 \\
\end{tabular} & \begin{tabular}{|l|}
2 \\
$\alpha$ \\
$a$ \\
\end{tabular} & \begin{tabular}{|l|} 
\\
$n$ \\
$n$
\end{tabular} & 1 & 1 & 1 & \begin{tabular}{|l|} 
\\
0 \\
0 \\
8
\end{tabular} & \begin{tabular}{|l|}
5 \\
5 \\
\end{tabular} & 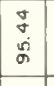 & \begin{tabular}{l|} 
\\
\\
5 \\
$\$$
\end{tabular} & 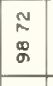 & 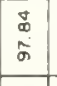 & 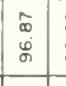 & $\begin{array}{ll}8 & 5 \\
8 & 5 \\
5 & 5\end{array}$ & 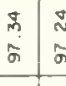 & 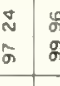 & & $\stackrel{2}{2}$ \\
\hline 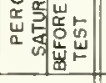 & \begin{tabular}{|l}
$\bar{N}$ \\
$\bar{a}$ \\
\end{tabular} & $\begin{array}{l}5 \\
0 \\
\delta \\
\end{array}$ & \begin{tabular}{|c|} 
\\
$\infty$ \\
$\infty$ \\
\end{tabular} & $\begin{array}{l}\bar{\sigma} \\
\sigma \\
\end{array}$ & \begin{tabular}{|l|} 
\\
0 \\
0 \\
$\infty$ \\
$o$ \\
\end{tabular} & 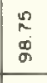 & 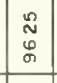 & \begin{tabular}{|l|} 
\\
0 \\
0 \\
0 \\
\\
\end{tabular} & 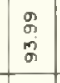 & $\mid \begin{array}{l}0 \\
0 \\
0 \\
0 \\
\end{array}$ & 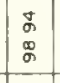 & \begin{tabular}{|l|} 
\\
$\tilde{a}$ \\
\\
\end{tabular} & \begin{tabular}{|l|}
0 \\
\\
\\
\end{tabular} & \begin{tabular}{|l|} 
\\
0 \\
0 \\
\end{tabular} & \begin{tabular}{|c|}
0 \\
$w$ \\
0 \\
0 \\
\end{tabular} & $\begin{array}{l}2 \\
i \\
\end{array}$ & \begin{tabular}{|l|} 
\\
0 \\
0 \\
\end{tabular} & $\begin{array}{l}\bar{j} \\
\text { o. } \\
\text { bi } \\
\sigma\end{array}$ & $\begin{array}{l}\tilde{N} \\
\text { g } \\
\end{array}$ & \begin{tabular}{|l|} 
\\
$\infty$ \\
0 \\
\end{tabular} & \begin{tabular}{|l|} 
\\
0 \\
0 \\
\end{tabular} & \begin{tabular}{|l|} 
\\
0 \\
$\dot{8}$ \\
\end{tabular} & 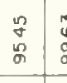 & 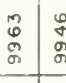 & \begin{tabular}{l|l}
0 \\
$\vdots$ \\
$\sigma$ \\
$\sigma$ \\
$\sigma$
\end{tabular} & & $\stackrel{0}{\circ}$ \\
\hline 412 & $\stackrel{n}{-}$ & $\frac{a}{-}$ & 1 & 1 & 1 & 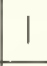 & 1 & 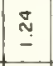 & 1 & - & $\stackrel{\sim}{\sim}$ & \begin{tabular}{|l|} 
\\
0 \\
-2
\end{tabular} & 1 & 1 & 1 & 年 & $\begin{array}{l}0 \\
2 \\
\end{array}$ & $\stackrel{\mathfrak{N}}{-}$ & 1 & 1 & 1 & 1 & 15 & \begin{tabular}{l|l} 
& $\cong$ \\
&
\end{tabular} & \begin{tabular}{l|l}
$\cong$ & 4 \\
&
\end{tabular} & 多 & $\tilde{\xi}$ \\
\hline 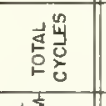 & \begin{tabular}{|l|} 
\\
\\
0 \\
$\infty$ \\
$\infty$ \\
$\infty$ \\
\end{tabular} & $\begin{array}{l} \\
8 \\
0 \\
0 \\
0\end{array}$ & \begin{tabular}{|l|}
0 \\
\\
0 \\
$0^{\circ}$ \\
\end{tabular} & 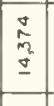 & \begin{tabular}{|l|}
8 \\
0 \\
0 \\
\\
\end{tabular} & 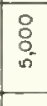 & 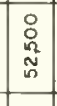 & \begin{tabular}{|l|}
$\circ$ \\
$\circ$ \\
$\circ$ \\
\end{tabular} & $\begin{array}{l} \\
\vdots \\
0 \\
\end{array}$ & \begin{tabular}{|l|}
0 \\
0 \\
0 \\
0.2 \\
0 \\
0 \\
\end{tabular} & \begin{tabular}{|l|} 
\\
$\vdots$ \\
$\circ$ \\
$\circ$ \\
\end{tabular} & \begin{tabular}{|l|}
8 \\
0 \\
\\
0 \\
\end{tabular} & 1 & 1 & 1 & \begin{tabular}{|l|} 
\\
0 \\
0 \\
0 \\
\\
\end{tabular} & \begin{tabular}{|c|}
0 \\
0 \\
0 \\
0
\end{tabular} & \begin{tabular}{|l|}
0 \\
0 \\
0 \\
0 \\
0 \\
\end{tabular} & \begin{tabular}{|l|} 
\\
$\vdots$ \\
$i$ \\
in
\end{tabular} & \begin{tabular}{|l|}
0 \\
0 \\
0 \\
\end{tabular} & 总 & \begin{tabular}{|l|}
5 \\
0 \\
0 \\
0 \\
0 \\
\end{tabular} & \begin{tabular}{l|l}
$\bar{n}$ & $\xi$ \\
$\dot{\sim}$ & $\xi$ \\
\end{tabular} & 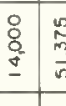 & 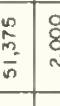 & 8 & : \\
\hline 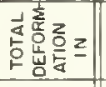 & 品 & $\underline{\tilde{g}}$ & $\underset{\sim}{N}$ & $\frac{m}{m}$ & 品 & 离 & $\bar{\sim}$ & \begin{tabular}{|l|}
$m$ \\
$m$
\end{tabular} & 号 & \% & $\stackrel{O}{\sim}$ & 等 & 8 & $\begin{array}{l}8 \\
\vdots \\
\end{array}$ & $\frac{9}{8}$ & \begin{tabular}{|l|} 
\\
0 \\
$m$ \\
$n$
\end{tabular} & 号 & $\hat{\tilde{q}}$ & $\mid \begin{array}{l}0 \\
0 \\
0\end{array}$ & $\mid$ & 离 & $\underset{\tilde{q}}{\tilde{q}}$ & 吕 & 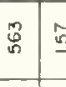 & $\underline{n} 5$ & & ๕ू \\
\hline 言学 & 总 & $\stackrel{\underline{Q}}{\underline{\Phi}}$ & $\underline{m}$ & \begin{tabular}{|l|} 
\\
$\Phi$ \\
\end{tabular} & $\underline{\underline{\mathbf{m}}}$ & $\underline{\bar{g}}$ & $\underline{\bar{\Phi}}$ & $\overline{\mathbf{\Phi}}$ & $\stackrel{\tilde{\sigma}}{\sigma}$ & $\bar{N}$ & $\stackrel{\circ}{\circ}$ & \begin{tabular}{|l} 
\\
$\stackrel{\infty}{\infty}$
\end{tabular} & 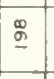 & 盟 & 虫 & $\overline{\mathrm{N}}$ & $\hat{a}$ & 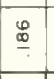 & 吾 & 䯩 & 亮 & 号 & $\stackrel{\circ}{\circ}$ & \begin{tabular}{l|l}
$\stackrel{\infty}{\Phi}$ & $\bar{\sigma}$
\end{tabular} & \begin{tabular}{l|l}
$\bar{\sigma}$ & \multicolumn{0}{|}{} \\
&
\end{tabular} & & $\stackrel{m}{g}$ \\
\hline 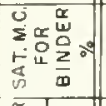 & \begin{tabular}{|c|}
$\tilde{w}$ \\
\\
$\underline{G}$ \\
\end{tabular} & $\begin{array}{l}f \\
\dot{d} \\
\dot{d}\end{array}$ & $\begin{array}{l}0 \\
0 \\
\dot{1} \\
\end{array}$ & $\frac{\sigma}{\underline{a}}$ & \begin{tabular}{|l|}
\multirow{u}{*}{} \\
$\underline{u}$ \\
$\underline{m}$
\end{tabular} & $\begin{array}{l}0 \\
0 \\
0 \\
\text { Di }\end{array}$ & 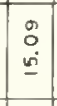 & $\begin{array}{l}0 \\
0 \\
\dot{0} \\
\dot{\Xi}\end{array}$ & $\begin{array}{l}\hat{\theta} \\
\underline{\sigma}\end{array}$ & $\frac{m}{m}$ & $\begin{array}{l}\stackrel{g}{\circ} \\
= \\
=\end{array}$ & \begin{tabular}{|l|} 
\\
$\infty$ \\
\\
\end{tabular} & \begin{tabular}{l|} 
\\
0 \\
0 \\
$\underline{\dot{w}}$ \\
\end{tabular} & \begin{tabular}{|l|} 
\\
0 \\
0 \\
\end{tabular} & \begin{tabular}{|l|} 
\\
$N$ \\
$N$ \\
$N$
\end{tabular} & $\frac{m}{m}$ & $\begin{array}{l}\tilde{\alpha} \\
\simeq \\
\simeq\end{array}$ & \begin{tabular}{l|}
$\overline{\hat{N}}$ \\
$\underline{\underline{N}}$
\end{tabular} & \begin{tabular}{|l|}
$\hat{p}$ \\
$\hat{w}$ \\
\end{tabular} & $\mid \begin{array}{l}\bar{\sigma} \\
0 \\
i\end{array}$ & $\frac{n}{m}$ & 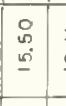 & $\begin{array}{l}\overline{\bar{v}} \\
\underline{\dot{v}}\end{array}$ & \begin{tabular}{l|l}
$\bar{\sigma}$ & $\underline{8}$ \\
$\underline{j}$ & $\underline{g}$
\end{tabular} & 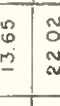 & & $\begin{array}{l}\text { i̊ } \\
\text { @i }\end{array}$ \\
\hline & $\stackrel{\circ}{2}$ & $\begin{array}{l}0 \\
0 \\
0 \\
\end{array}$ & \begin{tabular}{|l|} 
\\
0 \\
0
\end{tabular} & .1 & \begin{tabular}{|l|} 
\\
8 \\
6 \\
\end{tabular} & $\bar{i}$ & . & \begin{tabular}{|l|}
0 \\
0 \\
0 \\
6 \\
\end{tabular} & 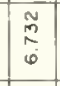 & \begin{tabular}{|l|}
0 \\
0 \\
0 \\
0
\end{tabular} & $\begin{array}{l} \\
\vdots \\
\end{array}$ & \begin{tabular}{|l|} 
\\
0 \\
0 \\
\end{tabular} & 1 & 1 & 1 & $\begin{array}{l}\infty \\
0 \\
0 \\
0\end{array}$ & $\begin{array}{l}\infty \\
0 \\
0 \\
\end{array}$ & $\begin{array}{l}2 \\
0 \\
0\end{array}$ & \begin{tabular}{l}
0 \\
\multirow{2}{*}{} \\
0
\end{tabular} & 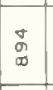 & \begin{tabular}{|l|l}
0 \\
0 \\
$\infty$ \\
$\infty$
\end{tabular} & $\bar{i}$ & \begin{tabular}{c|c|c}
0 & 5 \\
0 & 0 \\
0 & 0 \\
\end{tabular} & \begin{tabular}{l|l} 
\\
0 \\
0 \\
0
\end{tabular} & \begin{tabular}{c|c}
8 & 0 \\
1 & 0 \\
& 0 \\
\end{tabular} & : & مo \\
\hline 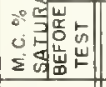 & 号 & $\begin{array}{l}0 \\
0 \\
0 \\
\end{array}$ & \begin{tabular}{|l|}
2 \\
0 \\
\end{tabular} & $\begin{array}{l}1 \\
0 \\
0\end{array}$ & \begin{tabular}{|l}
$\infty$ \\
$\infty$ \\
0 \\
0 \\
\end{tabular} & $\bar{z}$ & $\begin{array}{l}\tilde{\alpha} \\
0 \\
0\end{array}$ & \begin{tabular}{|l|}
0 \\
0 \\
0 \\
6 \\
\end{tabular} & $\begin{array}{l} \\
0 \\
0 \\
0 \\
\end{array}$ & $\begin{array}{l}= \\
2\end{array}$ & \begin{tabular}{|c|}
9 \\
9 \\
\end{tabular} & \begin{tabular}{|l|}
0 \\
0 \\
0
\end{tabular} & $\mid$ & \begin{tabular}{|l|} 
\\
0 \\
0 \\
\end{tabular} & \begin{tabular}{|l}
0 \\
0 \\
0 \\
\end{tabular} & \begin{tabular}{|l|}
$\begin{array}{l}0 \\
0 \\
6 \\
\end{array}$ \\
\end{tabular} & $\begin{array}{l}\infty \\
0 \\
6 \\
\end{array}$ & $\begin{array}{l}\hat{6} \\
\dot{0}\end{array}$ & $\frac{\square}{\sigma}$ & \begin{tabular}{|l|}
$\infty$ \\
$\infty$ \\
$\infty$ \\
$\infty$
\end{tabular} & \begin{tabular}{|l|}
0 \\
0 \\
0 \\
0 \\
\end{tabular} & $=$ & \begin{tabular}{l|l}
$m$ & $y$ \\
5 & 0 \\
0 & 1 \\
\end{tabular} & 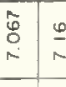 & 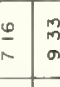 & & g. \\
\hline & $\begin{array}{l}0 \\
\vdots \\
n\end{array}$ & $\mid \begin{array}{l}0 \\
0 \\
0\end{array}$ & $\mid$ & $\mid \begin{array}{l}0 \\
0 \\
\dot{0}\end{array}$ & $\mid \begin{array}{l}\hat{D} \\
\hat{\sigma} \\
\end{array}$ & 焉 & $\frac{m}{6}$ & $\mid$ & $\underset{\underline{\omega}}{\underline{\omega}}$ & $\begin{array}{l}m \\
6 \\
b\end{array}$ & 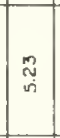 & \begin{tabular}{|l}
9 \\
0 \\
$\vdots$ \\
$b$
\end{tabular} & $\frac{9}{6}$ & $\overline{0}$ & 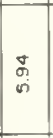 & $\mid \begin{array}{l}n \\
\tilde{\omega} \\
\omega\end{array}$ & $\mid \begin{array}{l}3 \\
0 \\
0\end{array}$ & $\begin{array}{l}8 \\
6\end{array}$ & 号 & $\begin{array}{l}n \\
n \\
n\end{array}$ & 悉 & $\begin{array}{l}0 \\
0 \\
0\end{array}$ & \begin{tabular}{l|l}
3 & 0 \\
0 & 0 \\
0
\end{tabular} & \begin{tabular}{l|l}
0 \\
0 \\
0
\end{tabular} & 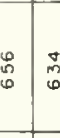 & & i \\
\hline 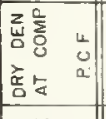 & $\mid \begin{array}{c}n \\
\cdots \\
\infty \\
n \\
-1\end{array}$ & : & $\begin{array}{l}0 \\
\vdots \\
0 \\
⿱ 亠 䒑\end{array}$ & $\begin{array}{l}\stackrel{0}{a} \\
\hat{\alpha} \\
\underline{2}\end{array}$ & \begin{tabular}{|c|}
0 \\
0 \\
0 \\
0
\end{tabular} & $\simeq$ & $\begin{array}{l}\frac{n}{\alpha} \\
\frac{a}{n}\end{array}$ & \begin{tabular}{|l|} 
\\
0 \\
$\dot{0}$ \\
$\underline{\dot{q}}$
\end{tabular} & $\begin{array}{l}m \\
0 \\
0 \\
0 \\
m\end{array}$ & $\mid \begin{array}{l}0 \\
0 \\
0 \\
m \\
-1\end{array}$ & 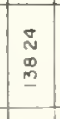 & $\begin{array}{l}\hat{D} \\
0 \\
0 \\
0\end{array}$ & $\mid \begin{array}{c}0 \\
0 \\
\infty \\
m \\
-\end{array}$ & 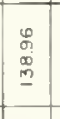 & 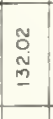 & $\frac{0}{\infty}$ & 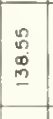 & 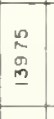 & 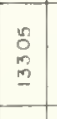 & \begin{tabular}{|l|}
$\overline{5}$ \\
0 \\
\end{tabular} & $\mid \begin{array}{c}\overline{1} \\
n \\
n\end{array}$ & $\mid \begin{array}{l}0 \\
0 \\
0 \\
\\
-\end{array}$ & 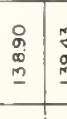 & 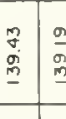 & 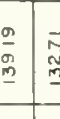 & 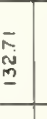 & $\begin{array}{l}0 \\
0 \\
0 \\
0 \\
2\end{array}$ \\
\hline 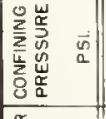 & 임 & 品 & 品 & $\stackrel{n}{m}$ & $\stackrel{n}{m}$ & $\stackrel{m}{m}$ & $\begin{array}{l}\circ \\
\checkmark\end{array}$ & o & $\stackrel{8}{q}$ & $\stackrel{\circ}{\circ}$ & o & in & 品 & 品 & 品 & $g$ & $\because$ & i & i & $\stackrel{m}{m}$ & a & 욤 & 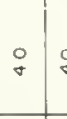 & $8:$ & $: \because$ & & 8 \\
\hline 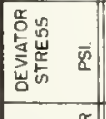 & i & $\hat{\sigma}$ & $\begin{array}{l}\text { D } \\
\end{array}$ & 8 & ○ & @ & D & $\underset{\infty}{+}$ & $\stackrel{8}{8}$ & 8 & $\stackrel{n}{n}$ & $\because$ & 1 & 1 & 1 & $\approx$ & : & $\Phi$ & $\tilde{\infty}$ & $\begin{array}{ll}\infty \\
\infty\end{array}$ & : & in & 8 & 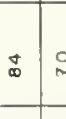 & $\therefore:$ & ๙ & 8 \\
\hline 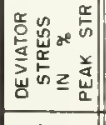 & | & $\%$ & in & 品 & g & 只 & 욤 & g & in & m & 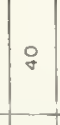 & in & | & & 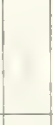 & 品 & $g$ & in & : & 只 & 品 & 品 & 용 & \& & 8 : & in & 요 \\
\hline 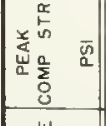 & $\mid \begin{array}{l}\infty \\
\bullet \\
\bullet\end{array}$ & $\stackrel{\infty}{0}$ & $\begin{array}{l}\stackrel{0}{\oplus} \\
\underline{\varphi}\end{array}$ & 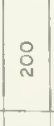 & ¿ & ֻ & $\frac{0}{y}$ & $\frac{0}{N}$ & $\frac{0}{N}$ & $\underline{\tilde{m}}$ & $\stackrel{n}{a}$ & $\stackrel{\tilde{n}}{\underline{n}}$ & $\tilde{\sigma}$ & $\underline{\varphi}$ & $\stackrel{\infty}{\infty}$ & $\stackrel{0}{2}$ & $\stackrel{\bullet}{=}$ & $\stackrel{\circ}{=}$ & $\stackrel{\square}{\stackrel{\oplus}{-}}$ & $\stackrel{\infty}{=}$ & $\stackrel{\sim}{\sigma}$ & \begin{tabular}{l}
$\infty$ \\
0 \\
\hdashline
\end{tabular} & $\frac{0}{\sim}$ & 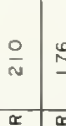 & $\stackrel{0}{1}:$ & - & $\frac{O}{N}$ \\
\hline 㟧 & $\mid \begin{array}{l}0 \\
0 \\
0 \\
0 \\
0 \\
\end{array}$ & q & \begin{tabular}{|c|}
0 \\
0 \\
$\vdots$ \\
\end{tabular} & . & ơ & 总 & $\begin{array}{l}0 \\
\text { aे } \\
\vdots \\
0\end{array}$ & $\begin{array}{l}0 \\
\vdots \\
\vdots \\
\vdots\end{array}$ & 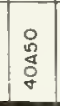 & \begin{tabular}{|l|}
0 \\
0 \\
0 \\
0 \\
0 \\
$n$
\end{tabular} & \begin{tabular}{|l|}
0 \\
0 \\
0 \\
0 \\
\end{tabular} & \begin{tabular}{|l|} 
\\
0 \\
0 \\
0 \\
0 \\
\end{tabular} & 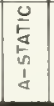 & \begin{tabular}{|l|}
0 \\
5 \\
5 \\
0 \\
0 \\
\end{tabular} & \begin{tabular}{|l|} 
\\
5 \\
5 \\
$\vdots$ \\
$\vdots$ \\
\end{tabular} & 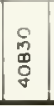 & \begin{tabular}{|l|} 
\\
0 \\
0 \\
0 \\
0
\end{tabular} & \begin{tabular}{|l}
0 \\
0 \\
0 \\
$g$ \\
\end{tabular} & $\begin{array}{l}0 \\
0 \\
0 \\
0 \\
m\end{array}$ & 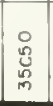 & $\begin{array}{l}0 \\
: \\
0 \\
\end{array}$ & \begin{tabular}{|l|}
$x$ \\
0 \\
0 \\
0 \\
0 \\
0 \\
\\
\end{tabular} & 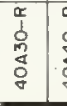 & 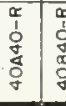 & 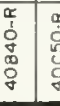 & & 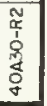 \\
\hline
\end{tabular}




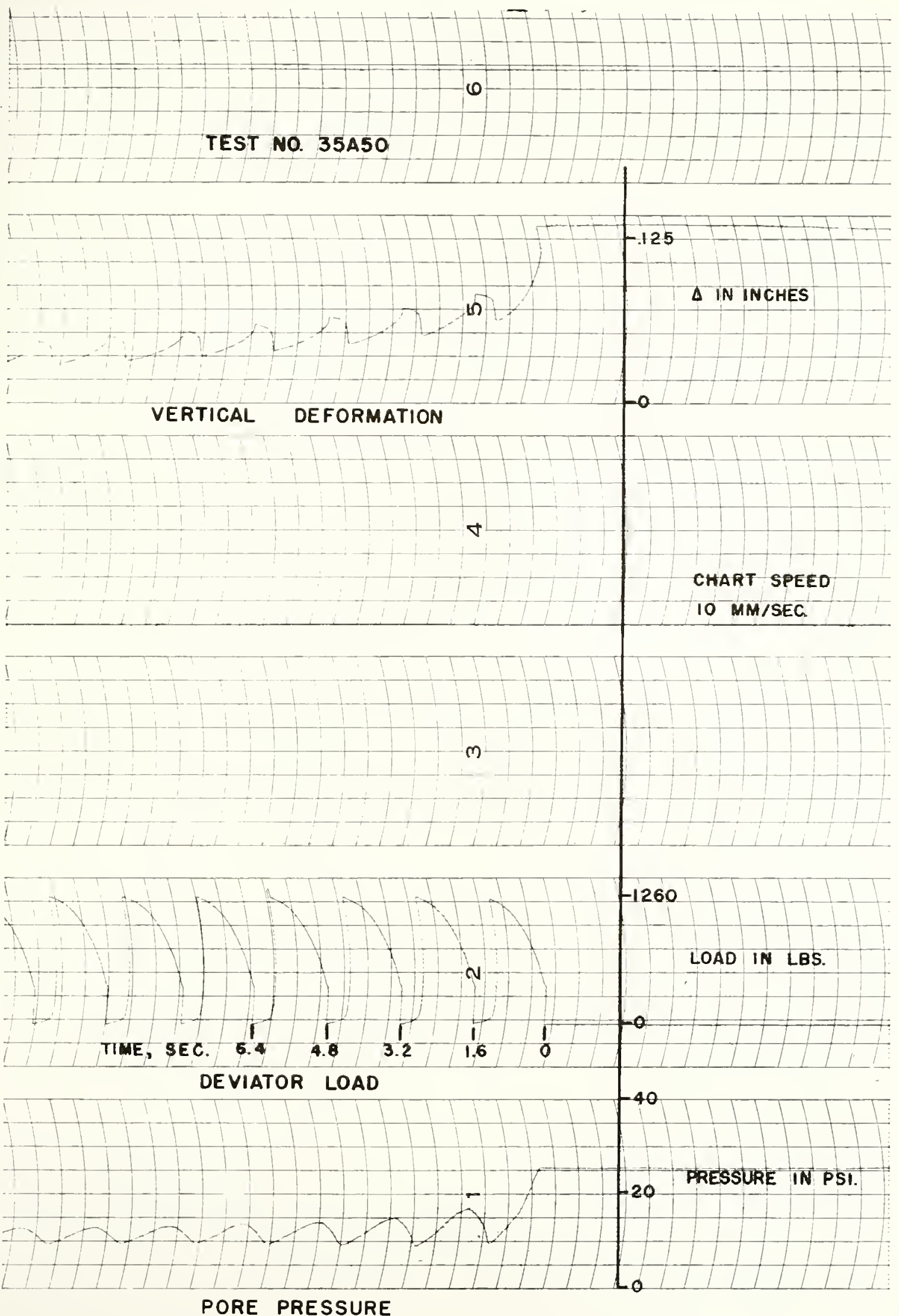

FIGURE 8 TYPICAL OSCILLOGRAM SHOWING RECORDED TEST RESULTS 
corresponds to the percentage of binder used in the mix, 1.e. A = 19 percent binder, $B=29$ percent binder and $C=14$ percent binder. The last number indicates the deviator stress in terms of percentage of the peak compressive strength as determined from a static test. In the case where an $R$ is shown, it denotes that the test is a repeat of the same type of test, either to provide information which was not provided initially such as pore pressure or volume change, or to corroborate previously obtained data for the same test specimen. Thus test number $35 \mathrm{~A} 50$ indicated in Figure 8 was a test run at 35 psi confining pressure on a sample containing 19 percent binder and loaded at an axial stress of 50 percent of the peak campressive strength.

Column headings in Table 2 correspond to standard nomenclature with the possible exception of those shown below.

1. $\frac{\Delta \sigma_{r}}{\Delta \sigma_{s}}$ is defined as the ratio of the peak compressive strength of the mix after repeated loading to the peak compressive strength of the mix as determined from the static load triaxial test, (UU).

2. $E_{\mathrm{d}}$ is defined as the dynamic modulus of deformation and corresponds to the slope of the stress-strain curve (Appendix D).

3. Pore pressure response is defined as the ratio in percent of the recorded pore pressure in the sample with application of confining pressure to the confining pressure itself. It is recognized that $\sigma_{r}$ is commonly used to denote radial stress; here the term is used as shown. 
Test Schedule

I. Tests on dense graded sand with optimum binder (19 percent) Series A. Confining Pressure
psi

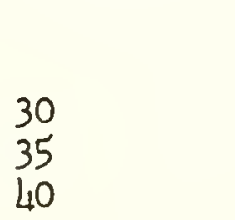

Devlator Stress, (percent peak static compression)

$30 \quad 40 \quad 50$

$\begin{array}{lll}1 & 1 & 1 \\ 1 & 1 & 1 \\ 1 & 1 & 1\end{array}$

II. Tests on sand wh excess binder (29 percent) Series B.

Confining Pressure psi

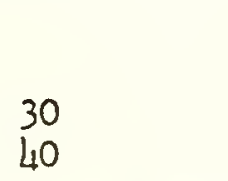

Deviator Stress, (percent peak static compression)

\begin{tabular}{lll}
30 & 40 & 50 \\
\hline 1 & 1 & 1 \\
1 & 1 & 1
\end{tabular}

III. Tests on Sand with minimum binder ( 14 percent)

Series C.

Confining Pressure Deviator Stress, (Percent psi peak static compression)

\begin{tabular}{ll} 
& 50 \\
\cline { 2 - 2 } 30 & 1 \\
35 & 1 \\
40 & 1
\end{tabular}




\section{Deformation Characteristics}

Total deformation was recorded by two methods; the first by means of a linear variable differential transformer and secondly by means of a micrometer dial indicator reading to .001 inch. The LVDT provided accurate deformation versus time data for a maximum total deformation of .250 inch. For deformations in excess of this value, the dial indicator was used. The deformation data obtained for the tests are presented graphically in Figures 9 to 14 as a function of the load repetitions (logarithmic). The dashed portion of some of the curves indicates that the initial deformation reading was taken after ten or more cycles; thus the graph is extended to intercept the ordinate which corresponds to five cycles of load repetition. The same data are show in Figures 15 to 17 where the load repetitions are plotted arithmetically against deformation.

In soils, including mixes such as used in this study, the deformations which occur are elastic below the yield stress value or the proportional limit. The yield stress is here defined as corresponding to that for a ductile metal and is the stress which when exceeded, further deformation occurs without any increase in load. For most soils the yield stress is very small with the result that most of the deformations are plastic. This fact is demonstrated herein by the graphs of deformation where large plastic deformations occurred with application of the initial load. Since the axial load was at least 30 percent of the peak static compressive strength (UU), high initial deformation could be expected.

From inspection of the graphs for the A-mixes ( 19 percent binder) 


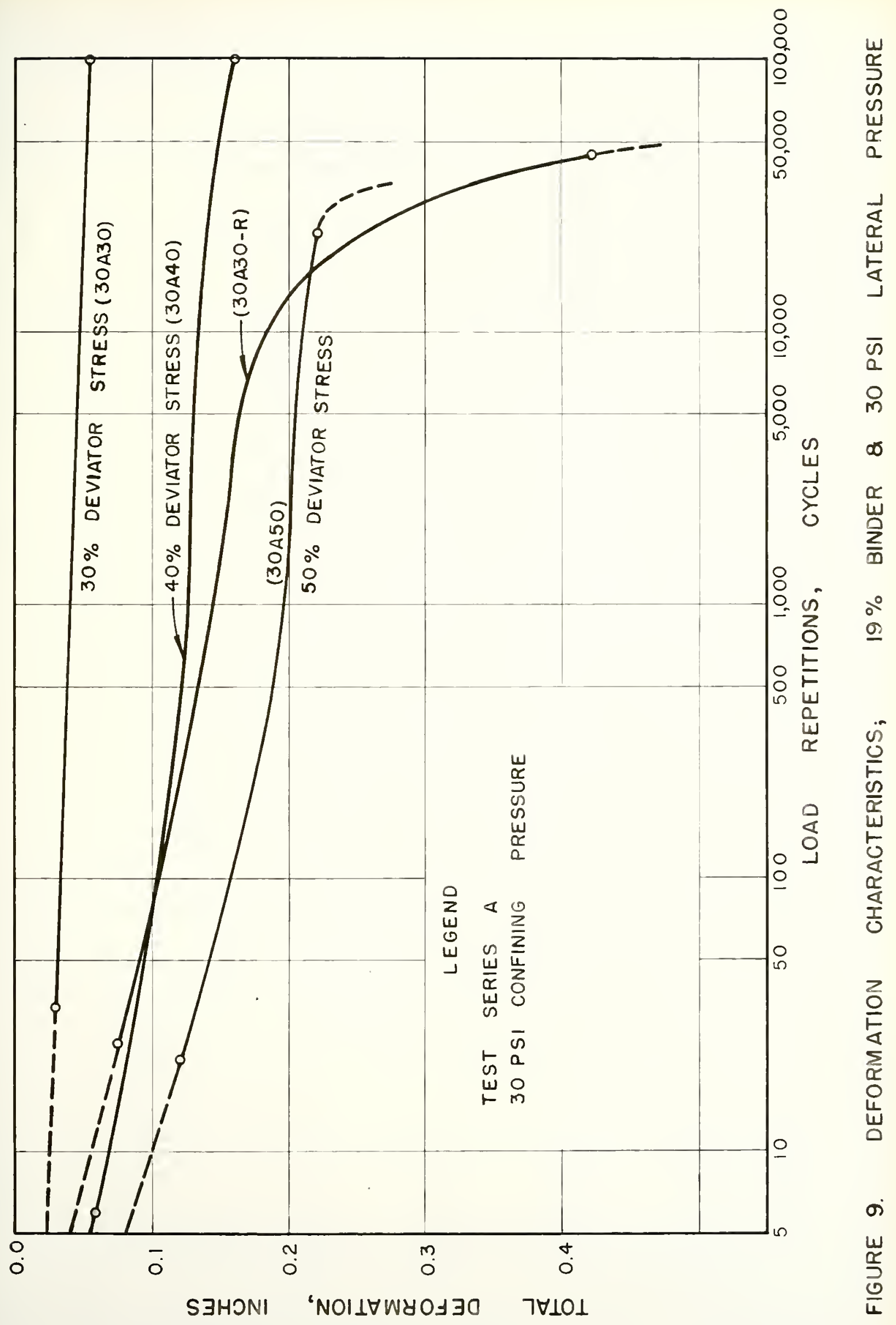




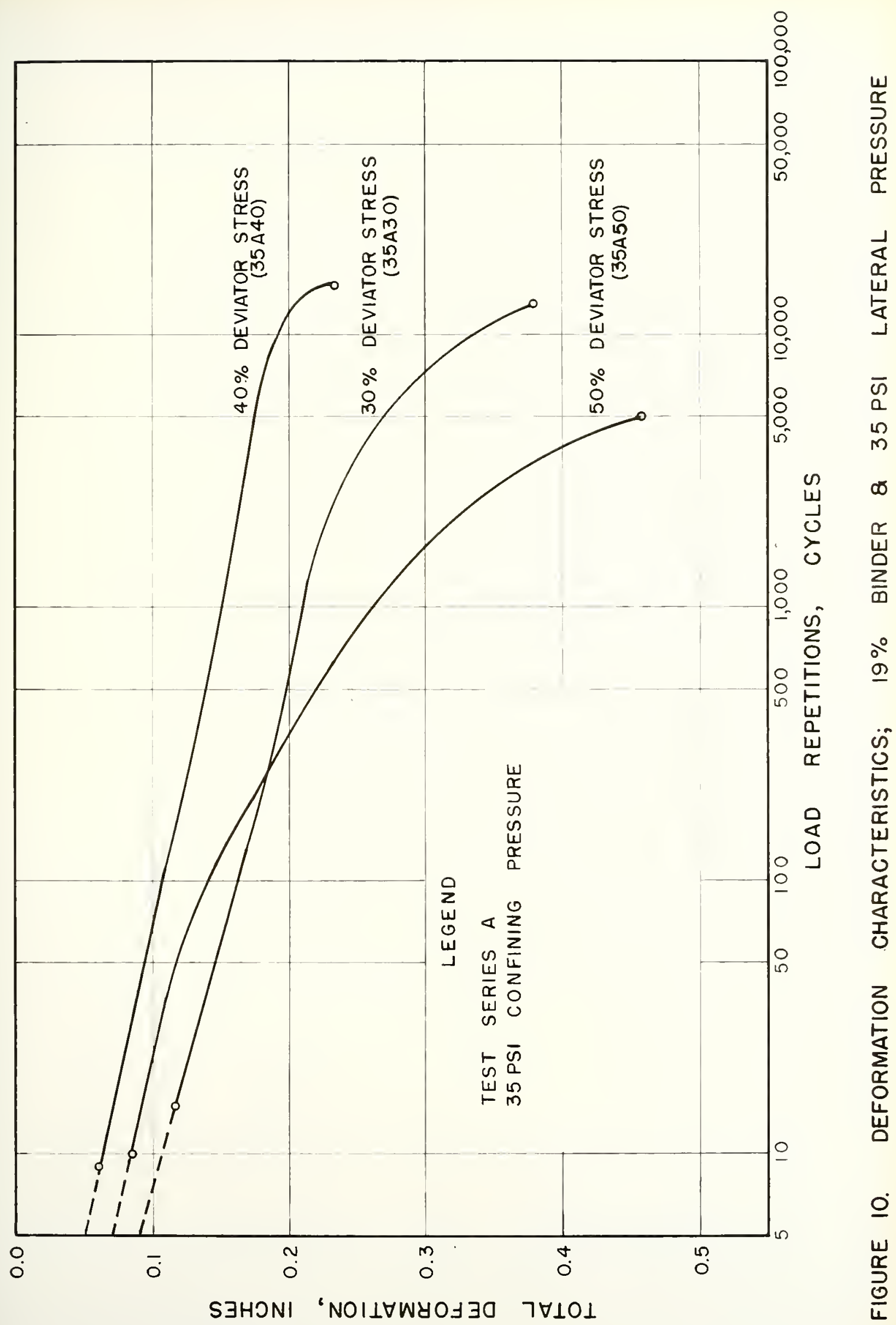


응

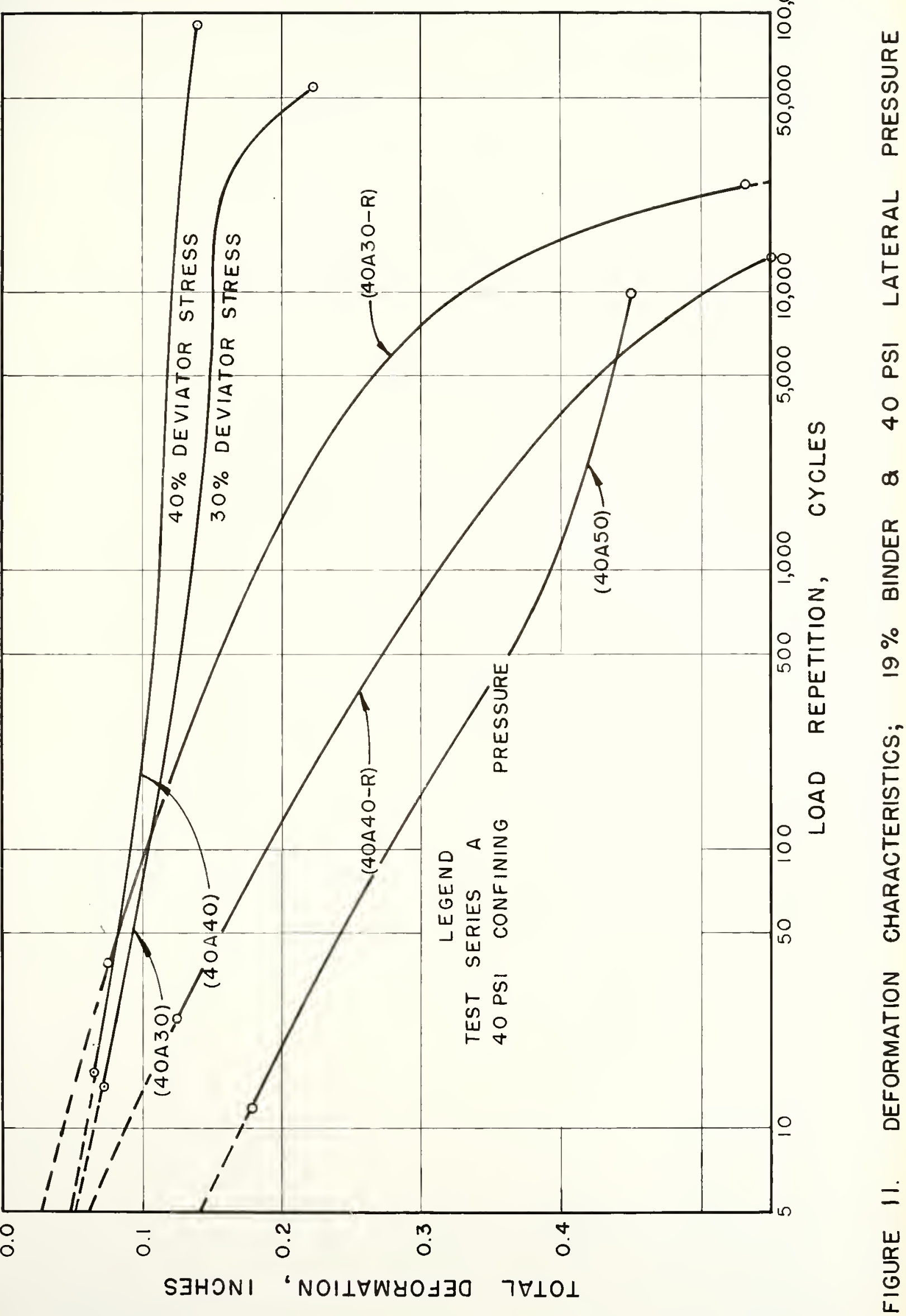




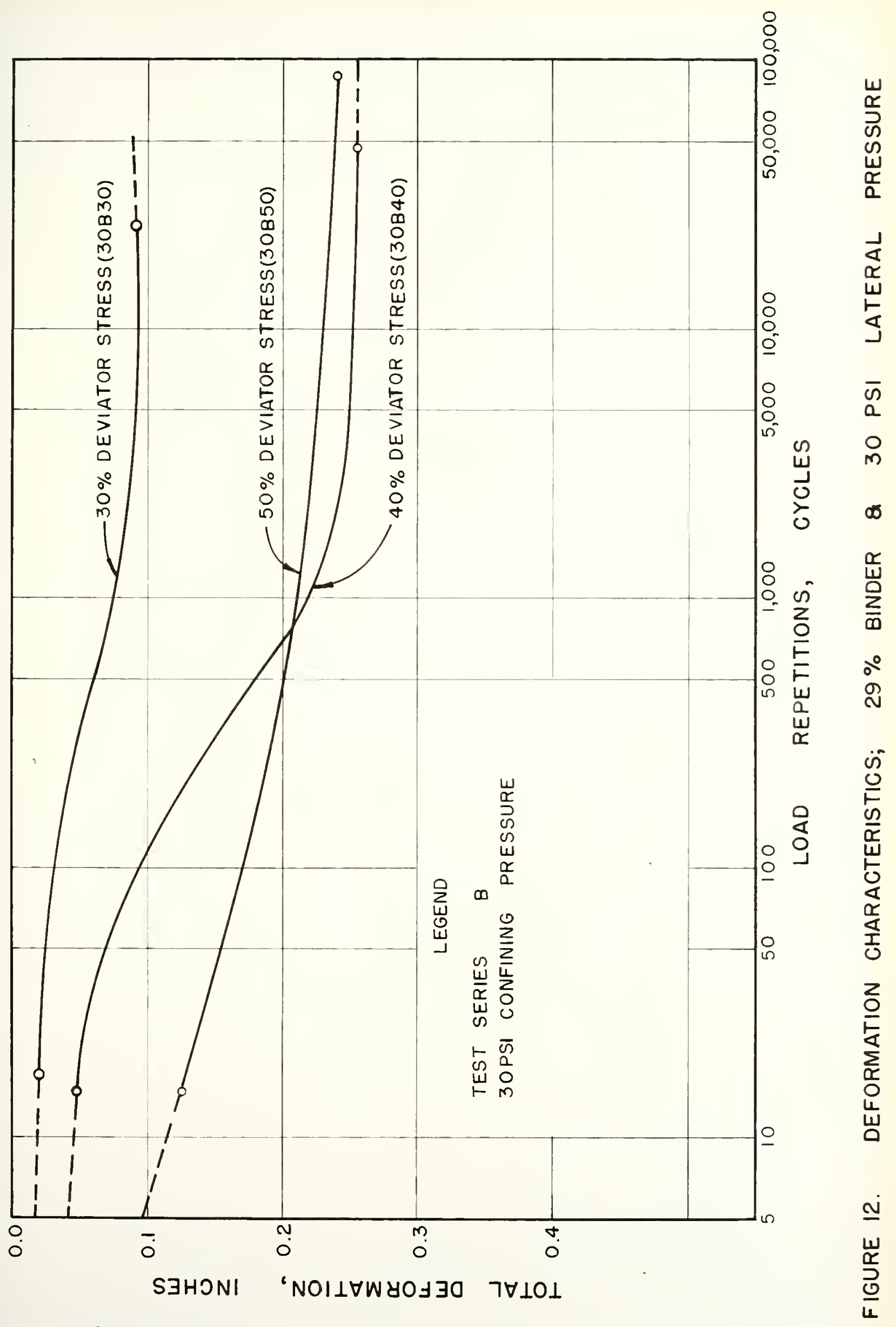




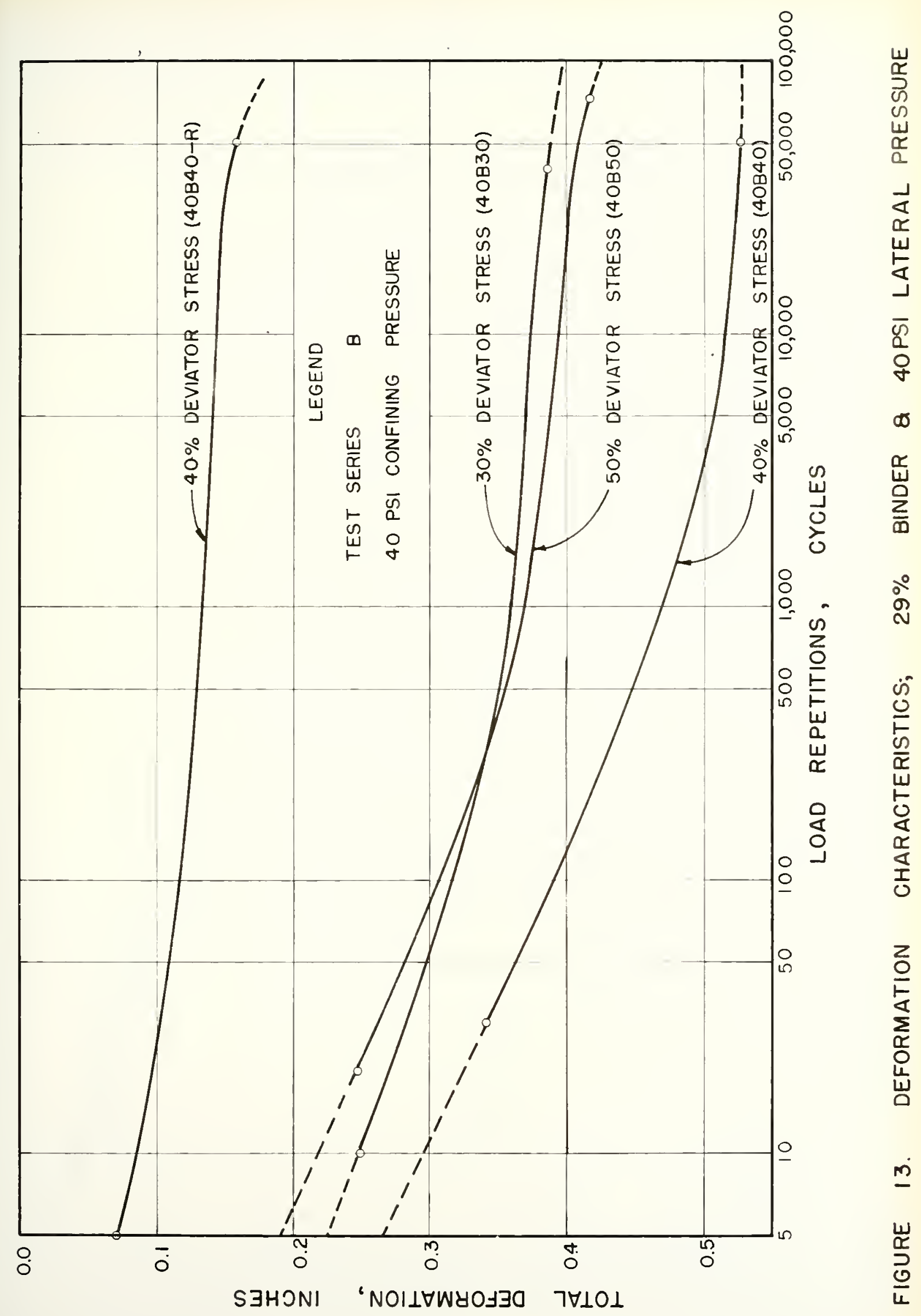




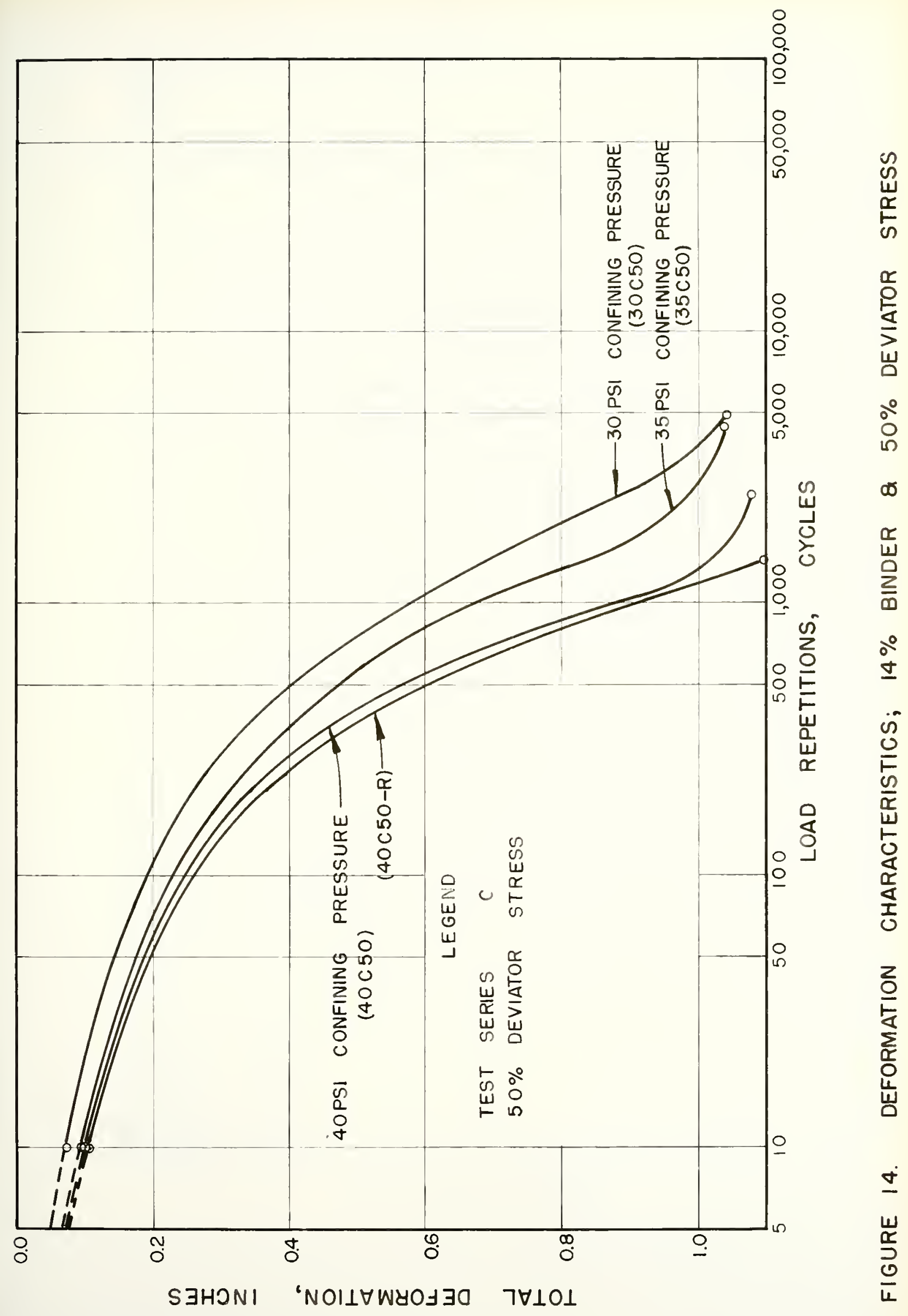




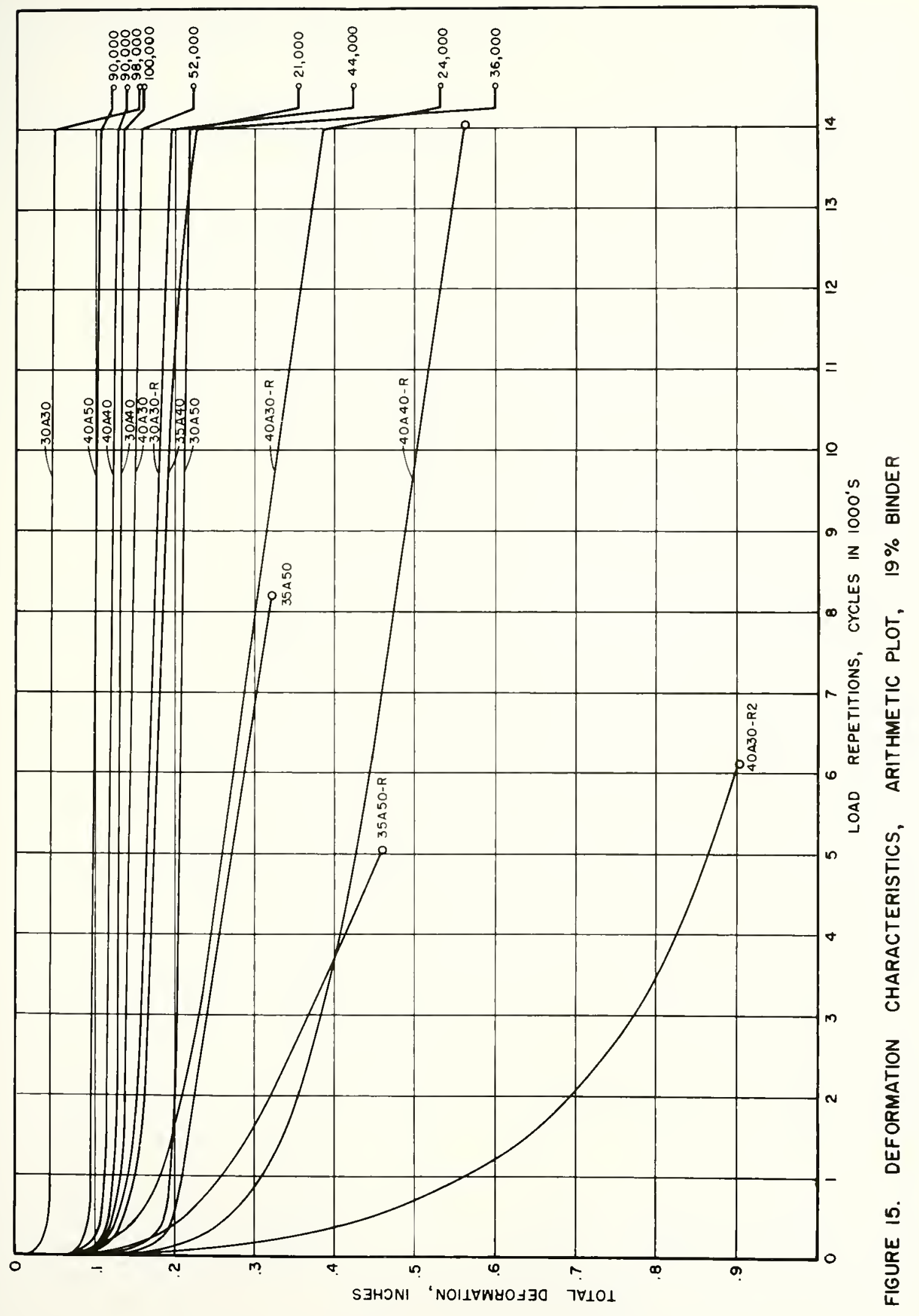




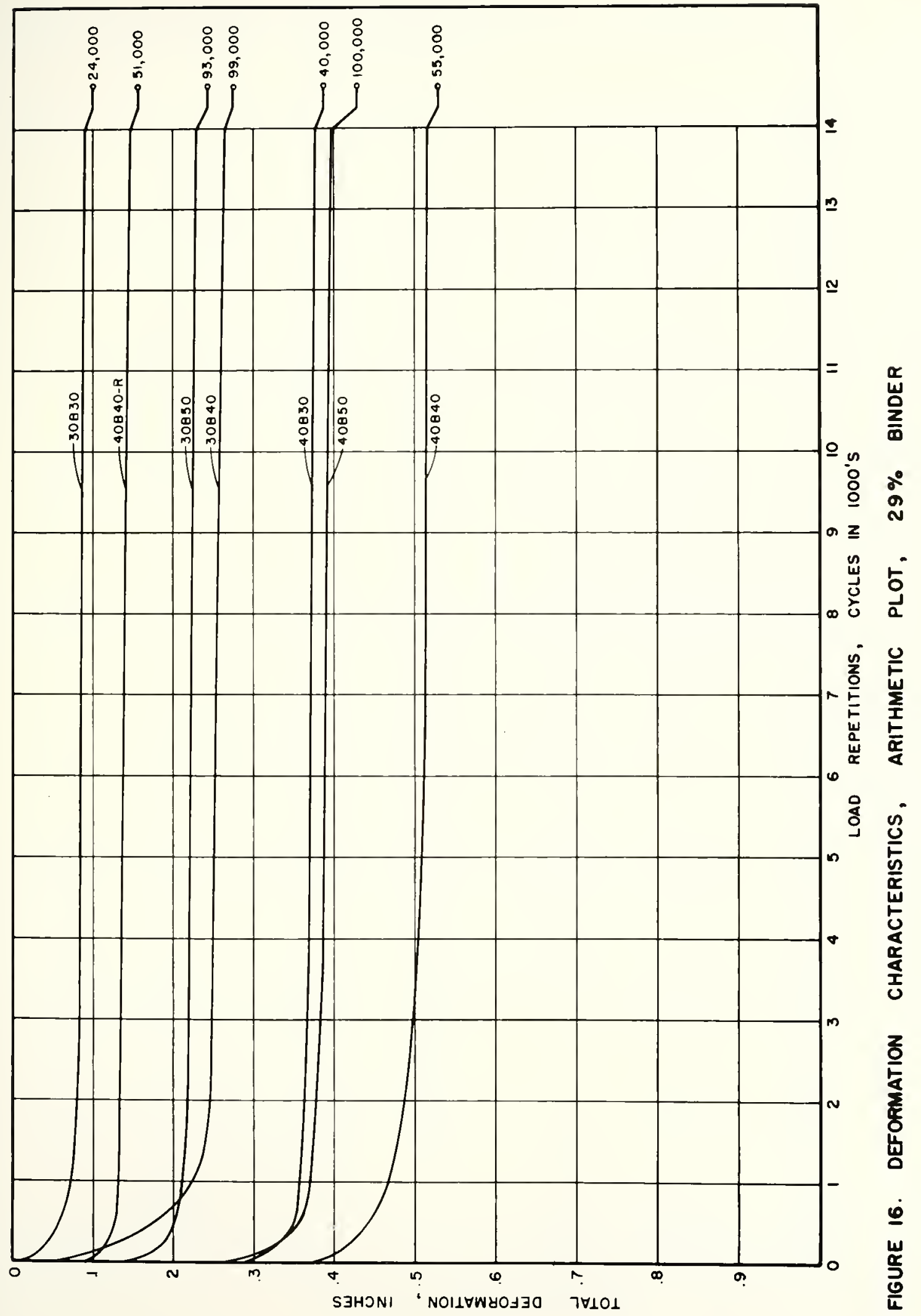




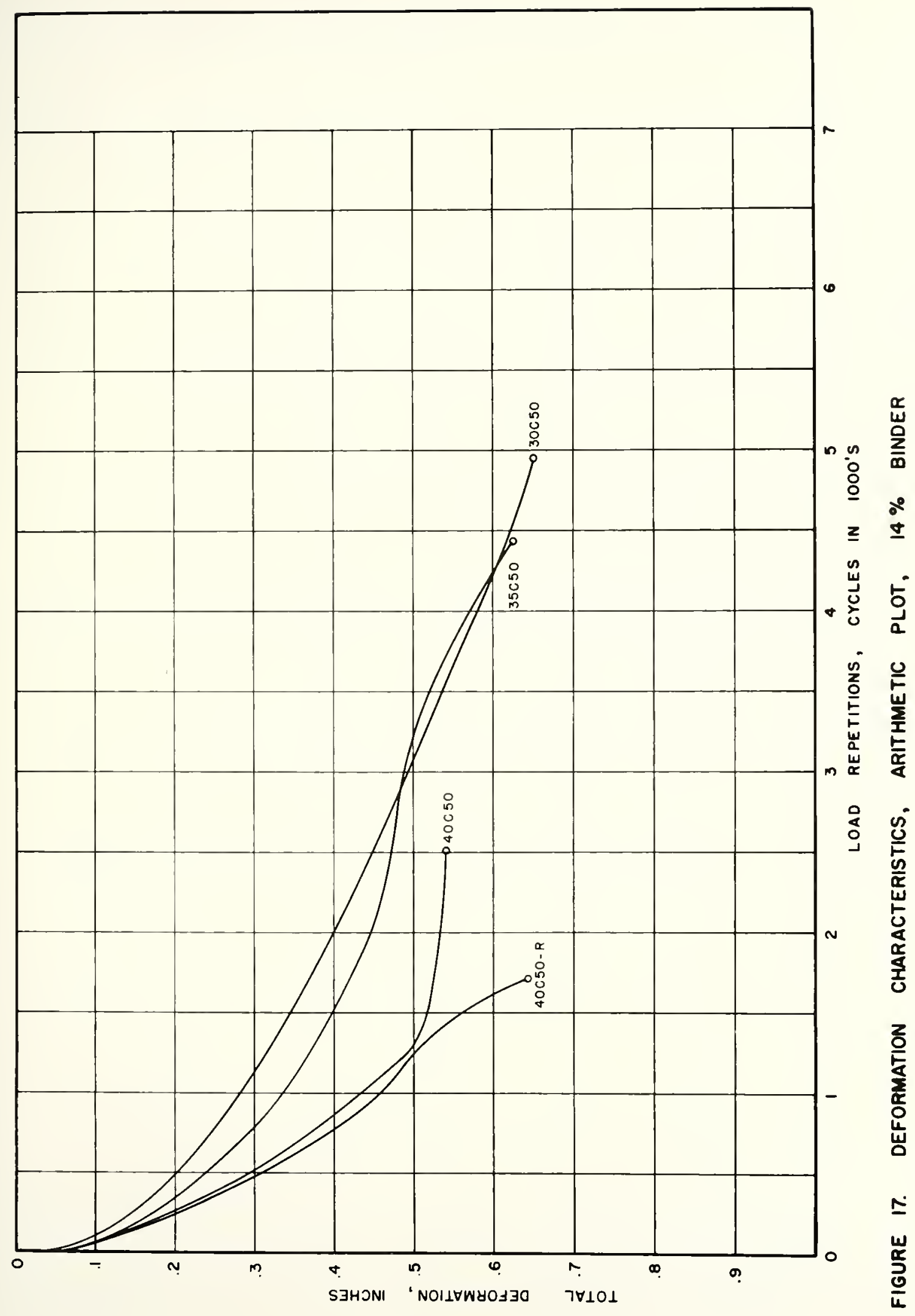


it is readily seen that the deformation increased wh increase in deviator stress and with increase in confining pressure. Furthermore these deformations were not low as one might expect, but were on the contrary quite large, the majority being above a limiting value of 0.1 inch and in the case of the higher confining pressures they were much greater than allowable by most strength criteria. Examination of the maximum densities and optimum moisture contents, (Table 2) shows that for 19 percent binder densities in the range of 136 pcf. were obtained for the Modified AASHO compaction test at molsture contents of 6.3 percent. At these high densities the deformations should have been less than those shown even with relatively saturated soils. Table 2 shows that the compacted specimens were usually denser than the values reported above. This deformation phenomenon will be discussed later under volume change.

The variation of deformation with confining pressure may be better understood by considering total stresses as show below.

\begin{tabular}{cccc}
$\begin{array}{c}\text { Confining Pressure, } \\
\text { psi. }\end{array}$ & \multicolumn{3}{l}{$\begin{array}{l}\text { Percent of Peak Static } \\
\text { Compressive Stress }\end{array}$} \\
& 30 & 40 & 50 \\
& Total Stress, psi. & \\
30 & 80 & 97 & 114 \\
35 & 95 & 115 & 135 \\
40 & 103 & 124 & 145
\end{tabular}

It is seen, in terms of total stress, that stress increased with confining pressure for each of the three ranges of deviator stress. Thus the deformations should bear, as they do, the same relationship as the deviator stress and increase with increasing 
deviator stress.

Considering the deformations for the 29 percent binder mix (B-mix) it can be seen that the remarks made above pertain as well to these soils, with the exception that the deformations were of a greater magnitude than for the 19 percent binder mixes. This is not an unexpected result since the peak static canpressive strengths averaged 20 percent less than strengths of the 19 percent binder mixes even though the maximum density was slightly more for the 29 percent binder soil. Discussion of test No. 4OBLO-R will be onitted at this time although it will be noted under Remarks, Table 3 that it was campressed under the confining pressure (undrained) for one hour prior to testing. For the 29 percent binder series, tests at 35 psi confining pressure were not run, although the results of such tests would plot between the results for the 30 and $40 \mathrm{psi}$ confining pressures. Again, from a total stress standpoint the deformation increased directly with increase in total stress.

Confining Pressure
psi.

\begin{tabular}{llrr} 
psi. & \multicolumn{3}{l}{$\begin{array}{l}\text { Percent of Peak Static } \\
\text { Compressive Stress }\end{array}$} \\
& 30 & 40 & 50 \\
& Total & Stress, & psi. \\
& & & \\
30 & 70 & 83 & 96 \\
40 & 92 & 110 & 128
\end{tabular}

The results obtained from tests on the C-mixes ( 14 percent binder) were quite unexpected but can be readily understood from a mechanistic standpoint. Due to the shape of the sand grains and 
the low binder content, it is believed that essentially sand grain to grain contact resulted in the compacted state. Saturation acted to reduce the intergranular pressure during the test and thus aided in intergranular displacement. Lastly, upon removal from the saturation cell the sample was observed to be moderately free draining. Thus it is believed that the water migrated under gravitational forces to the lower portion of the specimen prior to test, and during testing under repeated load this migration was accelerated. This action was observed by the bulging of the sample at the bottom much more than towards the top as the test progressed. Similar results were reported by Haynes (26) in his study of repeated load tests on AASHO Test Road base course mixes. Volune changes taking place during this period aided in producing greater deformations by increasing the moisture migration to the bottom as the test progressed and deformations and bulging increased. Removal of the specinen from the cell confirmed the above observations by the presence of considerable free water at the bottom of the sample, whereas the top was much drier with more open voids. For this reason, the tests on the 14 percent binder were limited to 50 percent deviator stress at each confining pressure. Since the deformation was over one inch in all cases and number of repetitions did not exceed 5000 cycles in any test, it will be seen that the tests were not indicative of potential good behavior under pavements. The trend was the same as for series $A$ and $B$ in that the deformations were higher at any given number of cycles as the confining pressure was increased, due to higher total stresses. 
Considering the results of the three series collectively it will be seen that the percent saturation achieved varied inversely as the binder content was increased. The 29 percent binder soils were most difficult to saturate, giving results which were lower than desired for this study. The 14 percent binder soils on the other hand gave good results with saturation very near 100 percent. Further, it can be seen that the deformation increased as the percent binder was increased above an optimum amount. As the percent binder was decreased below optimum, the deformations increased also but for different reasons, as explained above.

\section{Elastic Characteristics}

Each cycle of load application and release involved two movements within the specimen. The first movement was that of a permanent total deformation which at a low number of repetitions was relatively high. The second movement was that of a quasielastic ${ }^{7}$ rebound occurring with load release immediately after the plastic deformation had taken place. As with the recording of total deformation the determination of elastic rebound was recorded in two ways; the first by means of the LVDT and oscillograph previously described and secondly by means of a visual micrometer dial indicator reading. At any given cycle the reading taken from the dial indicator was recorded at the peak deflection for that cycle with the axial load applied as well as at the minimum value

7 The term elastic as used here is somewhat in error in that perfect elastic behavior in the strict sense does not take place. As used here the term means elastic-like behavior. 
reached on the dial indicator when the laad was removed. The difference between these two readings was recorded as the elastic rebound of the cycle. Referring to Flgure 8 again the rebound recorded by the LVDT is graphically portrayed. These rebound data were plotted graphically in Flgures 18 to 23 for each sub-series of tests. That is, the data on each graph except Flgure 23 show rebound histories for the three or more specimens tested at a given binder content and confining pressure. Figure 23 shows the graphs for the C-mixes mun at constant deflator stress.

Inspection of these graphs shows several interesting facts. The first fact is that for nearly every sample the rebound was higher at low repetitions than at high repetitions. The rebound decreased in magnitude until after a certain number of repetitions a quasi-equilibrium value was reached which remained constant during the remainder of the test period. Furthemore, inspection of the individual graphs shows that the magnitude of both the initial rebound and the equilibrium rebound value increased directly as the deviator stress was increased. At low repetitions there appears to be approximately 25 percent increase in rebound with each 10 percent increase in devlator stress whereas at higher number of repetitions the increase was reduced to 10 or 15 percent with each 10 percent increase in deviator stress. It should be noted however that part of this trend at least was due to the fact that the deviator stress did not remain constant throughout the period of test. As the total deformation increased, the effective area increased with the result that the devlator stress was reduced. 


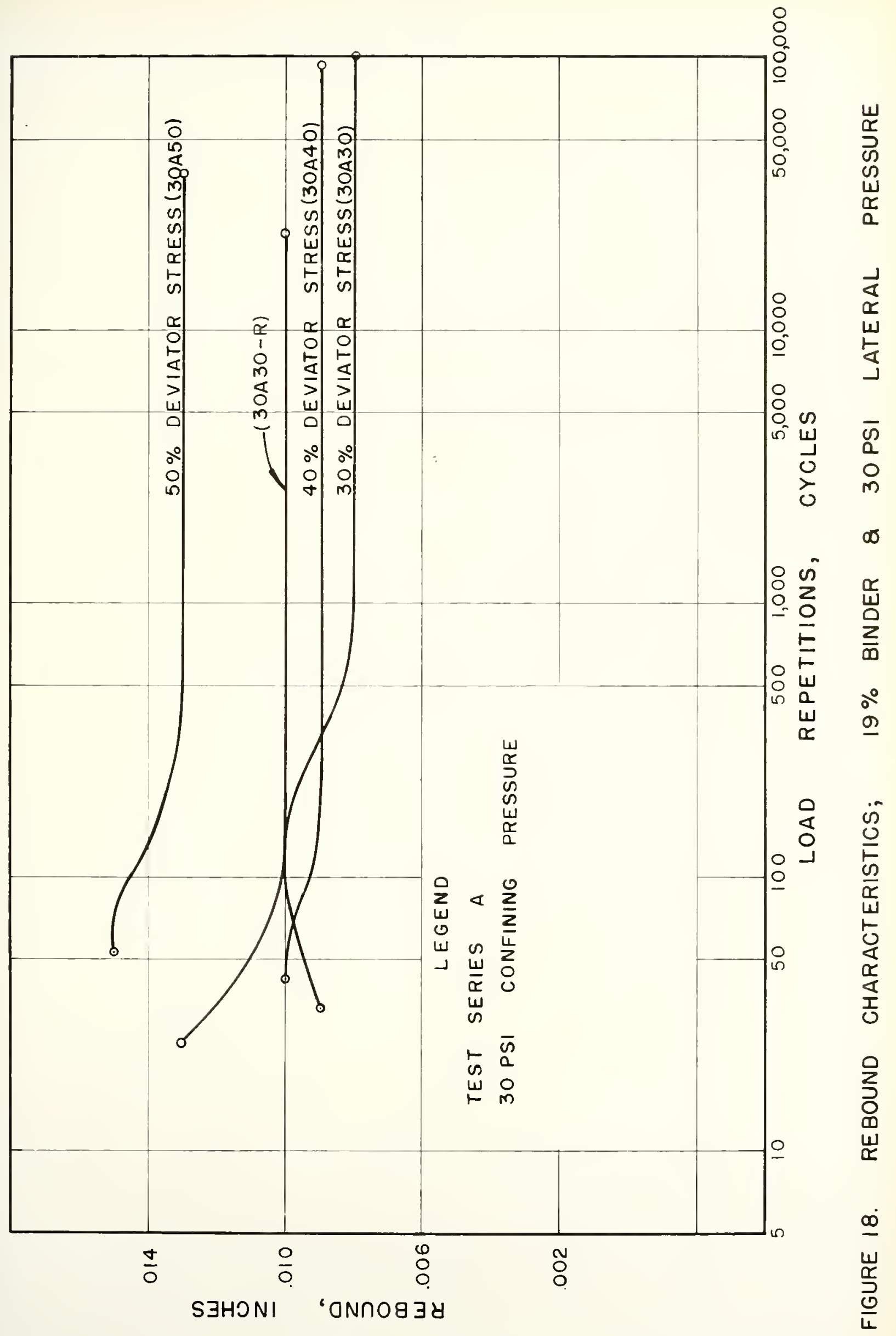




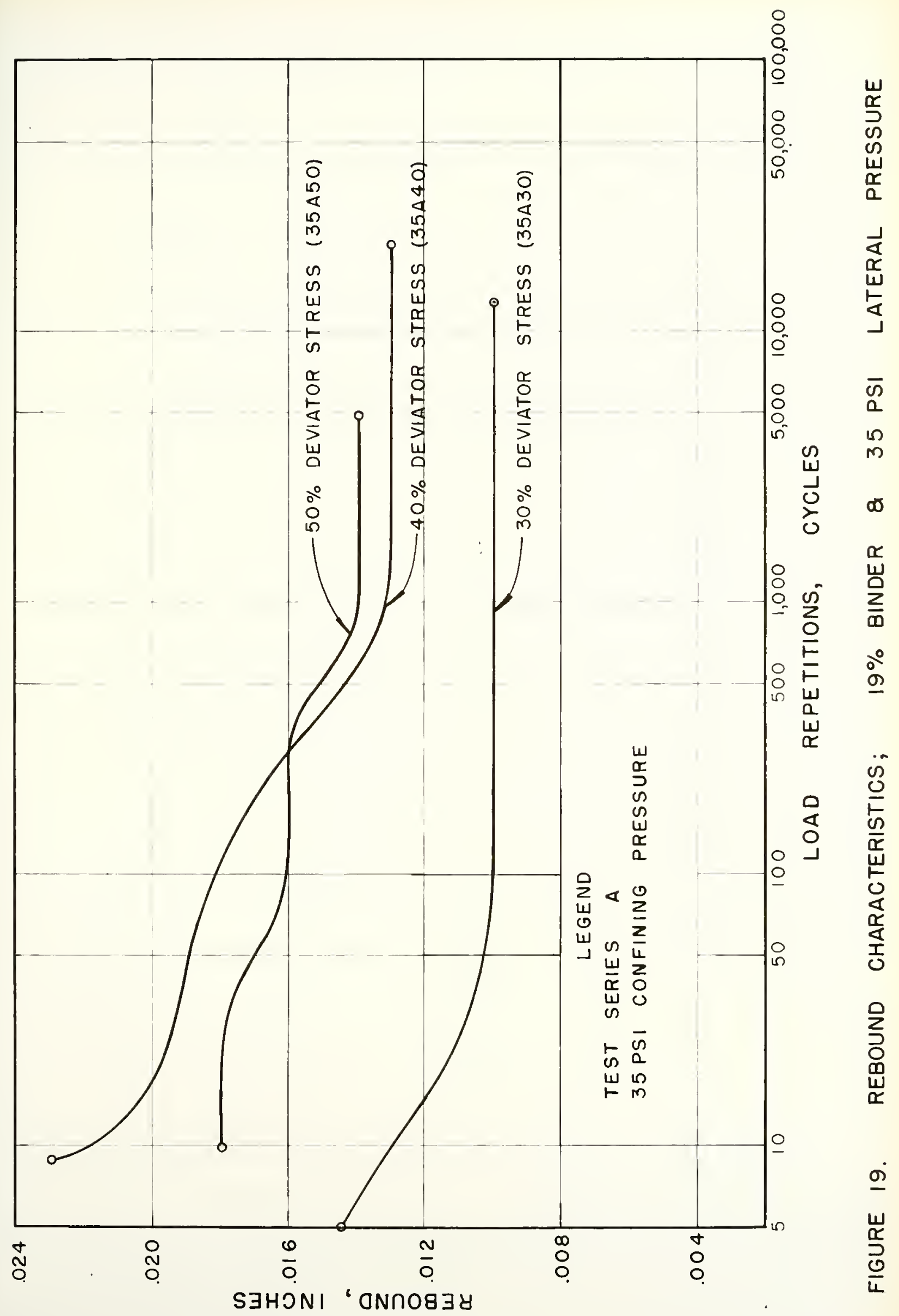




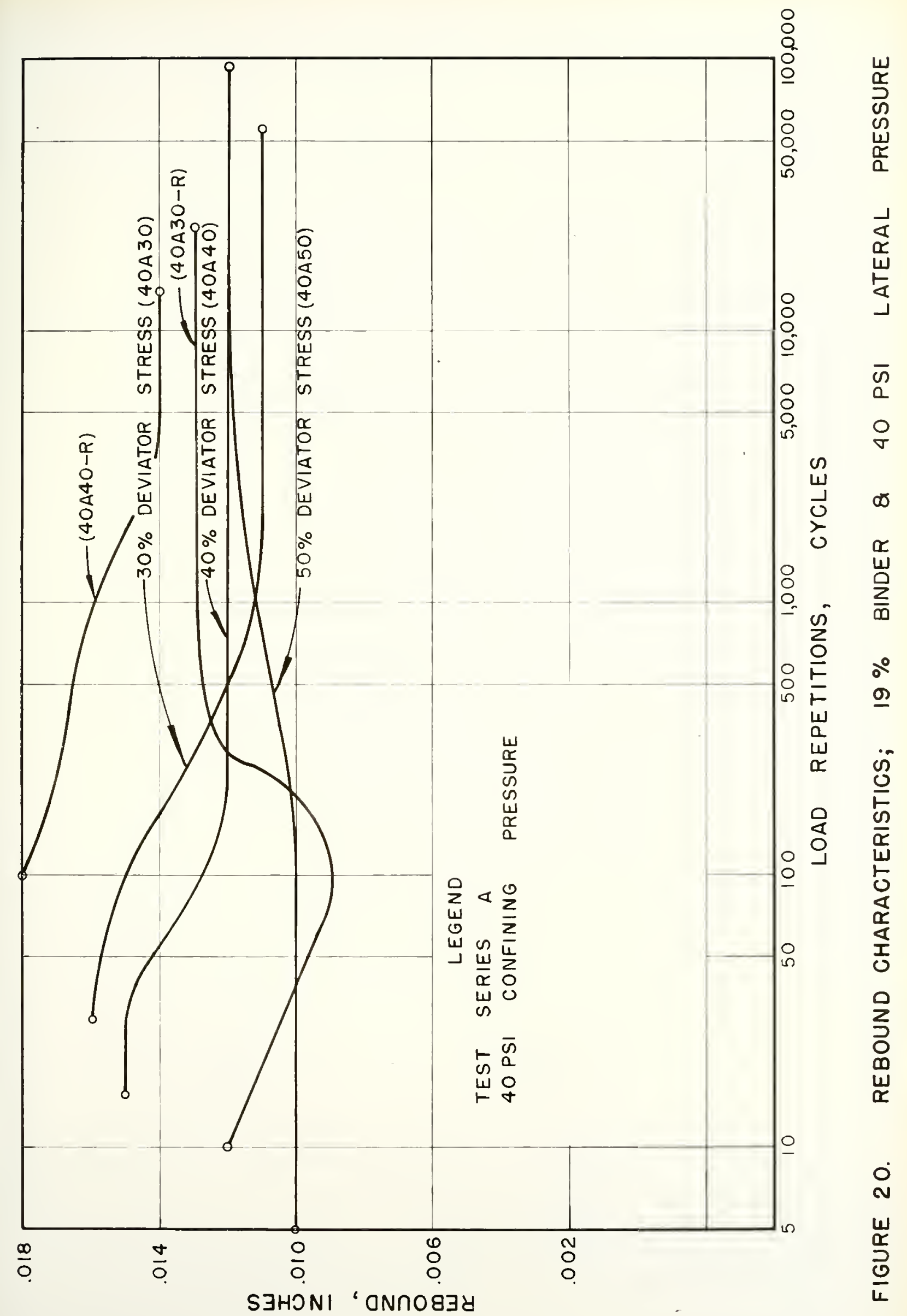




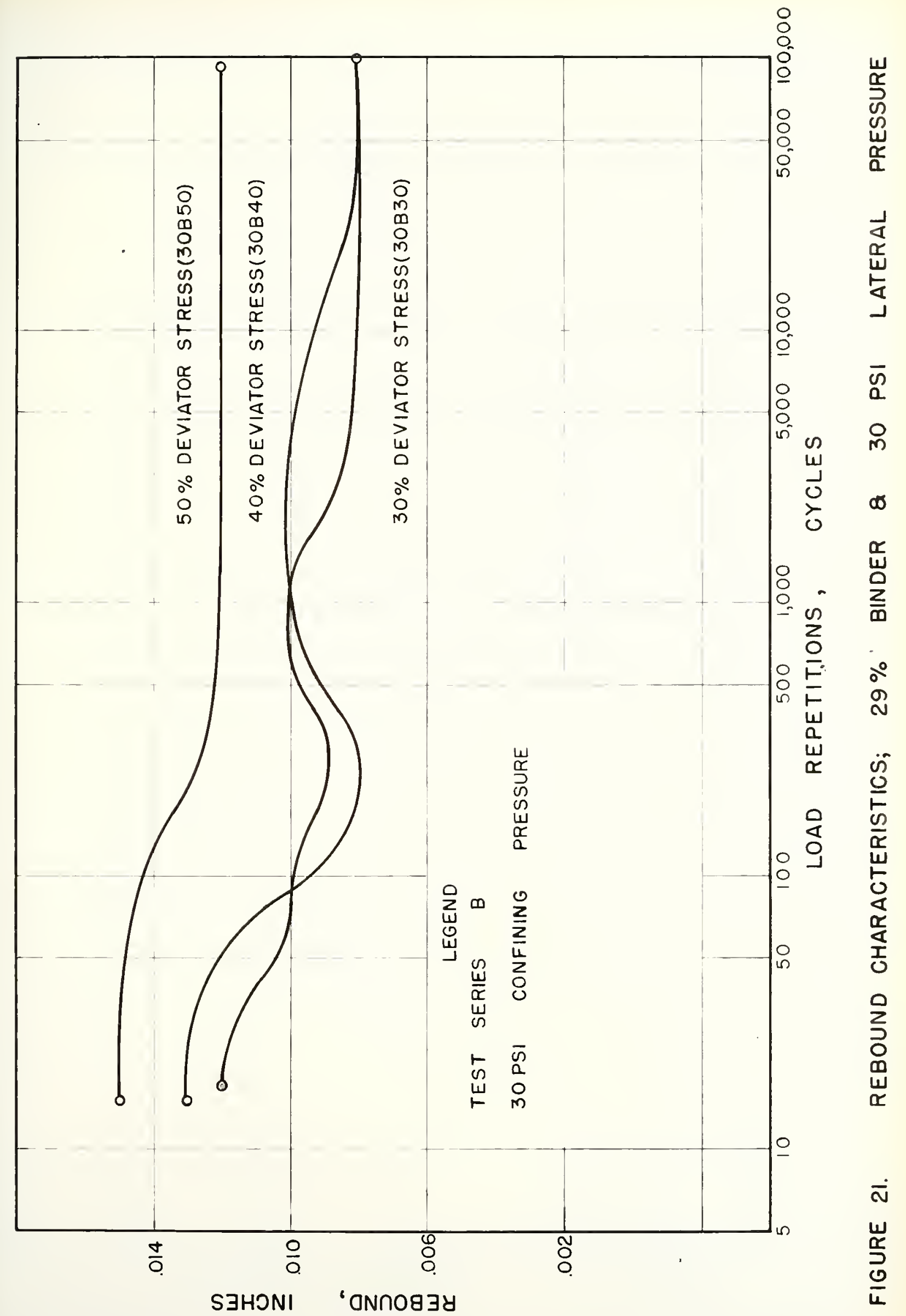




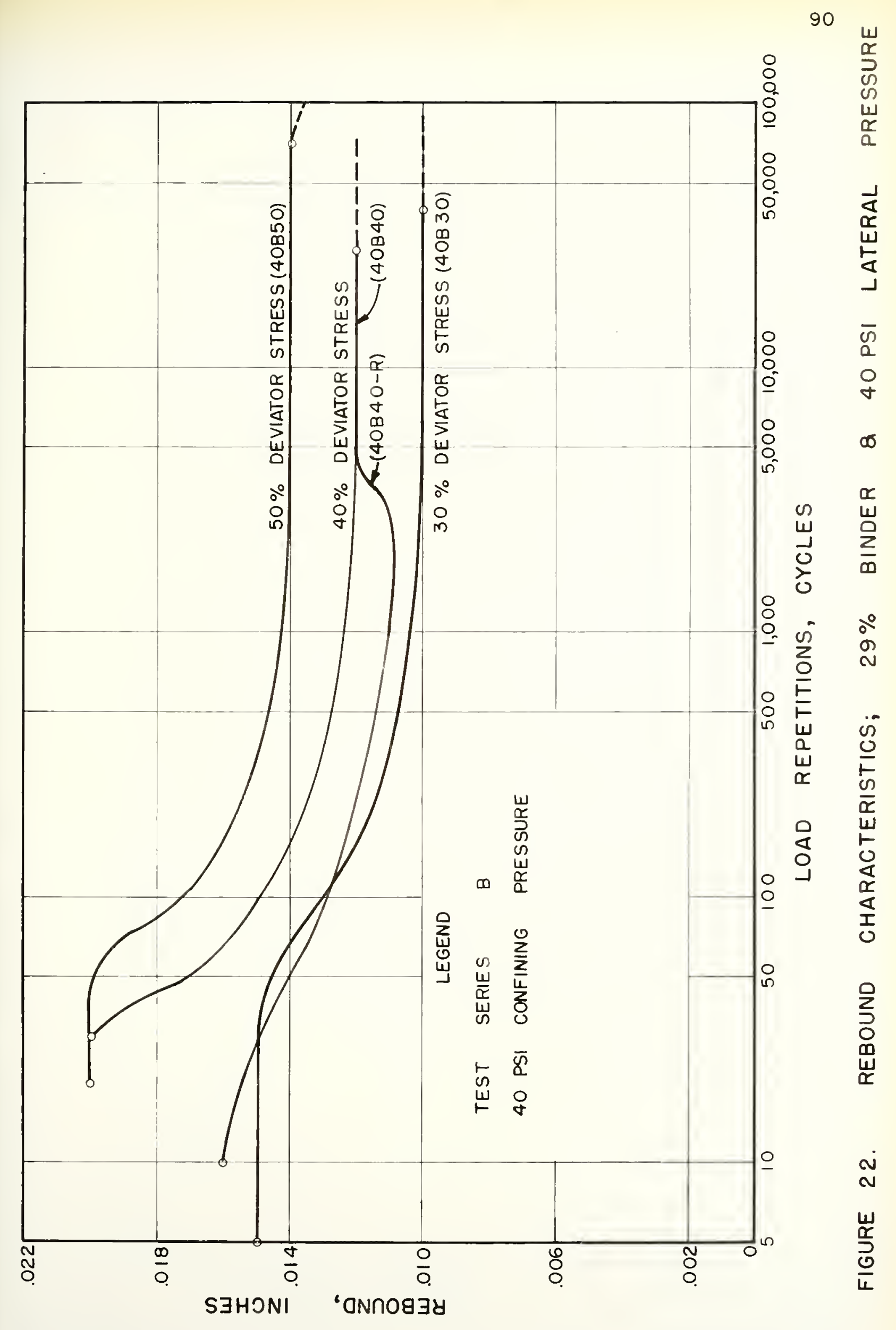




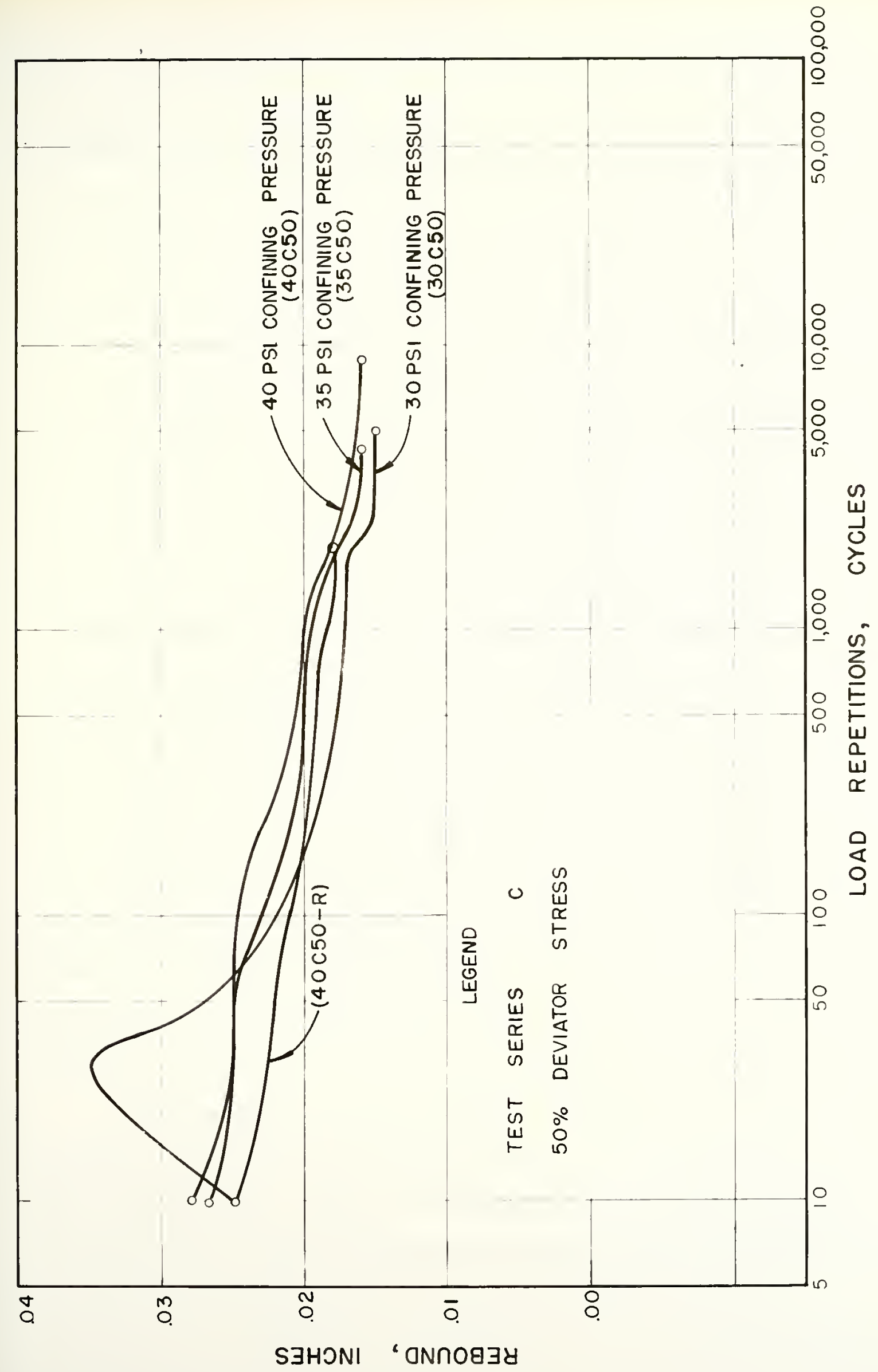

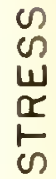

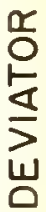

0
0
0



$\frac{\pi}{山}$

$\stackrel{0}{0}$
d

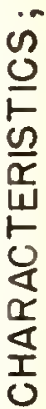

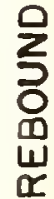

i

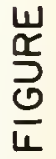


Table 2 includes the value of the final deviator stress showing the magnitude of this reduction. Thus the equilibrium rebound represents a compatibility between the total deformation which has occurred and the reduction in deviator stress. The significant fact here appears to be that an equilibrium rebound value is reached and not so much the relationship between initial and final rebound values.

Examining the effect of confining pressure it is seen that the rebound increased in magnitude both initially and finally as the confining pressure was increased, the binder content remaining constant. This was due of course to the higher total stresses and attendant increase in soll strength.

The effect of binder can be determined by inspection of the several graphs. As the binder was increased above optimum (19 percent) the rebound initially increased slightly for the same percentage of deviator stress but reached a final value which was slightly lower for the higher (29 percent) binder contents. At minimum binder contents ( 14 percent) the rebound was again greater both initially and finally than for the mixes at higher binder contents. This was probably due to the much higher total deformations and resulting increase in resistance to deformation, coupled wh the increased reduction in deviator stress.

From inspection of these graphs it is apparent that in the majority of cases, the equilibrium rebound value was reached at or before 1000 cycles. This is in agreement with the results reported by Larew (25) in which the soils having elastic rebound characteristics 
reached an equilibrlum value after 1000 cycles. In order to assess the nature of these rebound trends more fully, it was therefore decided to utilize the deformation-time and load-time data to calculate the dynamic modulus of deformation, $E_{d}$ for some load cycle below 1000 and for sane higher cycle of repetition. Where the total deformation did not exceed the range of the LVDT, the low cycle selected was No. 100. The high cycle number selected was the one in which the total deformation was just within the range of the LVDT. Usually this was between 20,000 and 50,000 cycles. The method whereby $E_{d}$ was computed is presented in Appendix D. The results of the computations are shown in Table 2. While values were obtained for most tests at low repetitions, few were obtained at high repetitions due to excessive deformations. This was particularly true of the 29 percent binder mixes for which only three high-repetition values were obtained. Generally, the trends noted are as follows. At low number of repetitions the value for $E_{d}$ is usually higher than at high repetitions although three exceptions (30A40, 4OA30,30B50) are noted. The decrease in magnitude appears to follow no set pattern. The explanation for this was considered to be related to the lowered deviator stress and resulting lower equilibrium rebound values. A very significant difference was noted however between the 19 percent and 29 percent binder contents. At low number of repetitions the magnitude of $E_{d}$ was much less at 29 percent binder than at 19 percent binder in the order of 50 percent. This is true for the C-mixes ( 14 percent binder) also. Evidently soil structure is important. Wilson and 
Dietrich (37) have reported same values for $E_{d}$ as a function of compressive strength for several types of clays and sand soils. Their data show that at any given compressive strength, $E_{d}$ is greater for well graded sands and gravels than for poorly graded sands, and least for highly plastic clays. While their values are about 100 percent greater than those reported herein, the total time interval over which $\mathrm{E}_{\mathrm{d}}$ was computed is much less than the one second interval used in this study. It is known that $E_{d}$ varles wth the time of loading, i.e. increases with a reduction in time of loading.

\section{Strength Characteristics}

From the work of Seed, et al (19-24), Larew (25) and Haynes (26) the general nature of the effect of repeated loads on soil strength was known. An important conslderation of this study was to determine the strength of the campacted, saturated sample by same standard static test and relate the strength of the sample under repeated loads to this, value. Thus, comparison could be made between strengths under both static and repeated load tests and same relationship between the two empirically derived. In this way, preliminary steps to the derivation of a repeated load strength criterion might be developed.

Referring to Appendix $B$, the results of triadal static $Q$ tests which were run on each of the design mixes are shown. The difficulty of saturating the higher binder-content mixes is readily seen from the tabulation of soll data. Since these tests were run prior to any repeated load tests, the method of saturation was improved with 
the result that higher degrees of saturation were obtained for the repeated load tests than are reported in the appendix. It is not considered that these percentage of saturation are so significantly low as to have resulted in a marked change in the peak compressive strength.

The mixture for each test was prepared in the same manner as prevlously described, compacted and saturated according to the procedure established for the research program. Some of the A-mixes were saturated only 12-14 hours and for this reason the saturation is low. Part of this effect is due to the higher densities achieved, with attendant increased difflculty in obtalning high saturation contents. This is shown dramatically by comparing the 30 psi confinIng pressure value ( $A-m i x)$ with the 35 and 40 psi confining pressure results.

After saturation, the sample was placed in the triaxial cell and loaded at a rate of .05 inches per minute. Readings were taken of load and deformation either until fallure or until the deviator lad fell significantly from the maximum value. Results of the tests are plotted in Figures 53 to 55, for canpressive strength versus axial strain. The peak compresslve strength was then used to plot Mohr clrcles of stress for each design $m i x$ at the various confining pressures. These are portrayed in Figures 56 to 58.

Inspection of the Mohr envolopes for each mix design shows that the shear strength is dependent on the percentage of binder used in the mix. The highest shear strength was obtained for the 
19 percent binder mix which was expected. As the binder content was increased to 29 percent the shear strength was correspondingly reduced approximately 15 percent.

Decrease in binder content below optimum resulted in decrease in shear strength also, but not as much as for excess binder content. Furthermore, the strains occompanying shear stresses were much higher for the excess binder (29 percent) mixtures than for optimum binder (19 percent) mixtures although the strain accompanying the shearing of low ( 14 percent) binder mixtures was only a little below that obtained for optimum binder. This would lead one to suspect the same type of behavior under repeated loads, although the C-mixes were an exception as was found under the deformation resurts previously discussed.

While it appears impractical to define strength parameters under repeated loading, these could be determined by loading samples statically at conventional rates of strain after a history of preshear repeated loading. Thus the strength under repeated load could be reported as a function of the static load strength. For those samples in this study which did not fail in the repeated load test, this was done. After the sample had undergone the desired number of load repetitions, usually at or near 100,000, the sample was removed from the repeated load apparatus and tested In conventional triaxial compression. Load and deformation data were recorded until failure occurred. The compressive strength at failure was then related to that obtained under static tests. These data are reported in Table 2 under the column, $\frac{\Delta \sigma_{r}}{\Delta \sigma_{s}}$ 
Comparison of these data reveals some interesting facts. First it is seen that the majority of the optimum binder content mixtures failed during the repeated loading test. Those few which did not fail, show strength gains of about 14 to 24 percent with the lower values more conmon. For those mixtures having excess binder, loaded and tested under identical conditions, it can be seen that the strength gain was significantly less, about 4 to 23 percent with an average of about 10 percent. (Equipment malfunction in the static test for 30350 is considered to account for the high value of 39 percent gain for that test. It is omitted from these discussions). Thus it appears that as the binder content is increased above an optimum amount content the strength gain is decreased. The C-mixes, due to high deformations, could not be tested statically except the repeat test, No. 40C50-R. Here the sample did not gain strength, but rather lost strength due to the large change in effective area accompanying the high strain.

In summary, it appears that as long as neither high total deformations nor fallure occur in the repeated load test, the strength gain is related to binder content alone; the degree of strength gain decreasing with increase in binder content above the optimum amount. Phrased in another way, the strength gain for these mixtures appears to be less for lower static shear strengths than for higher shear strengths, all other test conditions being similar. Again, this result may be due to volume change characteristics which are thought to have influenced the developed strength. Failure, when it occurred, for the A-mixes was always a shear 
failure. For B-mixes it was usually by bulging at the center of the sample or in a few cases by a combination of bulging and shear fallure. The C-mixes invariably produced extreme bulging at the base of the sample. Plate 7 shows some fallures obtained for vartous mixes.

\section{Pore Pressure Behavior}

Referring again to FIgure 8 , the oscillogram of a typical test specimen, the trace of pore pressure behavior is indicated. Examination of this trace shows that with the application of load the pore pressure decreased a certain amount and upon release of the load the pore pressure rose. Load application again depressed the pore pressure below the previous maximum pore pressure change. Thus several characteristics of pore pressure are noted. One is the cyclic change which occured during one cycle of loading and unloading. Another is the trend of the maximum pore pressure change as referred to that reached with the load applied, to change incrementally with each succeeding cycle. This might be referred to as base line change. A third characteristic not so readily apparent is that of pore pressure response. This is defined as the ratio expressed in percent, of the recorded pore pressure compared to the lateral pressure. The response is tabulated in Table 2 for each test mun in which pore pressures were measured. It can be seen that these varled widely fram lows of 65 percent to highs of 98 percent with 80 percent the calculated average. Pore pressures w1ll be discussed in terms of these three characteristics. 

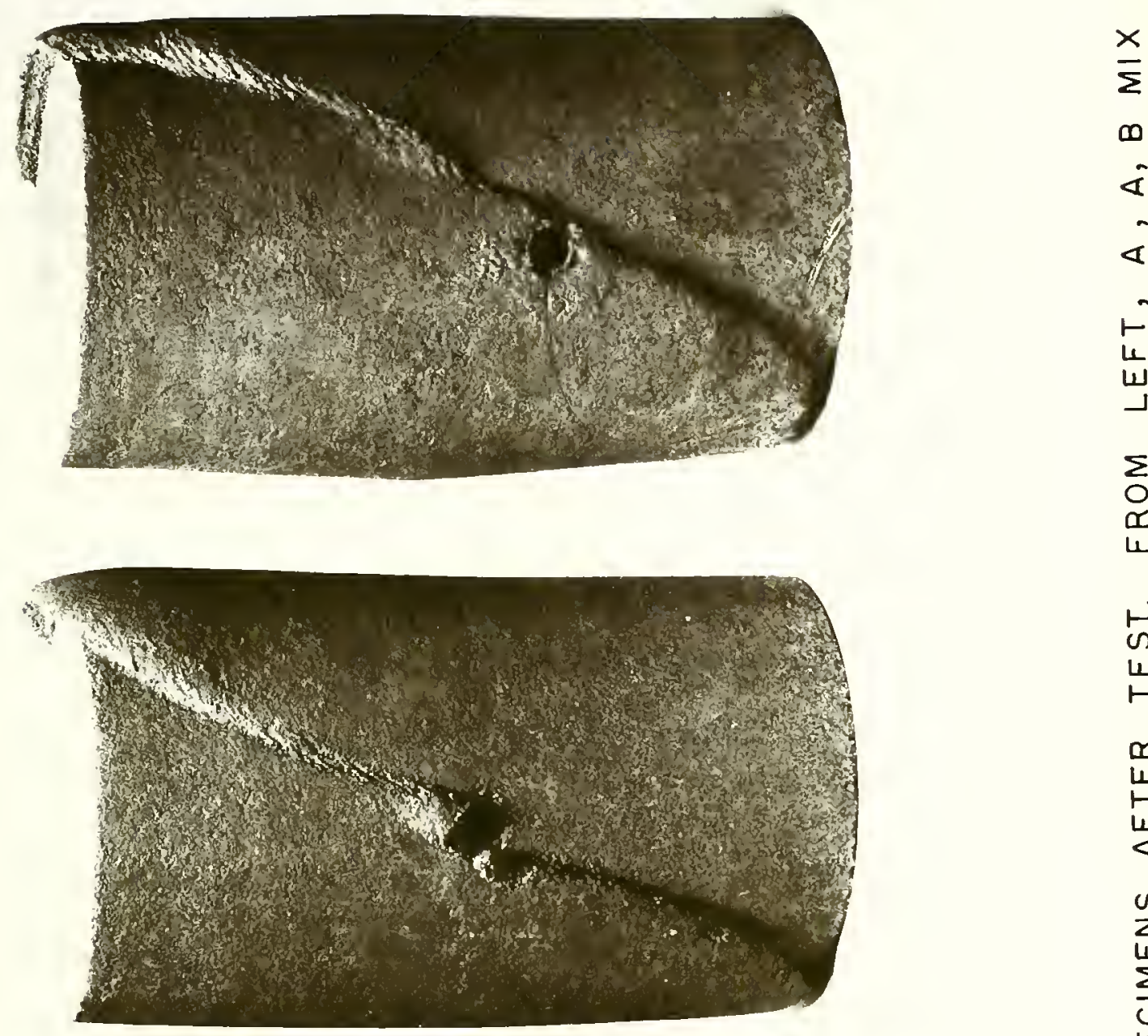

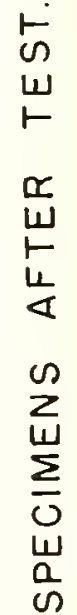

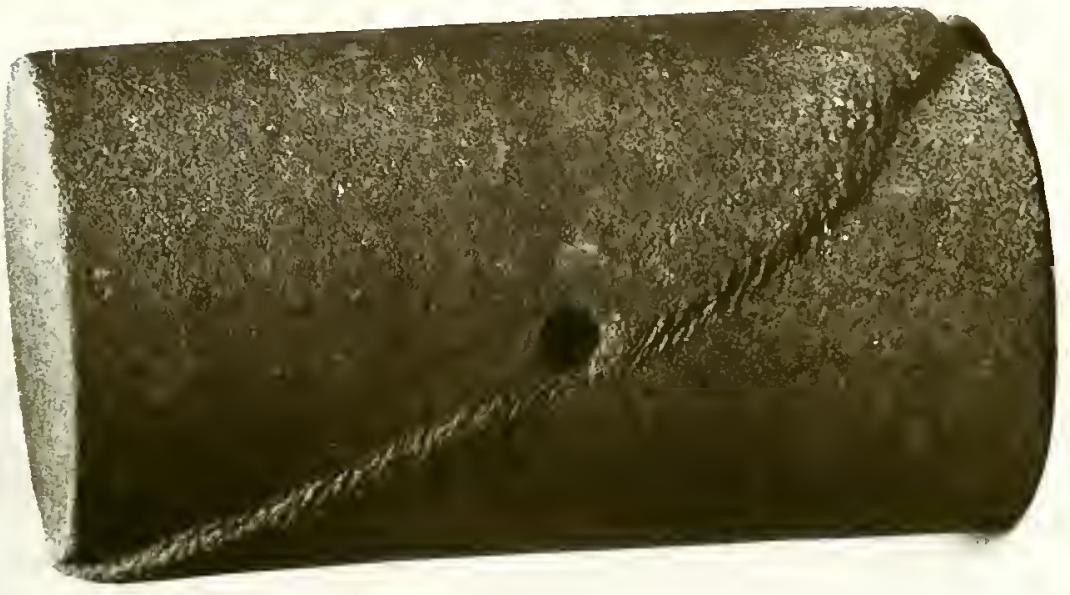

0
1
4

$\frac{\frac{1}{5}}{\frac{1}{2}}$ 


\section{Initial Pore Pressure Change}

Referring to FIgures 24 to 29 the graph of change in pore pressure versus stress difference for the first two cycles of load is presented. These data are considered to be significant because the relationship between various confining pressures as well as the effect of binder content can be readily seen. In addition, the rather large difference between cycle 1 and cycle 2 pore pressures is evident. It is noted here and is emphasized, that a departure fram correntional terminology has been made for ease in plotting. Whereever change in pore pressure is plotted, it will be expressed as a negative value if the change acted to reduce the initial or previous pore pressure. Conversely, it is expressed as a positive value if it acted to increase the previous recorded pore pressure. The reference pore pressure is that value recorded when the confining pressure was applied, before the test canmenced. In subsequent passages where absolute values of pore pressure are given, they are expressed comventionally, 1.e. a negative pore pressure indicates a value below atmospheric or zero gage pressure. If one examines the three graphs Figures 24 to 26 for the 19 percent binder molsture one similarity is noted, the change in pore pressure is a direct function of the applied deviator stress. As the deviator stress was increased, the pore pressure change also increased in magnitude, as one would most certainly expect. Again it is seen that the change in pore pressure increased for an increase in confinting pressure; again a trend which is readily understood in terms of total stresses. 


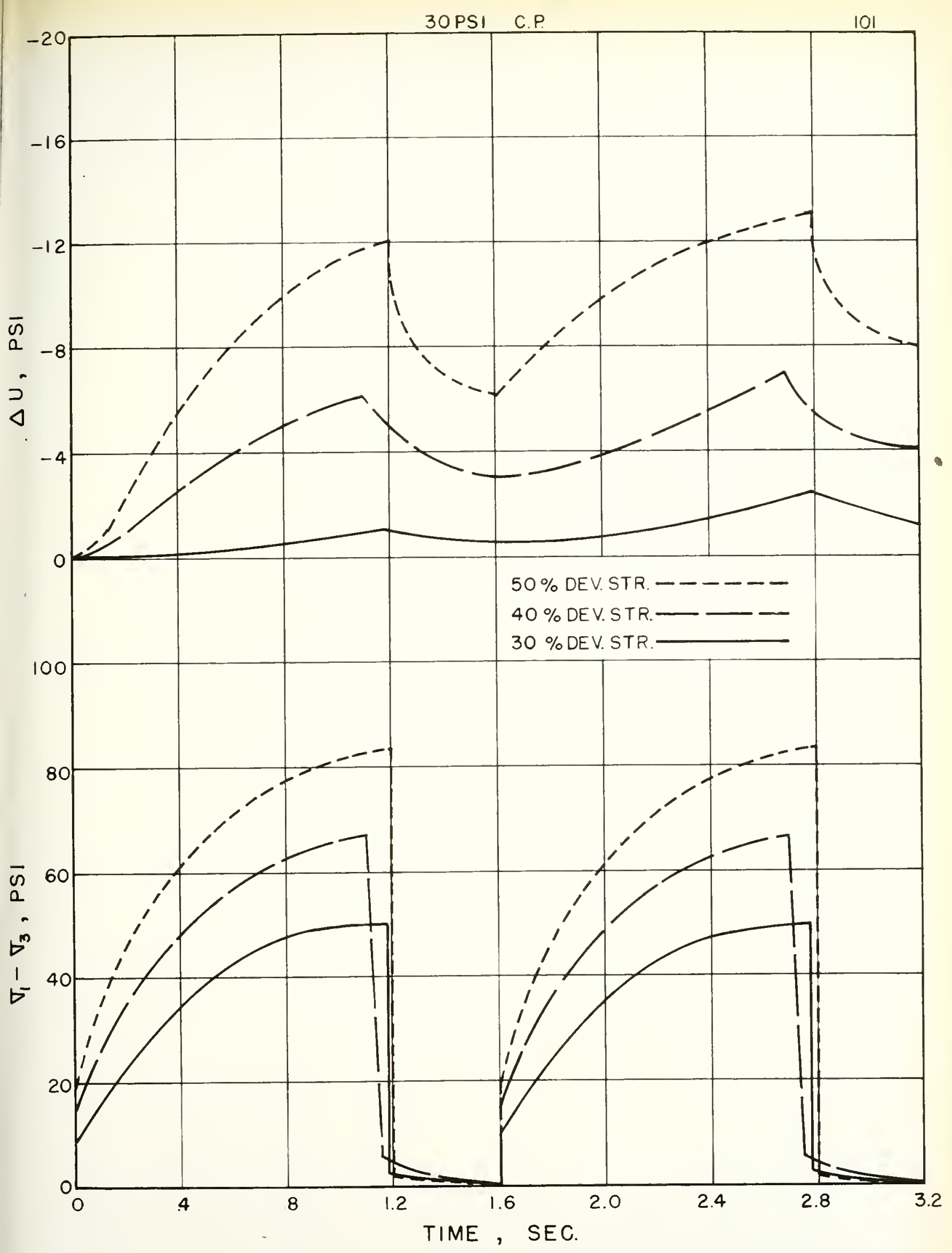

FIGURE 24. CHANGE IN PORE PRESSURE VS. STRESS DIFFERENCE CYCLES $182,19 \%$ BINDER, 30 PSI. C.P. 


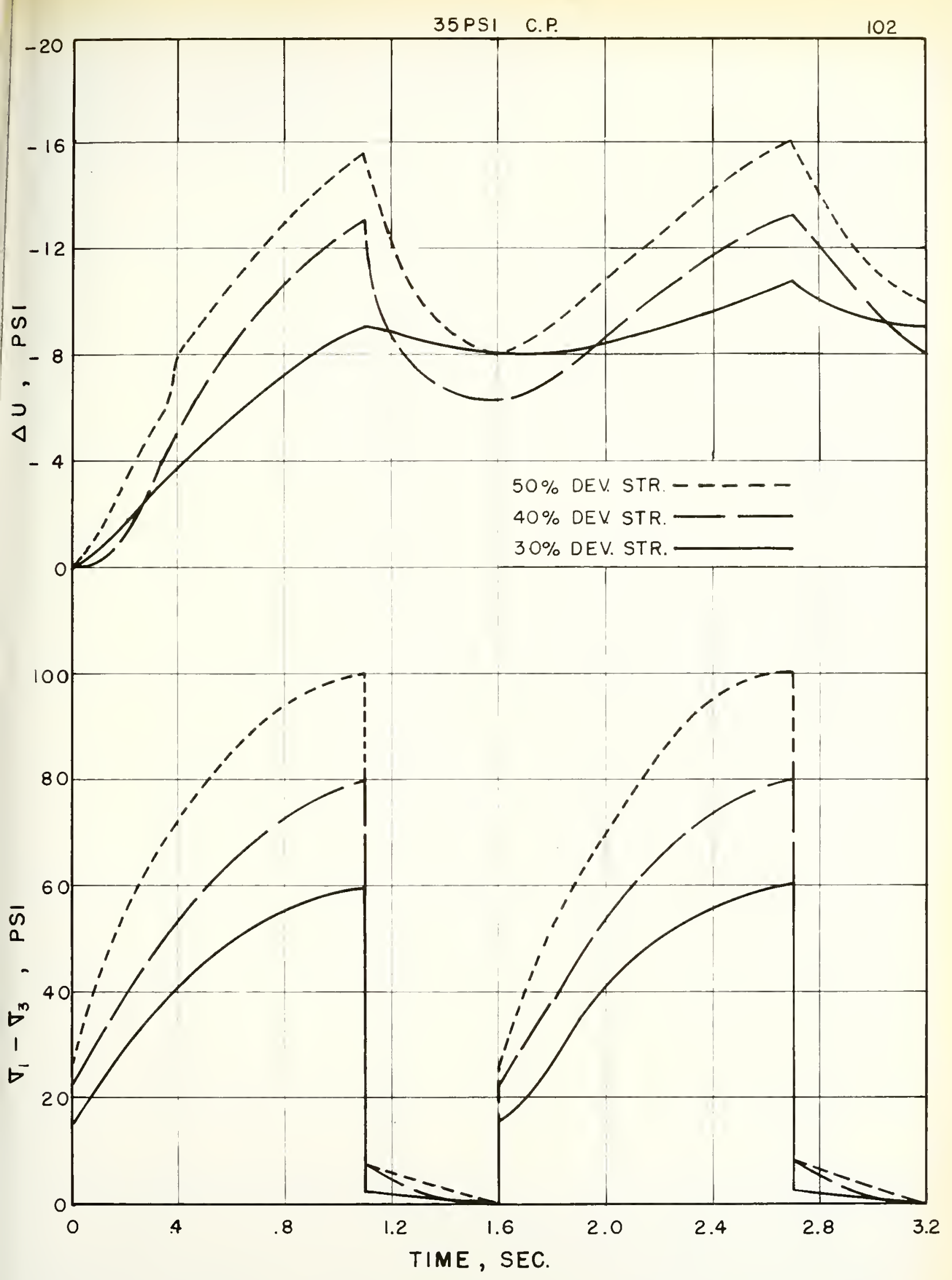

FIGURE 25. CHANGE IN PORE PRESSURE VS. STRESS DIFFERENCE CYCLES 1 \& $2,19 \%$ BINDER, 35 PSI. C.P. 


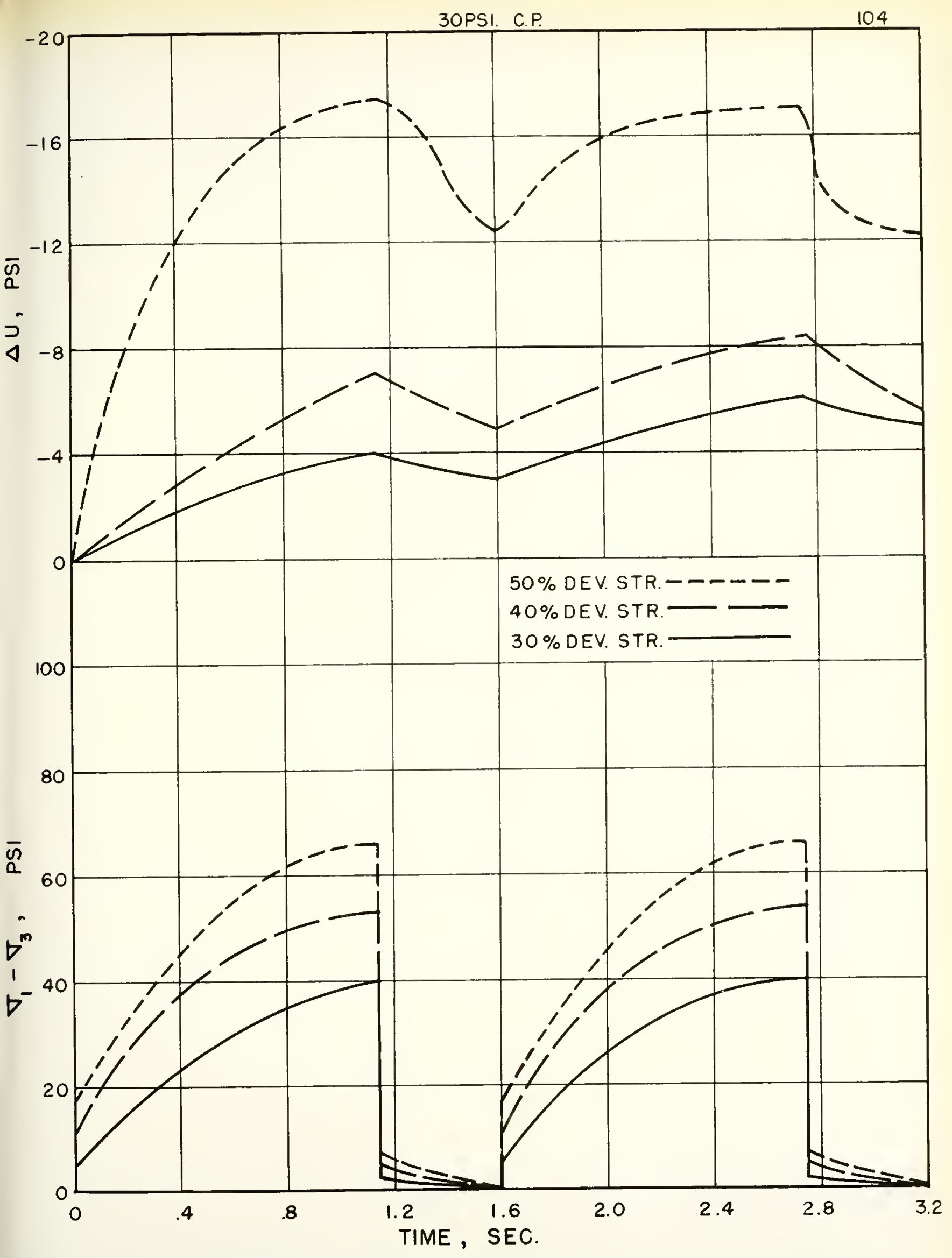

FIGURE 27. CHANGE IN PORE PRESSURE VS. STRESS DIFFERENCE CYCLES 1 \& $2,29 \%$ BINDER, 30 PSI. C.P. 


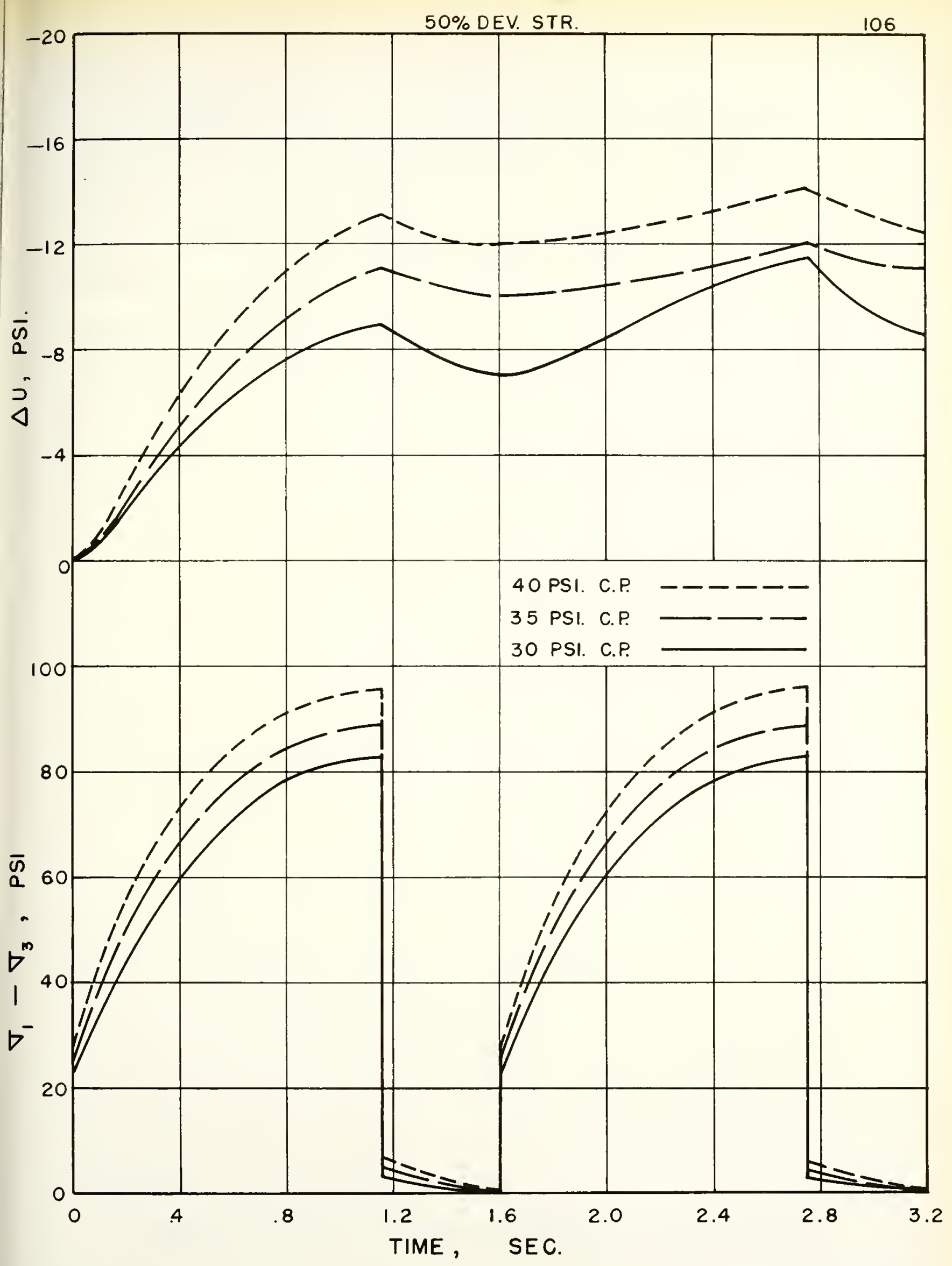

FIGURE 29. CHANGE IN PORE PRESSURE VS. STRESS DIFFERENCE CYCLES I \& $2,14 \%$ BINDER, $50 \%$ DEV. STR. 
In Flgure 24 for 30 psi confining pressure it wlll be noted that at zero time the instantaneously applied axial load varied from 10 psi to 20 psi according to the percent devlator stress. When the ohange in pore pressure is examined howerer, it did not change Instantaneously or even change rapidly. It should not be supposed that this reflects a time lag in the response of the pore pressure measuring equipment, elther mechanical or electronle, for If one refers to the subsequent graphs for the 35 and 40 psi tests, it will be seen that this lag was reduoed as the total stress was increased and disappeared for test 40A50. Evidently the mobllization of pore pressure was dependent on the magnitude of the first cycle strain, and at low strains, resulting from small axlal loads the pore pressure did not change rapidly. There are other aspects to this phenomenon also, whlch will be discussed later under volume change - pore pressure behavior. Deformations which occur at the top of the sample may not be indicative of strains whioh produce pore pressure change.

According to the time plot for the axlal load, nearly the entire load was instantaneously released at the end of the load oycle. However, it should be recalled that the specimen reacts during the unloaded Interval agalnst the dead welght of the moving parts of the air cylinder. Thus the pore pressure will tend to redistribute Itself slowly as the sample expands during rebound. The graphs portray this offect as a doep curve for high deviator stresses, Indicating the time change rolationship.

Very similar results to those described above were recorded 
for the 29 percent binder mixtures also, although the results are more erratic. (Test $40 B 40-R$ will be discussed later). This nonunifomity was attributed to the greater difficulty experienced with these mixtures in achieving uniform compaction throughout the sample and obtaining complete saturation, as well as high swell tendencies.

The Iow binder content soils ( 14 percent) Figure 29, behaved much as the 19 percent binder soils in that uniform pore pressure changes resulted with change in confining pressure. These samples were all mun at 50 percent deviator stress, thus the change as a function of total stress is readily observed.

Considering the entire data, it appeared that the greatest change in pore pressure was recorded for mixtures at optinum or lower binder contents. The tendency to want to change volume semed to be greater at low strains for these mixtures than for the samples with high binder contents.

\section{Change in Pore Pressure Per Cycle}

The change in pore pressure per cycle versus load repetitions was plotted to determine the trend of the cyclic change (Figures 30 to 35). From inspection of these graphs, it can be seen that the greatest change occurred during the first cycle after which it decreased at a decreasing rate, until after the first 10 cycles it fluctuated rather uniformly at a magnitude of 1 to 2 psi. At low deviator stress values for all binder contents, the change per cycle declined to zero before the test ended, indicating that the strains produced were too low to reflect a change. This was 


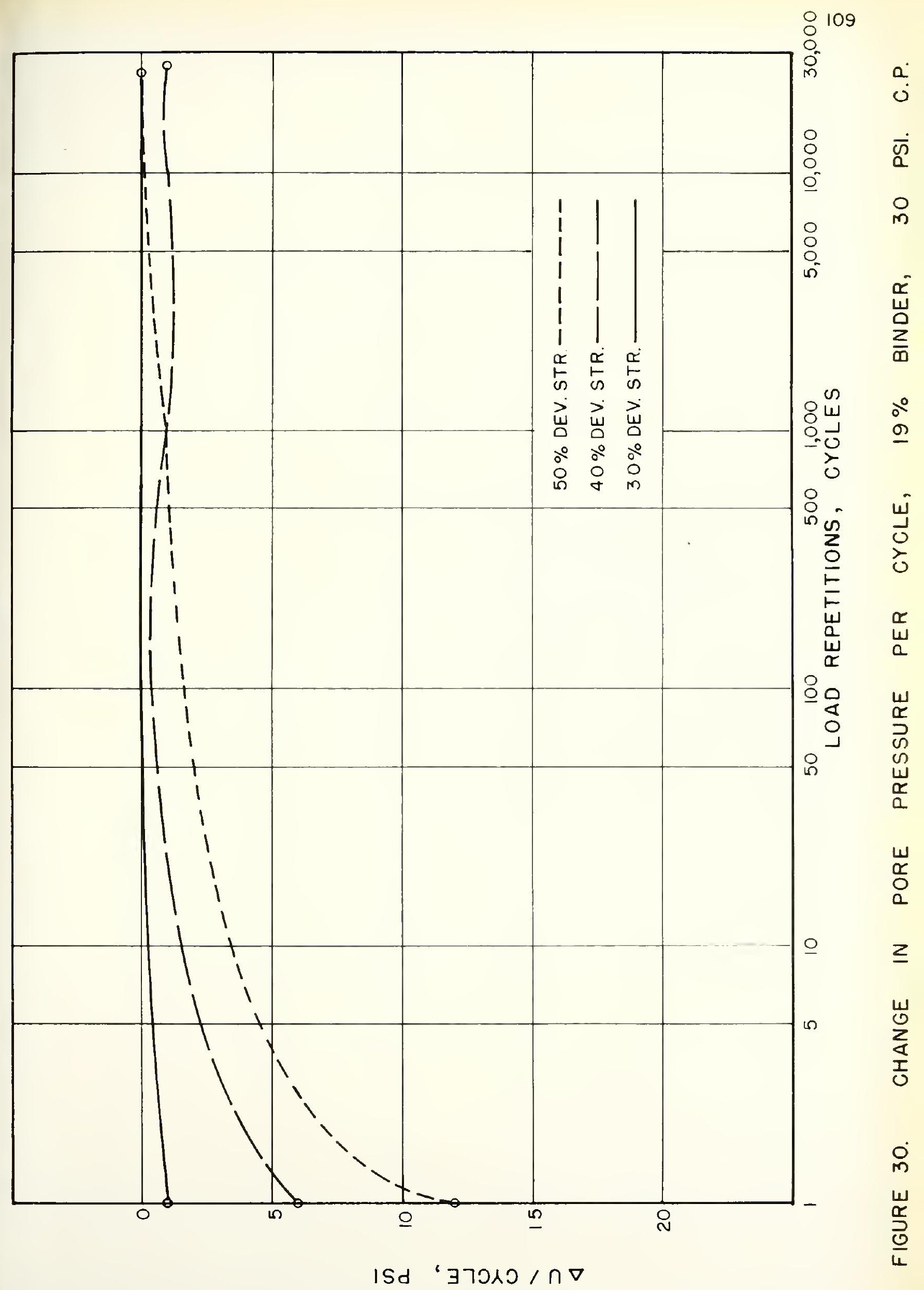




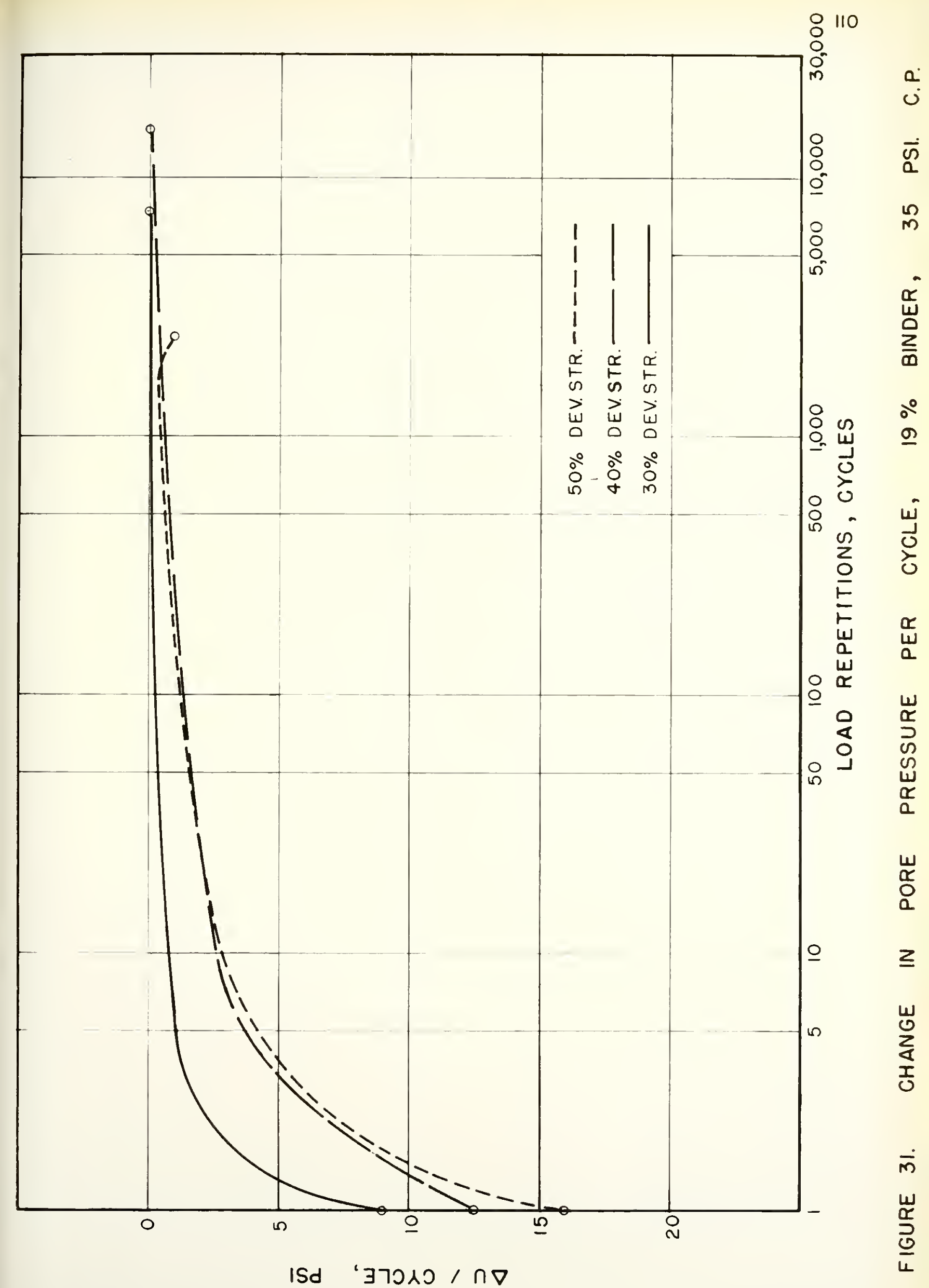




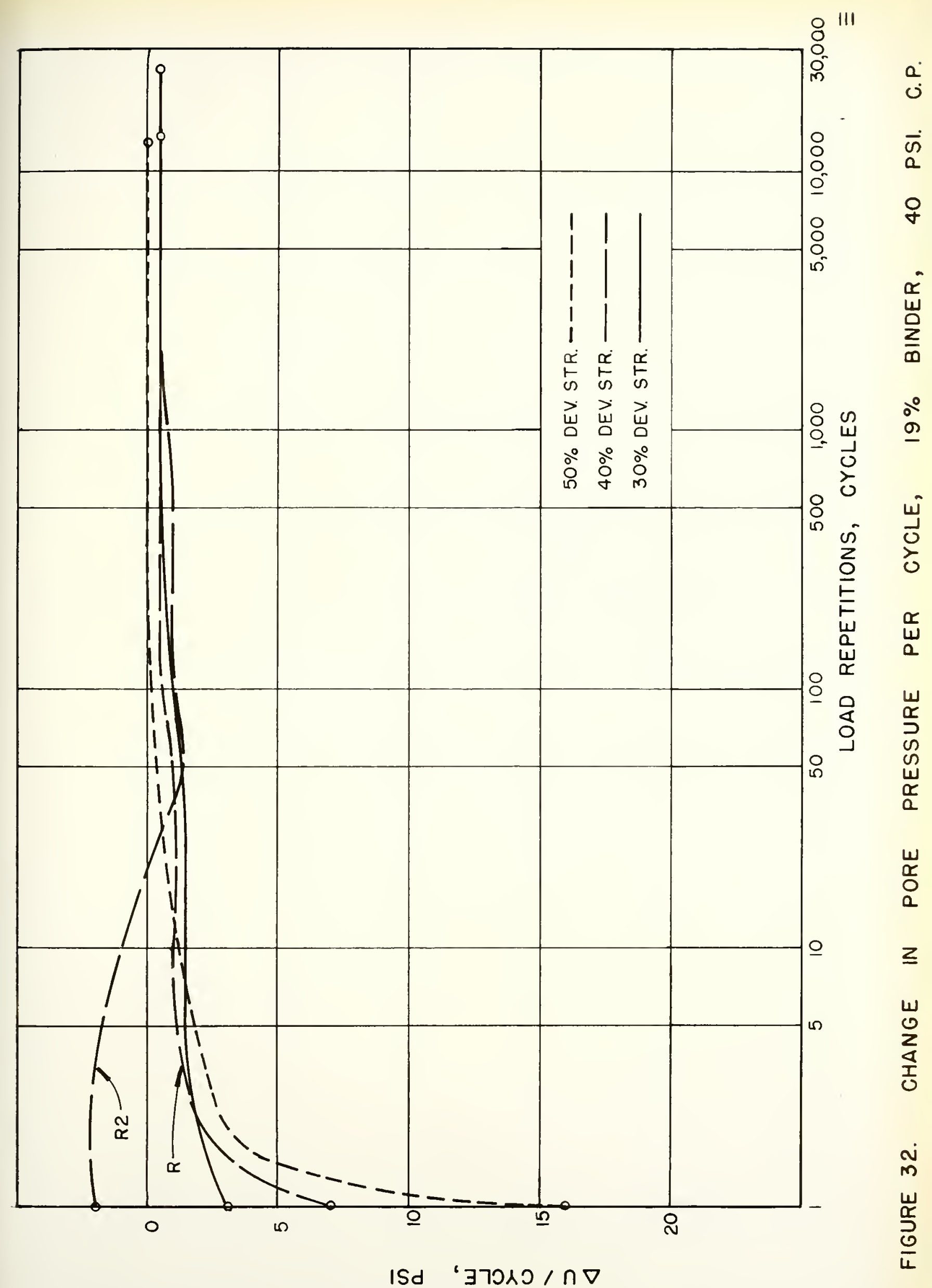




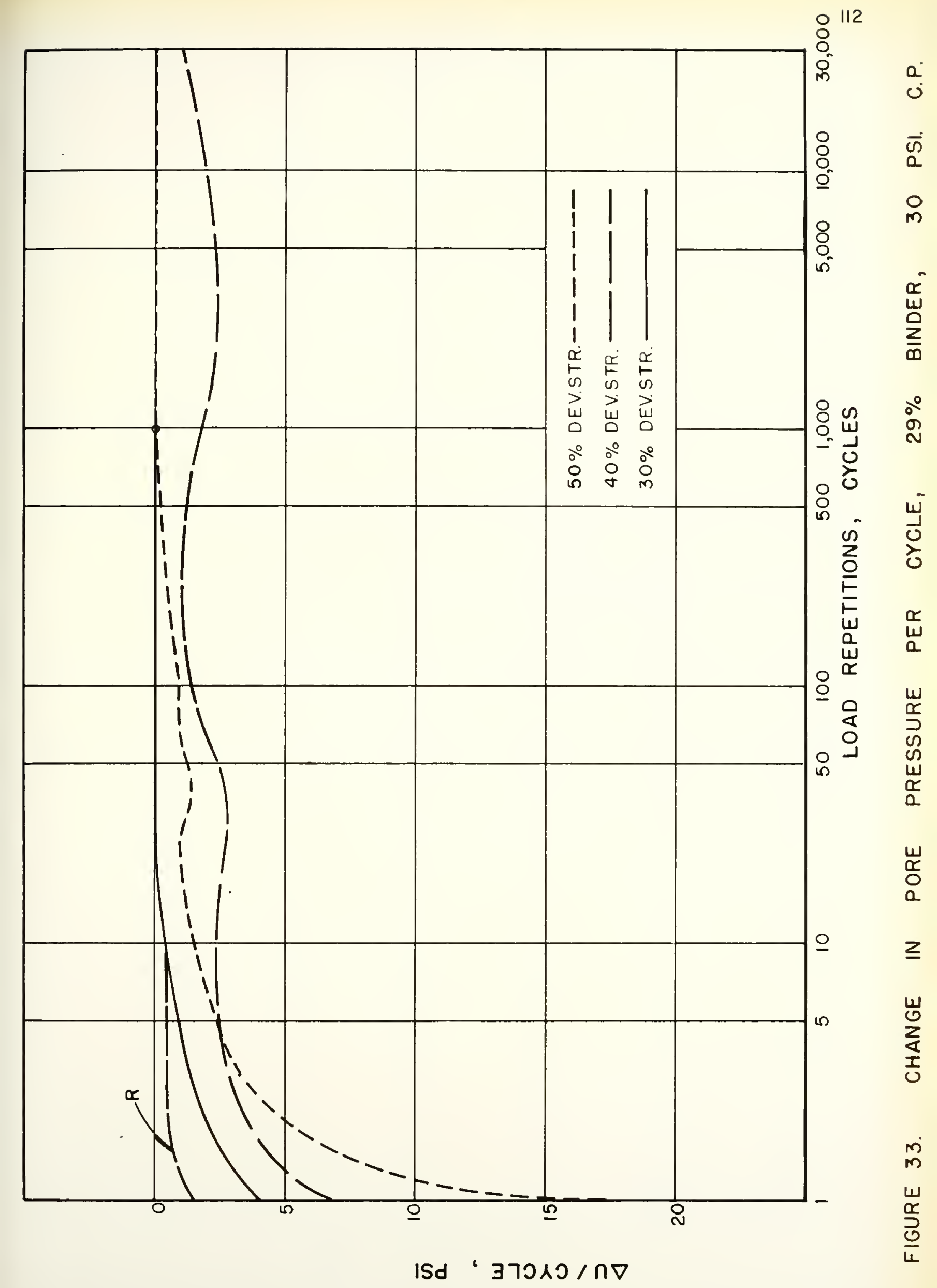




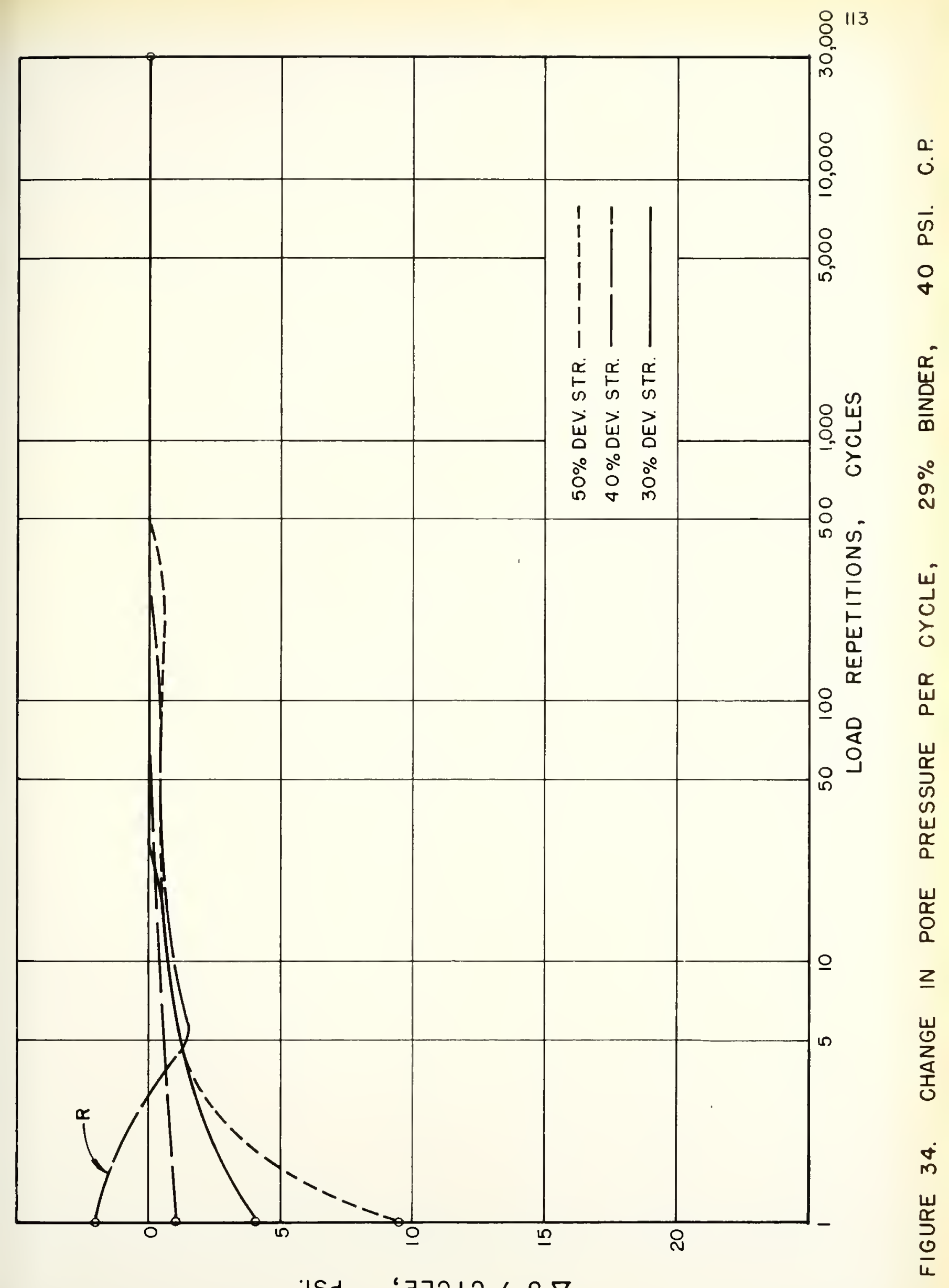




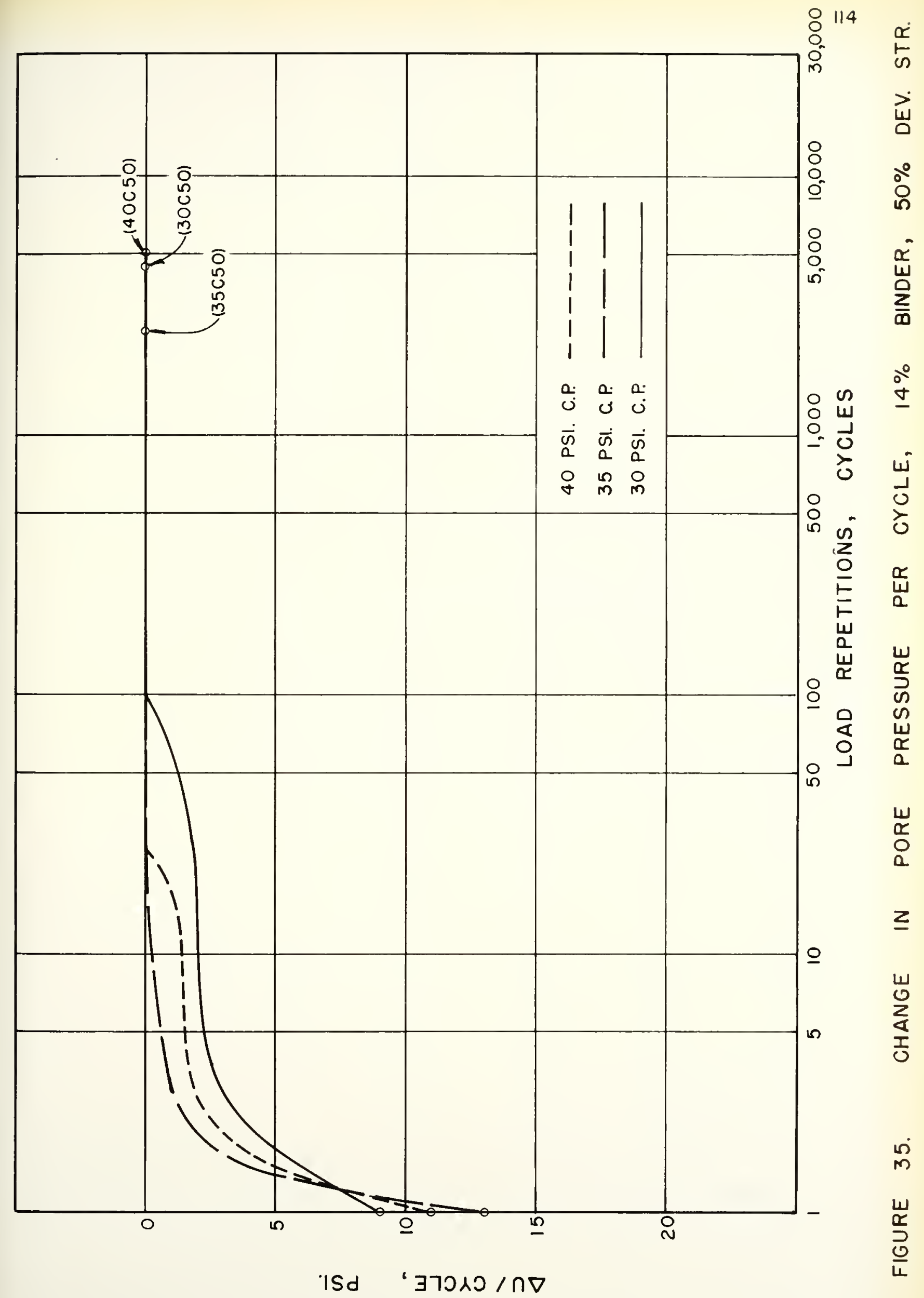


particularly true of the tests run at 40 psi confining pressure and 29 percent binder content as well as all of the 14 percent binder tests. These mentioned test series were run with the Type D probe which permitted pore pressure measurements in the exact center of the sample only. It seems that cyclic change was affected by probe location and that the Type $C$ probe gave a better average pore pressure measurement.

The relationship between deviator stress and cyclic change appeared to be quite uniform at all binder contents and deviator stresses. Increasing deviator stresses produced higher cyclic changes which were maintained for longer periods during the test. Results portrayed for the C-mixes, 14 percent binder in Figure 35 are not considered very significant due to the extreme deformations accompanying these tests.

\section{Maximum Change in Pore Pressure}

The third and last type of pore pressure change whlch occurred was that which took place during the entire test period. The change is described as that maximum change between the initial pore pressure and the cycle in question. Plotting of these data show the characteristics presented in Figures 36 to 41.

Examining the entire group, it is readily seen that the maximum change in pore pressure increased with an increase in deviator stress. This relationship held for all the tests mun. In addition, as the confining pressure was increased for any binder content, the maximum pore pressure change also increased as could be expected; again from an understanding of total stress. The effect of change 


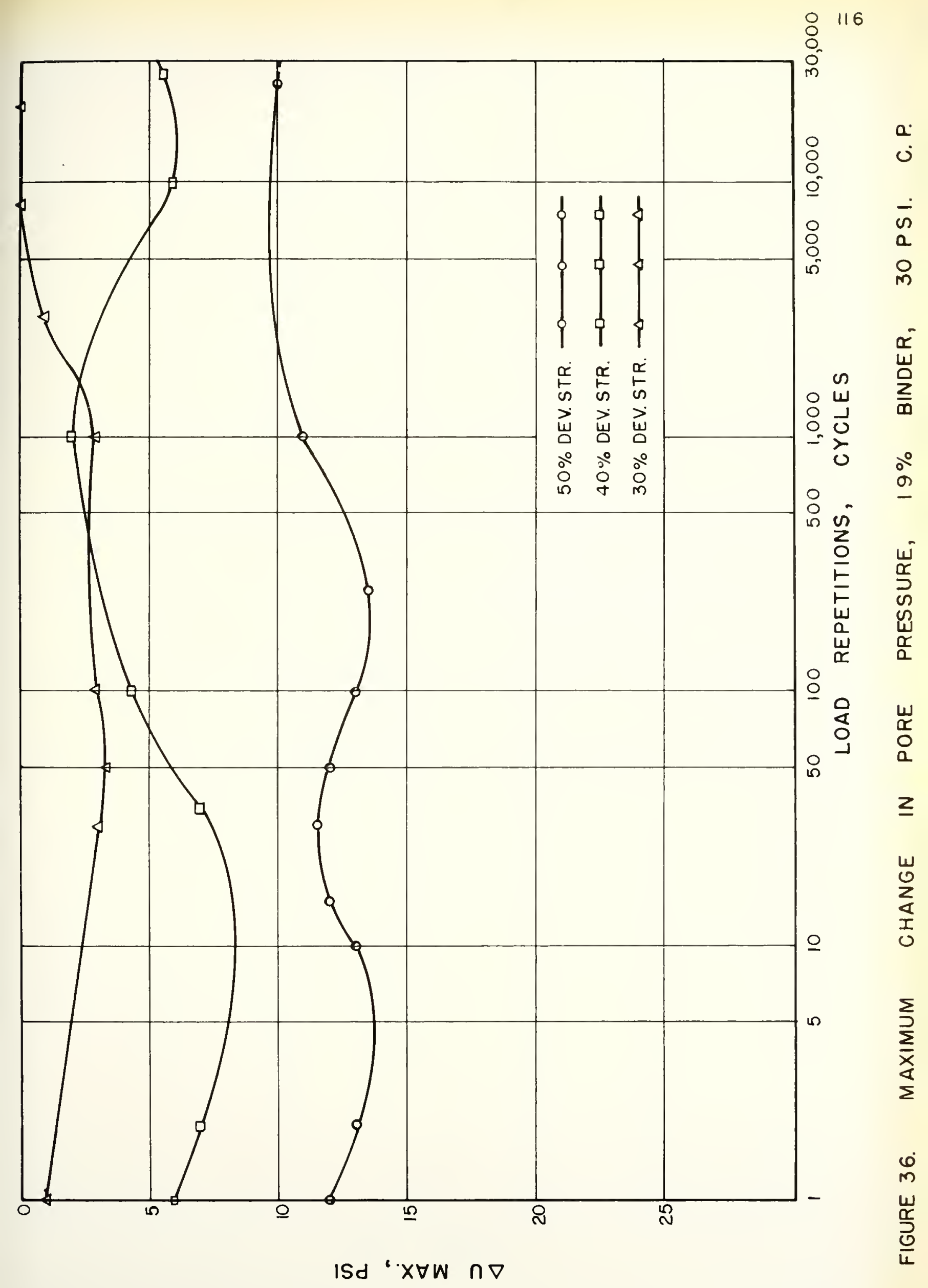




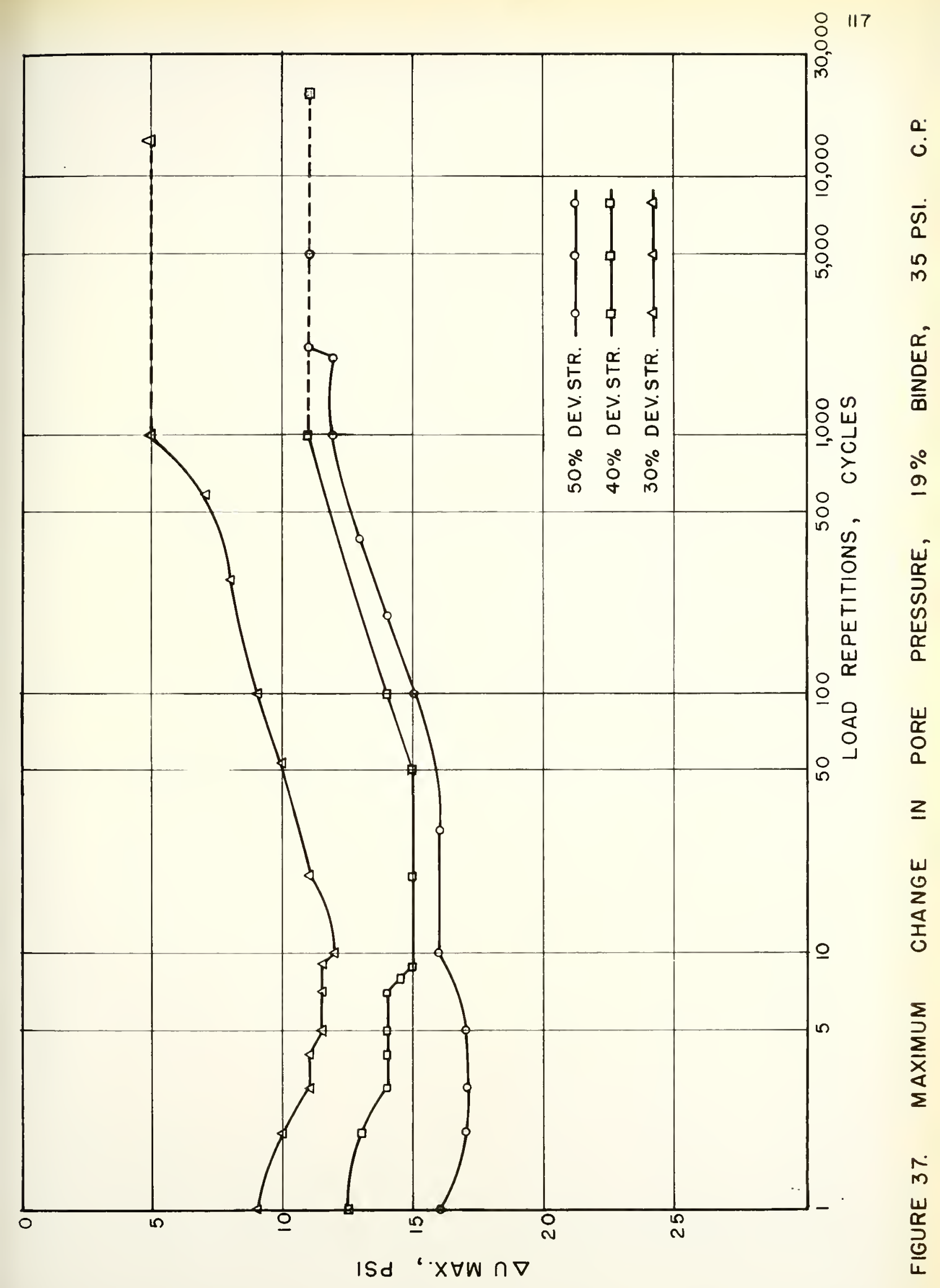




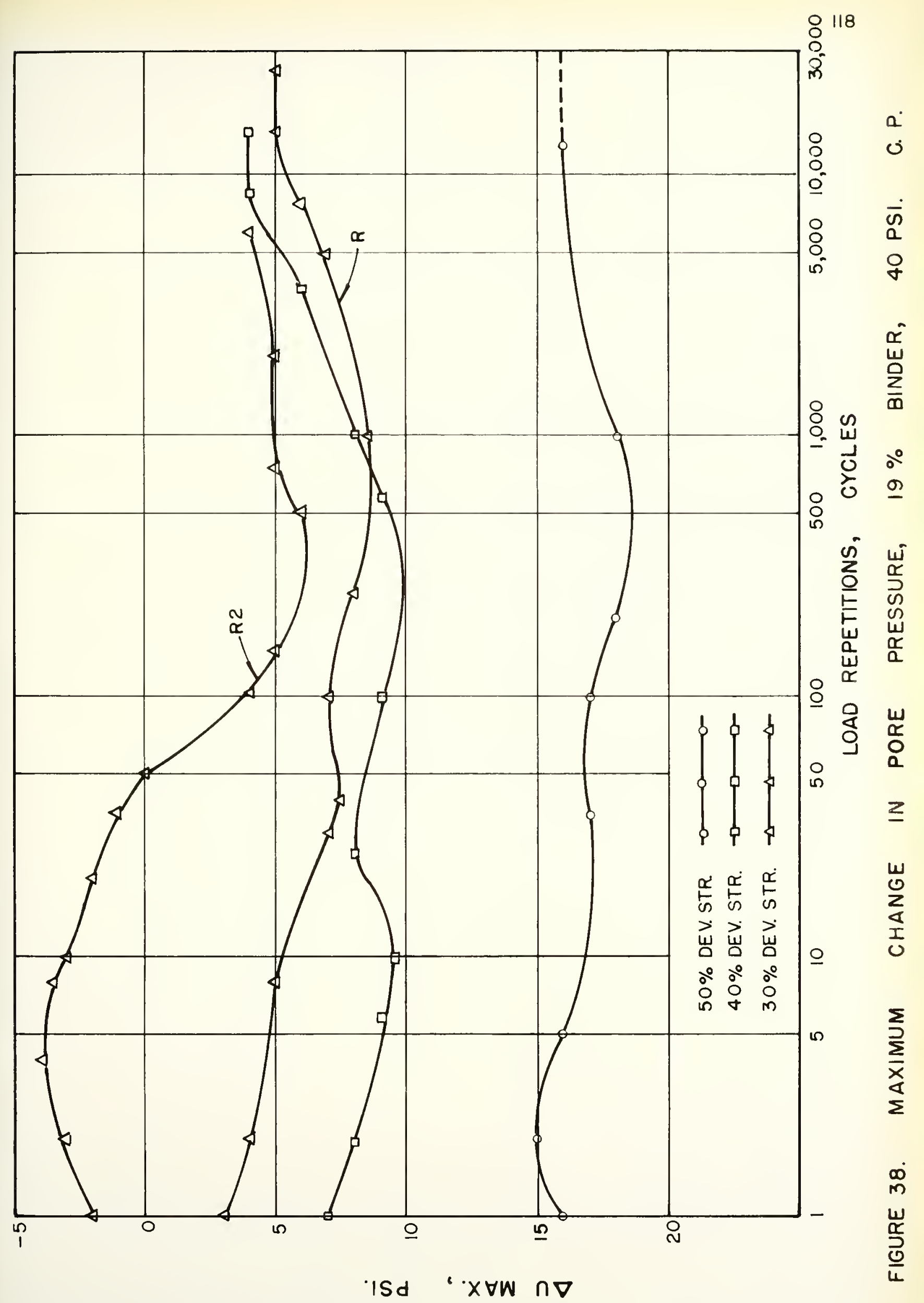




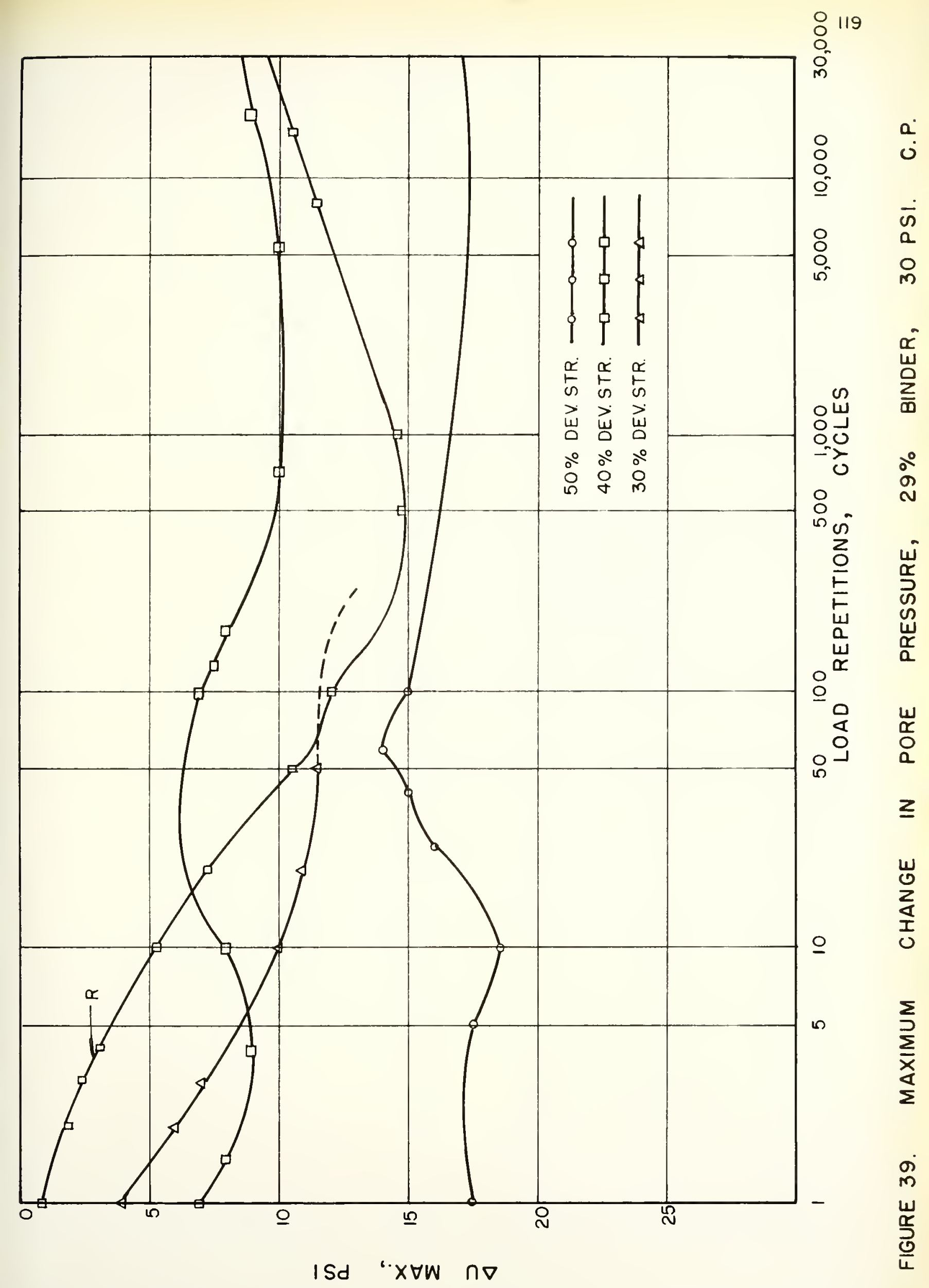




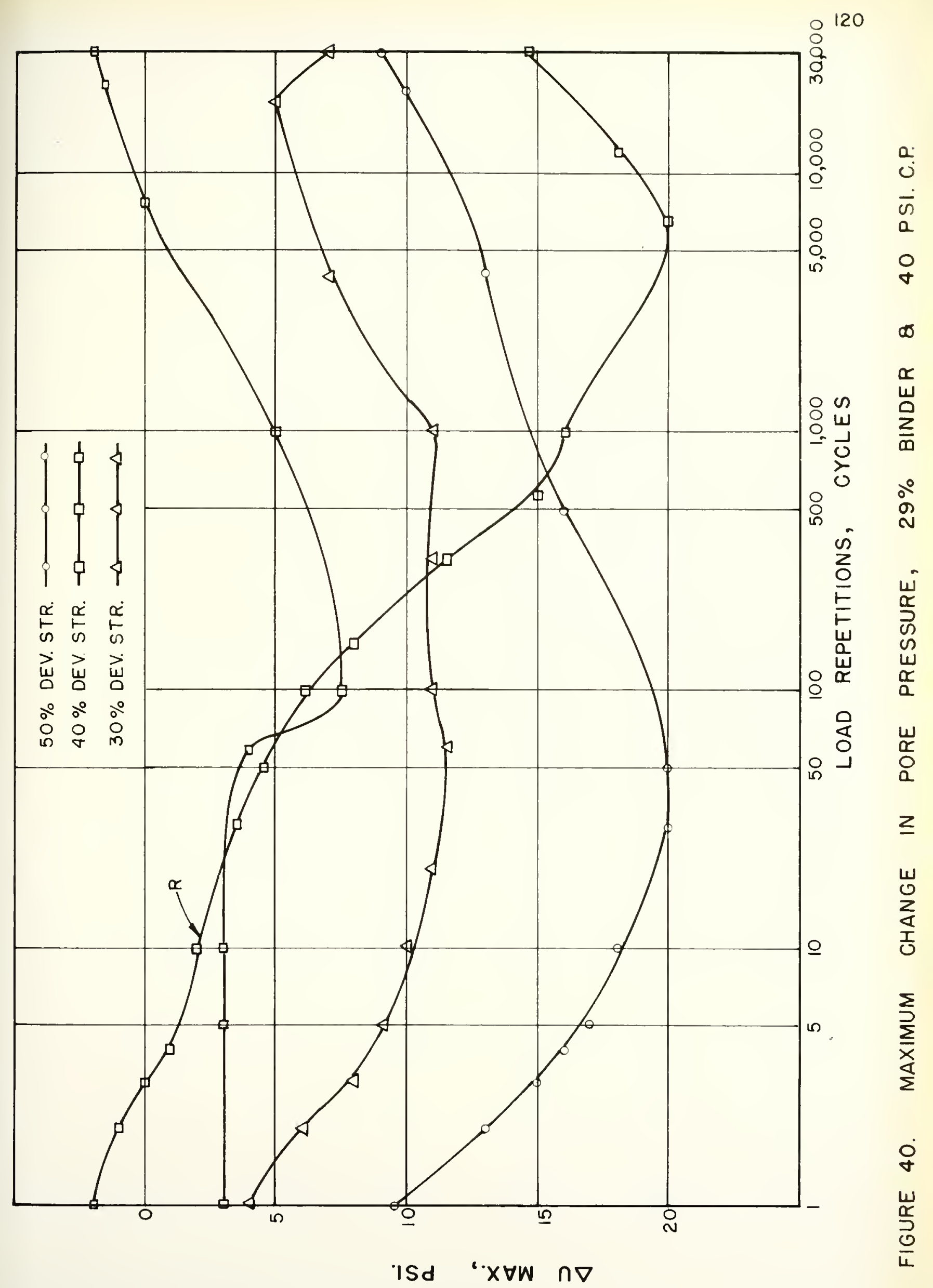




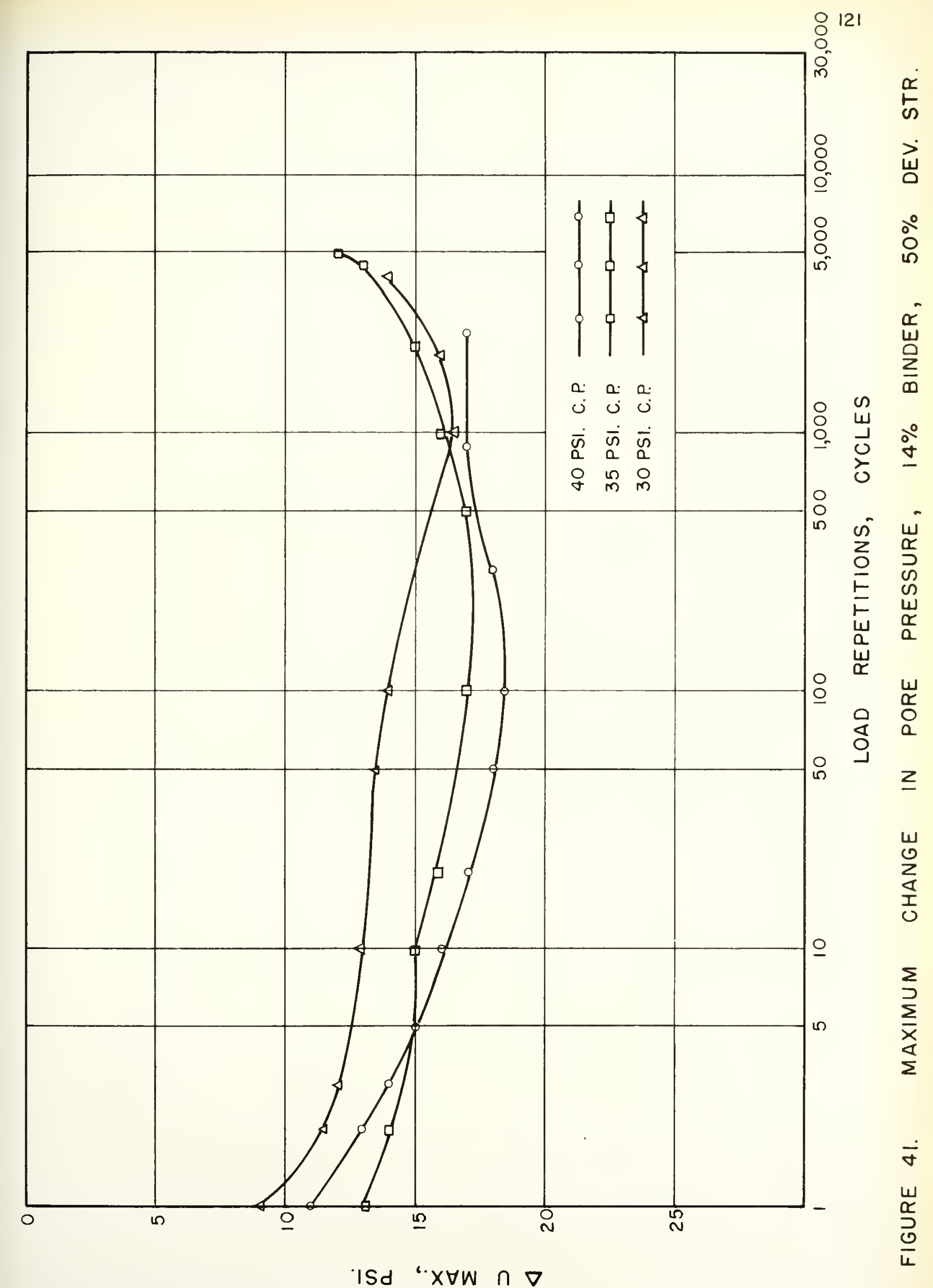


in deviator stress was most pronounced for the 29 percent binder soils and least for the low, 14 percent binder soils. At optimum binder the effects were quite regular and uniform.

In addition to the foregoing, it can be seen that during the early period of test, up to 100 cycles (approxinately 2.6 minutes) the change in pore pressure increased in magnitude. Thereafter it reached an equilibrium value and then decreased. Th1s decrease continued until the test failed or was terminated. If the test was continued beyond 50,000 cycles and fallure did not occur, an equilibrium value was reached and maintalned during the rest of the test period. It is noted here, that the tests as normally conducted included continuous muning of the recorder up to 1000 cycles. Thus any change in electronic gear adjustments was elirinated. After 1000 cycles the recording apparatus was shut down and was not run until additional readings were taken. Thus errors could be reflected in the data taken after 1000 cycles due to electronic gear adjustments. If these occurred, which was not proved, they are considered to have been very small and would not have changed the trend of data appreciably.

\section{Volume Change}

Figures 42 to 45 are presented to portray the trend of volume changes during the tests. For greater ease in understanding the change in volume, a time scale has been superimposed over the load repetition scale. Since some of the volume change data were meager, all tests are not represented. Enough tests were conducted with volume change measurements to permit an understanding of the behavior. 


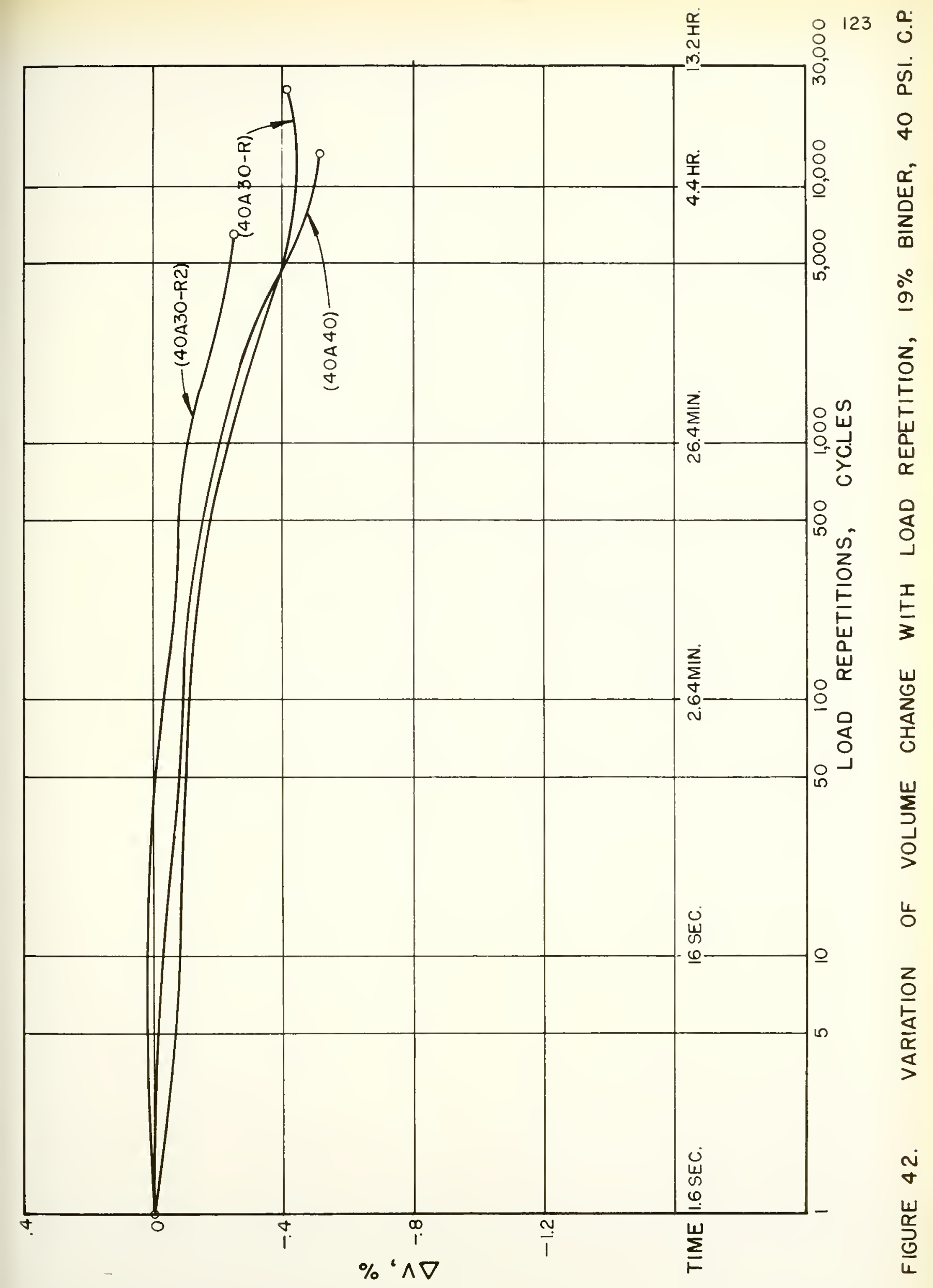




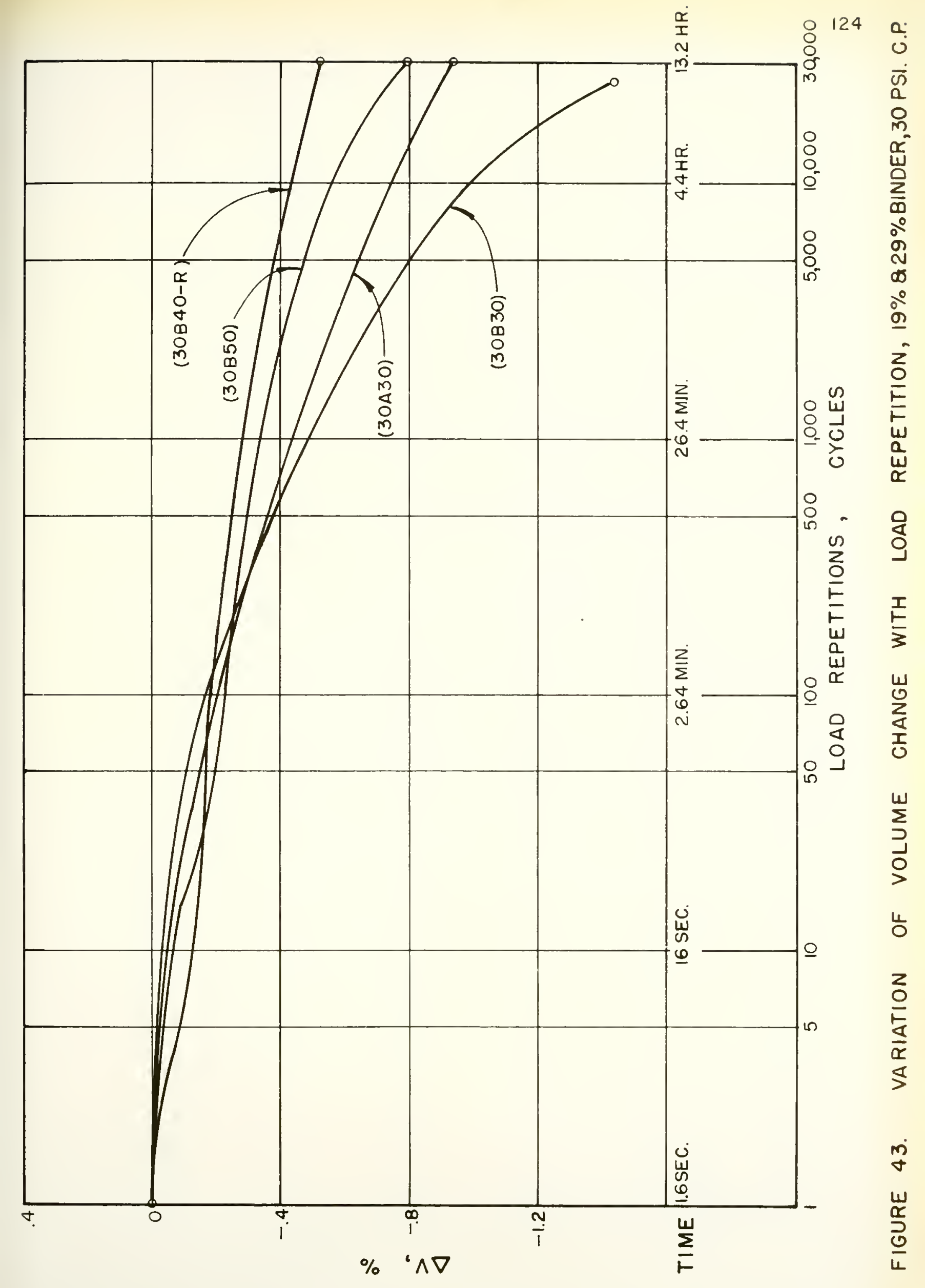




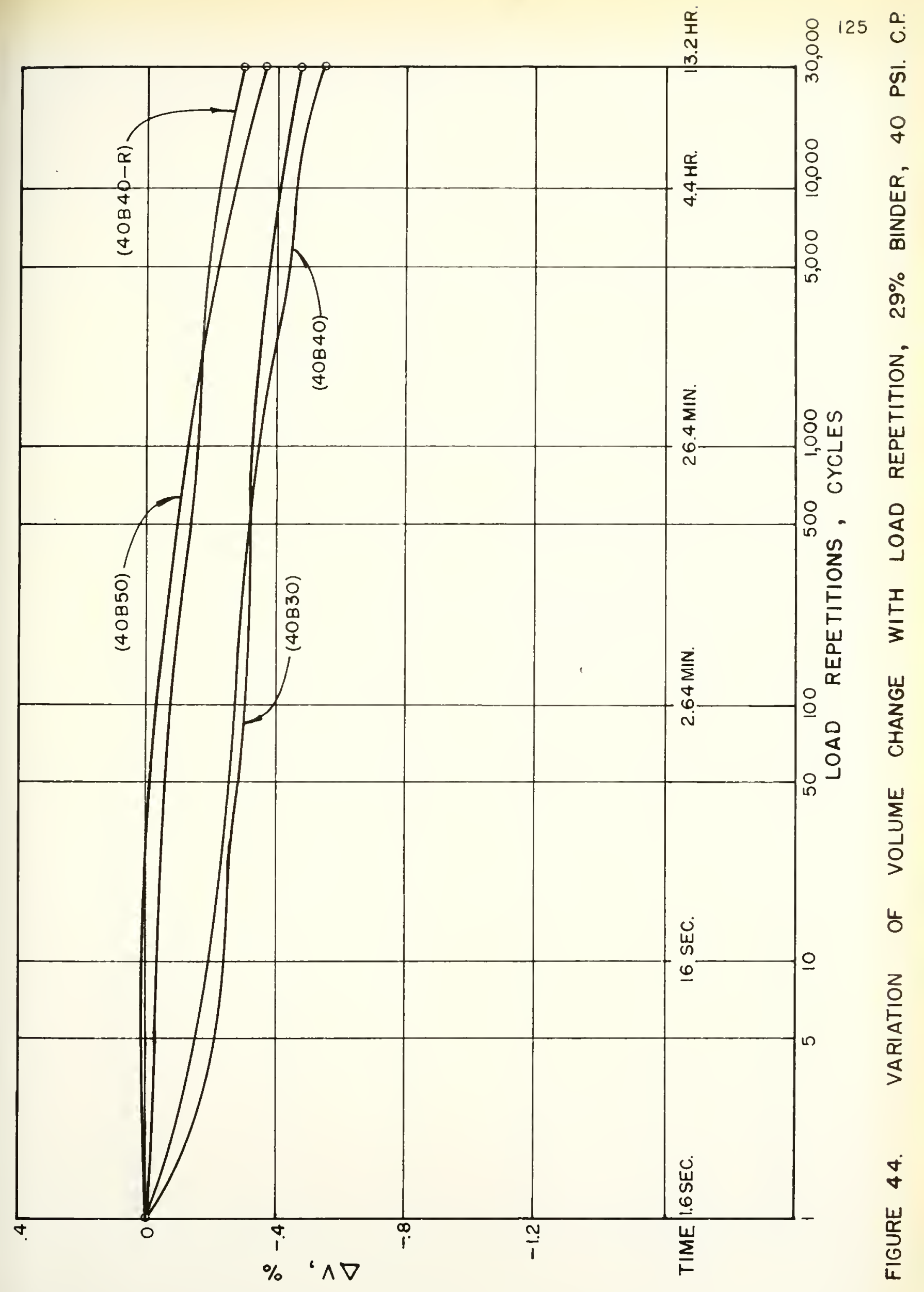




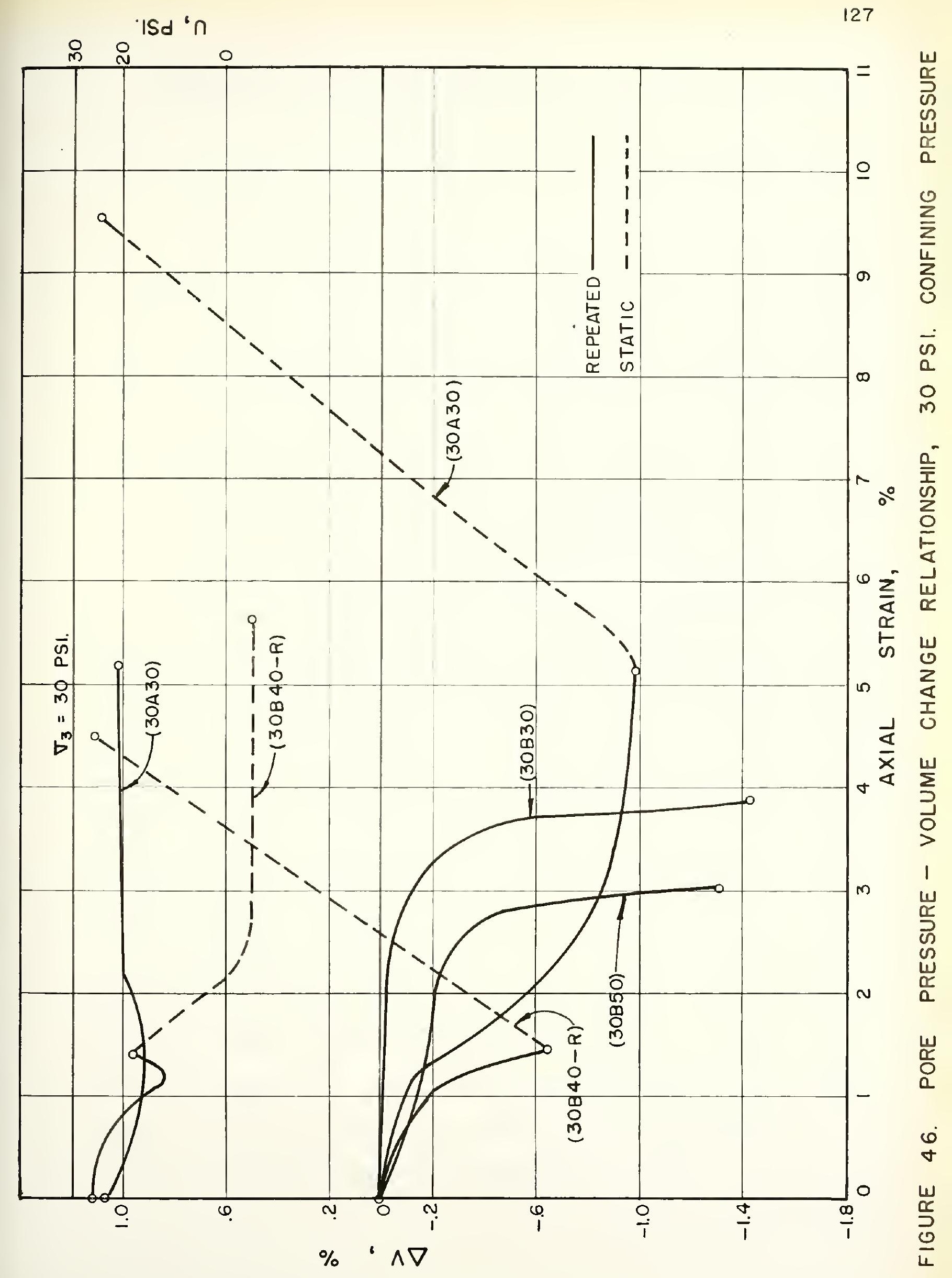


Examination of the four graphs shows that except for three tests, 30A30, $30 \mathrm{~B} 30$ and $30 \mathrm{~B} 50$ the total volume change did not exceed 0.5 percent. The three mentioned tests are considered to be in error due either to leakage in cell fluld or air in the system or both. This can be seen fran Flgure 46 where with no appreciable increase in axial strain the volume changed considerably. These three tests were the first ones run and for this reason, the equipment needed refinements as the testing revealed deficiencies. These three mentloned tests are therefore antted from this and subsequent discussion.

Comparison of Flgure 42 and Figure 44 indicates the magnitude of volume change was somewhat less for the 29 percent binder solls than for the 19 percent binder solls, and the 14 percent binder solls changed volume least of all. Due to the immediate high deformations which occured in a very short period of time, the 14 percent binder soils actually increased in volume before the densifying effect of load repetition could decrease the volume. Undoubtedly, this would not have been the case had the devlator stress been lower, say only 30 percent of the peak static campressive strength instead of 50 percent.

The bulk of the decrease in volume for all mixtures took place during the first 1000 cycles or one-half hour of test, after which the rate of change decreased to essentlally an equilibrium value after 10,000 cycles or $4 \frac{7}{2}$ hours. This effect would tend to be expected fram reference to total deformation where deformations after 10,000 cycles were negligible in most of the tests. 


\section{DISCUSSION OF RESULTS}

Included in this section is discussion of the results of the research as well as pertinent remarks concerning the equipment and its performance in relation to the results obtained. Topical headings correspond to those contrined in the preceeding section.

\section{Dolume Change}

The sequence of the discussion will be changed slightly to permit discussion of those characteristics of the mixture which are related to other characteristics and which help to explain them. Thus, volume change will be discussed first. Moreover 1t will be brought out that volume change is of paramont importance in understanding the behavior of the sample as well as the measured strength and pore pressure data.

As was mentioned earlier, the difficulty experienced in designIng accurate volume change measuring equipment for use in the repeated load test coupled with some equipment failures resulted in considerable lag in obtaining valid volume change data. For this reason same additional tests were run beyond the original test program. These tests are designated by an $\mathrm{R}$ following the test code number. If the test was repeated more than once a numeral follows the $R$, e.g. $40 B 40-R 2$ indicates that this test was repeated for the second time on the $40 \mathrm{~B} 4 \mathrm{O}$ sample. 
Referring to Figures 47 to 49 , volume change and pore pressure are plotted against axial strain in percent for those tests in which these data were obtained. The repeated load portion of the test is shown as a solid line, whereas the static test to failure portion is shown as a dotted IIne. Number of repetitions for each test is shown in Table 2. Examining Flgure 46 in detail it w1ll be noted at once that the results are more erratic than would normally be expected. As mentioned under Volume Change, in the previous section, tests $30 \mathrm{~A} 30,30 \mathrm{~B} 30$ and $30 \mathrm{~B} 40$ were mun during the period when the volume change equipment was under development. Fluid leakage as well as some entrapped air account for the high volume changes recorded, particularly for tests 30830 and $30 B 50$ where fluid leakage resulted in high volume changes being recorded even though the axial strain did not change appreciably. Test $30 \mathrm{~A} 30$ was loaded statically to failure; note the immediate increase in volume which conmenced as the load was increased after the repeated load portion run at a constant deviator stress. This is significant and was found to be the case in all tests run. The densification which occurred under repeated loads reached a maximum, volume change was stabilized and thus further loading caused an immediate increase in volume to occur. This was true regardless of the magnitude of the deviator stress at which the repeated load test was run. Furthermore, much as reported by Newland and Allely (28), the volume increase which took place in the static test portion is quite linear and does not increase at a decreasing rate as one might expect. 


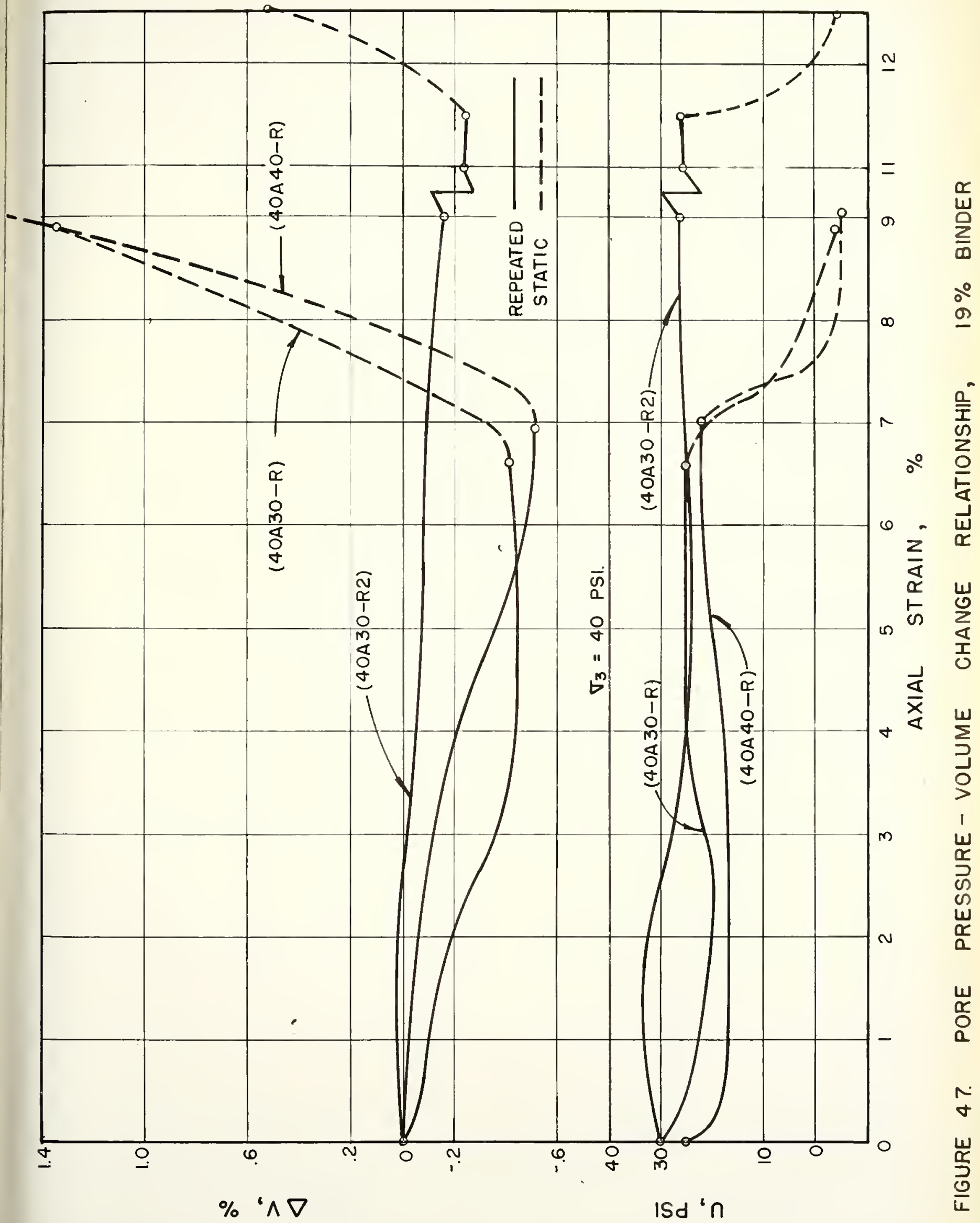




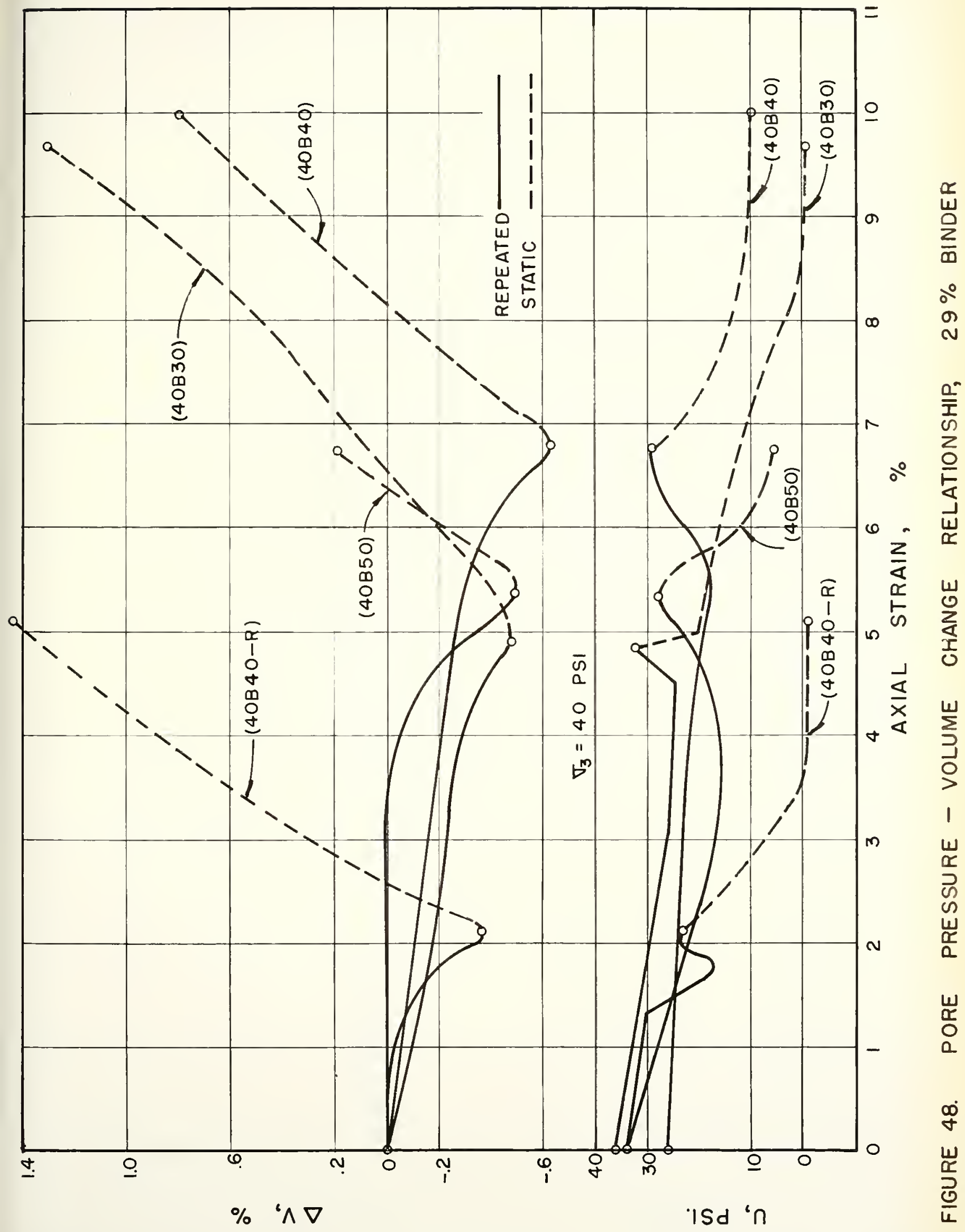




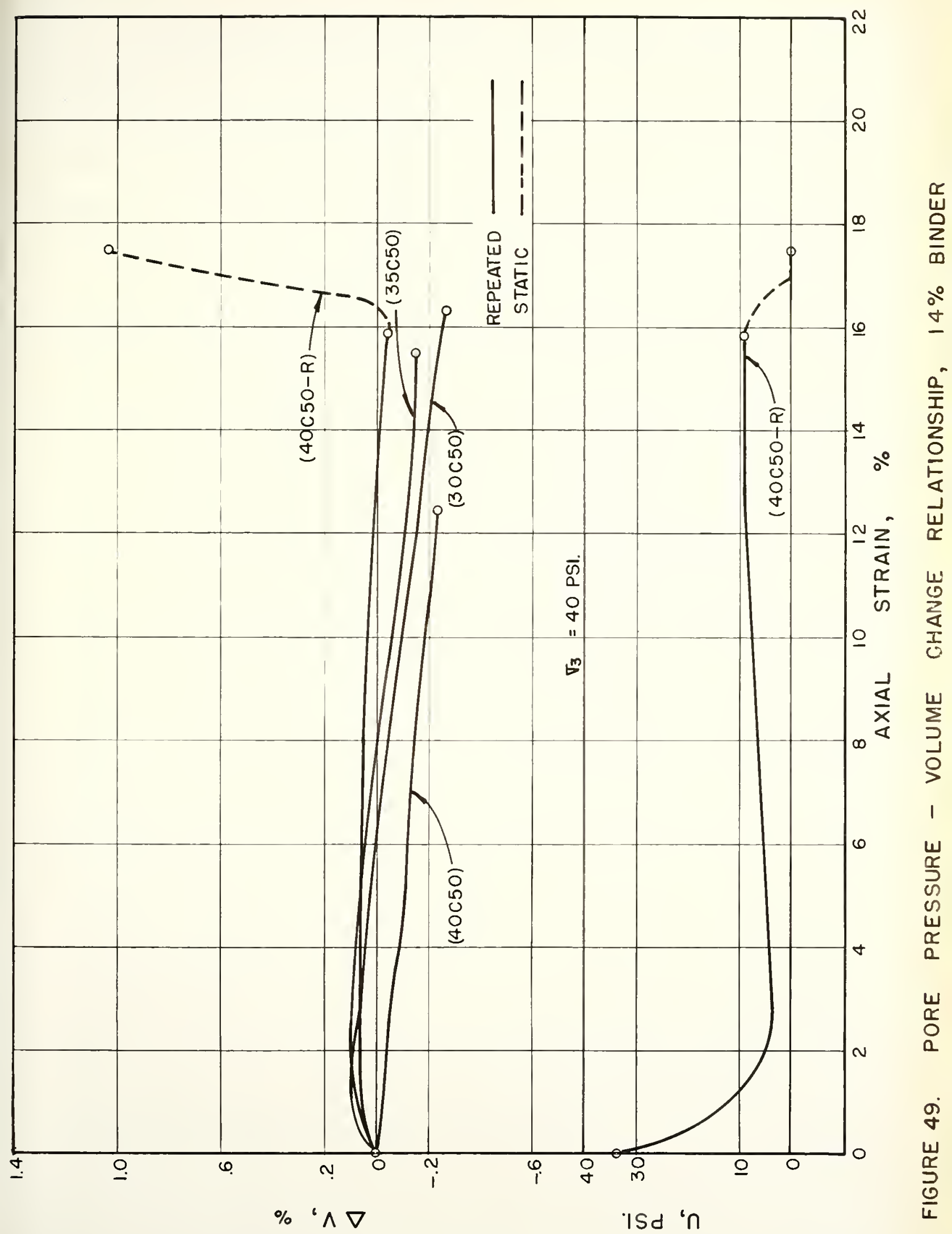


The effect of time is not show on these grpahs under discussion, but referring to Figures 42 to 45 it will be noted that the greatest volume reduction took place in the first one-half hour of test, with very little occurring after 2.2 hours. Thus the volume change-deformation characteristics were quite similar during this period. After the total deformation became stabilized however, any further change in volume, i.e. densification during the repeated load test was accompanted by very modest increases in axial strain. Hence it can be concluded that the decrease in volume occurred at an increasing rate as axial strain increased in the repeated load test. Figure 49 depicts the volume change results for the 14 percent binder mixtures. With the exception of test 40C50, all tests run show an increase in volume up to an axial strain of 6 to 12 percent and then a densification below the original volume. In these tests the sample deformed very rapidly (Figure 17) at low number of repetitions. This was attributed to the moisture migration by gravity to the base of the sample and reduced intergranular pressure. Yet the pore pressure was observed to decrease during the test. It is reasoned that this was due to the probe being located at mid-height in the sample and in the failure zone. If the probe had been at the botton, pore pressures would probably have been higher and if measured at the top, less than in the failure zone. In other words, for this soil sample under the given test conditions, the pore pressure recorded In the failure zone did not indicate what was happening to the soil. It is believed that at least three probes, located at top, center and bottom would be necessary for optimum results. 
In order to assess the importance of volume change-density relationships which the specimen experienced at the various stages of pre-testing and testing a study was conducted on the 19 percent and 29 percent binder mixes. The 14 percent binder mix did not appear as susceptible to swell nor did it permit the necessary handling in the saturated condltion.

A sample of $\operatorname{mix} A$ and $B$ was prepared in the same identical manner as for a repeated load test. The A sample was then saturated under vacuum in de-alred water for two days ( 48 hours) and the $B$ sample similarly for four days (96 hours). Each was then removed fram the saturation cell, weighed, immediately coated with parafin and weighed again both in air and submerged in water.

The parafin was then removed, placed in a beaker of bolling water and cooled. The cake of hard parafin in the beaker was weighed and the soil remaining in the beaker was added to the oven dry welght of the sample. The table below indicates the results which were obtained.

\begin{tabular}{|c|c|c|c|c|}
\hline Mix & $\begin{array}{l}\text { Percent } \\
\text { Binder }\end{array}$ & $\begin{array}{l}\text { Compacted Dry } \\
\text { Density pef. }\end{array}$ & $\begin{array}{l}\text { Calculated } \\
\text { Saturation } \\
\text { Percent } \\
\end{array}$ & $\begin{array}{l}\text { Volume } \\
\text { Change } \\
\text { Percent }\end{array}$ \\
\hline A & 19 & 137.76 & 95.47 & 5.2 \\
\hline B & 29 & 138.02 & 93.47 & 7.7 \\
\hline
\end{tabular}

Upon being released from the saturation mold which has the same dimensions as the compaction mold, the swell whlch occurred amounted to 5.2 percent and 7.7 percent respectively for the 19 percent binder mixture and the 29 percent binder mixture. 
Accordingly, the tests for which volume change measurements were obtained were examined in the light of this discovery. In recording the readings on the measuring tube of the volume change apparatus, a recording was made both before and after the confining pressure was applied. In addition, a calibration curve had been derived which indicated the volume change which occurred with a 4" $x$ 8" aluminum dumy in the cell. These data are recorded in Appendix C, Figure 59. By subtracting the reading of the volume change device at the start of the test from the initial reading and then subtracting from this difference that change due to the membrane effect and lucite cylinder for the confining pressure in question, the volume change (densification) resulting from the application of the confining pressure could be computed.

The results for all tests in which volume changes were measured are shown below:

\section{TABLE 3}

Tabulation of Volume Change Resulting Fram Application of Confining Pressure

Test Number

40A30-R

$40 A 30-R I$

LOALO-RI

$30 B 30$

$30 \mathrm{B50}$

$40 B 30$

$40 B 40$

4OBLOO-R

40850

30650

$35 \mathrm{C50}$

40650

LOC5O-R
Volume Reduction, percent

2.49

1.69

1.64

2.61

3.22

2.24

2.43

2.13

1.64

1.33

2.49

1.70

1.64 
In the case of the $\mathrm{A}$ and $\mathrm{C}$ mixes whose behavior is considered to be similar (although the C mix certainly did not swell as high as the A mix; perhaps as much as 3.5 or 4.0 percent maximum), the volume reduction was less than one-half of the calculated swell. For $B$ mixes the volume reduction was even less, averaging about one-third of the calculated swell. Evidently the specimens at time of test had greater volume than the compacted volume and consequently lower densities and molsture contents.

As a result, it was decided to run a series of tests in which the sample would be compressed at the confining pressure for a period prior to test. One hour was chosen as the compression period. These tests are portrayed in Flgure 46, Test 30BLO-R; Flgure 47, Test 40A30-R2; Figure 48, Test 40B40-R and Flgure 49, Test 40C50-R. For the 29 percent binder soils, 30B4O-R and $40 B 40-R$, the axial strain was reduced to one-third its previous value by the end of the repeated load test period. Furthermore, where the confining pressure was high, e.g. 4OBLO-R, the volume change was much lower, indicating that some densification had occurred during the compression period (Flgure 48).

In the case of the 19 percent and 14 percent binder mixtures the effect of the compression period was to increase the axial strain and decrease the total volume change appreciably. The decrease in volume change, or lowered densification is readily understood. The increase in axial strain however is not so readily explained. It appears that a stiffening of the sample took place under the action of the repeated load application where high densifica- 
tion accompanied load application. When the densification was less, as a result of pre-test compression, the stiffening did not occur, i.e. no stmuctural change took place. Hence, the deformation increased rapidly (see Figure 11 also) and reached a greater magnitude.

In order to verify these results it was decided to run tests on three specimens, one on each of the design mixes, which would be compressed for one hour, but then would be loaded statically at conventional rate of strain, as nearly as possible, in the repeated load apparatus to failure. Volume change, axial load, and pore pressure were measured. All three tests were mun at 30 psi lateral pressure; the results are shown in Figure 50. It will be noted that the results of the tests on lower binder content soils were very similar to each other; on the 29 percent binder soil, the results are quite different. The low binder content soils did not densify but increased in volume to failure. The 29 percent binder soil densifled slightly and then increased in volume to failure; however at much greater axial strain than the $A$ and $C$ soils.

It would appear from this that densification occurs more as a function of load repetition than any other factor; although if higher confining pressures had been used, greater densification would probably have occurred, even in the low binder content mixtures. Flgure 51 shows that even over a long duration of test, in this case two days, little densification occurred in the static test. 


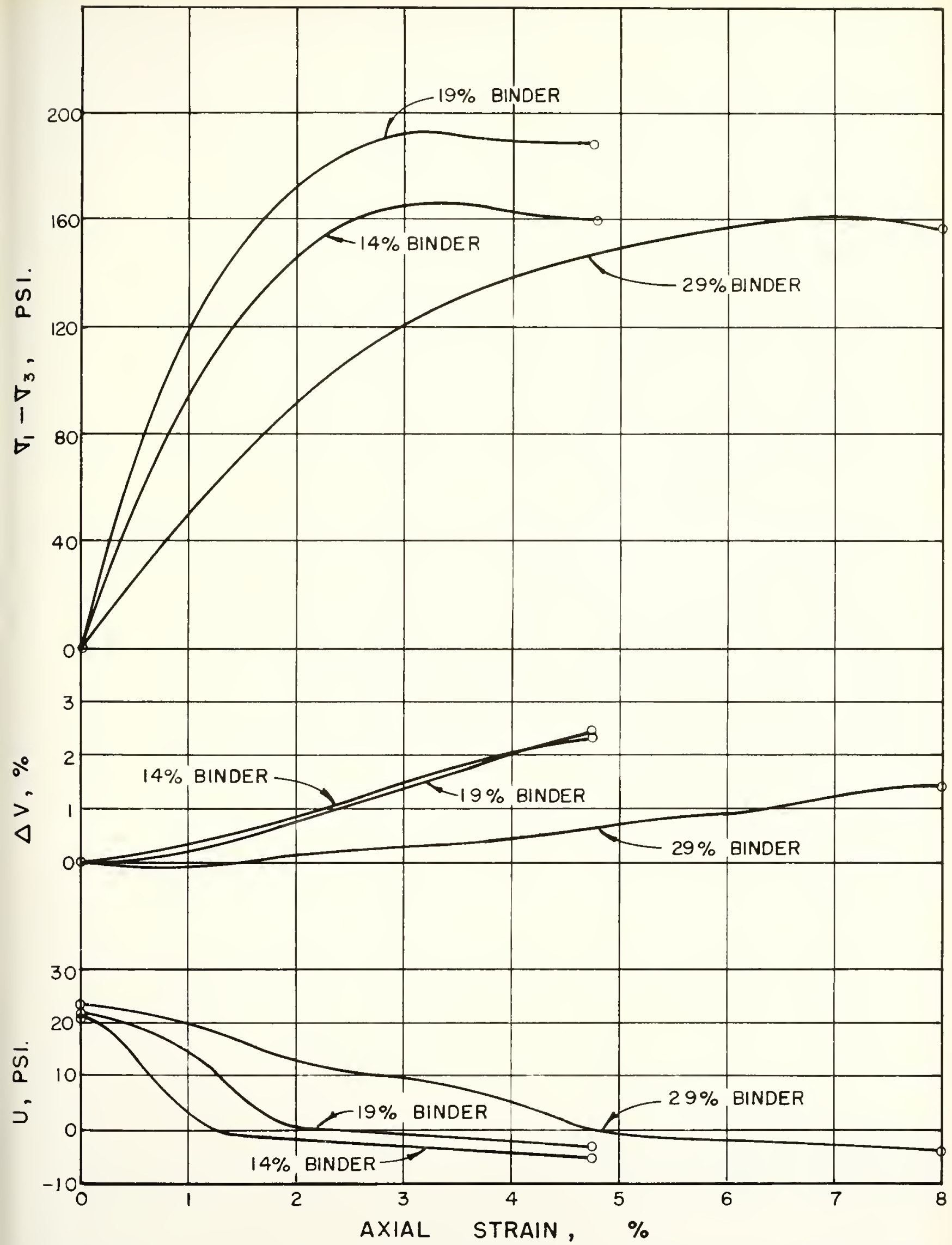

FIGURE 50. COMPRESSED - UNDRAINED TESTS ON DESIGN MIX, 30 PSI LATERAL PRESSURE 


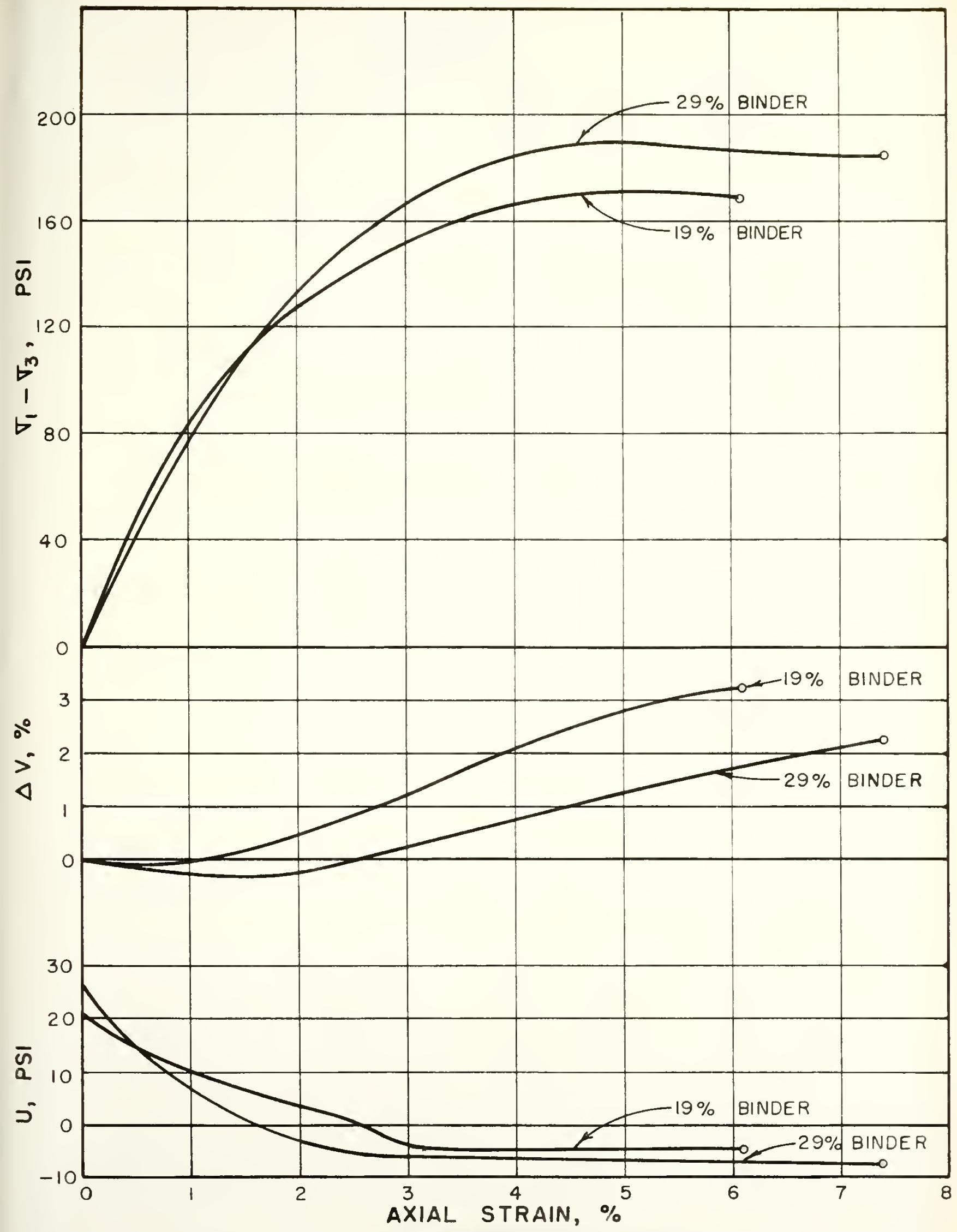

FIGURE 5I. LONG DURATION COMPRESSED - UNDRAINED TESTS, 


\section{Deformation}

Based on total stresses, the deformation was shown to increase as the total stress was Increased; that 1s, the higher deviator stresses developed greater total deformations. Furthermore, the total deformation increased as the percent of binder was increased above an optimum amount. Low binder content mixtures did not perform at all well in the repeated load test.

Examining the magnitude of total deformation, it w1ll be noted that solls tested at low confining pressures and low devlator stress did not deform beyond 0.1 inch, whereas solls tested at higher confining pressures and deviator stresses of 40 to 50 percent of the peak campressive strength deformed three and four times as much, and after fewer repetitions. This behavior, while a valid trend indicator, does not tell the entire story, however. The swell behavior of the individual samples influenced the deformation of the sample to a large degree. This was due to the fact that swell causing greater sample volume in turn resulted in a lesser average density of the sample. For the two swell tests reported the calculated density changed considerably. The $\mathrm{A} \mathrm{mix}$ or 19 percent binder mix changed from 137.76 pof to 131.27 pef; a reduction of 4.72 percent. The B mix or 29 percent binder mix changed from a density of 138.02 pef to 128.46 pef or a reduction of 6.93 percent. An approximate relationship of one percent change in density resulted from each one percent change in volume. Thus the deformation was related both to swell and to the reduction in swell which takes place with application of the confining pressure. This is show dramatically 
by- Figure 13 where the plot of test 4OBLO-R which was compressed one hour prior to test shows a much lesser deformation than any other of the same series. It can thus be concluded that exactly the same volume must exist in the triaxial cell for each sample, if the absolute deformations recorded are to be of any value in pavement design or subgrade analysis.

\section{Elastic Characteristics}

The elastic properties of the samples were discussed in some detail under RESULTS AND COMPUTATIONS. In addition to these it will be noted from plots of compressed tests (e.g. 40B4O-R, 40C5O-R) that rebound is not affected much by compression, although changes in density should result in proportionate changes in rebound. Referring to Table 2 it will be seen that for test $40 \mathrm{~B} 4 \mathrm{O}-\mathrm{R}$ the magnitude of $E_{\mathrm{d}}$ increased after compression. It would seem that at high number of repetitions, after the sample has decreased in volume, higher densities would result in higher values of $E_{d}$. This is apparently not the case since lower rebound values were observed at high repetitions. The lower rebound again, is a function of the reduction in deviator stress resulting from large total deformations.

\section{Strength Characteristics}

Strengths of soils subjected to repeated loading can be evaluated by comparing the peak compressive strength after repeated loading with the peak compressive strength prior to repeated load applications. This strength increase is a function of increased density and structural change in the sample. There is some 
permanent change in structure which occurs with application of deviator stress until the quasi-equilibrium structure is reached. Moreover, upon examination of Table 2, column $\frac{\Delta \sigma_{r}}{\Delta \sigma_{s}}$ it will be noted that the strength increase is greater for samples carried to large number of repetions. Thus the effect of number of repetitions is apparently significant. This result is in agreement with the work of Seed, et al (19) on fine grained solls where the strength Increase was related to number of repetitions.

From the results of the work on volume change, it appears that fallure of these mixes is not so much a function of total deformation as it is of volume change.

\section{Pore Pressure Behavior}

The three major types of pore pressure behavior indicated by the repeated load test were ennumerated and discussed briefly under RESULTS AND COMPUTATIONS. They are:

1. Response and initial pore pressure change,

2. Change in pore pressure per cycle,

3. Maximum change in pore pressure.

These characteristics will now be explained in some detail, but prior to the discussion, some remarks concerning the mechanism of pore pressure behavior observed in these tests are pertinent. These can best be considered in terms of time of occurrence.

1. The sample, upon belng withdrawn from the saturation cell, Immediately began to change volume which was ultimately stopped by the mobilization of negative pore pressure, 1.e. below atmospheric pressure. (any cohesionless un-saturated sample capable 
of standing unsupported is under negative pore pressure). This negative pore pressure was considered to have been mobilized throughout the entire sample, although it is quite likely that it was of lesser magnitude near the center than at the surface of the sample. If these had been other than granular solls, the negative pore pressure would probably have been a net negative value based on a statistical average. In a saturated clay, the pore pressure at the center and ends might be slightly positive. This fact was noted previously under comments pertaining to probe performance. The probe which measured pore pressures at the center of volume, (Type D) consistently recorded lesser magnitudes of change than did Type C, Plate 6.

2. When the sample was placed in the triaxial cell, and confining pressure applied, a reduction in volume occurred. This reduction, however, was not of sufficient magnitude to cause the sample to return to its compacted volume. Therefore the sample was only partially saturated. As a result $\frac{\Delta u}{\Delta \sigma_{3}}$ was not equal to unity but some value less than 1 .

There was now a water deficiency in the sample, and it should have gained water through the membrane. In some tests, a net gain was noted, but in others a net loss was recorded. Which one occurred was a function of time. Larew (25) reported moisture loss through the sample. Table 2 indicates the percent saturation before and after testing with the attendent moisture decrease or increase. Samples which were compressed prior to test gained in moisture during the test. The same was true of short duration 
tests, e.g. 14 percent binder series. Iong duration tests tended to loose moisture regardless of degree of initial saturation.

3. The application of stress difference (deviator stress) caused a further reduction in volume which was considered to be a negative volume change or densification. The pore pressure became more positive but remained less than $\sigma_{3}$.

4. With increasing number of stress repetitions of a relatively low level the volume continued to decrease with reference to its initial volume in the triaxial cell but the total volume remained greater than the compacted volume which explains the consistent negative pore pressure and pore pressure change. If the sample was not strained sufficiently to cause an increase in volume due to dilatency, the test indicated a volume decrease or densification throughout.

5. Increasing the deviator stress caused the sample to increase in volume, and this increase in volume produced a reduction in pore pressure. At failure the pore pressure was negative and the volume greater than at start of triaxial test. It is probable that at no time did the specimen return to its initial compacted volume.

From the work of Larew and Leonards (38) it has been shown that the stress level which produces failure is a critical one in repeated load tests on fine grained soils. It appears that a similar relatIonship may be true for sands where failure occurs if the volume change approaches a critical value (void ratio) much as shown by Casagrande for static tests.

\section{Initial Pore Pressure}

The intial recorded pore pressure was a function of several variables in the specimen. One was the amount of swell or expansion 
which took place above the as-compacted volume. If the sample swelled, the soil could not be saturated, but only partially so. Another was the degree of initial saturation, which if less than 100 percent would result in less than 100 percent response. A third was that of surface voids (as well as internal voids) between the soil grains and the rubber membrane. These volds can be considerable in the case of a granular material with low binder contents such as were used in this study. Considering these variables, particularly that of swell as already discussed, it can be seen that high pore pressure response is difficult to obtain. The fact that the soil sample is not completely saturated does not negate the effective stress principle. As long as the gas bubbles and the soil grains are completely surrounded by water, the stress in the pore fluid will change as the sample is loaded.

If Flgures 28,34 and 39 are examined it can be seen that preload compression caused the sample ( $40 \mathrm{~B} 40)$ to show an increase in pore pressure with application of the first load increment. Here the sample has decreased in volume enough so that the initial strains act to produce further densification sufficient to increase the pore pressure. This effect was lost after a very few cycles however. The same resurt was obtained for sample 40A4O-R2 with 19 percent binder (Figures 32 and 38).

Change in Pore Pressure Per Cycle

Initially the strains produced by the application of the deviator stress caused a large change in pore pressure per cycle to take place. This change was reduced in magnitude as certain internal 
adjustments took place in the sample under the action of the fluctuating load application.

Ideally, in the non-failure case it seems that some equilibrium value would be reached. In the failure case there should be a progressive decrease in the cyclic fluctuation as well as total pore pressure as the soil sample expands in volume. The failure case did not occur often in the repeated load test as conducted in this study. The non-failure condition of equilibrium occurred in most tests (see Figures 30 to 35 inclusive). In a very few cases where the cyclic change dropped to zero, the use of too low airentry ceramics may have permitted pore air to enter the probe. This condition was corrected after the first few tests. It may be that after the total deformation had exceeded a certain value and the sand grains were so orlented that each loading acted to cause a volume increase, the strains which took place in the failure zone were carried entirely by the soil skeleton and a cyclic change was no longer reflected. Such an hypothesis is indicated by the immediate increase in volume which took place after a sample with a large pre-shear history of load repetitions was loaded to failure (Figures 46 to 49 ).

Change in Maximum Pore Pressure

The measured reduction in pore pressure which took place in the repeated load test accompanied by a net reduction in volume (densification) must be considered from the viewpoint of tine and location within the sample. Examination of Figures 42 to 45 shows that most of the densification took place within the first half hour of 
the test period or after some 1000 cycles had been run. During this time the sample was densifying over all, but the pore pressure being recorded in the failure zone reflected a desire to expand in volume. Two things occurred simultaneously. Consolidation (or more properly densification) was taking place at the ends of the sample where the end restraint was greatest. This produced a measured net volume decrease. At the same time the pore pressure in the failure zone decreased due to the high strains tending toward failure at this location. For this reason the magnitude of the pore pressure was less. Furthermore it will be noted from the graphs of change in pore pressure per cycle that the magnitude of cyclic change decreased rapidly during the first few cycles and approached zero usually within the first half hour. It is considered that the following took place. As the load was applied the pore pressure recorded in the failure zone decreased for the reasons cited above. But when the load was released, only one-half second elapsed before the load was reapplied. This interval was not sufficient for the pore pressure to be regained fully before the next load application occurred. Hence the overall pore pressure was depressed even more and the magnitude of the cyclic change decreased incrementally with each load application. The process continued until equilibrium (no failure) was reached. At this stage the maximum change in pore pressure (with reference to the pre-shear value) was reached, the volume change was stabilized, and vertical deformation was slowed to a very slowly increasing rate. After this period elapsed the pore pressure redistributed itself throughout the sample and the 
maximum pore pressure tended to rise. It did not rise to a value above its initial however since the rolume was still less than the compacted volume. This is readily apparent from examination of the graphs of absolute pore pressure shown in Figures 47 to 49.

Thus It can be concluded that there were below-average pore pressures in the failure zone from the beginning of the test; that there were pore pressure gradients in the sample fram the beginning; and that the mechanism of pore pressure redistribution acted right up to the quasi-equilibrium condition, short of failure. At equilibrium, average pore pressures throughout the sample were being measured.

\section{Suggested Failure Mechanism}

The mechanism of failure as related to the sand-soil mixtures used in the experimental portion of this study is postulated in the succeeding paragraphs.

Recapitulating the behaflor of the sample during the applicatIon of repeated loads it will be recalled that a quasl-equilibrium period was reached at approximately 10,000 cycles where the deformation, volume change and pore pressure behavior did not change appreciably up to fallure or test termination. Many of the tests were terminated at 100,000 cycles without fallure; these tests are not included in this discussion.

There were essentially two kinds of fallure observed in the sand-soll mixtures; that of shear failure occurring suddenly and without warning during the conduct of the test, and that of plastic deformation which took place during the test at a more or less 
constant rate until the specimen failed in shear. The first of these types of fallure usually occurred in the optimum binder (19 percent) mixtures and is shown by the two specimens to the left of Plate 7. The second type of failure was typical of the B mixtures (29 percent binder) and is illustrated by the specimen to the right of Plate 7.

Flrst of all, failure occurring after 10,000 cycles of load application represents an elapsed time interval of at least 4.5 hours. Thus the factor of change in the original sample conditions must be considered. In the event that a moisture content change took place during this time interval, the test would no longer be an undrained test. The factor of moisture migration has been discussed under Pore Pressure Behavior in this section where it was pointed out that in some tests a molsture change was observed. In the majority of cases this was a net loss, but some tests reflected a net gain (see Table 2). Furthermore, the factor of volume change discussed previously under Change in Maximum Pore Pressure should be considered in any discussion of conditions at time of failure.

It can be considered that the 19 percent binder mixtures (A-Series) represent a high degree of grain-to-grain contact of the sand particles; these comprised the skeleton which carried the imposed loads and the binder acted to fill the voids in the skeleton. These were essentially the same conditions described by Miller and Sowers (31). Grain-to-grain contact was established at the beginning of the test period between relatively rough contact surfaces on the sand grains. Subsequently the sample was compacted under the action 
of 10,000 or more repeated load applications was reduced in volume to a volume which did not exceed the as-compacted volume by a large amount; further compaction and volume change probably would not occur without an increase in deviator stress. The load was carried largely by the sand skeleton at this point as evidenced by the constant elastic rebound value. It is considered that the type of behavior described by Casagrande (27) occurred during failure of these mixtures where the repeated load action caused the sand particles to polish smooth contact faces; water acted as a lubricant. At some point the sand particles started to slide past each other and fallure resulted. Support for this theory is given by the graphs of pore pressure-volume change shown in Figures 47 and 48 . It can be seen from these figures that all tests loaded statically to failure after a history of repeated loading displayed an immediate increase in volume up to fallure and decrease in pore pressure. Higher negative pore pressures were produced in these mixtures at failure than in the 29 percent binder mixtures primarily as a direct result of lower swell tendency. The sample swelled prior to placement in the cell and repeated loading, but since the swell was of a low order of magnitude, the air which was trapped, compressed and eventually dissolved in the pore water during repeated loading was also a small amount. Cavitation, reflecting voids filled with water vapor and gas released from solution, took place at developed negative pore pressures of about 5 psi.

In the case of the 29 percent binder mixes where high plastic deformations took place prior to shear failure, the increased amount 
of binder is considered to have played an important role at failure. Again, these samples experienced an immediate increase in volume with increase in axial load after a history of repeated loading. It appears, therefore, that at this point in the test the particles began sliding up and over each other resulting in volume increase as shown in Figures 47 and 48 . Corresponding pore pressure decreases were initiated also (Figures 47 and 48 ) but the negative pore pressure developed at failure was significantly lower than for the 19 percent binder mixtures, lending support to the supposition that a greater quantity of air was trapped in the sample by the membrane due to greater swell prior to placement in the triaxial cell. It is believed that this greater swell was the basis for the difference in behavior between the $A$ and $B$ mixtures at failure in that under the compacting action of the repeated loads, the 29 percent binder sample had to undergo more densifying than the 19 percent binder sample in the same time period.

Opposing the densification of the sample was the cohesive nature of the binder soil which constituted nearly one-third of the sample by weight. Thus, the sample deformed by bulging until failure occurred; the particle action at failure is considered as being similar to that which took place in the 19 percent binder mixture. 
SUMMARY OF RESULTS

The Important results of this research program are recapitulated below. These results apply to dense sand-soll mixtures and not to loose sands.

1. A repeated load, triaxial test apparatus was designed and constructed having pore pressure measuring capability. (Figures 1-3, pp. 24-32)

2. Pore pressure sensing and recording equipment was developed which measured the pore pressures in the failure zone with a high degree of accuracy and rellability. (Figures 4-6, pp. 32-39)

3. Volume change measuring equipnent was developed for repetitive loading equipment to produce accurate volume change measurements based on changes in volume of fluld in the triaxial cell. (Flgure 7, pp. 40-4山)

4. A technique was developed for saturating soil samples which assured a high degree of saturation. (pp. 54-57)

5. A technique was developed whereby a pore pressure sensing element could be placed in a granular, highly compacted soil sample without altering the placement or integrity of the membrane. (Plate 5-6, pp. 57-65)

6. Total deformation experienced by the sample under the given test conditions was dependent on initial density, degree of saturation and magnitude of devlator stress. An increase or 
decrease in binder soll from an optimum amount resulted in larger total deformations. (F1gure 9-17, pp. 71-84, 141-142)

7. An axially loaded soll sample will rebound with each load application and removal. The magnitude of rebound reached a quas1equilibriun value after 10,000 cycles of load repetition. (Flgure 18-23, pp. 84-94)

8. The magnitude of equilibrium rebound was dependent on the applied deviator stress, increasing with increase in deviator stress. Measured rebound was greatest at optimum binder contents, applled devlator stress remaining constant. (F1gure 18-23, pp. 92, 142)

9. Using the type of recording equipment designed for this program, the modulus of deformation, $E_{d}$ could be computed for dynamic loading conditions. The magnitude of $\mathrm{E}_{d}$ was indicative of the density and particulate nature of the soil sample. (Appendix D, pp. 93-94, 142)

10. Permanent structural changes took place within the specimen under repeated loading until the quasi-equilibrium condltion was reached. (pp. 130-134, 143-145)

11. Volume change took place in the specimen under repeated loading which resulted in densiflcation of the soll. (Flgure 42-49, pp. 122-138)

12. The structural change and densification which the specimen experienced contributed to a strength increase in the soll after a history of pre-shear load repetition. (pp. 96-97, 142-143, 147)

13. The strength increase which the sample experienced was related to the binder content, decreasing with an increase in 
binder above an optimum amount. (pg. 97)

14. The strength gain increased with number of load applications, all other conditions being equal. (pg. 143)

15. The Initial pore pressure response was dependent on the initial degree of saturation and the swell which took place prior to loading. (pp. 146-147)

16. The pore pressure behavior during test was dependent on the swell existing above the as-compacted volume for similar specimens. (pp. 143-146)

17. Pre-loading compression altered the behavior of the pore pressure during the repeated load test by reducing the magnitude of change per cycle of load application. (pp. 146)

18. The magnitude of pore pressure change measured during the test was dependent among other things on the binder content. It was greatest for optimum binder content mixtures and decreased as the binder content was increased or decreased above optimum. (Figure 36-41, pp. 115-122)

19. The measured pore pressure changes were dependent on the location of the sensing element in the samples. Surface pore pressures changes in the failure zone tended to be higher than at the center of the sample. (pp. 148-149)

20. With each load cycle, a cyclic change in pore pressure was produced. Its magnitude was a function of the densiffcation of the sample and the magnitude of the deviator stress. (FIgure 30-35, pp. 108-115, pp. 146-147) 
21. The magnitude of pore pressure recorded in the repeated load test was related to volume change and structural changes in the sample. It changed erratically up to equilibrium, after which it reached an average, stabilized magnitude. An increase in axial load to fallure resulted in negative pore pressures being produced. (pp. 143-145) 


\section{CONCLUSIONS}

The results of the research program reported herein indicate a number of conclusions which appear warranted from analysis of the data.

For the type of soils used in this study, graded sand with varying binder content and compacted to high degrees of density the pore pressures measured in the fallure zone are not reppresentative of pore pressures existing throughout the sample under repeated axial load applications, except at equilibrium. Furthermore, the magnitude of recorded pore pressure as well as pore pressure changes during the repeated load test depends on the inftial degree of saturation, binder content, inftial volume change prior to test, applied devlator stress and whether the sample was consolidated prior to testing.

The soll samples tested in this study underwent rolume change during repeated load testing, in the form of volume decrease or densification. Little or no densification occurred when the same soils were tested statically to fallure. The magnitude of volume change is related to pre-load swell tendencles, degree of saturation, binder content and applied deviator stress. Pre-test consolidation will not reduce the total measured volume change (densification) but will reduce the axtal strain accompanging the volume change. 
The strength of a sand-binder soll mixture will increase with number of load applications of a relatively low level; the strength gain is related to binder content and magnitude of applied deviator stress. The modulus of dynamic deformation appears to be related to sample density as well as binder content of the mixture. At equilibrium, the elastic rebound reached a constant magnitude which did not change until the test conditions were changed. The magnitude of equilibrium elastic rebound varied directly with the applied deviator stress. Moreover, at equilibrium the structural changes in the soil sample were reduced to a minimum. These structural changes are considered to be responsible for the stiffening of the mixture which took place after 10,000 or more load repetitions.

Finally, it appears that re-evaluation of existing compactiondensity criteria for these soils should be made by placing more emphasis on control of swell. Volume change occurring beneath the parement related to changes in moisture content and load repetitions may lead to fallure of the pavement even though the shear strength of the base is not exceeded. The effective stress principle is valid for partially saturated solls as well as saturated solls; this fact can be considered to contribute to the failure of poorly drained bases in which the binder contents are below an optimum amount for maximum density.

As demonstrated by this study, pore pressure measurement in the fallure zone of a sand-soil mixture under repeated loads may not be a valid index to the structural changes taking place in the mixture, particularly where a tendency to swell is evident. Support 
for this conclusion is given by correlation of volume change with pore pressure behavior where volume reduction was observed simultaneously with decrease in pore pressure.

Lastly, as shown by Yoder and Woods (30) there is an optimum soil content at which maximum densities are attained for a given aggregate. Further this research program verified similar results reported in the cited paper by proving that a relation exists between density and strength of soil-aggregate mixtures if the soil quantity is considered. Above an optimum soil content the strengths were lower, for comparable densities, than those of the mixtures containing a quantity of soil less than optimum. Part of this loss in strength for low binder content mixtures is thought to be due to the saturation moisture contents of the binder soil. Referring to Table 2, page 67, it will be noted that the moisture contents of the binder soil in the saturated mixtures increased with decreasing binder content from an average of 13.16 percent for the B mixtures (29 percent binder) to 15.12 percent for the A mixtures (19 percent binder) and 21.46 percent for the $\mathrm{C}$ mixtures (14 percent binder). Thus at Iow binder contents ( 14 percent) the excess pore space was filled with water at saturation. The resultIng moisture content of nearly 22 percent compared with the LL of 34 percent for the binder soil was high enough to produce instability in the test specimen as well as prototype base courses. This trend was less pronounced at the higher densities reflected by the $A$ and $B$ mixtures. 


\section{SUGGESTIONS FOR FURTHER RESEARCH}

Several avenues of approach to profitable research are suggested by this program.

1. Investigate the suitability of various plastic films for use as triaxial test membranes. Suggested films would be mylar, nylon, teflon and polyethylene. Thickness and stiffness of each film would be investigated as related to ability to transmit water with time.

2. High cell pressure studies with a view to obtaining 100 percent saturation in the triaxial cell. That is, the sample would be tested at its as-compacted volume. One approach to use in conjunction with this procedure would be to compact in a mold whose volume had been decreased by lowered temperature. Both static and repeated load tests with pore pressure measurement would provide valuable data.

3. Determine the variation in pore pressure at the top and bottom of the sample and in the failure zone by varying the probe location. Pore pressure gradients could thus be defined, as well as consolidation effects which take place under repeated loads.

4. Investigate volume change - pore pressure characteristics of cohesionless sands.

5. Determine the effect of variations of load duration and interval between loads on soil-aggregate mixes as related to volume 
change, pore pressure and strength increase. Pore pressure bohavior may be considerably different where the interval between load application $1 \mathrm{~s}$ suffioient to permit redistribution of pore pressures.

6. Definition of the critical deviator stress as related to load repetitions for a soll-aggregate $\mathrm{mix}$ would provlde valuable parement design data, as well as indicate possible reasons for fallure of parements and bases. 
LIST OF REFERENCES 


\section{LIST OF REFERENCES}

1. Terzaght, K., "Die Berechnung der Durchlässigkeitsziffer des Tones aus dem Verlauf der Hydrodynamischen Spannungserscheinungern," Sitzungsberichte, Akademie der Wissenschaften in Wien, MathematIschnaturwssenschaftliche Klasse, Part IIa, Vol. 132, pp. 125$138,1923$.

2. Putledge, P.C., "Soil Mechantes Fact Flnding Survey: Progress Report - Triaxlal Shear Research and Pressure Distribution. Studies on Soll," Waterways Experiment Station, Vicksburg, Mississippi, 1947.

3. Horslev, M.J., "Conditions of Fallure for Remolded Cohesive Soils," Proceedings, First International Conference on Soll Mechanics and Foundation Engineering, Vol. III, 1936.

4. Bishop, A.W., "The Measurement of Pore Pressure in the Trlaxial Test," Pore Pressure and Suction in Soils, Butterworths, London, pp. $38-46,1961$.

5. Skempton, A. W., "Effective Stress in Solls, Concrete and Rocks," Pore Pressure and Suction in Solls, Butterworths, London, pp. L-I6, 1961.

6. Rendulic, L., "Porenziffer and Poremresserdruck in Tonen," Bauingenieur, Vol. 17, pp. 559, 1936.

7. Rendulic, L., "Ein Grundgesetz der Tormechanik und sein Experimenteller Bewels," Baulngenfeur, Vol. 18, pp. 459-467, 1937.

8. Taylor, D. W., "Shearing Strength Determinations by Undrained Cylindrical Compression Tests with Pore Measurements," Proceedings of the Second International Conference on Soll Yechantes, Vol. V, pp. 45, 1948.

9. Lambe, T. W., Soll Testing for Engineers, John Wiley and Sons, Inc., N.I. pp. 122-138, 1951.

10. Skempton, A. W., "The Pore Pressure Coefflcients A and B," Geotechnique, Vol. 4, pp. 143-147, 1954.

11. Bishop, A. W., "The Use of Pore-Pressure Coefficients in Practice," Vol. 4, Geotechnique, pp. 148-152, 1954. 
12. Nash, K. L. and Dixon, R. K., "The Measurement of Pore Pressure In Sand Under Rapid Triaxial Test," Pore Pressure and Suction in Solls, Butterworths, London, pp. 21-24, 1961.

13. Lambe, T. W., "Residual Pore Pressures in Compacted Clay," Proceedings, Flfth Intermational Conference on Soll Mechanics, Dunod, Paris, pp. 207-211, 1961.

14. Whitman, R.V., Richerdson, A. M., Healy, K.A., "Time-Lags in Pore Pressure Measurements," Proceedings Flfth International Conference on Soll Mechanles, Dunod, Par1s, pp. 407-411, 1961.

15. Healy, K. A., "Investigation of Strain Rate Effect on Coarse Sands," Internal Report, M.I.T., 1961.

16. Bishop, A. W., Henkel, D. J., The Measurement of Soll Properties in the Trlaxial Test, Edward Arnold, Itd., London, 1957.

17. Bishop, A. W. \& Donald, I.B., "The Experimental Study of Partly Saturated Soil in the Trlaxial Test," Proceedings, Flfth International Conference on Soil Mechantes, Dunod, Paris, pp. 13-21, 1961.

18. Whitman, R. V., "Some Considerations and Data Regarding the Shear Strength of Clays," Proceedings, Research Conference on the Shear Strength of Cohesive Solls, ASCE, Boulder, Colorado, pp. 581614,1960 .

19. Seed, H.B., Chan, Clarence K., Monlsmith, Carl, "Effects of Repeated Loading on the Strength and Deformation of Compacted Clay," Proceedings, Highway Research Board, pp. 541-558, 1955.

20. Seed, H.B., McNe1ll, Robert L., "Soll Deformations in Normal Compression and Repeated Loading Tests," Bulletin 14l, Highway Research Board, pp. Wh, 1956.

21. Seed, H.B., Chan, C. K., "Effect of Stress History and Frequency of Stress Application on Deformation of Clay Subgrades Under Repeated Loading," Proceedings, HLhway Research Board, pp. 555$575,1958$.

22. Seed, H. B., McNelII, R. L., deGuenin, J., "Increased Resistance to Deformation of Clay Caused by Repeated Laading, "Joumal of the Soll Kechanics and Foundations Division, ASCE, No. SM 2, Paper 1645, May 1958.

23. Seed, H.B., Chan, C. K., "Structure and Strength Characterlstics of Compacted Clays," Journal of the Soil Mechanles and Foundations Division, ASCE, No. SM 5, Paper 2216, October 1959.

24. Seed, H. B. \& Chan, C. K., "Effect of Duration of Stress Application on Soll Deformation Under Repeated Loading," Proceedings, 
Flfth International Conference on Soil Mechanics, Dunod, Paris, pp. 341-345, 1961 .

25. Larew, H. C., "Strength and Deformation Characteristics of Compacted Solls Under the Action of Repeated Axial Loads, " Ph.D. Thes1s, Purdue University, 1960.

26. Haynes, J. H., "Effects of Repeated Loading On Gravel and Crushed Stone Base Coarse Materials Used In the AASHO Road Test, n M.S. Thes1s, Purdue University, 1961.

27. Casagrande, A., "Characteristics of Coheslonless Soils Affecting the Stability of Slopes and Earth Fills," Journal Boston Society of C1vil Engineers, pp. 13-32, 1936.

28. Newland, P. L. , Allely, B. H., "Volume Changes in Drained Triaxtal Tests On Granular Materials," Geotechnique, No. 1, pp. 17-34, March 1957.

29. Newland, P. L., Allely, B. H., "Volume Changes During Undrained Triaxial Tests on Saturated Dilatent Granular Materials," Geotechnique, No. 4, pp. 174-182, December 1959.

30. Toder, E. J., and Woods, K. B., "Compaction and Strength Characterlstics of Soll Aggregate Mixtures, " Proceedings, Highway Research Board, pp. 511-520, 1946.

31. Miller, Eugene, A., Sowers, George F., "The Strength Characteristics of Soll-Aggregate Mixtures," Bulletin 183, Highway Research Board, pp. 16-31, 1957.

32. Holtz, W. G., Gibbs, H. J., "Trlaxial Shear Tests on Pervlous Gravelly Solls" Journal of the Soil Mechanics and Foundations Division, ASCE, No. SM 1, Paper 867, January 1956.

33. Havers, J. A., "A Study of the Interactions of Selected CombinatLons of Subgrade and Base Courses Subjected to Repet1tive LosdIng Tests," Ph.D. Thes1s, Purdue UnIversity, 1956.

34. Geldmacher, R. C., et al, "Subgrade Support Charaoteristics Experimental and Theoretical, "Report No. 38, Joint Higmray Research Project, Purdue UnIrersity, pp. 135-175, 1956.

35. Schaub, J. H., "Strength and Volume Change Characteristics of a Bituminous Mixture Under Triaxial Testing," Ph.D. Thesis, Purdue University, 1960.

36. Chamberl1n, W. P. and Yoder, E. J., "Effect of Base Course Gradation On Results of Laboratory Pumping Testa," Bulletin 202, Highway Research Board, p. 59, 1958. 
37. Wilson, S. D. \& Dletrich, R. J., "Effect of Consolidation Pressure on Elastic and Strength Properties of Clay,"

Proceedings, Research Conference on the Shear Strength of Cohesite Solls, ASCE, Boulder, Colorado, pp. 419-435, 1960.

38. Larew, H. O. \& Leonards, G. A., "A Repeated Load Strength Criterion," Paper prepared for Presentation at the Anmual Meeting of the Highway Research Board, Washington, D.C., 1962. 
APPENDIX A 
Procedure for Putting Electronic Equipment into Operation When

Using Schaevitz Different1al Transformers - Galvanometer Recording

Schaevitz Type OLO M-L Transducer

1. Turn all switches to "off" position. Connect power supplies to amplifying and control units. Turn switches on F. M. unit to down position.

2. Put both $A C$ switches on each power supply in the "on" position.

3. Turn filament voltage control to the maximum clockwlse position.

4. Put filament switches on power supply and amplifying units in "on" position. At this instant the filament roltage indicated on the filament meter will fall to approximately $1 \frac{1}{2}$ volts but will start to rise again. As the voltage rises the filament voltage control should be adjusted to obtain a 7 volt operating level. Under no circumstances should the filament voltage be allowed to go above 7.5 volts or below 6.7 volts (below 6.7 volts the gains of the amplifiers are quite sensitive to changes in fillament voltage).

5. Turn the $B+$ switches on the power supply and amplifying units to the "on" position.

6. Connect portable volt-meter to output jacks on power amplifier unit.

7. Adjust meter 5 volt scale.

8. Adjust control marked $3 \nabla$ on power ampliffer until meter reads approxdmately 3 rolts. Disconnect meter and comnect primary distribution leads to output jacks marked $3 \nabla$. Connect primarles of transformers to distribution box at end of distribution lead. 
9. Connect portable volt-meter to meter jacks on power panel of amplifying unit.

10. Turn all "coarse" amplifier attenuators to white position 3 (yellow positions are for 125 SL differential transformers).

11. Turn all "fine" amplifier attenuators as far as possible clockwise.

12. Turn meter selector switch on power panel to position corresponding to amplifier being adjusted.

13. Turn meter switch on amplifier to position "T". In this position the meter reads the output of the transformer alone.

14. Adjust scale of portable meter until needle of meter is near middle of scale.

15. Null differential transformer, using meter on as sensitive a scale as possible. Note magnitude of voltage obtained.

16. Turn meter switch on amplifier to position "C". In this position the meter reads the level of the additive carrier. Using the coarse, medium and fine amplitude attenuation controls adjust this carrier voltage to approximately mull (minimum voltage).

17. Turn the meter switch now to position "S". In this position the meter reads the sum of the differential transformer output and the additive carrier.

18. Adjust the three phase controls to obtain the best null on the meter.

19. Adfust the three amplitude attenuation controls to obtain the best nuzl on the meter.

20. Repeat steps, 18 and 19 until there is no improvement in the null; to Insure the best null the fine controls should not end up at 
their extreme positions.

21. Turn differential transformer calibrator through distance chosen for calibration.

22. Flfteen volts measured at the portable meter is the approximate voltage required to drive the galvonometers to full scale. Therefore the amplifier attenuators should now be adjusted until the meter reads fifteen volts.

23. Return transformer to null position.

24. For all amplifiers not to be used adjust the fine amplifier attenuator to infinity.

25. Turn voltmeter switch on power panel to "off" position.

26. Turn on galvanometer paper drive.

27. Adjust the galvanameter pen comected to channel being adjusted to edge of coordinates by means of mechanical adjustment.

28. Turn differential transformer calibration micrometer through the distance chosen for full scale.

29. If galvanameter pen moves beyond opposite edge of the coordinates turn fine attenuator counter clockrise until pen is writing at edge of coordinates.

30. If galvanameter pen has not moved to opposite edge of chart, turn fine attenuator clockwise until pen is writing at edge of coordinates. If pen does not reach edge of coordinates, turn fine attenuator to Infinity and coarse attemuator to position 23 gradually turn fine attenuator clockrise until pen is at edge of coordinates. If pen still does not reach edge of coordinates, turn fine attenuator to 
infinity and coarse attenuator to position 13 gradually turn fine attenuator clockwise until pen is at edge of coordinates. If pen reaches edge of coordinates in less than one-half turn with coarse attemator on position 3, turn fine attemuator to infinity and coarse attemuator to 43 adjust fine attemuator until pen travels across chart.

31. Return micrometer to null position.

32. Turn off galvanometer paper drive.

33. Turn meter selector switch on power panel to amplifier in use.

34. Turn meter switch on amplifier to position "T".

35. Check mull of differential transformer.

36. Turn meter switch on amplifier to position "S".

37. Check adjustment of phase and amplitude controls.

38. Turn voltmeter switch on power panel to "off" position.

39. Turn on galvanometer drive.

40. Readjust galvanometer scale.

41. Calibrate record by turning micrameter through the distance chosen for full scale. Allow a second or two at each position in order to record these positions.

42. Return micrometer to position corresponding to desired position of galvanometer pen.

43. Repeat above process for each chamel used.

44. Instrument is ready for recording. 


\section{Schaevitz Type 125 S-I Transducer}

The procedure is the sane as the above except for the following sections:

7. Adjust meter to 15 volt scale.

8. Adjust control marked $7 \nabla$ on power amplifier until meter reads approximately 7 rolts. Disconnect meter and connect primary distribution leads to output jacks marked $7 \nabla$. Connect primaries of transformers to distribution box at end of distribution lead.

9. Connect portable volt-meter to meter jacks on power panel of amplifying und.

10. Turn all "Coarse" amplifier attenuators to yellow position 3. (Fran this point on repeat as described in previous section 11 through 44 with the exception that the yellow coarse attenuator settings will be used rather than the white).

Modifled Starting and Stopping Procedure for Use With External DC Power Supply

1. Turn off $B+$ swltch on power distribution panel of amplifying unit. Tum on both $300 \nabla D C$ power supply switches.

2. With filament switch on distribution panel in "on" position, turn filament power supply on after setting selector switch to $6 \nabla$ range.

3. Gradually increase voltage control clockwise to prevent possible orerload.

4. When auxiliary filament meter indicates $7 \vee D C$, ammeter on filament supply should be about 18-21 amperes. 
5. Tum on $B+$ switch on power distribution panel and allow amplifyIng unit to stabilize before calibration.

6. To shut down equipment, turn $B+$ switch on distribution panel to "off".

7. Decrease voltage control on filament power supply to minimum (counterclockwise), then shut off power supply and $300 \mathrm{~V}$ DC supply switches. 
FRONT

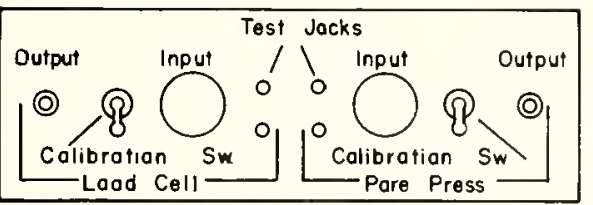

REAR

\begin{tabular}{|c|c|}
\hline 21 & (O) \\
\hline $\begin{array}{l}\text { To Dist } \\
\text { Ponel }\end{array}$ & $\begin{array}{c}\text { Power } \\
\text { Amp }\end{array}$ \\
\hline
\end{tabular}

BRIDGE

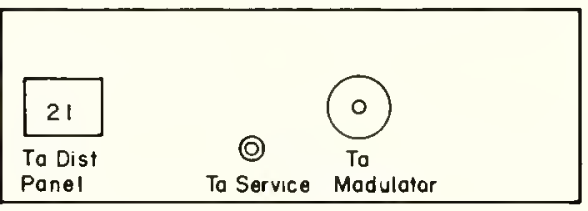

Ta Service Madulatar

CHANNEL AMPLIFIER

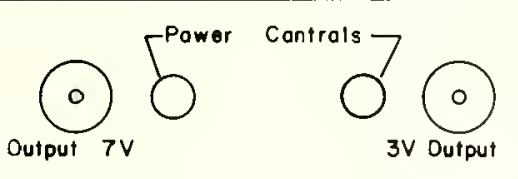

POWER AMPLIFIER

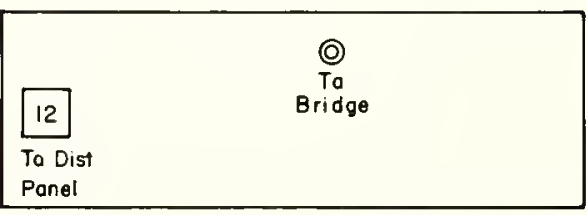

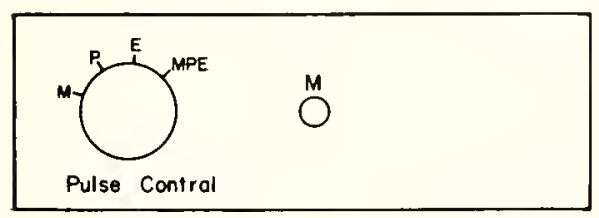

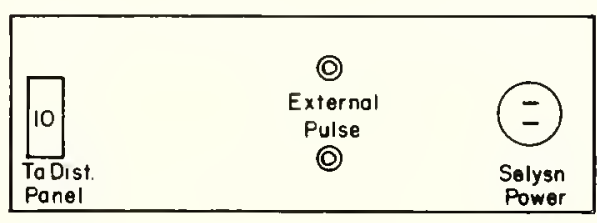

OSCILLATOR
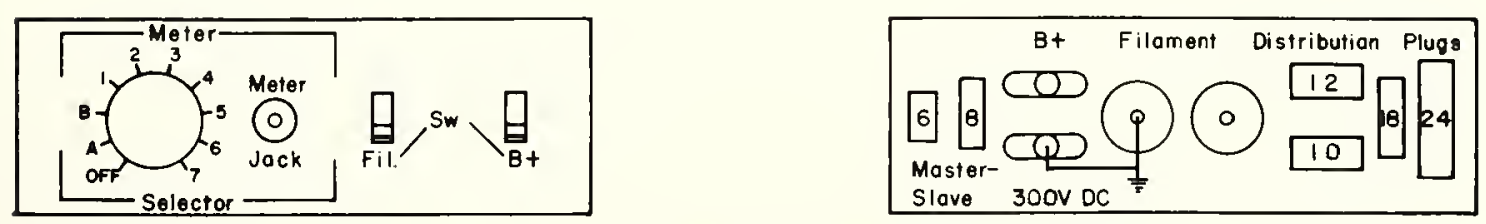

DISTRIBUTION PANEL

FIGURE 52. AMPLIFIER CONTROLS AND CONNECTIONS IDENTIFICATION DIAGRAM. 
APPENDIX B 


\section{Triaxial Q Test}

So1I Data

\begin{tabular}{|c|c|c|c|c|c|}
\hline $\begin{array}{l}\text { Design } \\
\text { Mix } \\
\end{array}$ & $\begin{array}{l}\text { Confining } \\
\text { Pressure, psi }\end{array}$ & $\begin{array}{l}\text { Compacted } \\
\text { m.c. percent }\end{array}$ & $\begin{array}{l}\text { Compacted } \\
\text { Dry Density }\end{array}$ & $\begin{array}{l}\text { Percent } \\
\text { Saturat- } \\
\text { Ion } \\
\end{array}$ & e \\
\hline A & 30 & 6.76 & 137.4 & 96.2 & .207 \\
\hline A & 35 & 5.79 & 139.99 & 90.8 & .184 \\
\hline A & 40 & 5.87 & 140.18 & 91.5 & .183 \\
\hline B & 30 & 6.00 & 138.4 & 97.7 & .198 \\
\hline$B$ & 35 & 6.40 & 139.2 & 93.4 & .191 \\
\hline B & 40 & 6.45 & 138.6 & 95.1 & .196 \\
\hline$c$ & 30 & 6.08 & 133.9 & 99.9 & .236 \\
\hline$c$ & 35 & 6.02 & 134.8 & 98.6 & .228 \\
\hline$c$ & 40 & 6.00 & 133.9 & 99.9 & .236 \\
\hline
\end{tabular}




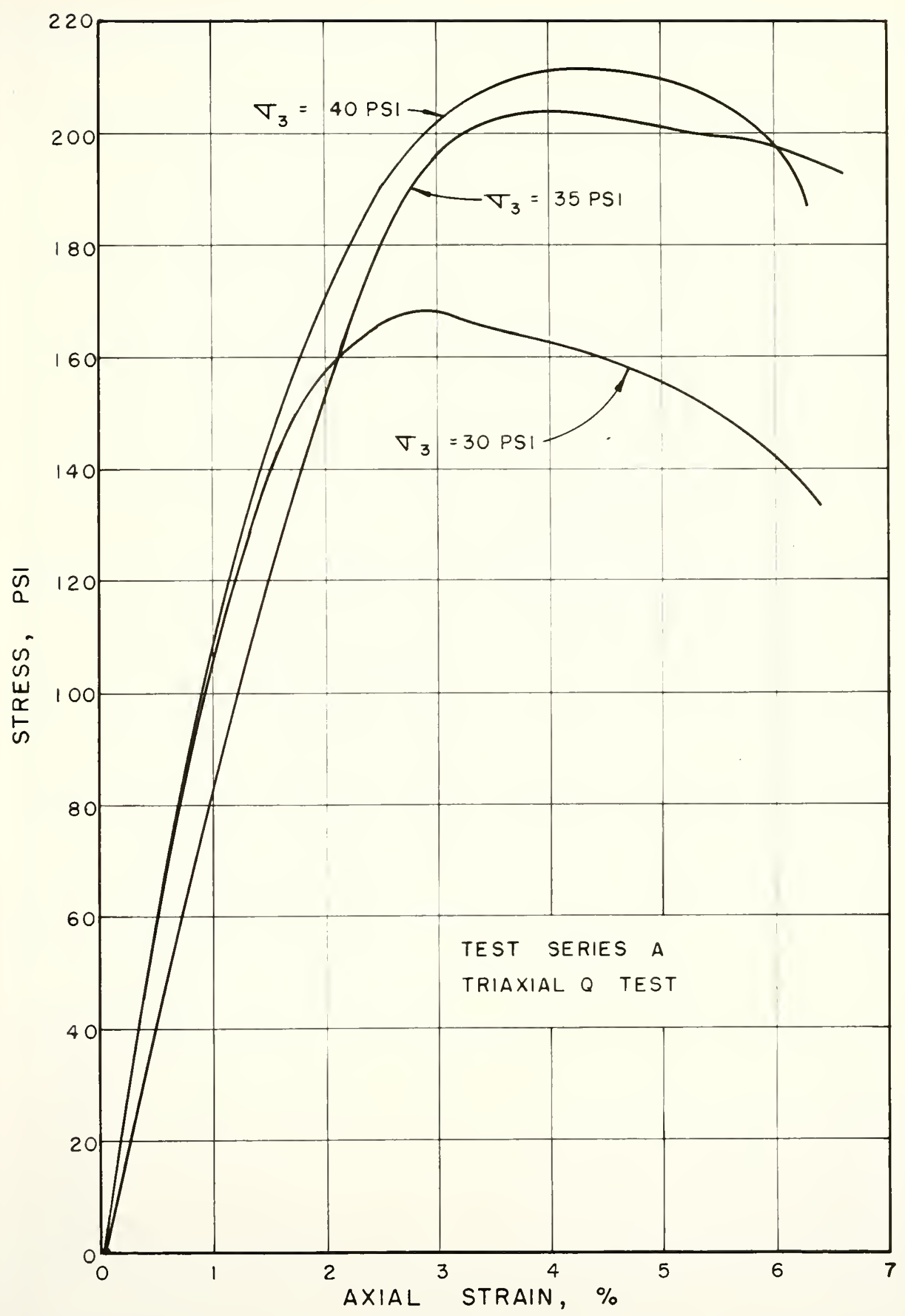

FIGURE 53. STRESS STRAIN CURVES, $19 \%$ BINDER. 


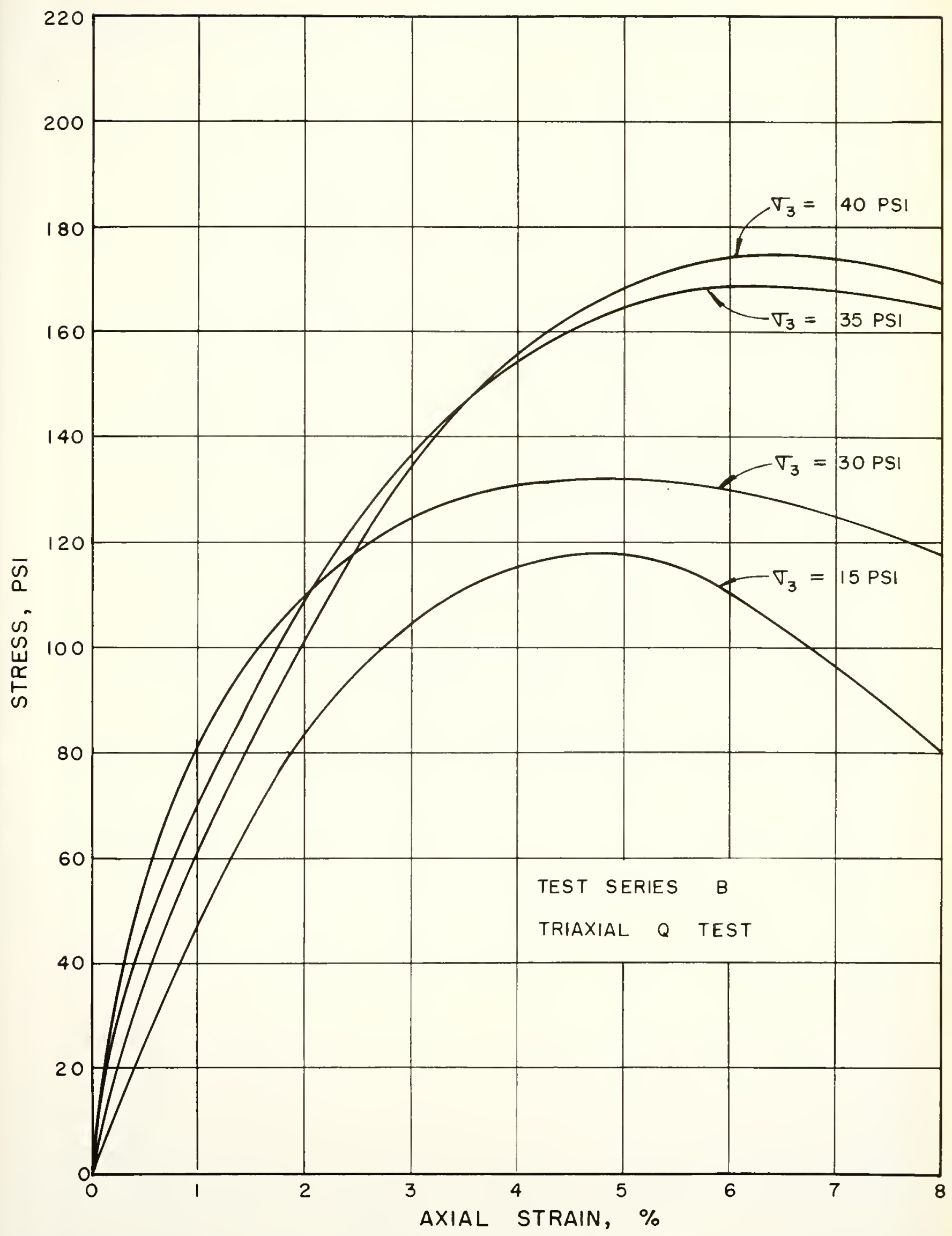

FIGURE 54. STRESS STRAIN CURVES, $29 \%$ BINDER 


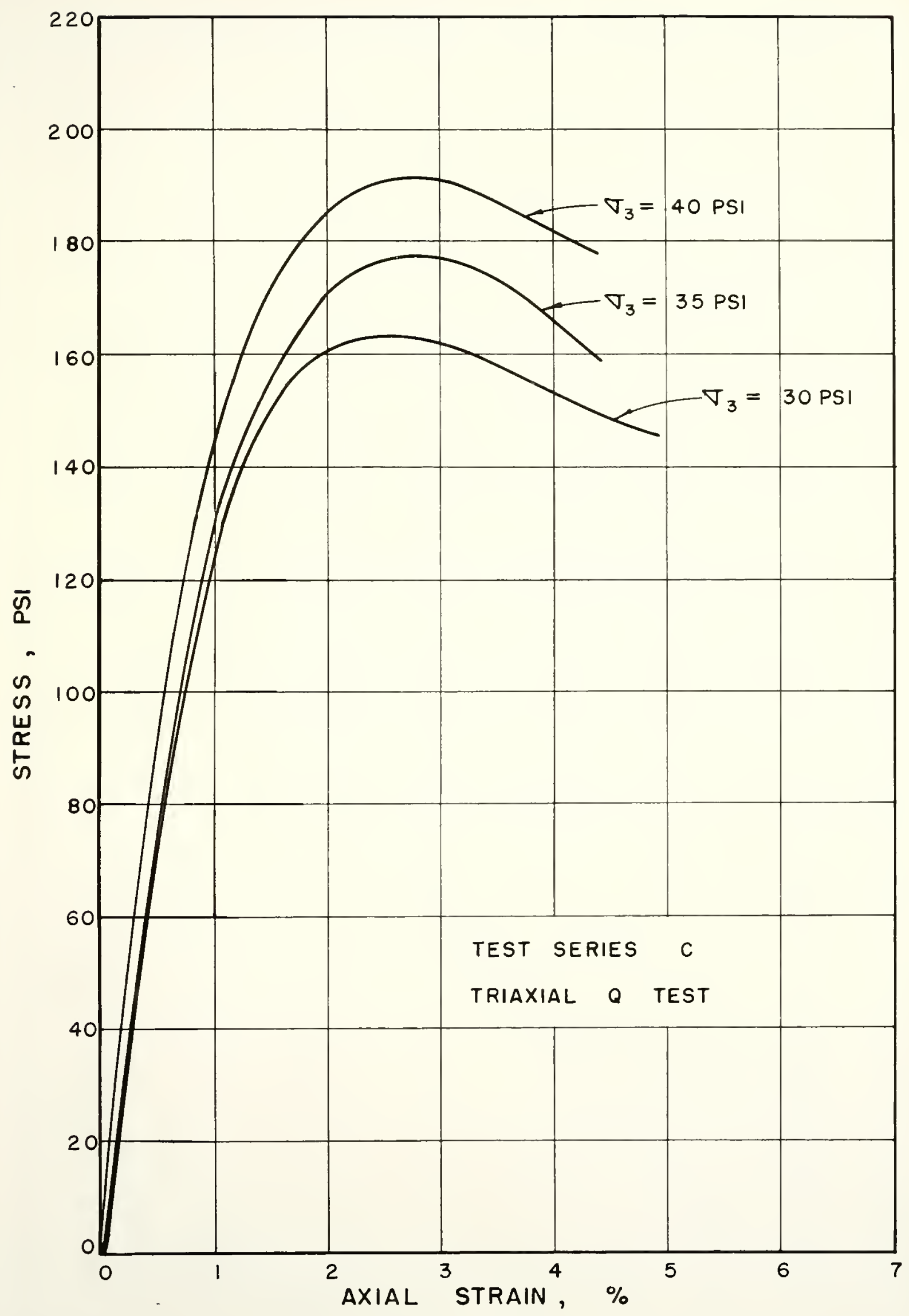

FIGURE 55. STRESS STRAIN CURVES, $14 \%$ BINDER. 


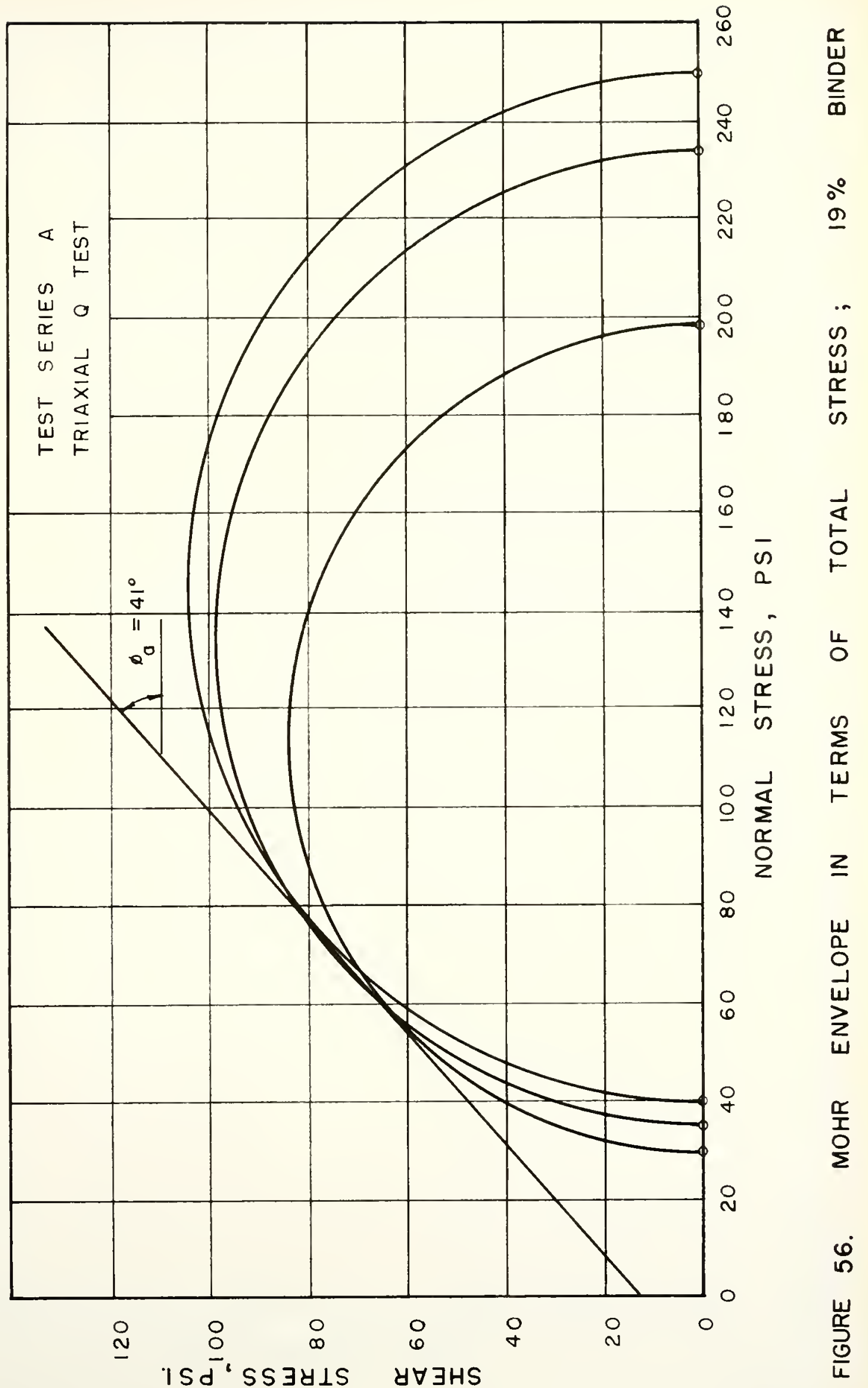




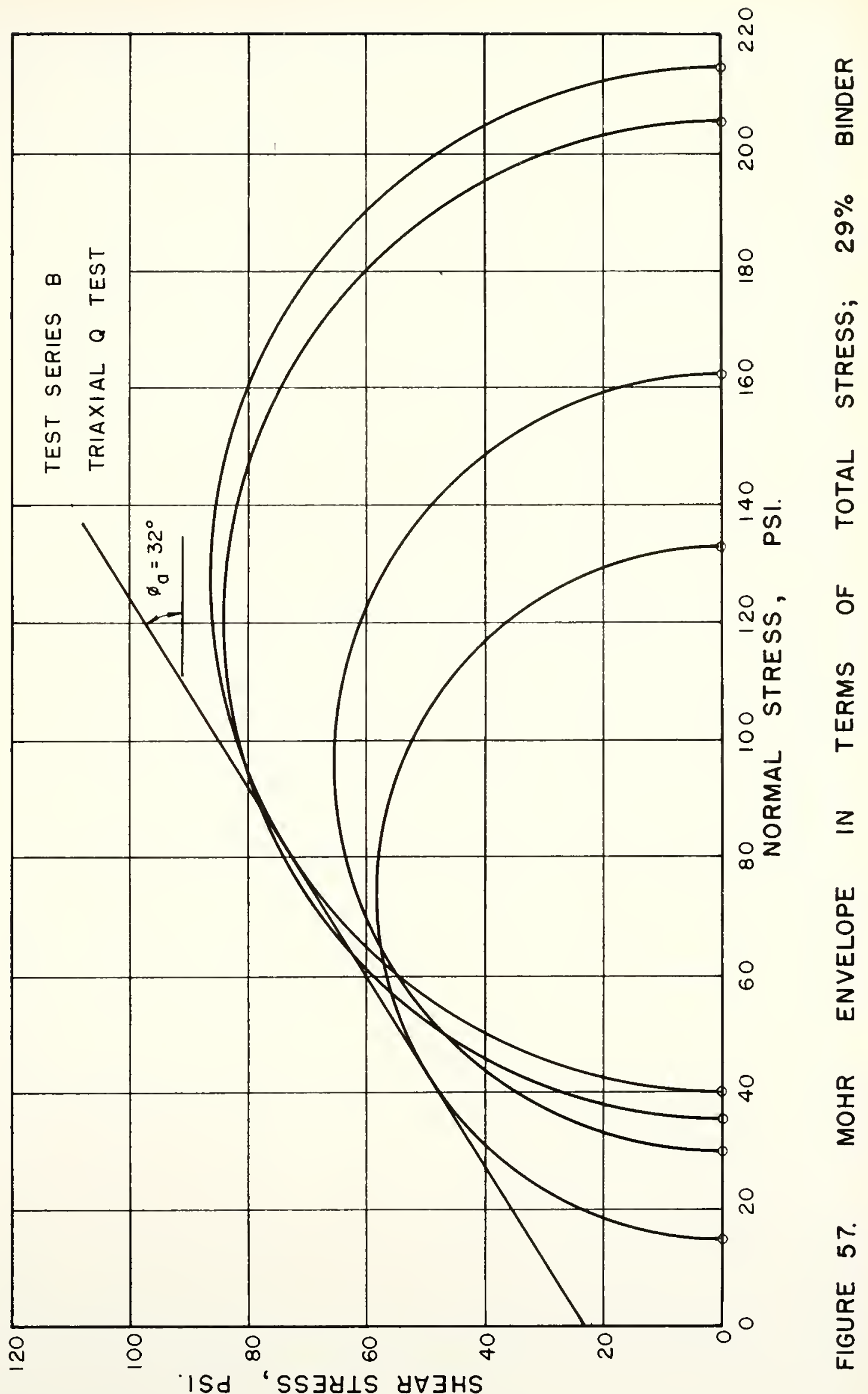




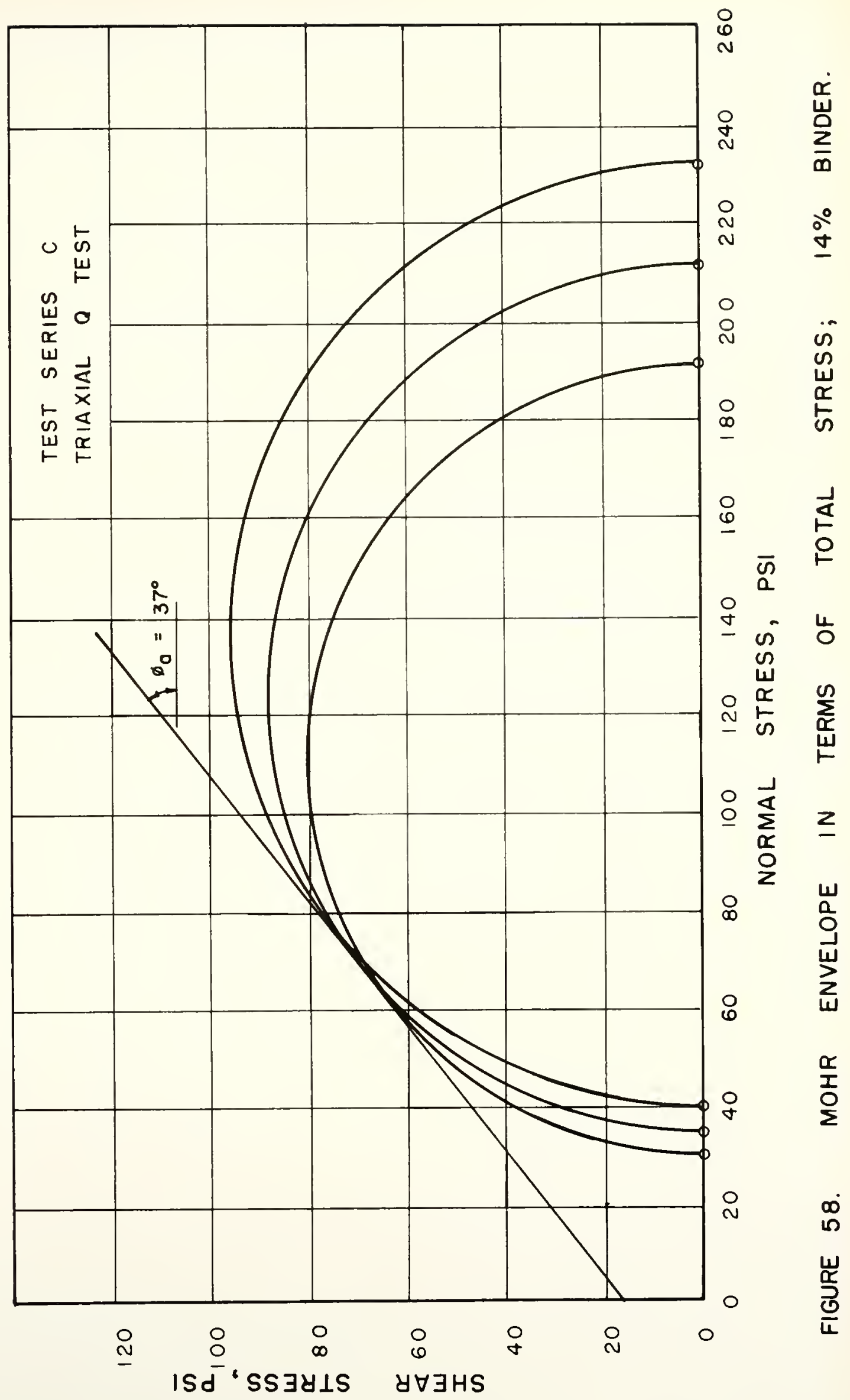


APPENDIX C 


\section{Volume Change Resulting From Loading Ram}

During the loading of the sample the cell liquid is displaced by the movement of the ram into the cell. The observed volume change which takes place during the conduct of the test must be corrected for this morement. Since the volume displaced is equal to the area of the piston ( $3 / 4^{\prime \prime}$ diameter) times the movement, a table was prepared to show the volume change in cubic inches resulting from any increment of movement. This table is shown belows

Deformation, In.

.001

.002

.003

.004

.005

.006

.007

.008

.009

.01

.02

.03

.04

.05

.06

.07

.08

.09

.1
.2
.3
.4
.5
.6
.7
.8
.9
Volume Change, cu. In.

.00044

.00088

.00133

.00177

.00221

.00265

.00309

.00353

.00398

.00442

.00884

.01325

.01767

.02209

.02651

.03093

.03534

.03976

.0448

.08836

.13253

.17671

.22089

.26507

.30925

.35343

.39761 
181

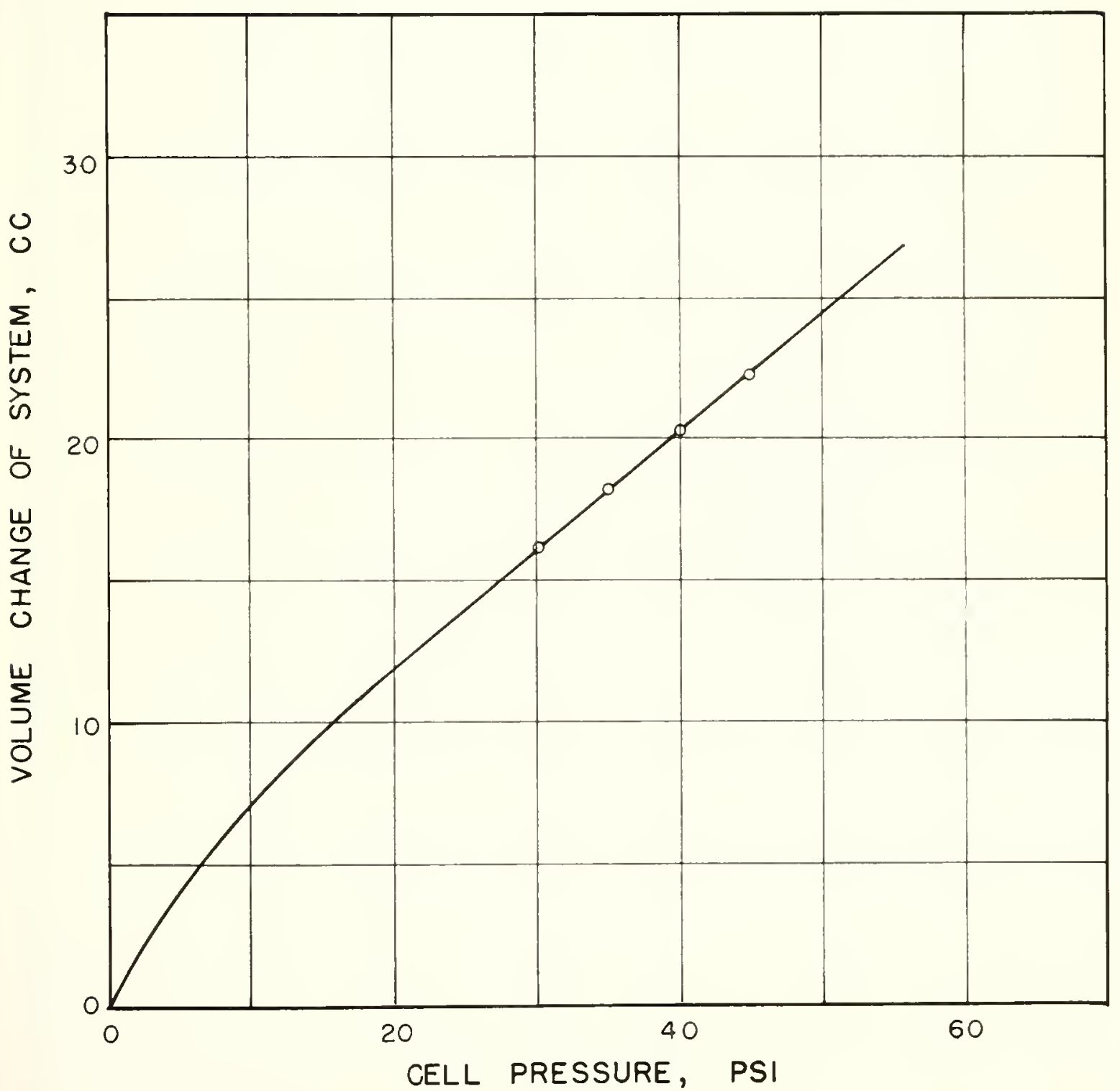

FIGURE 59. CALIBRATION CURVE FOR VOLUME CHANGE DEVICE AND TRIAXIAL CELL 
APPENDIX D 


\section{Dynamic Modulus of Deformation}

The dynamic modulus of deformation, $E_{d}$ can be obtained for and cycle of load application providing the data for load and deformation were recorded. Since the tape was running through the galvanameter at a certain known constant time, It was possible to plot curves of stress versus time and strain versus time for the cycle of load in question, Flgure 60 . The stress and strain value for the same time Instant was then plotted for the several mornents of time and the graph shown in Flgure 61 obtalned. The slope of the straight-line portion was then used to compute $E_{d}$. 


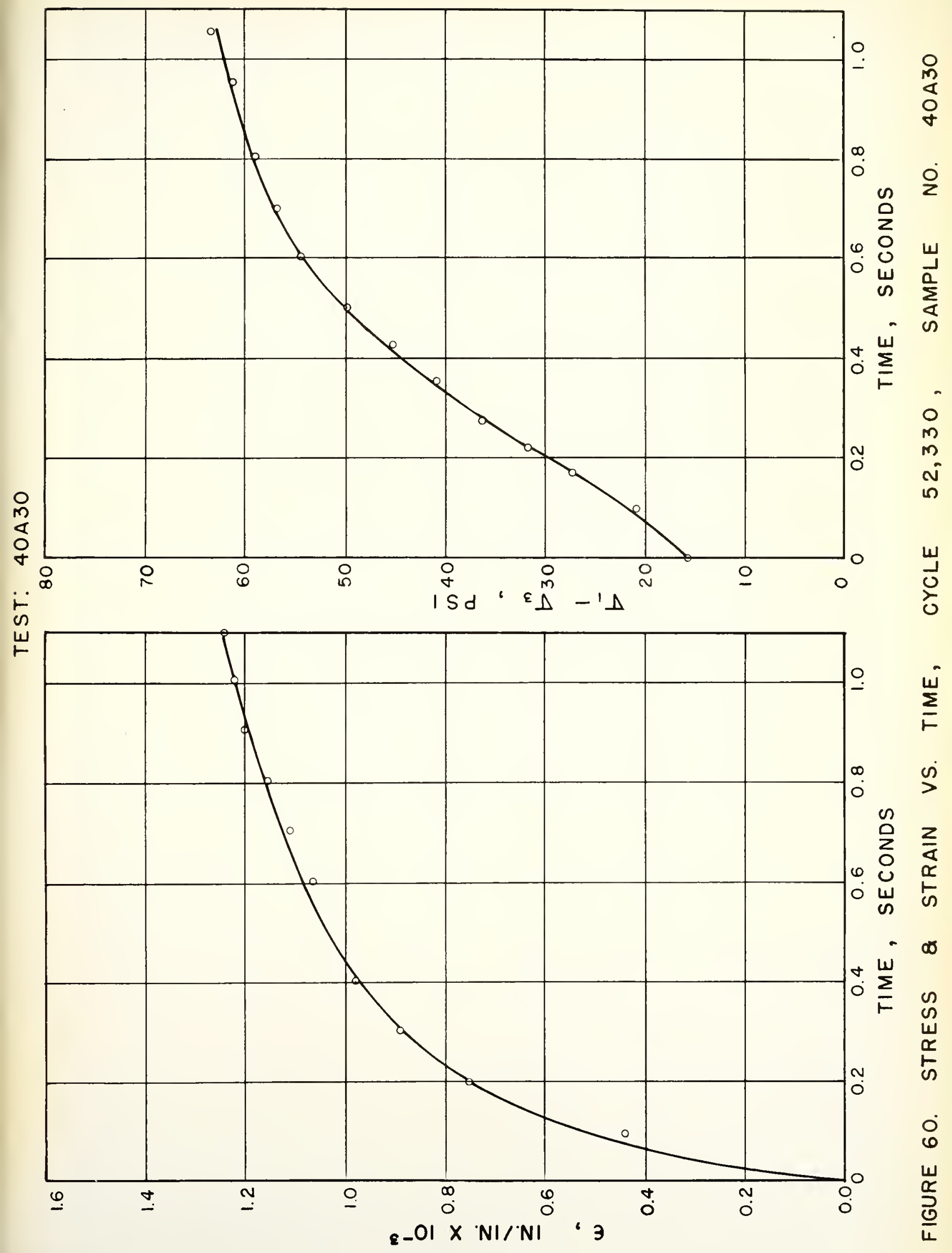


TEST: $\quad 40 A 30$

CYCLE: $\quad 52,330$

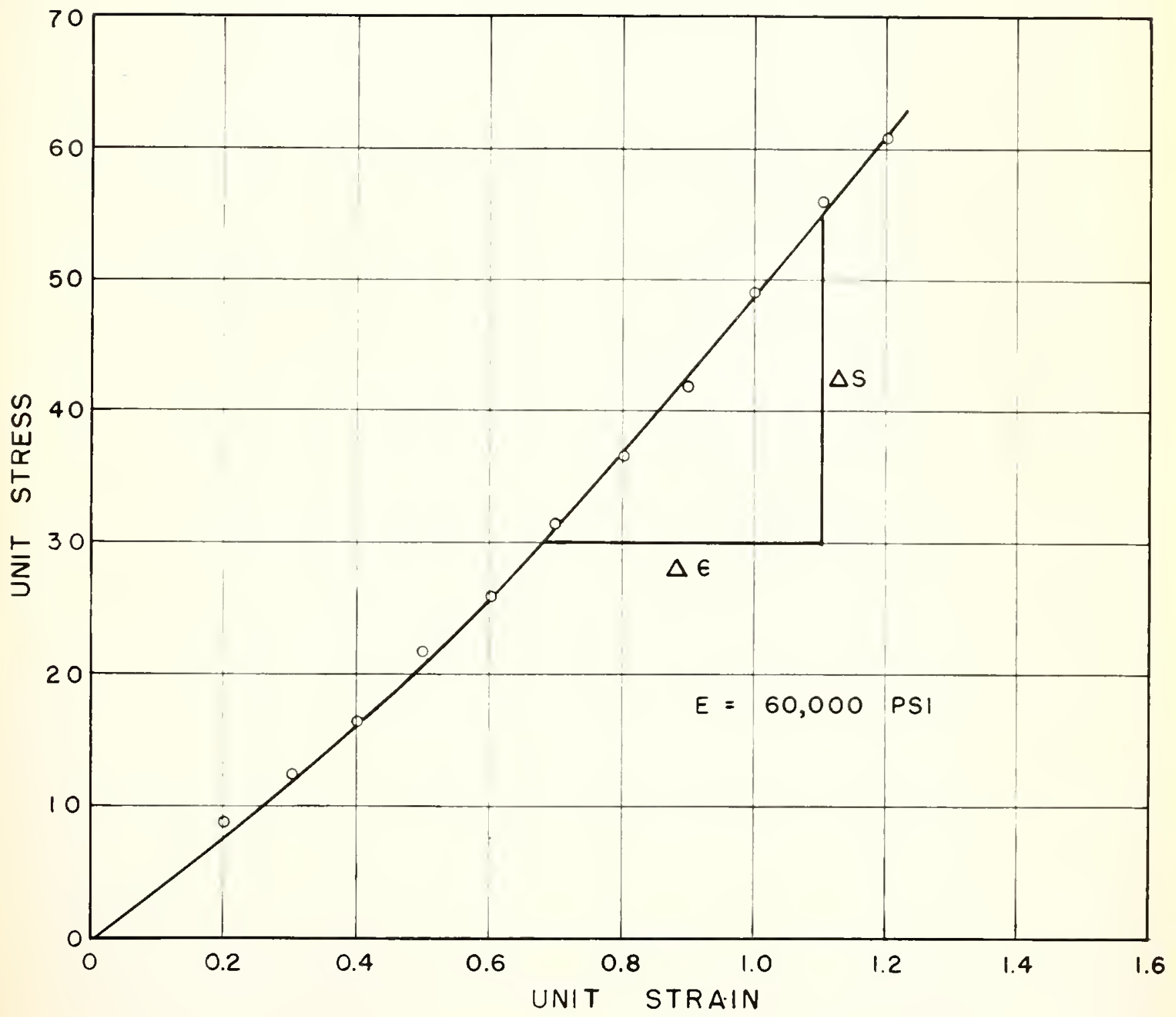

FIGURE 61. MODULUS OF DEFORMATION, CYCLE 52,330 SAMPLE NO. $40 A 30$ 
VITA 
VITA

Rodney Wendell Johnson was born on October 4, 1925, at Duluth, Minnesota, where he recelved his primary and secondary education. After an association with the U.S. Arny, Corps of Engineers from October, 1944 to November, 1946 he entered the University of Minnesota, Institute of Technology in December, 1946 and recelved the Bachelor of Cirll Englneering degree in June, 1950. Active in R.O.T.C. activities during his undergraduate years at the University of Minnesota, Mr. Johnson was selected for further active duty with the Corps of Engineers in Germany fran February, 1951 to January, 1953 during the Korean conflict.

Following a short assoclation with the California Department of Highrays, he entered the Graduate School of the University of Minnesota for advanced studies in Civll Engineering, and received the M.S.C.E. degree in December, 1954.

Subsequently, Ur. Johnson returned to Europe as a clvilian engineer with the U.S. Army Construction Agency, Germany where he directed planning and design of protective and defensive construction. He resigned this position to return to the Graduate School. Purdue University at Lafayette, Indlana. Appointed to the staff of the School of Civil Englneering as Instmuctor in Engineering Graphics and Surveying Mr. Johnson continued studies and research leading to the Ph.D. degree In CIVIl Engineering. 
Mr. Johnson was marrled in September, 1949 to the former

Lorraine J. Gunderson of Duluth, Minnesota. They have three children, Rodney A.3 Wanda M.3 and Connle L.

Mr. Johnson is a member of The American Soclety of Clvil Engineers, The American Soclety for Engineering Education, The National Soclety of Professional Engineers, The Soclety of American Milltary Engineers, and an Associate of the Highway Research Board. He is a registered engineer in the state of Minnesota. His publications in the fleld of engineering include: "An Investigation of Frost Penetration Under Bituminous Pavement," Bulletin lll Highway Research Board, 1955. "Determination of the $0.02 \mathrm{~mm}$ Fraction in Granular Solls," Journal of the Soll Mechanics and Foundations Dirlsion, ASCE, V01. 83, No. SK 3, July, 1957.

"Problems of Professtonal Engineers in Federal Jobs," Engineering News-Record, March 6, 1958.

"Photogrammetry in Missile Base Site Selection," The Military Engineer, November-December, 196I. 

